UCRL-LR-124998 Vol I

\title{
Near Field and Altered Zone Environment Report Volume I: Technical Bases for EBS Design
}

Dale G. Wilder

August 1997

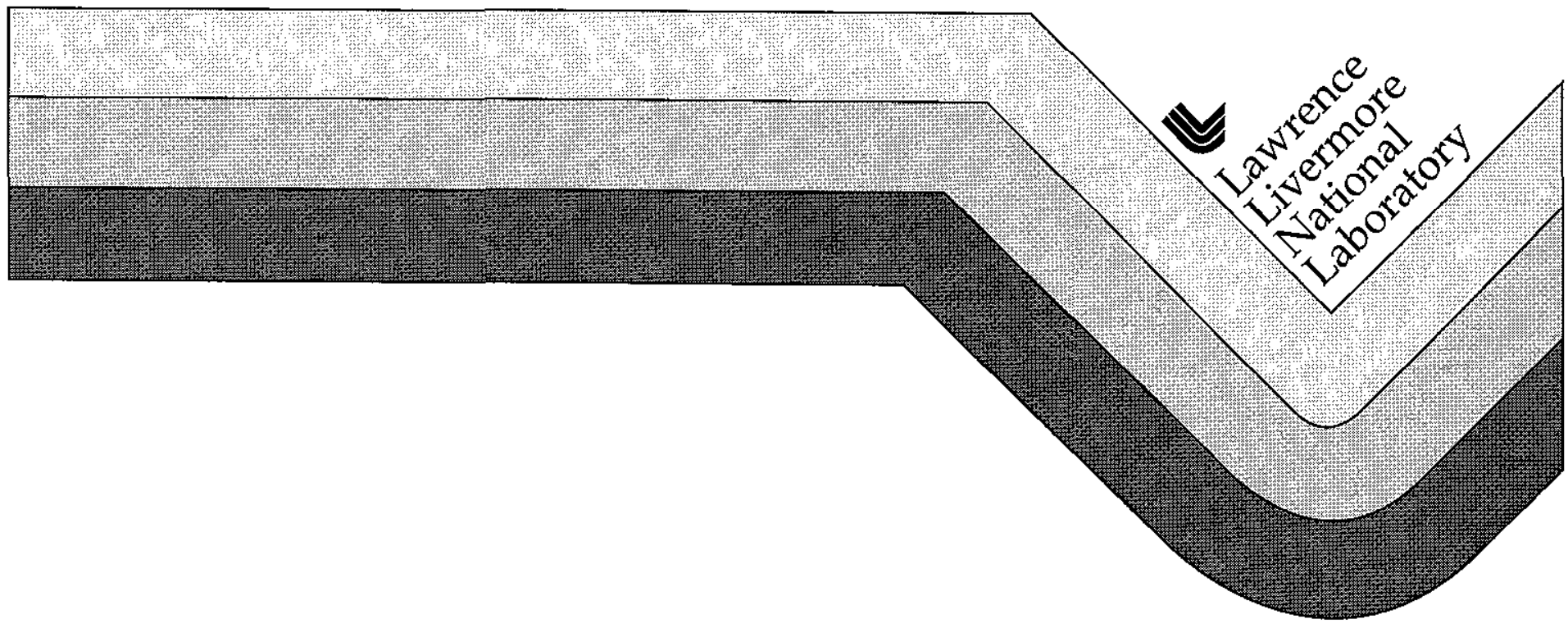




\section{DISCLAIMER}

This document was prepared as an account of work sponsored by an agency of the United States Government Neither the United States Government nor the University of California nor any of their employees, makes any warranty, express or implied, or assumes any legal liability or responsibility for the accuracy, completeness, or usefulness of any information, apparatus, product, or process disclosed, or represents that its use would not infringe privately owned rights Reference herein to any specific commercial product, process, or service by trade name, trademark, manufacturer, or otherwise, does not necessarily constitute or imply its endorsement, recommendation, or favoring by the United States Government or the University of California The views and opinions of authors expressed herein do not necessarily state or reflect those of the United States Government or the University of California, and shall not be used for advertising or product endorsement purposes

This report has been reproduced directly from the best available copy

\section{Available to DOE and DOE contractors from the Office of Scientific and Technical Information \\ PO Box 62, Oak Ridge, TN 37831 \\ Prices available from (423) 576-8401}

Available to the public from the National Technical Information Service

US Department of Commerce 5285 Port Royal Rd, Springfield, VA 22161

Work performed under the auspices of the US Department of Energy by Lawrence Livermore National Laboratory under Contract W-7405-ENG-48 


\section{Table of Contents}

\section{List of Figures}

List of Tables

Acronyms and Abbreviations

Glossary

Executive Summary

1.0 Overview

11 Purpose and Scope of This Report

111 Limitations

112 Emphasis on Processes. .

113 Revisions

114 Quality Assurance Controls

115 Importance of NFE/AZ to Waste Isolation

11.6 Importance to Performance Assessment .

11.7 Importance of NFE Conditions to Design

12 Changes Since Publication of the Preliminary NFER

1 2.1 Definitions of Near-Field ver sus Altered-Zone Environments

122 Emplacement and Repository Concepts

123 Waste Age

124 Prioritization of Variables and Parameters

125 Single versus Multiple Repository Design Efforts

13 Modeling Advances

14 Focus of Current Work
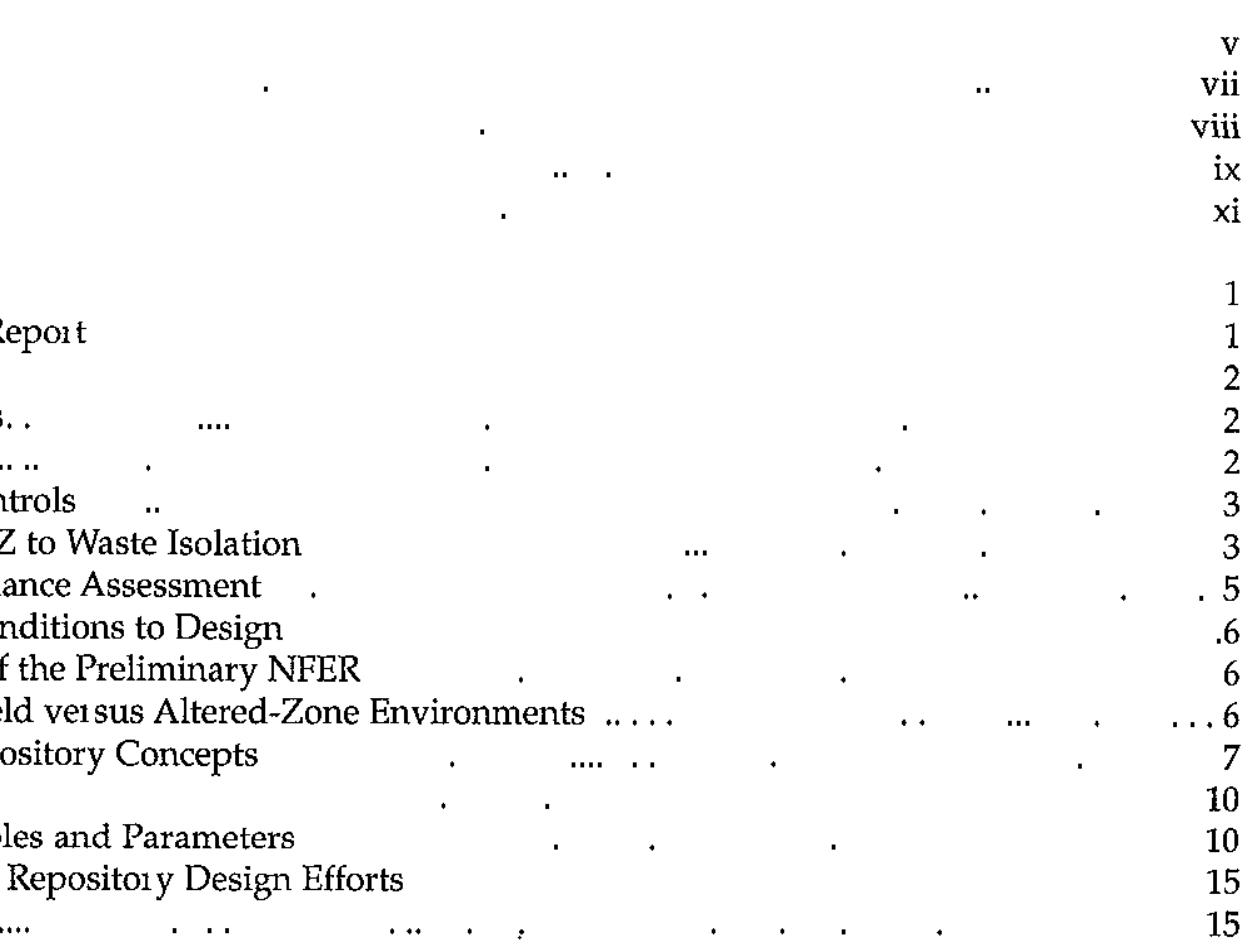

\subsection{Ambient Yucca Mountain Environment}

21 Geologic Framework

22 Geochemistry

23 Hydrology ...

24 Geomechanics

3.0 Processes That Form the NFE.

31 Construction

311 Excavation of Rock

312 Fluids Introduced during Drilling and Mining

313 Mine Ventilation

314 Introduction of Materials by Man . . ...

32 Emplacement of Waste

3 2.1 Thermal Loading

322 Introduced Materials

33 Backfilling .

34 Closure. .

35 Climate or Site Environment Changes with Geologic Time .. 
4.0 Near-Field Environment

41 Temperatures of the NFE

411 Thermal Output of the Waste

412 Configuration (Layout) of the Waste

413 Thermal Conductivity of the Rock .

414 Heat Redistribution by Moisture and Vapor

415 Results Temperatures in the NFE

42 Water (Liquid/Vapor) Fluxes in the NFE

43 Relative Humidity Conditions in the Drift/NFE

44 Guide to Temperature and $R H$ Data in Volume II

45 Geochemistry of the NFE

451 Results.

452 Introduced Materials

453 Conclusions ...

46 Geomechanics

461 Ambient Mechanical Rock Properties

462 Ambient Joint/Fracture Properties

463 Ambient Rock Mass Properties.

464 Temperature-Dependent Rock Properties

465 Time-Dependent Joint/Rock Mass Properties

466 Mechanical Loading Conditions on WPs ..

467 Predictive Modeling

. . . 30

. 30

.. . 32

32

32

33

33

37

40

43

50

52

57

58

59

59

59

.. 59

60

.. 61

61

64

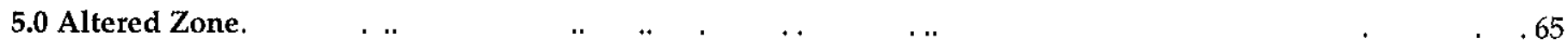

51 Introduction $\quad$. . . . $\quad .65$

5 1.1 Definitions and Organization $\quad . . \quad$. . $\quad 65$

512 Background $\quad$. . . $\quad .65$

52 Thermal-Hydrology in the Unsaturated Zone $\quad$. $\quad 67$

521 Assumptions and Calculations $\quad$. $\quad .71$

522 Influence of Fracture Permeability Distribution $\quad \ldots \quad \ldots \quad \ldots \quad \ldots \quad \ldots 2$

523 Influence of Water Vapor and Relative Humidity $\quad$... $\quad . \quad$.. $\quad$. 78

524 Overburden Thickness . . . . $\quad 79$

53 Thermal-Hydrology in the Saturated Zone $\quad \ldots . \quad \ldots . .79$

54 Altered Zone Geochemistry and Mineralogy $\quad$.. $\quad$. $\quad 80$

541 Summary of Recent Studies $\quad$. . .... . ..... . . 81

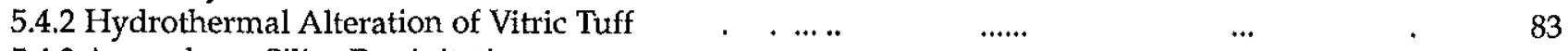

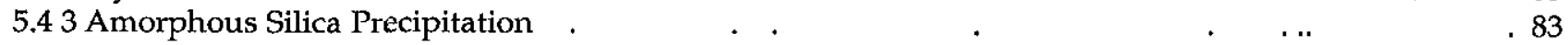

54.4 Bounds on Water Consumption and Secondary Mineral Development in the AZ 84

54.5 Formation of Flow and Transport Barriers in the AZ. $\quad \ldots \quad .86$

6.0 Performance Implications $\quad$.. $\quad . \quad .96$

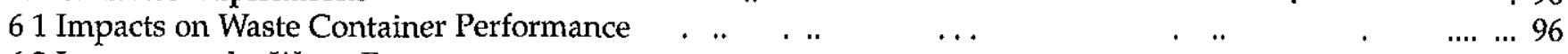

62 Impacts on the Waste Form . . . $\quad . \quad$. $\quad . \quad . \quad 401$

63 Impacts on Flow Fields and Transport . $\quad$.. $\quad$.. $\quad 102$

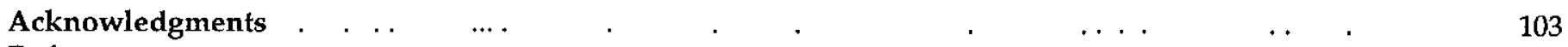

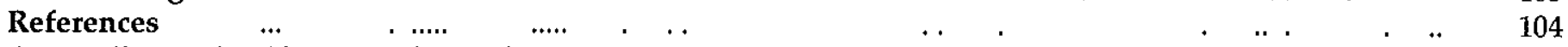

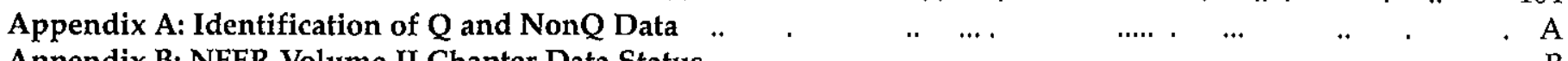

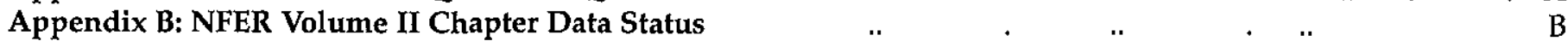




\section{List of Figures}

Figure 1-1

Figure 1-2

Figure 1-3

Figure 1-4

Figure 1-5

Figure 1-6

Figure 2-1

Figure 2-2

Figure 2-3

Figure 2-4

Figure 2-5

Figure 2-6

Figure 2-7

Figure 2-8

Figure 4-1

Figure 4-2

Figure 4-3

Figure 4-4

Figure 4-5

Figure 4-6

Figure 4-7

Figure 4-8

Figure 4-9

Figure 4-10

Figure 4-11

Figure 4-12

Figure 4-13

Figure 4-14

Figure 4-15

Figure 4-16

Figure 4-17

Figure 4-18

Figure 4-19

Figure 4-20

Figure 4-21

Figure 4-22

Figure 5-1

Figure 5-2

Figure 5-3

Figure 5-4
Location of the Yucca Mountain site

Schematic representation of near-field environment (NFE) and altered zone (AZ)

Plan view of the WP layout for ACD point-load and line-load (LL) designs

Plan view of the WP layout for the 1997 modified repository design

Simplified matrix showing coupled processes in the NFE

Forward and back coupling processes in the NFE

Distribution of fractures by azimuth in the main drift

Fracture-density histograms of fractures, cooling joints, and vapor-phase

partings per meter along the main drift

...

General stratigraphic column at Yucca Mountain

East-west cross section through the repository siting volume $\quad$.

Suction potential and matric potential as a function of saturation

Suction potential as a function of water saturation for Topopah Spring Tuff .

Axial stress vs axial strain for uniaxial measurements on Topopah Spring Tuff samples

Ultimate strength vs sample diameter for uniaxial measurements

on Topopah Spring Tuff samples

Matrix of coupled processes in the NFE

Calculated temperatures around the $\mathrm{d} 1$ ifts for the ACD and LL designs ..

Calculated temperatures on the WP surface for the ACD and LL designs

Temperature on WP surface and in drift wall rock for TSPA95 reference case

Temperature distribution for ACD vs LL designs at 100 and $500 \mathrm{yr}$

Liquid-phase flux at the repository horizon

Calculated relative humidities around drifts for the ACD and LL designs

Calculated relative humidities on the WP sur face for the ACD and LL designs

Matrix of coupled processes in the NFE related to water chemistry

Evolving $\mathrm{pH}$ as a function of temperature

$\mathrm{Eh}$, in volts, as a function of temperature

Total $\mathrm{Na}$ in solution, in $\mathrm{mg} / \mathrm{kg}$, as a function of temperature

Total $\mathrm{S}$ in solution, in $\mathrm{mg} / \mathrm{kg}$, as a function of temperature .

Total $\mathrm{Cl}$ in solution, in $\mathrm{mg} / \mathrm{kg}$, as a function of temperature .. .

Total $\mathrm{F}$ in solution, in $\mathrm{mg} / \mathrm{kg}$, as a function of temperature .

Total $\mathrm{Ca}$ in solution, in $\mathrm{mg} / \mathrm{kg}$, as a function of temperature ..

Total $\mathrm{P}$ in solution, in $\mathrm{mg} / \mathrm{kg}$, as a function of temperature... ... .

Total $\mathrm{Si}$ in solution, in $\mathrm{mg} / \mathrm{kg}$, as a function of temperature .

Log moles of calcite precipitated as a function of temperature

Log moles of dolomite precipitated as a function of temperature

Log moles of saponite precipitated as a function of temperature

Log moles of stilbite precipitated as a function of temperature

Model of coupled processes in the AZ

Moisture balance in the UZ and above the repository

Thermal-hydrologic coupling matrix .

Schematic of hydrothermal flow near the emplacement drift
. 19

20

22

23

23 
Figure 5-5 Various time and length scales involved in how decay heat influence the three major sources of liquid water flow . .. $\quad . .$.

Figure 5-6 Vertical temperature profiles and vertical liquid saturation profiles defining the AZ

Figure 5-7

Figure 5-8 Model calculations of repository-heat-driven vapor and condensate flow Duration of boiling period versus percentage of repository area enclosed for different bulk permeabilities .

Figure 5-9 Net buildup of liquid water above the repository vs time for various kb values

Figure 5-10 Maximum net buildup of liquid water above the repository as a function of bulk permeability

Figure 5-11 Liquid-phase flux above the emplacement drift for an AML of $834 \mathrm{MTU} /$ acre

Figure 5-12 Liquid-phase flux above the repository horizon and relative humidity in rock at the upper drift wall for the LL design

Figure 5-13 Temperature history at locations below the center of the repository for an AML of $834 \mathrm{MTU} /$ acre .

Contours of temperature rise above ambient and velocity vectors for liquid-phase flow

Figure 5-14 in fractures in the SZ at 5000 and $20,000 \mathrm{yr}$..

Figure 5-15 Figure 5-16 Figure 5-17 Figure 5-18 Figure 5-19 Figure 5-20 Matrix of coupled geochemical and mineralogical processes Estimates of sanidine abundance over time Matrix of coupled processes Mineral saturation indices vs time at the inlet node of a GIMRT simulation at $90^{\circ} \mathrm{C}$. Mineral saturation indices vs time at the outlet node of a GIMRT simulation at $90^{\circ} \mathrm{C}$ Porosity and volume fractions of primary and secondary minerals as a function of distance at six months for a GIMRT simulation at $90^{\circ} \mathrm{C}$

Figure 5-21 Porosity and volume fractions of trace secondary minerals as a function of distance after six months for a GIMRT simulation at $90^{\circ} \mathrm{C}$

Figure 5-22 Porosity and volume fractions of primary and secondary miner als as a function of time at the inlet node of a GIMRT simulation at $250^{\circ} \mathrm{C}$

Figure 5-23 Mineral saturation indices vs time at the inlet node of a GIMRT simulation at $250^{\circ} \mathrm{C}$

Figure 5-24

Figure 5-25 Mineral saturation indices vs time at the outlet node of a GIMRT simulation at $250^{\circ} \mathrm{C}$ Porosity and volume fractions of primary and secondary minerals as a function of time at the outlet node of a GIMRT simulation at $250^{\circ} \mathrm{C}$..

Figure 5-26 Mineral saturation indices as a function of distance after six months for a GIMRT simulation at $250^{\circ} \mathrm{C}$

Figure 5-27 Porosity and volume fractions of primary and secondary minerals as a function of distance after six months for a GIMRT simulation at $250^{\circ} \mathrm{C}$

Figure 5-28 Mineral saturation indices as a function of time at the inlet node of a GIMRT simulation at $95^{\circ} \mathrm{C}$

Figure 5-29 Mineral saturation indices as a function of time at the center node of a GIMRT simulation at $95^{\circ} \mathrm{C} .$.

Figure 5-30 Mineral saturation indices as a function of time at the outlet node of a GIMRT simulation at $95^{\circ} \mathrm{C}$

Figure 5-31 Porosity and volume fractions of primary and secondary minerals as a function of time at the inlet node of a GIMRT simulation at $95^{\circ} \mathrm{C}$ 
Figure 5-32 Porosity and volume fractions of primary and secondary minerals as a function of distance after $100 \mathrm{yr}$ for a GIMRT simulation

Figure 5-33 Porosity and volume fractions of primary and secondary minerals as a function of distance after $1000 \mathrm{yr}$ for a GIMRT simulation

Figure 5-34 Porosity and volume fractions of primary and secondary minerals as a function of distance after $5000 \mathrm{yr}$ for a GIMRT simulation .

Figure 5-35 Porosity and volume fractions of primary and secondary minerals as a function of distance after $10,000 \mathrm{yr}$ for a GIMRT simulation

Figure 6-1

Location of individual waste packages for the modified design .

Figure 6-2

Heat output as a function of the location (axial position) of individual waste packages for var ious averaging lengths

Figure 6-3 Corrosion rate of the outer WP barrier at ambient conditions compared with the rate predicted for a 24-MTU/acre repository

Figure 6-4 Cumulative corrosion depth of the outer WP barrier at ambient conditions compared with the values predicted for a 24-MTU/acre repository

Figure 6-5 WP relative humidity versus surface temperature for the ACD design with no backfill WP relative humidity versus surface temperature for the $01-\mathrm{m}$ LL design with sand backfill

\section{List of Tables}

Table 1-1 Near-field and altered-zone environmental parameters

Table 2-1

Geologic units as reported in ISM2 0 (CRWMS M\&O, 1997)

Table 4-1

Peak temperatures in rock at the upper drift wall and on the WP surface for ACD

Table 4-2 and LL designs Temperature on the upper WP surface by waste type for the ACD versus LL design 


\section{Acronyms and Abbreviations}

\begin{tabular}{|c|c|}
\hline $\mathrm{ACD}$ & advanced conceptual design \\
\hline AML & areal mass loading \\
\hline APD & areal power density \\
\hline AZ & altered zone \\
\hline BWR & boiling water reactor \\
\hline $\mathrm{CH}$ & Calico Hills Formation \\
\hline DHLW & defense high-level waste \\
\hline $\mathrm{DOE}$ & US Department of Energy \\
\hline EBS & engineered barrier system \\
\hline ECM & equivalent continuum model \\
\hline ESF & Exploratory Studies Facility \\
\hline FFE & far-field environment \\
\hline LA & license application \\
\hline LAD & license application design \\
\hline LLNL & Lawrence Livermore National Laboratory \\
\hline LML & lineal mass loading \\
\hline LPL & lineal power loading \\
\hline MTU & metric tons of uranium \\
\hline NF & near field \\
\hline NFE & near-field environment \\
\hline NFER & Near-Field Environment Report \\
\hline NTS & Nevada Test Site \\
\hline PPw & Prow Pass welded unit \\
\hline PTn & Paintbrush Tuff vitric nonwelded unit \\
\hline PWR & pressui ized water reactor \\
\hline QA & quality assurance \\
\hline QARD & Quality Assurance Requirements and Description (DOE, 1997) \\
\hline RIB & Reference Information Base (DOE, 1995) \\
\hline $\mathrm{SCP}$ & Site Characterization Plan (DOE, 1988) \\
\hline SNF & spent nuclear fuel \\
\hline SHT & Single Heater Test \\
\hline SZ & saturated zone \\
\hline TBM & tunnel boring machine \\
\hline TDIF & Technical Data Information Form \\
\hline $\mathrm{T}-\mathrm{H}$ & thermal-hydrological \\
\hline $\mathrm{T}-\mathrm{H}-\mathrm{M}-\mathrm{C}$ & thermal-hydrological-geomechanical-geochemical \\
\hline $\mathrm{TCW}$ & Tiva Canyon welded unit \\
\hline Tpt & Topopah Spring Tuff of the Paintbrush Group (stratigraphic un \\
\hline TSPA & Total System Performance Analysis \\
\hline TSw1, 2, and 3 & Topopah Spring Tuff (thermal/mechanical units, per Fig 2-3) \\
\hline UNE & underground nuclear explosion \\
\hline $\mathrm{UZ}$ & unsaturated zone \\
\hline WP & waste package \\
\hline WPP & Waste Package Plan (Harrison-Giesler, 1991) \\
\hline YM & Yucca Mountain \\
\hline YMP & Yucca Mountain Site Characterization Project \\
\hline YMSCO & Yucca Mountain Site Characterization Project Office \\
\hline
\end{tabular}




\section{Glossary}

ACD rev 00 design

Altered Zone (AZ)

Areal mass loading

Axial WP spacing

Cladding

Drift diameter

$\Delta T_{\text {drift }}$

EBS performance

Emissivity of WP

Lineal mass loading

Line-load design

Near-field environment (NFE)
This report uses the Advanced Conceptual Design (ACD) from TRW, 1996, as the Reference Design for the repository The geometry of the ACD has a spacing between drift centerlines roughly the same as axial spacing between WPs The drift spacing is $225 \mathrm{~m}$, and the areal mass loading AML is $834 \mathrm{MTU} /$ acre

In general, the region extending from tens to hundreds of meters outward from the repository, where temperatures are sufficiently low to allow liquid water to exist in pores and fractures In this region, fundamental changes to hydrologic, mineralogic, or chemical conditions may take place, but these conditions do not interact directly with the waste packages Rather, they interact with the near-field environment

AML is expressed as metric tons of uranium emplaced per acre of drift (MTU/acre)

The spacing of waste packages along the emplacement drift axis, expressed as center-tocenter spacing

The tubes in which nuclear fuel pellets are incased

Diameter of di ift excavation, but does not account for ground support or other engineered structures

Temperature difference between the WP and drift wall

The extent to which the engineered barrier system contributes to isolation of radionuclides, either by containment or limits to release from the waste package Although the EBS may also contribute to performance by physical/chemical inclusion of radionuclides into its components, this is not normally considered as part of isolation performance

Determines how efficiently heat is transferred by thermal radiation between a WP and the drift floor, drift wall, or adjacent WPs.

LML is expressed as metric tons of uranium emplaced per meter of drift $(\mathrm{MTU} / \mathrm{m})$

One of several possible alternative WP arrangements in a repository at $\mathrm{YM}$, which lineally concentrates decay heat by placing WPs nearly end to end along drifts, i e, tight axial spacing For this report, the line-load design has the same AML (83 4 MTU/acre) as the ACD rev 00 design, although the AML could vary depending on drift spacing Two line-load (LL) designs are considered

- The $01-\mathrm{m}$ spacing, 1 11-MTU/m line-load design, which assumes a $01-\mathrm{m}$ gap between WPs, resulting in an LML of $111 \mathrm{MTU} / \mathrm{m}$ and drift spacing of $538 \mathrm{~m}$

- The 10-m spacing, $094-\mathrm{MTU} / \mathrm{m}$ line-load design, which assumes a $10-\mathrm{m}$ gap between WPs, resulting in an LML of $094 \mathrm{MTU} / \mathrm{m}$ and drift spacing of $461 \mathrm{~m}$

Encompasses the region of rock and drift that is proximal

to the waste packages and inter acts with them, sometimes called the waste package environment (WPE) In general, the NFE or WPE is where temperatures reach above the boiling point, thus contact time for rock-water interactions are shorter, and where resulting changes in environmental conditions dominate These changes may be reversible 
Percolation flux

Point-load design

Reference Design

Thermal conductivity

Thermal conductivity

Thermal conductivity

Waste container

Waste form

Waste package

WP layout
Generally refers to the volume of water moving downward through unit cross-sectional area per unit time within the rock mass below the zone where evapotranspiration returns moisture to the atmosphere For this report, the term refers specifically to downward water flux through the potential repository host rock (the TSw2 thermomechanical unit)

A repository design wherein waste is placed with sufficient spacing that environmental conditions of temperature and moisture do not reflect the influence of adjacent waste packages. To a large extent, the ACD rev 00 design is a point-load design

See ACD rev 00 design

The measure of how effectively heat is conducted through of invert or backfill introduced invert or backfill materials

The measure of how effectively heat is conducted through of rock the repository rock

The measure of how effectively heat is conducted through of WP the waste package

The container that encloses the waste form, any handling or shipping containers, fillers, support structures, etc The term "container" refers to the container itself, not to the entire package including waste

The type of radioactive waste material, e $g$, spent fuel or defense wastes in reprocessed glass waste logs

The complete package of waste and containers that includes the waste, any internal structural and criticality-control items, fillers, and the container

The geometric configuration of waste emplacement For this study, the layout consists of axial spacing along a drift between waste package (WP) centers and lateral spacing between drift centers (called drift spacing) Although other design options exist (e g, two parallel rows of WPs in a drift or WPs placed off-center in a drift), this report is limited to layouts of WPs centered within drifts 
The natural system contributes to isolation in three ways, first, it limits the amount of water that can contact the waste and WPs Factors that limit the amount of water include the unsaturated rock mass and the tight rock matrix Second, the natural system can prevent radionuclide migration through chemical exchange or sorptive processes with the rock minerals and pore water Third, the natural system contributes to isolation by delay in transport, which will either allow shorter-lived radionuclides to decay or will allow for delayed releases and dilution processes to lower the dose rates Of course, there are also processes within the natural system than can concentrate radionuclides by allowing them to accumulate over time

The rate of radionuclide release (and dose rate) at the accessible environment depends on the time that release from the EBS begins, the magnitude and duration of the release, and decrease in magnitude (attenuation) of radionuclide concentration resulting from radioactive decay and dilution during the time required for radionuclides to move through the natural system from the repository to the accessible environment. A conceptual model for the release of radionuclides from the WPs and the EBS is summarized below

Radionuclide release from the EBS requires two conditions

- A breach, or failure, of the metal barriers of the WP, including the outer portion of the container that is designed to consist of a thicker corrosion-allowance material, and the inner portion of the container designed to consist of a thinner corrosion-resistance material, as well as the cladding around the spent fuel pellets or pour canisters around the Defense High Level glass waste forms

- Contact of the waste for $m$ by liquid water, which can dissolve or suspend radionuclides and transport them through the failed WP and other elements of the EBS to the unexcavated rock host

Postemplacement cladding failure will be controlled primarily by the temperature within the WP Breach of the outer barrier is determined by it's corrosion rate, particularly the localized rate of attack or "pitting rate "Breach of the inner corrosion-resistant barrier will be controlled almost entirely by the internal environment until the outer barrier is breached Even if a container fails, negligible amounts of radioactive material will be released from the repository unless liquid water is advected into the drift, into the breached WP, into the waste form, out of the WP, and into the repository horizon rock Hence the timing of advected water entry, flux of liquid water, and its chemistry will be the most important NFE variables for performance assessment after failure of the WPs

The Performance Assessment implications of NFE conditions suggest that design goals should include the development of an EBS that, in concert with the natural system, will provide a long delay between emplacement and the first contact of waste by water The overall design goal is to prevent water from contacting the waste form as long as possible and to limit the amount of waste contacted by water after contact begins. An overriding characteristic of the interaction between the WPs/repository and the NFE is that it results from coupled processes The significance and magnitude of the coupling varies both spatially and temporally To assist in the prioritization, the dominant processes were considered

As stated, interactions between the EBS components and the NFE are, to large extent, dominated by the possible presence of liquid water and elevated humidity Thurs, an assessment of EBS performance can focus on hydrological aspects and associated geochemistry Fracture flow is a key issue. We are now focusing almost entirely on the following processes as priorities

1 Understanding how and when water will contact the WPs

2 Determining the chemical composition of fluids and gases that contact the container or waste forms

3 Understanding what happens in the $\mathrm{AZ}$ at distances that can extend more than hundreds of meters away from the repository

4 Determining how geomechanics couples to the hydrology and geochemistry

5 Determining solubility and speciation of radionuclides in the near-field fluids 


\section{Executive Summary}

This report presents an updated summary of results for the waste package (WP) and engineered barrier system (EBS) evaluations, including materials testing, waste-form characterization, EBS performance assessments, and near-field environment (NFE) characterization Materials testing, design criteria and concept development, and waste-form characterization all require an understanding of the environmental conditions that will interact with the WP and EBS. The Near-Field Environment Report (NFER) was identified in the Waste Package Plan (WPP) (HarrisonGiesler, 1991) as the formal means for transmitting and documenting this information

The purpose of the new Near-Field and Altered-Zone Environment Report is to update the Preliminary NFER, to convey current understanding of environmental conditions, and to provide technical information needed for repository design decisions and performance analyses Volume I provides the technical bases for design of the EBS, which is derived from our current knowledge of the waste-package and altered-zone environment Volume I also discusses the altered zone (AZ) as it might impact performance analyses, however, Volume II is the principal source of information regarding the $\mathrm{AZ}$ Volume II consists of 11 sections providing much more detailed discussion of the topics in Volume I as they pertain to particular fields of study

The design and performance of the WP and EBS will depend on the hydrological, geochemical, and geomechanical conditions that develop over time in the rock extending for considerable distances into the mountain For that reason, emphasis in this report is placed not only on conditions that will result and their associated parameter values, but also on processes that will change the environmental conditions That is, it is necessary to understand not just the statistical distribution of environment conditions, but also the physical processes themselves

The emphasis of the safety argument has changed over the years, both in response to changing understanding of the regulations as well as of the repository and natural system When the Site Characterization Plan (SCP) was prepared, it was understood that the containers must contribute to satisfy requirements of the regulations by substantially complete containment of the waste for 300 to 1000 years The waste form was required to release no more than 1 in $10^{5}$ of the 1000-year radionuclide specific inventory for up to 10,000 years Because the container was assumed to perform for 1,000 years--as opposed to the waste form for 10,000 years-the stress on the NFE was to provide an environment that was compatible with waste form performance One of the decisions this lead to was keeping the $\mathrm{pH}$ close to neutral and avoiding high $\mathrm{pH}$ in an effort to minimize leaching of glass waste forms

The current strategy has placed more reliance on the Engineered Barrier System, specifically the container Current information indicates that geochemical processes that result from the coupling of heat and fluids generated from waste emplacement will form large volumes of sorptive minerals within the AZ Furthermore, there will likely be a significant change in the hydrologic system However, there are large uncertainties in our understanding of the natural system, and recent evidence suggests much higher percolation fluxes than originally anticipated As a result, there has been a tendency to place greater emphasis on very robust WPs (e.g., ceramics) that will be able to last for times that exceed 10,000 years regardless of the water and water chemistry to which they are exposed

The impact of the NFE on the evolving waste isolation strategy depends, to a large degree, on the portion of the waste isolation system being considered The three main aspects of the system that will contribute to isolate waste from the accessible environment are

- The waste form itself

- The container in which the waste is placed.

- The natural system (rock mass)

The waste form contributes to isolation of radionuclides mainly by limiting the rate at which the waste can be released. The NFE factors that influence the rate of release are the amount, temperature, and chemical content of water that is able to contact the waste

Container performance depends on the container design and material selected, and on their interaction with the $\mathrm{NFE}$, specifically the quantity, temperature, and chemical content of both liquid water and water vapor as well as drift gaseous makeup (i.e., presence or absence of oxygen and $\mathrm{CO}_{2}$ ). The mode of contact of water (dripping, continuous contact, condensation) also is an important factor in the performance of the container, or more specifically, on corrosion kinetics. 


\subsection{Overview}

The United States Department of Energy (DOE) is investigating the suitability of Yucca Mountain as a potential site for the nation's first high-level nuclear waste repository As shown in Fig 1-1, the site is located about $120 \mathrm{~km}$ northwest of Las Vegas, Nevada, in an area of uninhabited desert

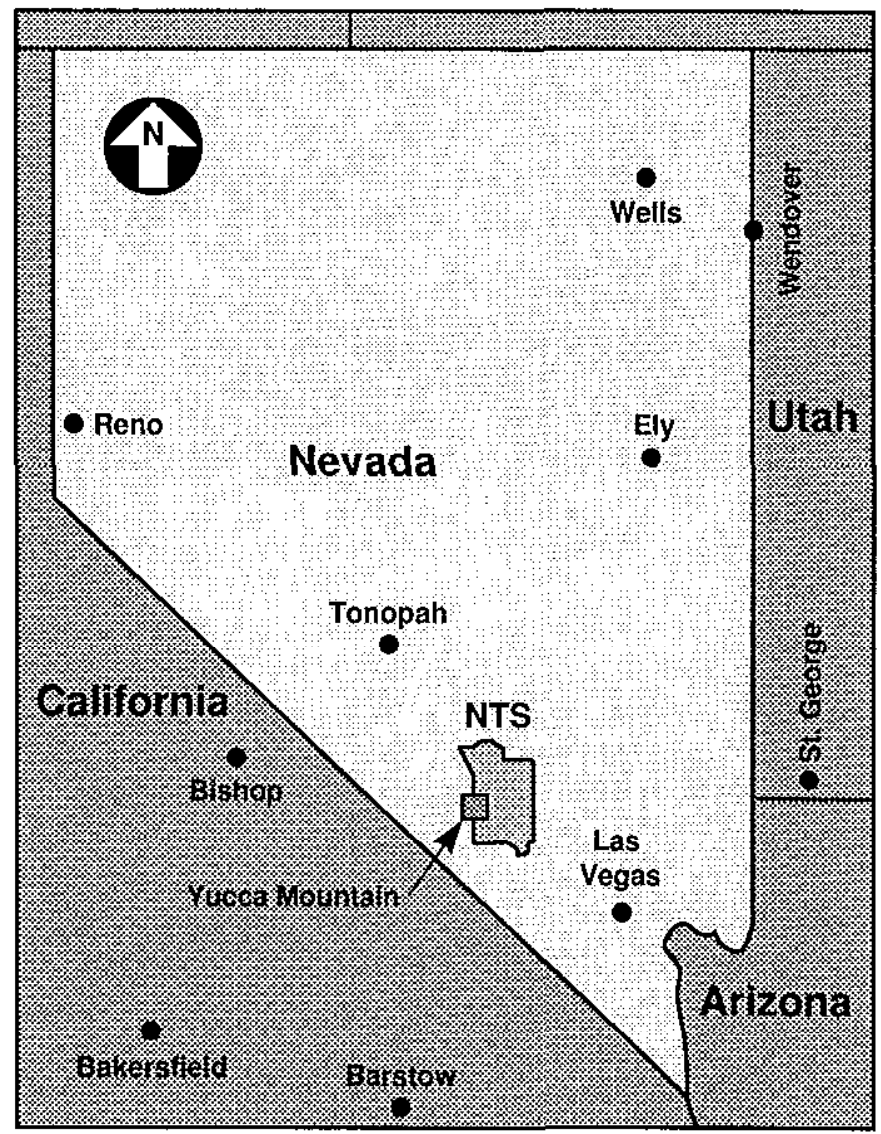

Figure 1-1. Location of the Yucca Mountain site.

Favorable aspects of Yucca Mountain (YM) as a potential repository site include its arid nature and the sorptive properties of the rock materials The arid environment results in unsaturated conditions at the potential emplacement horizon, which is the Topopah Spring Tuff (Tpt) of the Paintbrush Group The major advantages of unsaturated conditions are that container corrosion, waste-form leaching, and radionuclide transport mechanisms are minimized because of the lack of contact between liquid water and the waste package (WP) Although recent studies indicate that percolation fluxes may be higher than or iginally anticipated, the major advantages should still apply, but their significance must be evaluated

Lawrence Livermore National Labor atory (LLNL) is a Yucca Mountain Site Characterization Project (YMP) participant and is responsible for WP and engineered barrier system (EBS) evaluations, including materials testing, waste-form characterization, EBS performance assessments, and near-field environment (NFE) characterization Materials testing, design criteria and concept development, and waste-form characterization all require an understanding of the environmental conditions that will interact with the WP and EBS The Near-Field Environment Report (NFER) was identified in the Waste Package Plan (WPP) (Harrison-Giesler, 1991) as the formal means for transmitting and documenting this information

\subsection{Purpose and Scope of This Report}

The first NFER was published in April, 1993 as a preliminary report (Wilder, 1993) because the design and characterization studies were not mature Since publication of the Preliminary NFER, information regarding the environment of the potential repository site has progressed considerably This new report is Revision 1 of the NFER The term "Preliminary" has been dropped from the title to reflect the greater maturity of both design and characterization efforts In addition, at the time the Preliminary NFER was published, a companion report was intended that would focus on the altered zone (AZ) environmentthat is, the environment that develops away from the WPs and impacts the waste and its containers only in terms of its influences on the WP environment Subsequently, a decision was made to combine both WP and AZ reports into the NFER This decision recognizes the interdependence of the $W P$ and $A Z$ environments and the fact that the studies documented in the companion volume (Volume II of this report) apply to both of these zones of the environment

The purpose of this new Near-Field and AlteredZone Environment Report is to update the Preliminary NFER, to convey current understanding of environmental conditions, and to provide technical information 
needed for repository design decisions and performance analyses Volume I provides the technical bases for design of the EBS, which is derived from our current knowledge of the waste-package and alteredzone environment. Volume I also discusses the AZ as it might impact performance analyses, however, Volume II is the principal source of information legarding the $A Z$

Volume II consists of 11 sections providing much more detailed discussion of the topics in Volume I as they pertain to particular fields of study Volume II includes information on many different design options, property values, and sensitivity analyses Volume I focuses on the ACD (reference) design and on project reference property values To allow scientists and enginees sto determine the validity of information in Volume I, Volume II documents the scientific and engineering data, models, and approaches used to gather information Of particular relevance in Volume II are an extended and updated description of hydrother mal modeling (Sec 1) and new discussions of the AZ environment (Sec. 10) and thermodynamic data determination of radionuclides (Sec 11) Volume II documents the state of knowledge of relevant processes, conditions, and properties as of August 23, 1996, and, unless otherwise noted, it constitutes the basis for the material presented in this Revision 1 of Volume I

\subsubsection{Limitations}

Evaluations of the expected environment are based on cur rently available understanding of properties, parameters, analyses, and assumptions, as well as reference designs, and on prototype or scoping tests and analyses. In some cases, information from similar rock type or formations as well as from specific mineral or chemical conditions is used Field tests needed to characterize the responses of YM and to test the model conceptualizations have not been completed at the time of this report Although the information in this report is considered accurate vis-avis modeling approximations, the validation exercises have not been completed Future assessments will be required to determine if the environment as described here is appropriate for conditions at YM

\subsubsection{Emphasis on Processes}

The design and performance of the WP and EBS will depend on the hydrological, geochemical, and geomechanical conditions that develop over time in the rock extending for considerable distances into the mountain For that reason, emphasis in this report is placed not only on conditions that will result and their associated parameter values, but also on processes that will change the environmental conditions That is, it is necessary to understand not just the statistical distribution of environment conditions, but also the physical processes themselves

A mechanistic understanding of processes and events as they unfold over time is essential for several reasons For example, the degree of rock saturation is one important aspect of the repository environment However, what the initial saturation happens to be is insufficient information for design and decisions It is the amount, timing, and temporal distribution (steady-state or episodic) of water contacting the waste that are pertinent to design To estimate the amount of water expected to contact waste at or over a given time, we must integrate saturation data with other factors to evaluate the coupled processes that lead to water entry into the drifts and onto WPs These factors include (1) percolation flux, (2) fracture-matrix flow models, (3) fracture distribution, (4) emplacement configuration, (5) ar eal mass loading, (6) projected WP thermal characteristics, and (7) repository design To a large extent, factor (1) is a product of factors (2) through (7) Similarly, events as wide ranging as construction activities, microbial processes, climate change, and many others may modify repository conditions For these reasons, the report focuses not only on detailed technical information but also on the interaction of processes and the integration of values

\subsubsection{Revisions}

This Near-Field and Altered-Zone Environment Report is the first of the scheduled NFER revisions identified in the WPP However, the WPP has been superseded by the Annual Planning process Although the process does not have the same revision points as those specified in the WPP, it includes updating the NFER at major milestones, such as at completion of field testing, and at times needed for major decisions or documents, such as viability assessment and license application This revision (Rev 1 of the NFER) will support the viability assessment and associated design and performance assessment $A$ second revision of the NFER will be based on the Large Block Test at Fran Ridge and the single heater test (SHT) in the 
Exploratory Studies Facility (ESF). The second revision will support the license application design (LAD) phase and will be produced in accordance with the planning process as documented in the multi-year planning system (MYPS) A third revision based on ESF test results will support defense of the license application (LA) and the LA amendment to emplace waste Additional reports are likely, and they will cover subsequent work related to the performance confirmation phase

\subsubsection{Quality Assurance (QA) Controls}

At the time of the Preliminary NFER, a distinction was made between quality-affecting work and work that was not quality-affecting Subsequently, changes have been made in the QA program All of the work or activities reported in this Near-Field and Altered-Zone Environment Report comes under the control of the Quality Assurance Requirements and Description (QARD, DOE, 1997) All data included in this report, except for referenced information from other sources not collected under YMP controls, were collected under controls of the QARD and can therefore be qualified for use The NFER is not an activity that gener ates data itself, rather, the material presented in this report is a compilation/synthesis of data and other information that have been collected under other activities and reported elsewhere The QA status of the data is determined by the activities and reports from which they were synthesized with the specific controls for those activities noted in Scientific Notebooks associated with those activities For the most part, the data reported in Volume I was taken from Volume II, which identified the QA status of the data by sections in an appendix For convience, this information is included in this volume (see Appendixes A and B), even though it is a duplication No new data are transmitted in this report that were not already transmitted to YMP by Technical Data Information Form (TDIF)

The NFER is a synthesis of information, where "synthesis" is used in the dictionary sense of being a combination of thesis (data, etc) and logical deduction It was also defined to be a synthesis report in the YMP sense, that is, a compilation of all relevant data regarding the NFE and AZ environments. It is not, however, a synthesis in the sense that is sometimes used in the YMP to mean a final, one-time compilation of all the data that will be used Rather, as pointed out in Section 113 , the NFER is revised periodically to reflect the information that will be developing This revision (Revision 1) is based on a mixture of qualified and nonqualified information that must be used as a whole to make the conclusions and assessments Therefore, Revision 1 of the NFER is considered to be qualified, having gone through appiopriate reviews, having been prepared in accordance with requirements outlined in the QARD, and with qualification of the data identified in Appendix $\mathrm{A}$

\subsubsection{Importance of NFE/AZ to Waste Isolation}

The emphasis of the safety argument has changed over the years, both in response to changing understanding of the regulations as well as of the repository and natural system When the Site Characterization Plan (SCP) was prepared, it was understood that the containers must contribute to satisfy requirements of the regulations by substantially complete containment of the waste for 300 to 1000 years The waste form was required to release no more than 1 in $10^{5}$ of the 1000-year 1adionuclide specific inventory for up to 10,000 years Because the container was assumed to pe1 form for 1,000 yearsas opposed to the waste form for 10,000 years-the stress on the NFE was to provide an environment that was compatible with waste form performance by keeping the $\mathrm{pH}$ close to neutral and avoiding higher $\mathrm{pH}$ This was the reason for the requirement in the SCP to limit the use of concrete or cementitious materials in the repository There were also SCP requirements to prevent water contact by maintaining a capillary barrier (gap between WP and borehole rock) and limiting rock sloughing into waste-emplacement boreholes The natural system was then relied on to provide a ground water travel time that exceeded 1000 years and also to retard the transport of the radionuclides by sorption and similar processes The natural system was assumed to provide this function for times that extended up to $1,000,000$ years under some regulatory interpretations Because of the emphasis on long times and on retardation of radionuclides, it was deemed important to keep from destroying the sorptive minerals (zeolites) To protect the sorptive minerals as well as other components of both natural and engineered systems a series of constraints were placed on temperatures In the case of sorptive minerals, these temperature limits were placed because dehydration of zeolites would impact their sorptive capacities These limits are reflected in the SCP 
At the time of the Preliminary NFER, the greatest emphasis for isolation continued to be on the unperturbed natural system, although credit for lifetimes of the container beyond 1000 years was being considered, and thus concepts to maintain a very dry NFE (extended dryout) were being stressed Because of the possibly conflicting goals of high temperatures to keep packages dry and lower temperatures to prevent dehydration or alteration of sorptive minerals (as well as thermal performance issues of other components of the repository/waste disposal system), a series of thermal goals was formalized During this time, the requirement for $\mathrm{pH}$ control or limits on use of concrete was relaxed

The current strategy has placed more reliance on the Engineered Barrier System, specifically the container This emphasis is illustrated by several draft Waste Isolation Strategies. Although none have been formally accepted by the DOE, they place increased emphasis on the EBS with either greatly reduced emphasis on the natural system or at least equal emphasis on the EBS The strategy is in transition, and the thermal goals have remained largely as they were during the time of the Preliminary NFER Current information indicates that geochemical processes that result from the coupling of heat and fluids generated from waste emplacement will form large volumes of sorptive minerals within the AZ Further more, there will likely be a significant change in the hydrologic system However, there are large uncertainties in our understanding of the natural system, and recent evidence suggests much higher percolation fluxes than originally anticipated As a result, there has been a tendency to place greater emphasis on very robust WPs (e $g$, ceramics) that will be able to last for times that exceed 10,000 years regardless of the water and water chemistry to which they are exposed. The much greater emphasis on very robust containers occurred since publication of Volume II of this report This evolving strategy has not fully addressed performance issues beyond the 10,000 year time frame Because the strategy has not been officially adopted and is evolving, this report will not focus on it but recognizes and addresses the implications

The impact of the NFE on the evolving waste isolation strategy depends, to a large degree, on the portion of the waste isolation system being considered The three main aspects of the system that will contribute to isolate waste from the accessible environment are

- The waste form itself
- The container in which the waste is placed

- The natural system (rock mass)

In addition, many engineering options (such as drip shield or backfill) can enhance the performance of these three components However, the actual isolation of waste as required by regulations (e $\mathrm{g}, 10 \mathrm{CFR} 60$ ) depends only on the functioning of these three components For instance, a drip shield will not contain the waste or control the rate of release, except as it impacts water contact Thus, a drip shield is more a determinant of the NFE that a component of the isolation system Whereas other components can contribute to isolation, it is the author's contention that they can be covered as part of the NFE rather than the isolation system Perhaps the distinction is not as cleat for backfill because such material can provide performance similar to that of the natural system, although at a much smaller geometric scale As discussed below, the NFE impacts the three major components listed above in different ways, but is a very important factor in the performance of each of them

The waste form contributes to isolation of radionuclides mainly by limiting the rate at which the waste can be released The NFE factors that influence the rate of release are the amount, temperature, and chemical content of water that is able to contact the waste The properties of the waste that determine this rate are discussed in the Waste Form Characteristics Report (Stout and Leider, 1997) Note that this does not address the gaseous radionuclide releases $\left(\mathrm{e} g,{ }^{14} \mathrm{C}\right)$, which are not expected to be the major releases The NFE will be a major factor in the release rates from the waste form because the quantity, temperature, and chemistry of water contacting the waste are all parts of the NFE. Water chemistry contacting the waste will likely be dominated by introduced materials (including potentially significant amounts of corrosion products), and the quantity of water will certainly be influenced by the mobilization of water due to waste emplacement Microbial activities as well as the presence of colloids from corrosion products and microbes can have a major impact on the mobilization of radionuclides from the waste form

Container performance depends on the container design and materials selected, and on their interaction with the NFE, specifically the quantity, temperature, and chemical content of both liquid water and water vapor as well as drift gaseous makeup (i e., presence or absence of oxygen and $\mathrm{CO}_{2}$ ) The mode of contact of water (dripping, continuous contact, condensation) also is an important factor in the performance of the 
container, or more specifically, on corrosion kinetics Once again, these factors are all components of the $\mathrm{NFE}$, and the processes noted for the waste form will be important to the container performance, although the influence of corrosion products and colloids will not be as significant Even if a ceramic waste container is selected, it will be impossible to guarantee $100 \%$ per formance of the ceramic because of undetected manufacturing flaws, damage, and other issues Thus, the NFE becomes critical, and given the trend toward increased reliance on the container, it will be the most critical portion of the environment

The natural system contributes to isolation in three ways. First, it limits the amount of water that can contact the waste and WPs Factors that limit the amount of water include the unsaturated rock mass and the tight rock matrix Second, the natural system can prevent radionuclide migration through chemical exchange or sorptive processes with the rock minerals and pore water Third, the natural system contributes to isolation by delay in transport, which will either allow shorter-lived radionuclides to decay or will allow for delayed releases and dilution processes to lower the dose rates Of course, there are also processes within the natural system that can concentrate radionuclides by allowing them to accumulate over time

Processes within the NFE/AZ can impact the water distribution, specifically the redistribution of water due to waste heat Processes that occur in the AZ can also contribute to significant changes in porosity and permeability, which can have dramatic impacts on the water contact issues These processes can also result in significant modifications of the mineralogy of the system, resulting in vastly different sorptive capacities of the system (not all of which are detrimental) In addition, if dryout occurs within the $A Z$, there is increased capacity for imbibition so that radionuclides in any water that is imbibed from the fractures into the pores would tend to be physically held by capillary forces for very long times Thus, the $A Z$ can have potentially positive impacts on performance

\subsubsection{Importance to Performance Assessment}

The rate of radionuclide release (and dose rate) at the accessible environment depends on the time that release from the EBS begins, the magnitude and duration of the release, and decrease in magnitude (attenuation) of radionuclide concentration resulting from radioactive decay, retardation due to chemical sorption and diffusion, and dilution during the time required for radionuclides to move through the natural system from the repository to the accessible environment $A$ conceptual model for the release of radionuclides from the WPs and the EBS is summarized below

Radionuclide release from the EBS requires two conditions

- A breach, or failure, of the metal baniers of the WP, including the outer portion of the container that is designed to consist of a thicker corrosionallowance material, and the inner portion of the container designed to consist of a thinner corrosion-resistance material, as well as the cladding around the spent fuel pellets or pour canisters around the Defense High Level glass waste forms

- Contact of the waste form by liquid water, which can dissolve or suspend radionuclides and transport them through the failed WP and other elements of the EBS to the unexcavated rock host [Once again, this does not address release of gaseous radionuclides, such as ${ }^{14} \mathrm{C}$ However, these radionuclides are not identified by the Total System Performance Analysis (TSPA) or Waste Isolation Strategies as major concerns and are not included in NFE discussions ]

Postemplacement cladding failure will be controlled primarily by the temperature within the WP An additional factor is the amount of oxygen that is able to contact the cladding If temperatures are high at the time $\mathrm{O}_{2}$ contacts cladding, the cladding will oxidize rapidly In addition, if temperatures are high and $\mathrm{O}_{2}$ can contact the waste (penetrate the cladding) it will oxidize with significant volume increase thereby bursting the cladding. Furthermore, oxidized fuel is much more soluble than non-oxidized fuel WP temperature depends on the rate of heat transfer between the WP and its surroundings Heat transfer rate, in turn, depends on whether or not backfill is used, the spacing between drifts and between WPs, the thermal output of waste, and other factors The heat transfer rate from WPs is not expected to be particularly sensitive to the presence within the repository of liquid water or its chemistry The mode of heat transfer may be impacted, as well as distributed along the drift, but overall transfer will be fairly insensitive

Breach of the outer barrier is determined by its corrosion rate, particularly the localized rate of attack or "pitting rate." TSPA95 analysis suggests that the depth of pits in the corrosion-allowance material can be modeled statistically by a random pitting factor times the general corrosion depth The general corrosion 
rate is a function of NFE conditions (humid air or aqueous surroundings) For humid air conditions, the corrosion rate is much more sensitive to relative humidity than to temperature Some of the rate parameters also depend strongly on the chemical composition of solids on the WP surface, because the composition of salts can control the humidity at which a liquid film can for $m$ These solids could be manufacturing residues or salts left by the evaporation of water

Breach of the inner corrosion-resistant barrier will be controlled almost entirely by the internal environment until the outer barrier is breached At that time, the NFE could affect corrosion The materials being considered have extremely slow general corrosion rates under anticipated repository conditions The highly localized for ms of corrosion depend on the chemistry of water entering the drift and on microbiological attack The main considerations are halide ions entering the drift, which can substantially increase pitting, and nutrients for microbes, which can accelerate corrosion by creating a more aggressive microenvironment

Even if a container fails, negligible amounts of radioactive material will be released from the repository unless liquid water is advected into the drift, into the breached WP, into the waste form, out of the WP, and into the repository horizon rock Hence, the timing of advected water entry, flux of liquid water, and its chemistry will be the most important NFE variables for performance assessment after failure of WPs All of these issues may be dominated by changes within the NFE from processes involving.

- Introduced materials, such as corrosion products, backfill, and altered drift liner materials

- Mineralogical changes that can influence the hydrologic properties and water chemistry

- Coupled thermal-mechanical-hydrological processes within the $A Z$, which may completely change the flow fields above and below the repository

Such processes could alter the physical and geochemical processes in the NFE that control WP performance as well as the transport of radionuclides in both the unsaturated zone and in the saturated zone below the repository

\subsubsection{Importance of NFE Conditions to Design}

The Performance Assessment implications of NFE conditions suggest that design goals should include the development of an EBS that, in concert with the natural system, will provide a long delay between emplacement and the first contact of waste by water The overall design goal is to prevent water from contacting the waste form as long as possible and to limit the amount of waste contacted by water after contact begins The NFE that develops above the repository may change the amount, chemistry, and mechanisms (location, timing, and duration) of water seeping into drifts and ultimately contacting the waste form Calculated fluxes around the drifts during the first few hundred years, driven by decay heat, are in the range of hundreds of millimeters per year Thus, depending on the design, percolation flux into the drifts from condensed water may far exceed that of meteoric water

Survival of the WP can be greatly increased if the relative humidity at the WP surface is kept low Current calculations suggest that a thermal loading strategy can be used to reduce humid air corrosion during the thermal pulse to rates below those under ambient conditions. The duration and magnitudes of this reduction depend on many factors, including percolation flux Uncertainty exists in the validity of the models used in the calculations. Thus, it is important to experimentally test the thermohydrological model calculations that predict the ability to maintain low relative humidity for thousands of years If the model results are correct, then design decisions can be made to use heat constructively for increasing WP life.

The importance of NFE conditions to design can be seen by current discussions of design modifications Recent results of site investigations indicate that the ambient infiltration flux could average as high as 5 to $10 \mathrm{~mm}$ per year, with large temporal and spatial variations above and below those averages If these ambient fluxes were allowed to contact a significant fraction of the waste inventory, such contact could lead to releases larger than some of the proposed dose standards Hence, conceptual designs are being developed, including measures such as drip shields and ceramic coatings, to divert water from failed packages or to lengthen the package lifetimes, respectively

\subsection{Changes Since Publication of the Preliminary NFER}

\subsubsection{Definitions of Near-Field versus Altered-Zone Environments}

The Preliminary NFER focused on environmental conditions that will have a direct impact on the WP container materials and on the waste form From work that supported the Preliminary NFER, it was recognized 
that interactions between the environment and waste could potentially cause important property changes that could extend for considerable distances into the rock mass or natural system Although the same suite of processes exist in all zones of the perturbed environment, those that dominate the NFE or even the far-field environment (FFE) (essentially, the unperturbed environment) are not necessarily the same as those that dominate in the region between them Therefore, an altered zone (AZ) was defined and is now the focus of considerable attention As noted earlier, information on the AZ is included in this report to provide a complete description of all aspects of the perturbed environment Figure 1-2 is a schematic representation of the near-field environment, altered zone, the far-field environment as defined in this report.

This report defines the near-field environment (NFE) as encompassing the region of rock and drift that is proximal to the WPs and interacts with them The NFE has sometimes been called the WP environment (WPE) In general, the NFE or WPE is where temperatures reach above the boiling point, thus, contact times for rock-water interactions are shorter This environment evolves over time in response to waste emplacement Some of the resulting changes in environmental conditions may be reversible

The $\mathrm{AZ}$ refers to those regions where the rock mass undergoes changes due to coupled processes again related to emplaced waste These changes may also be reversible over long times but are typically long-lived or permanent In general, the $\mathrm{AZ}$ is a region where temperatures are sufficiently low to allow liquid water to exist in pores and fractures, although it may include vapordominated regions as well The $\mathrm{AZ}$ is the region where rates of geochemical interactions with the environmental parameters are a maximum Conditions in the $\mathrm{AZ}$ do not interact directly with the waste packages but, rather, interact with the NFE Furthermore, changes in the AZ are more significant than those in the FFE, where ambient conditions prevail The distinction between the NFE and FFE is based on processes and resultant changes rather than on a single geometric scale The AZ may extend considerably farther for some processes than for others, ranging from tens to hundreds of meters outward from the repository

\subsubsection{Emplacement and Repository Concepts}

An important development since publication of the Preliminary NFER is that major changes in the disposal concept have taken place Emplacement is no longer planned in open boreholes and thin-walled containers Rather, emplacement is currently envisioned in large, multi-barrier WPs within emplacement drifts (horizontal tunnels)

Three repository design options are evaluated in this Near-Field and Altered-Zone Environment Report The three designs are all based on an areal mass loading (AML) of $834 \mathrm{MTU} /$ acre The designs are

- The Advanced Conceptual Rev 00 Design (ACD) (CRWMS M\&O, 1996), as shown in Fig 1-3(a) In the ACD design, the axial center-to-center spacing of WPs varies from 103 to $146 \mathrm{~m}$, and the drift-to-drift spacing is $225 \mathrm{~m}$ Because WP spacing is large in comparison to their length and is from 46 to $65 \%$ as large as the drift spacing, the WP heat tends to be point (or isolated) sources The waste types ate indicated in the figure

- An alternative design has been suggested by LLNL in which the WPs are placed nearly end-toend, as shown in Fig 1-3(b) Two versions of WP spacings are analyzed one with $10-\mathrm{m}$, end-to-end WP spacing; and one with $01-\mathrm{m}$, end-to-end WP spacing (or gaps) This results in center-to-center spacings of 568 to $668 \mathrm{~m}$ The drift spacing to maintain an AML of $834 \mathrm{MTU} /$ acre is $53.8 \mathrm{~m}$, Thus, the WP spacing is roughly 10 to $12 \%$ of the drift spacing, and the WP heat tends to be a line source (conduction between packages of different waste types evens out the differences in heat output) This alternative design is refer red to as the line-load (LL) design

- The 1997 modified design, as shown in Fig 1-4 wherein a slightly larger drift spacing $(28 \mathrm{~m}$ versus $225 \mathrm{~m}$ for the ACD design) is used, together with closer WP spacing (6 6 to $1423 \mathrm{~m}$ versus 103 to $146 \mathrm{~m}$ for the ACD design) The end-to-end gap or spacing for this design is 1 to $85 \mathrm{~m}$ versus 5 to $10 \mathrm{~m}$ for the ACD design, so that there is somewhat less isolation of the heat output. In addition, the WP spacing is a slightly smaller percent of the drift spacing ( 20 to $51 \%$ versus 46 to $65 \%$ for ACD). Thus, the difference between drift and pillar thermal conditions is greater than that for the ACD design

The first two designs are the basis for analysis in Volume II Because the 1997 modified design falls somewhere between the ACD and line-load cases in terms of WP spacing and ratio of WP to drift spacing, the ACD and line-load designs can be viewed as the bounding cases for designs currently under consideration Where the modified design includes 1- to 2-m end-to-end spacing, the line-load analysis is more 


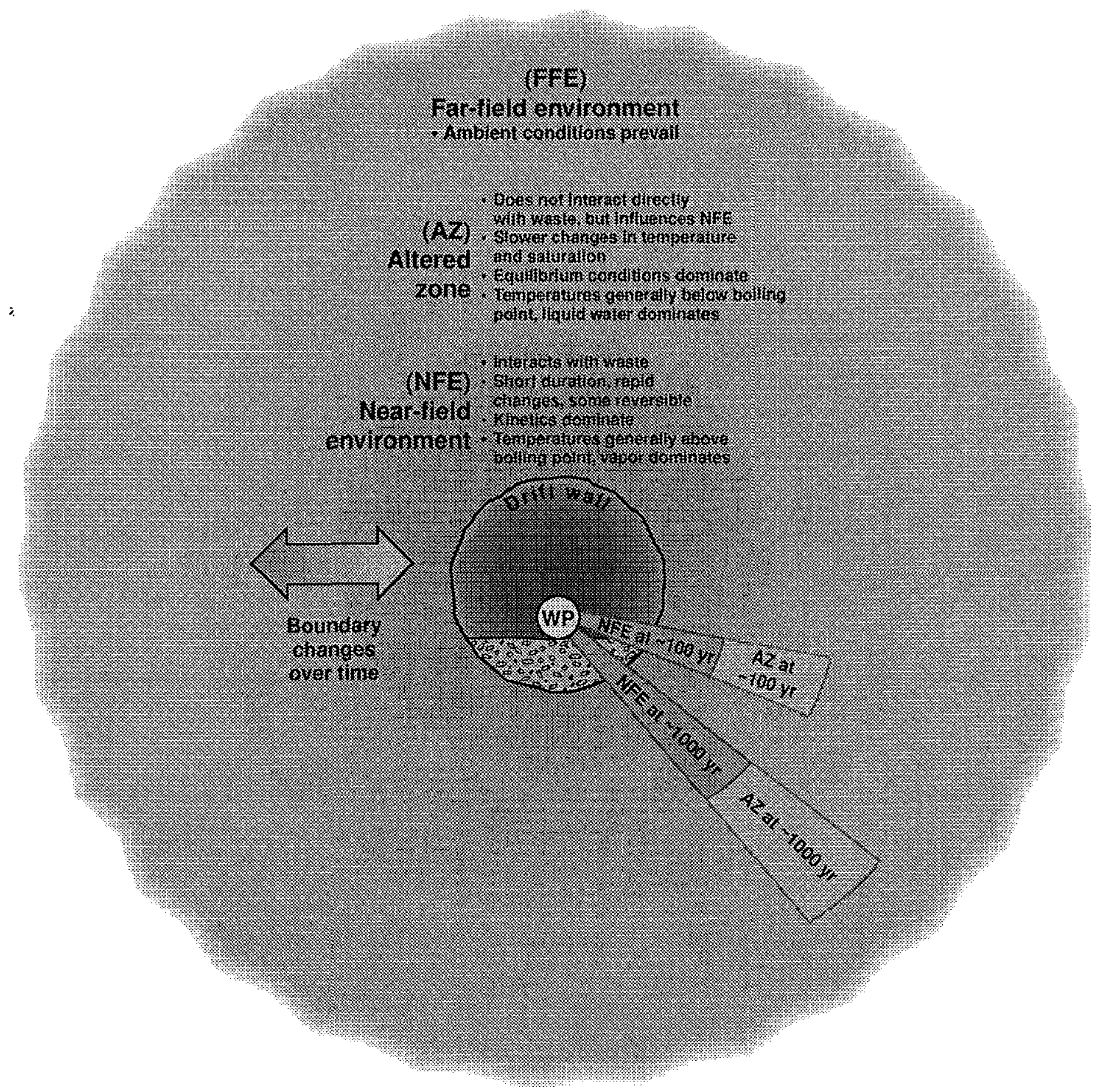

Figure 1-2. Schematic representation of near-field environment (NFE) and altered zone (AZ). 
(a) ACD design

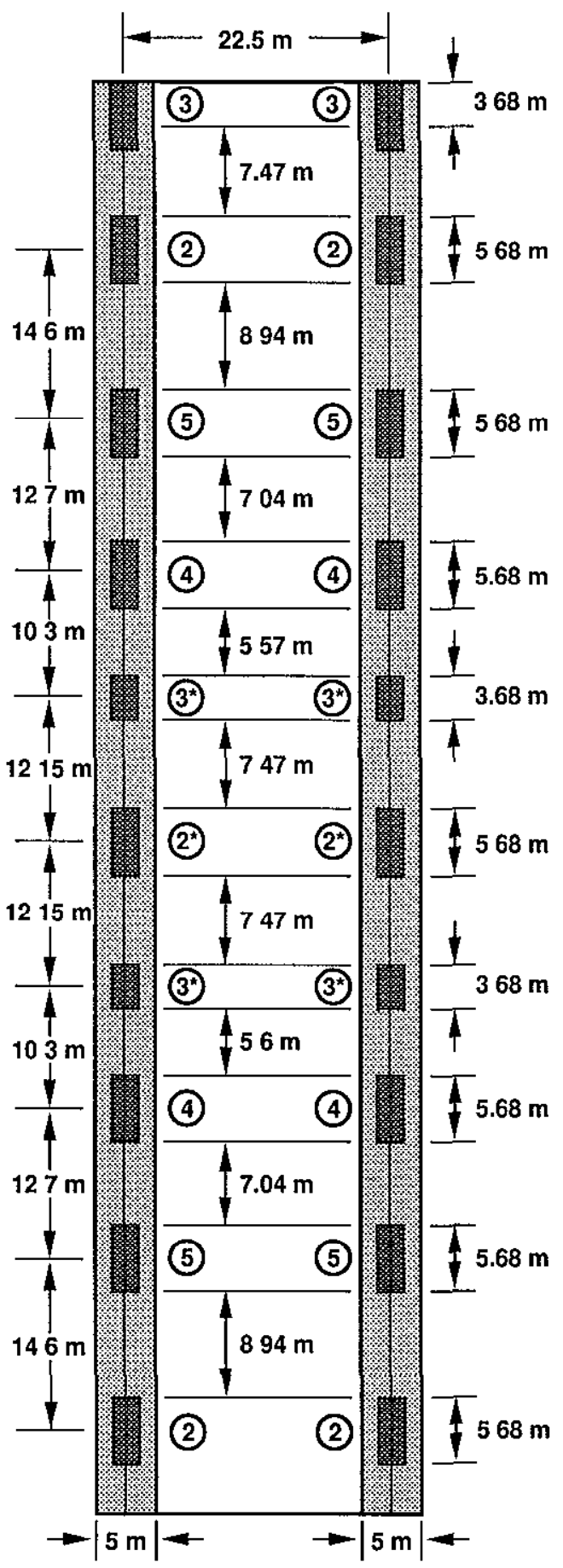

(b) Line-load (LL) design

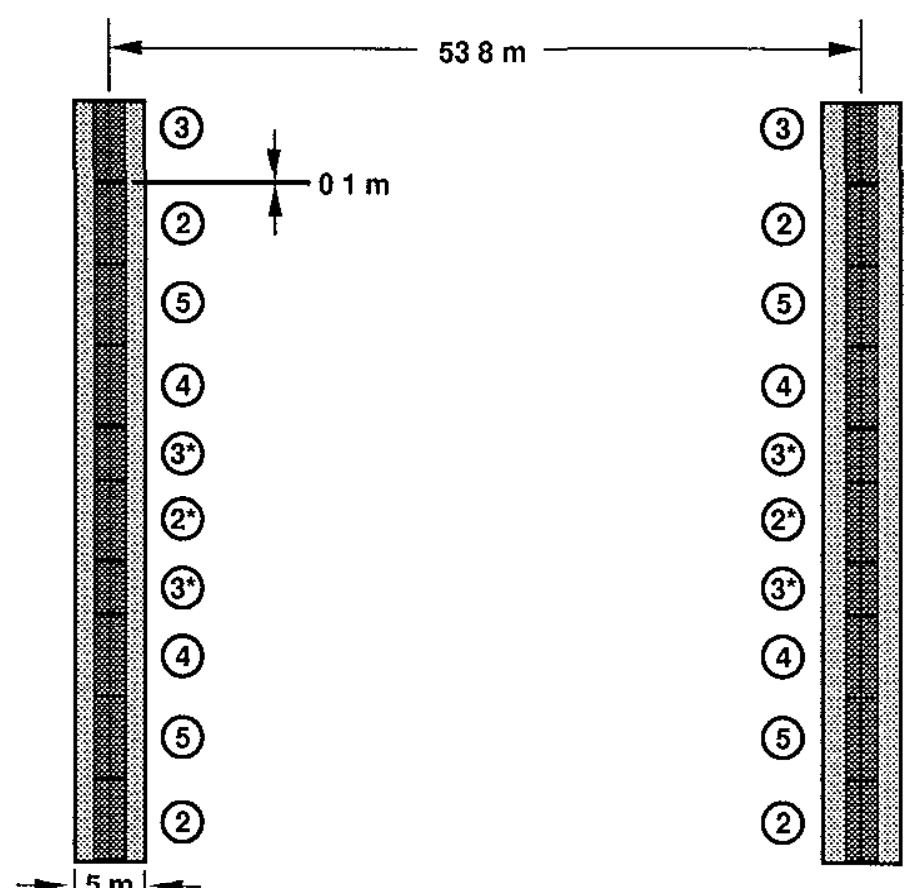

Figure 1-3. Plan view of the WP layout for (a) the ACD point-load design and (b) the LLNL-proposed line-load (LL) design. Both designs result in an AML of 83.4 MTU/acre. (The waste types are described in more detail in Section 4.1.1 of this report.) 

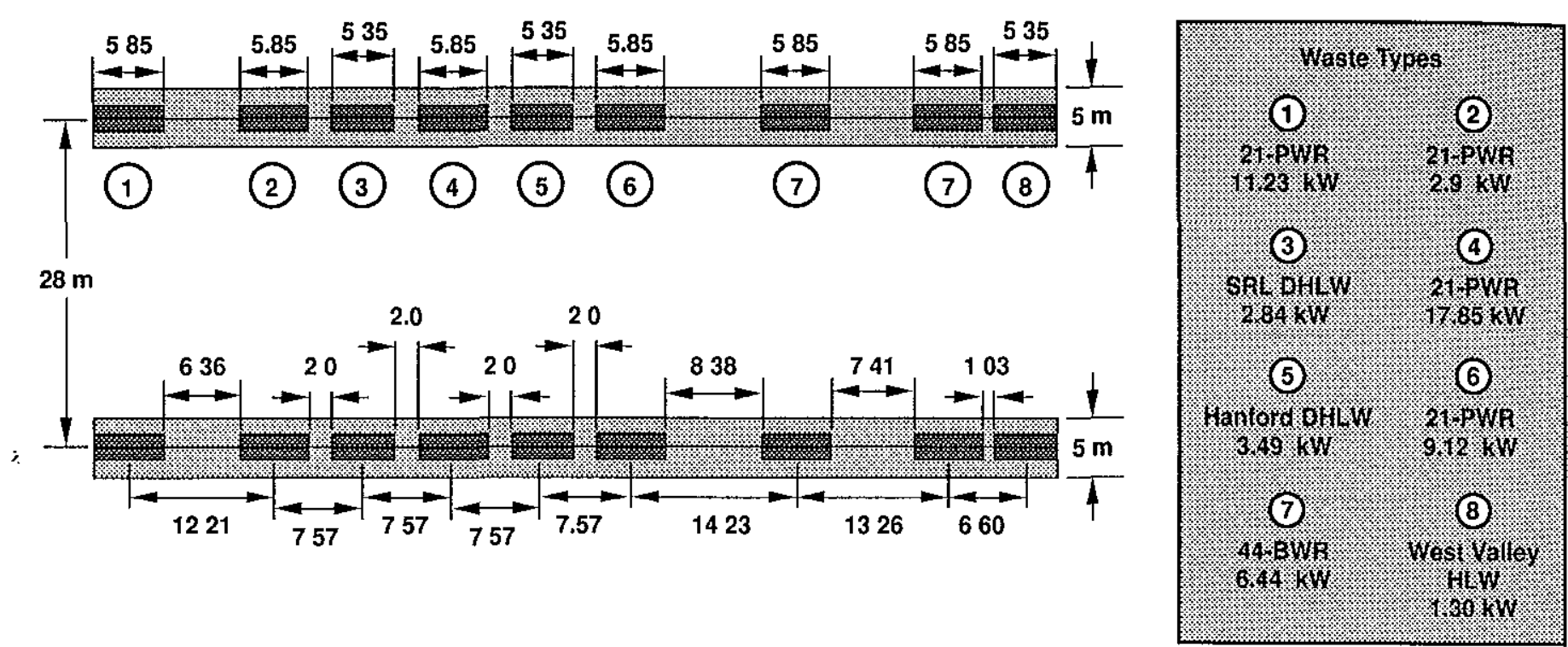

Figure 1-4. Plan view of the WP layout for the 1997 modified repository design. The AML is 85 MTU/acre, and drift spacing $=28 \mathrm{~m}$.

pertinent, where that spacing is closer to $85 \mathrm{~m}$, the ACD analysis is more germane Nevertheless, the $\mathrm{ACD}$ and line-load designs bound the conditions

Whereas the ACD and line-load designs bound the average conditions, the actual distribution of waste types can impact specific conditions associated with individual WPS The ACD and line-load designs use the same distribution of waste types, the only difference is the spacing of WPs and drifts However, the 1997 modified design not only varies the spacing, but also the way the waste types are distributed. Therefore, the environmental conditions given in this report for individual waste types should not be used to necessarily bound the conditions that could be expected for individual waste containers under the modified design The analysis of these environmental conditions will be included in future versions of this report, if the modified design remains pertinent

\subsubsection{Waste Age}

At the time the Preliminary NFER was published, many of the analyses were based on the hottest or youngest waste that was considered likely to be emplaced The age for that waste was approximately 10 years out of core No detailed information on what the actual emplacement age will be is available (some young waste could be emplaced first, depending on how waste is delivered from utilities) However, the age of the overall inventory has increased, and 10-yrold waste is probably an unrealistic value

The ACD design specifies a mix of $10-, 26-$, and 40-yr-old SNF, with 26-yr-old as the most prevalent This represents the typical waste age discussed in $\operatorname{Rev} 1$ As was the case at the time of the Preliminary NFER, several issues continue to make the age of SNF subject to great uncertainty Current discussions are considering interim storage, which could result in considerably older waste at the time of emplacement Waste age has the greatest impact on peak WP and rock temperatures and on the time that the peak occurs. In general, older waste results in a lower peak, which occurs at later times

\subsubsection{Prioritization of Variables and Parameters}

Another distinction between the Preliminary NFER and this report is in the organization of information according to environmental priorities The Preliminary NFER was organized by following a temporal sequence, from preemplacement activities and conditions to postemplacement conditions and performance implications. A primary purpose of that report was to inform the reader about the complexity of changing conditions and interactions over time, and it remains a valuable reference tool for that reason However, the earlier report made no attempt to prioritize processes that may change the environment or the most relevant environmental parameters themselves 
This report includes an attempt to rank order, or at least focus on, the factors or conditions that are important for design decisions and Performance Assessment. The purpose of prioi itizing the most germane factors and focusing on a few design options is to facilitate design decisions and to center attention on which of the myriad variables may be the most important for overall repository design considerations and performance of the EBS

A key consideration in the ranking is the inter actions between the WPs/repository and the NFE These interactions are not separable, that is, the $\mathrm{WP} /$ repository impacts the NFE, but the NFE also impacts performance of the WP/repository For example, we know that areal mass loading (AML) defines the repository environment to a larger extent than does a host of other factors, ranging from drilling and ventilation to radiation field from WPs, although they are also relevant Furthermore, we now know that the way WPs are configured in the repository has a far greater role in determining whether near-field thermal-hydrological (T-H) behavior is beneficial (versus deleterious) than the areal mass loading of the repository itself Indeed, WP layout may be more consequential than variability or uncertainty in the natural system parameters However, the processes within the NFE that are triggered by the waste loading can modify the thermal regime and locally impact the heat distribution so that it is more typical of other AMLs

An overriding characteristic of the interaction between the WPs/repository and the NFE is that it results from coupled processes The significance and magnitude of the coupling varies both spatially and temporally To assist in the prioritization, the dominant processes were considered

The forward and back coupling of processes makes the NFE an environment typified by interrelated interactions. This idea can be shown conceptually by using an interaction matrix of the type proposed by Hudson(1989) Figure 1-5 is an interaction matrix for the NFE, where the key components of the NFE are shown along the diagonal, and the interaction of processes is shown off diagonal Rather than showing all components and all coupling, which can be very complex, it is the objective of this matrix to focus on the key parameters or components and on the key processes The matrix reflects, in general, the organization of this report

Figure 1-6 shows two examples of forward and back-coupling that are typical of both NFE and AZ environments. The first example is the coupling between temperatures and moisture conditions Temperature regimes are directly coupled to moisture conditions through processes of evaporation/dryout Many more processes are discussed in greater detail in the hydrology section (Sec 4 of this report), but in a simplistic view, the moisture conditions are determined by the forward coupling shown on the matrix as the short anow (A) to the right However, the changes to moisture conditions will back-couple to the temperatures by processes involving moisture/heat transfer Vaporization of water and its condensation and return to the vaporization zone (heat pipe) can strongly alter the heat regime This is shown by the short arrow (a) to the left of moisture, indicating back-coupling Another example is the interaction of temperature and moisture conditions through rock-water interactions to change hydrologic properties (see the B-b loops in Fig 1-6) This is a multiply coupled process both temperature and moisture conditions couple to change hydrologic properties, which, in turn, back-couple to the temperature field in modification to convection, water flow pathways, and potential coefficient of conductivity changes, and also potentially to the moisture conditions by modifications of flow pathways

The boxes shown here on the diagonal are generalized topics that identify the major subject areas discussed in this report As Jiao and Hudson (1995) point out, a matrix such as this actually represents one part of a hierarchy of interaction matrices In this 1eport, the general matrix is either expanded as details are required, or a lower-level (more refined) matrix is used to explain the concepts and processes germane to a specific topic

1.2.4.1 Dominant Processes in the NFE. In the NFE, the dominant processes can be grouped into two categories those occurring during the heating phase and those occurring after the waste cools

During the heating phase, the processes will include

- Relative humidity reductions due to strong thermal gradients

- Removal of water from the system, slowing or shutting off many of the processes and resulting in weaker coupling between the geochemistry of system components.

- Thermal expansion under spatially varying thermal gradients, which will change rock and rock-support-system stresses

- Potential microcracking of both rock and rocksupport and invert systems

- Potential precipitation of salts by water removal from vaporization

- Dormancy or sporation of microbial colonies

- Potential carbonation, depending on $\mathrm{CO}_{2}$ availability, of concrete portions of the EBS.

- Displacement of $\mathrm{O}_{2}$ by water vapor 


\begin{tabular}{|c|c|c|c|c|c|c|c|}
\hline Temperaturo & $\begin{array}{l}\text { - Vaporization } \\
\text { - Mobilization }\end{array}$ & $\begin{array}{l}\text { - Rock-water } \\
\text { interactions } \\
\text { - Manmade } \\
\text { material } \\
\text { interactions } \\
\text { (kinetics) }\end{array}$ & $\begin{array}{l}\text { Thermodyn. } \\
\text { of vapor }\end{array}$ & $\begin{array}{l}\text { - Dehydration } \\
\text { - Rock-water } \\
\text { interactions } \\
\text { (kinetics) }\end{array}$ & $\begin{array}{l}\text { - Dehydration } \\
\text { - Rock-water } \\
\text { interactions } \\
\text { - Material } \\
\text { (kinetics) }\end{array}$ & $\begin{array}{l}\text { - Stress } \\
\text { changes } \\
\text { - Coefficlent } \\
\text { impacts }\end{array}$ & $\begin{array}{l}\text { - Microbe } \\
\text { survival } \\
\text { - Metabolic } \\
\text { processes }\end{array}$ \\
\hline \multirow[t]{3}{*}{$\begin{array}{l}\text { - Latent heat } \\
\text { - Heat pipes }\end{array}$} & Moristure & $\begin{array}{l}\text { Volumetrics } \\
\text { - Water } \\
\text { - Rock } \\
\text { - Materials }\end{array}$ & & & $\begin{array}{l}\text { - Volumetrics } \\
\text {-water } \\
\text {-rock } \\
\text { - Contact } \\
\text { modes }\end{array}$ & $\begin{array}{l}\text { Water } \\
\text { contribution } \\
\text { to crack } \\
\text { growth }\end{array}$ & Survival \\
\hline & & Walet & $\begin{array}{c}\text { Vapor } \\
\text { partial } \\
\text { pressure }\end{array}$ & & $\begin{array}{l}\text { - Reaction } \\
\text { thermodyn } \\
\text { - Solubility } \\
\text { - Precipitation } \\
\text { - Carbonation }\end{array}$ & & $\begin{array}{l}\text { - Biomass } \\
\text { generation } \\
\text { - Nutrient } \\
\text { supply } \\
\text { - Metabolic } \\
\text { processes }\end{array}$ \\
\hline & & & $\begin{array}{l}\text { Relative } \\
\text { humidity. } \\
\text { conditions. }\end{array}$ & $\begin{array}{l}\text { Vapor/rock } \\
\text { interactions }\end{array}$ & $\begin{array}{l}\text { Vapor/rock/ } \\
\text { solid } \\
\text { interactions }\end{array}$ & & \\
\hline $\begin{array}{l}\text { Altered } \\
\text { flow } \\
\text { paths }\end{array}$ & $\begin{array}{l}\text { Altered } \\
\text { flow } \\
\text { paths }\end{array}$ & & $\begin{array}{l}\text { Changed } \\
\text { flow } \\
\text { conditions }\end{array}$ & proproticies. & $\begin{array}{l}\text { Water } \\
\text { contact }\end{array}$ & $\begin{array}{l}\text { - Healing of } \\
\text { fractures } \\
\text { - Changes } \\
\text { water avail } \\
\text { for cracking }\end{array}$ & \\
\hline \multirow[t]{2}{*}{$\begin{array}{l}\text { Thermal } \\
\text { conductivity } \\
\text { changes }\end{array}$} & $\begin{array}{c}\text { Water } \\
\text { release/ } \\
\text { consumpt. } \\
\text { in reactions }\end{array}$ & $\begin{array}{l}\text { - Altered } \\
\text { minerals } \\
\text { - Rock-water } \\
\text { interactions }\end{array}$ & $\begin{array}{l}\text { Partial press } \\
\text { (salts) }\end{array}$ & $\begin{array}{l}\text { - Fracture/pore } \\
\text { plugging } \\
\text { - Fracture } \\
\text { healing } \\
\text { - Colloid } \\
\text { transport }\end{array}$ & $\begin{array}{l}\text { Mineral and } \\
\text { solld material } \\
\text { (chariges) }\end{array}$ & $\begin{array}{l}\text { Volume } \\
\text { changes } \\
\text { (phase } \\
\text { transform } \\
\text { and mineral } \\
\text { changes) }\end{array}$ & \\
\hline & & & & $\begin{array}{l}\text { - Closing/ } \\
\text { opening } \\
\text { fractures } \\
\text { - Microcracks } \\
\text { - Coalescence } \\
\text { flow path }\end{array}$ & $\begin{array}{l}\text { - Stress } \\
\text { impacts } \\
\text { - Mineral } \\
\text { phase } \\
\text { - Microcracks } \\
\text { (new surfaces) }\end{array}$ & $\begin{array}{l}\text { Mechanical. } \\
\text { Conditions: } \\
\text { (changes). }\end{array}$ & \\
\hline N/A & $\begin{array}{l}\text { Biomass } \\
\text { water } \\
\text { consumpt/ } \\
\text { release }\end{array}$ & $\begin{array}{l}\text { Biomass } \\
\text { micro- } \\
\text { chemistry }\end{array}$ & $\begin{array}{l}\text { Biomass } \\
\text { control } \\
\text { of T/RH } \\
\text { relations }\end{array}$ & $\begin{array}{l}\text { Biomass } \\
\text { plugging }\end{array}$ & $\begin{array}{c}\text { Biomass } \\
\text { dissolution } \\
\text { mineralization }\end{array}$ & $\begin{array}{l}\text { - Biomass } \\
\text { microcracking } \\
\text { - Volume } \\
\text { changes }\end{array}$ & $\begin{array}{l}\text { Mlarobiotic } \\
\text { conditions }\end{array}$ \\
\hline
\end{tabular}

Figure 1-5. Simplified matrix showing coupled processes in the NFE.

The rates and significance of coupling will depend on the balance between two factors that have opposite effects. At elevated temperature, kinetics are increased, which will increase the rates and significance of coupling with introduced materials and microbial communities However, when temperatures approach or reach the boiling point, evaporation and boiling will remove water from the system Without water, microbial processes become minimal or are eliminated, many geochemical processes are minimized or 


\begin{tabular}{|c|c|c|c|c|c|c|c|}
\hline Tenperatire. & $\begin{array}{l}\text { Yaporization } \\
\text { hobilization } \\
\end{array}$ & $\begin{array}{l}\text { - Rock-water } \\
\text { interactions } \\
\text { Manmade. } \\
\text { materatal } \\
\text { Interactions } \\
\text { (kinetics) }\end{array}$ & $\begin{array}{l}\text { B } \\
\text { Thermodyna. } \\
\text { of vaport }\end{array}$ & $\begin{array}{l}\text { Dehydration } \\
\text { pock-water } \\
\text { interactions } \\
\text { (kinetles) }\end{array}$ & $\begin{array}{l}\text { - Dehydration } \\
\text { - Rock-water } \\
\text { interactions } \\
\text { - Material } \\
\text { (kinetics) }\end{array}$ & $\begin{array}{l}\text { - Stress } \\
\text { changes } \\
\text { - Coefficient } \\
\text { impacts }\end{array}$ & $\begin{array}{l}\text { - Microbe } \\
\text { survival } \\
\text { - Metabolic } \\
\text { processes }\end{array}$ \\
\hline $\begin{array}{l}\text { - Latentu heat } \\
\text { - Heat pipes } \\
\text {. }\end{array}$ & . & $\begin{array}{l}\text { Volumetrics } \\
\text { Water: } \\
\text { - Rock } \\
\text { - Materials }\end{array}$ & $\mathrm{B}$ & & $\begin{array}{l}\text { - Volumetrics } \\
\text {-water } \\
\text {-rock } \\
\text { - Contact } \\
\text { modes }\end{array}$ & $\begin{array}{l}\text { Water } \\
\text { contribution } \\
\text { to crack } \\
\text { growth }\end{array}$ & Survival \\
\hline : & & chemisty & $\begin{array}{c}\text { Vapor } \\
\text { partial } \\
\text { pressure }\end{array}$ & & $\begin{array}{l}\text { - Reaction } \\
\text { thermodyn } \\
\text { - Solubility } \\
\text { - Precipitation } \\
\text { - Carbonation }\end{array}$ & & $\begin{array}{l}\text { - Biomass } \\
\text { generation } \\
\text { - Nutrient } \\
\text { supply } \\
\text { - Metabolic } \\
\text { processes }\end{array}$ \\
\hline 3 & 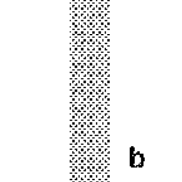 & & Relative. & $\begin{array}{l}\text { Vaporfrock } \\
\text { interactions } \\
\end{array}$ & $\begin{array}{l}\text { Vapor/rock/ } \\
\text { solid } \\
\text { interactions }\end{array}$ & & \\
\hline $\begin{array}{l}\text { Altered } \\
\text { flow } \\
\text { paths }\end{array}$ & $\begin{array}{l}\text { Altered } \\
\text { flont : } \\
\text { paths }\end{array}$ & & $\begin{array}{l}\text { Changed } \\
\text { condiowitions }\end{array}$ & Hydrologlo & $\begin{array}{l}\text { Water } \\
\text { contact }\end{array}$ & $\begin{array}{l}\text { - Healing of } \\
\text { fractures } \\
\text { - Changes } \\
\text { water avail } \\
\text { for cracking }\end{array}$ & \\
\hline $\begin{array}{l}\text { Thermal } \\
\text { conductivity } \\
\text { changes }\end{array}$ & $\begin{array}{c}\text { Water } \\
\text { releasel } \\
\text { consumpt. } \\
\text { in reactions }\end{array}$ & $\begin{array}{l}\text { - Altered } \\
\text { minerals } \\
\text { - Rock-water } \\
\text { interactions }\end{array}$ & $\begin{array}{l}\text { Partial press } \\
\text { (salts) }\end{array}$ & $\begin{array}{l}\text { - Fracture/pore } \\
\text { plugging } \\
\text { - Fracture } \\
\text { healing } \\
\text { - Colloid } \\
\text { transport }\end{array}$ & $\begin{array}{l}\text { Girieral and } \\
\text { solid material } \\
\text { (changes) }\end{array}$ & $\begin{array}{l}\text { Volume } \\
\text { changes } \\
\text { (phase } \\
\text { transform } \\
\text { and mineral } \\
\text { changes) }\end{array}$ & \\
\hline & & & & $\begin{array}{l}\text { - Closing/ } \\
\text { opening } \\
\text { fractures } \\
\text { - Microcracks } \\
\text { - Coalescence } \\
\text { flow path }\end{array}$ & $\begin{array}{l}\text { - Stress } \\
\text { Impacts } \\
\text { - Mineral } \\
\text { phase } \\
\text { - Microcracks } \\
\text { (new surfaces) }\end{array}$ & $\begin{array}{l}\text { Mechanical: } \\
\text { Conditions: } \\
\text { Ichangest? }\end{array}$ & \\
\hline N/A & $\begin{array}{l}\text { Biomass } \\
\text { water } \\
\text { consumpt/ } \\
\text { release }\end{array}$ & $\begin{array}{l}\text { Biomass } \\
\text { micro- } \\
\text { chemistry }\end{array}$ & $\begin{array}{c}\text { Biomass } \\
\text { control } \\
\text { of T/RH } \\
\text { relations }\end{array}$ & $\begin{array}{l}\text { Biomass } \\
\text { plugging }\end{array}$ & $\begin{array}{c}\text { Biomass } \\
\text { dissolution/ } \\
\text { mineralization }\end{array}$ & $\begin{array}{l}\text { - Biomass } \\
\text { microcracking } \\
\text { - Volume } \\
\text { changes }\end{array}$ & $\begin{array}{l}\text { Microbiotic } \\
\text { conditions }\end{array}$ \\
\hline
\end{tabular}

Figure 1-6. Forward and back coupling processes in the NFE.

eliminated (except vapor processes, which can be increased), and aqueous corrosion or interactions with man-made materials are shut down If water removal is significant, many of the coupled thermal-hydrologicalgeomechanical-geochemical processes are eliminated
After cooldown, water may possibly return to the NFE through the fractured, densely welded host rock mainly by relatively rapid fracture flow and by very slow movement of moisture and resaturation through the matrix The amount of water that can return 
through fractures will depend on how much of the condensate from water driven out of the NFE during the thermal phase can be stored in fractures, on percolation flux at the time, and on any irreversible thermal-hydrological-geochemical processes that will take place during the heating period

If water returns, the NFE will be dominated by strongly coupled processes Depending on how effectively the thermal field prevents water return during heating and on how far the water removal extends, the coupling will be te-established, but with lower kinetics because of lower temperatures The NFE will likely be strongly influenced by the effects of processes that took place during the thermal phase Water chemistry will mainly depend on interactions with introduced materials, precipitated salts left by the water that was removed, and, to some extent, on changes in mineralogy of the NFE rock. Interactions with introduced materials, particularly concretes, will depend on modifications to the concretes that resulted during the thermal pulse Some effects, such as precipitated salts, may decrease with time Because the time frames considered can be lengthy (hundreds to thousands of years), the significance of these processes must be based on the specific time of concern

\subsubsection{Dominant Processes in the AZ}

Environment. In the AZ, hydrological processes will be dominated by increased water availability and saturation associated with vapor condensation at elevated temperatures Geochemical processes will be dominated by rock-fluid interactions, vapor contact at elevated temperatures, and reactive transport The $\mathrm{AZ}$ will be less transient or dynamic than the WPE in that residence times for water will be much longer Because of the durations, the processes will tend to go toward completion, and the changes will tend to be more dramatic

Many of the geochemical processes in the regions of the NFE and AZ will be the same (for example, recrystallization, dissolution and precipitation, cation exchange, sorption, etc) However, their impact on rock properties will be different because of contrasts in heating and cooling rate and in the abundance and temperature of liquid water The difference will be in the magnitude and nature of chemical and mineralogical changes, and in the duration of specific processes As a result, performance of the overall repository system will be affected differently in the two regions because of mineral-water interactions In addition to mineral-water interactions, there will be a significant difference due to introduced material interactions This is true not only because the introduced materials are located mainly in the drifts or NFE but also because of the higher temperatures, dynamic or transient water conditions, and the very large volume percent of introduced materials that occurs in the NFE as opposed to the $\mathrm{AZ}$ Thus, introduced materials will be a significant, if not dominant, factor in determining the NFE, whereas mineral-water interactions will be one of the principal factors that determines the $\mathrm{AZ}$ environment

1.2.4.3 Summary of Prioritization. Although the dominant processes vary for the NFE and AZ, evaluations have shown the overriding importance of hydrology and geochemistry, and the strong influence of heat on those processes Thus, we can begin to prioritize the most essential issues related to EBS design and performance It is logical to break down the parameters and processes into two lists Table 1-1 identifies the most important NFE and AZ parameters, that is, the environmental parameters shown to have the greatest effects on

Table 1-1. Near-field and altered-zone environmental parameters.

I. Parameters shown to have the greatest effects on the EBS and WP

Amount of water contacting the WPs

Water chemistry

Relative humidity

II Parameters expected to have moderate or variable effects on the EBS and WP

Native microbial species

III Parameters expected to have minimal (little or controllable) effects on the EBS and WP

(These factors could have secondary effects through coupling with move significant parameters.)

Rock fall physically damaging metal waste containers (different priority if ceramic)

Geomechanics 
the EBS and WPs Table 1-2 identifies, in approximate order, the factors shown to have the greatest influence on the NFE and AZ Subsequent sections of this report discuss these parameters in more detail and some of the complex processes and interactions among them

\subsubsection{Single versus Multiple Repository Design Efforts}

Repository design must not only consider what the NFE is, but once design decisions are made, it must also consider how those decisions will affect the NFE This is an iterative process It involves a determination of the design that will function within the given environment, a consideration of the environment that will then develop as a result of that design, and revision of the design, as necessary, for the newly developed environment

An alternative to such an iterative approach is to assume different designs and then to assess the NFE for those design alternatives This is akin to a sensitivity study - which has the advantage of a shorter schedule because the second assessment is eliminated-and it is the approach taken in this report However, a disadvantage is that many different cases must be assessed and repor ted The Preliminary NFER included sensitivity analyses, however, it was more focused on the iterative approach In contr ast, $\operatorname{Rev} 1$ evaluates multiple designs and sensitivity To minimize the cumbersome nature of reporting all cases that have been considered, Volume I focuses on a few design assumptions that represent the most likely ones, or reference designs (ones that bound the 1997 modification) We refer the reader to Volume II for information on the many other design options that were evaluated

\subsection{Modeling Advances}

Whereas considerable progress has been made since publication of the Preliminary NFER in the characterization of YM, particularly in the availability of the underground drifts and ESF facilities for sampling and mapping, perhaps even more progress has been made in the conceptual understanding and models of coupling and in the computer codes available to assist in the analyses of those conceptualizations Of course, there have also been significant improvements in the capabilities of computers to handle the computationally intensive requirements of these models and codes This report is not focused on discussions of those advances The reader can find more detailed discussion in Hardin and Chesnut (1997) and in Glassley (1997)

Of course it needs to be understood that although there have been advances in models, they are nonetheless simplifications of the real world The material in this report relies heavily on numerical models of an idealized system with simplified processes and properties and should not be construed as actual, detailed $\mathrm{NFE}$ and $\mathrm{AZ}$ conditions unless verified by testing etc This does not mean that the analyses are useless, nor does it mean that they should not be used in making

Table 1-2. Factors that influence the near-field and altered-zone environment.

I Factors shown to have the greatest effects on the NFE and AZ

WP layout

WP heat output

Areal mass loading (AML)

Backfill

Introduced (man-made) materials

Percolation flux

Microbiological effects

II Factors expected to have minimal (little or controllable) effects on the NFE and AZ

Construction activities, including

- drilling

- excavation

- ventilation

Radiation field from intact WPs

Earthquakes 
decisions As discussed in the LBT status report (Wilder et al , 1997), it will be impossible to measure these processes and properties directly for the time scales required, and therefore models with their inherent assumptions will always be the basis for understanding the evolving environment and for making decisions It will be imperative that careful programs be conducted that are design to test these models While some of the uncer tainties will be reduced with time, the same caveat-that the models are idealized and simplified abstractions of the real world-will always apply

\subsection{Focus of Current Work}

As stated, interactions between the EBS components and the NFE are, to a large extent, dominated by the possible presence of liquid water and elevated humidity For example, leaching of most of the radionuclides from the waste forms is almost exclusively aqueous, and corrosion of most candidate container materials is either dominated by liquid water contact or by relative humidity that is sufficiently high to allow water films to form on the containers The transport of radionuclides through the rock mass depends exclusively on aqueous mechanisms (except for gaseous radionuclides associated with spent fuel and those generated slowly by radioactive decay from the glass waste form). Thus, an assessment of EBS performance can focus on hydrological aspects and associated geochemistry Fracture flow is a key issue As noted in the Preliminary NFER, "if radionuclide transport does occur, it will most likely involve fracture flow" (Wilder, 1993)
We are now focusing almost entirely on the following processes as priorities

1 Understanding how and when water will contact the WPs, especially during the first several thousand years following waste emplacement This work includes determining the amount of fluids, as well as vapor or gases, that contact the container or waste forms, and optimizing ways to keep water away from the WPs

2 Determining the chemical composition of fluids and gases that contact the container or waste forms Introduced man-made materials, such as the containers, invert material, cement grout, concrete, and rock-support system, will be a dominant factor in water chemistry The chemistry of water contacting the WPs will also depend on whether water drains quickly down fractures or migrates slowly in the matrix and on process such as refluxing

3 Understanding what happens in the $\mathrm{AZ}$ at distances that can extend more than hundreds of meters away from the repository This focus arises because conditions in the AZ set the initial water chemistry as well as changes in hydrological proper ties

4 Determining how geomechanics couples to the hydrology and geochemistry Issues include

- Microfracturing to create new flow paths and reactive surfaces.

- Fracture closing or changed hydrologic pathways

- Altered pore spaces

5 Determining solubility and speciation of radionuclides in the near-field fluids 


\subsection{Ambient Yucca Mountain Environment}

Yucca Mountain (YM) consists of a layered sequence of variably fractured, nonwelded to densely welded tuff units with an eastward tilt of about 5 to $30^{\circ}$ (Montazer and Wilson, 1984) At YM, the thickness of the unsaturated zone varies from 500 to $750 \mathrm{~m}$ The potential repository is located within this unsaturated zone, lying approximately $350 \mathrm{~m}$ below the ground surface and $225 \mathrm{~m}$ above the water table (Klavetter and Peters, 1988) Montazer and Wilson (1984) also report the absence of perennial streams at $\mathrm{YM}$ Therefore, recharge due to rainfall occurs episodically Flint (1991) reports that the mean annual precipitation at XM varies (areally) from 150 to $240 \mathrm{~mm} / \mathrm{yr}$

At the time of preparation of the Preliminary NFER in 1993, it was reported that overall infiltration was expected to be very low Percolation flux estimates based on equivalent continuum model (ECM) analysis for the repository horizon ranged from 005 to $10 \mathrm{~mm} / \mathrm{yr}$, possibly upward due to vapor transport from the underlying saturated zone (see Vol II, Sec 10) (Montazer and Wilson, 1984) More recent estimates based on infiltration studies, $36 \mathrm{Cl}$, calcite, and other evidence, have been levised upward to a range from 10 to $15 \mathrm{~mm} / \mathrm{yr}$ (Bodvarsson and Bandurraga, 1996) It is judged that $5 \mathrm{~mm} / \mathrm{yr}$ is the most likely value However this revision of Volume I, focuses on $03 \mathrm{~mm} / \mathrm{yr}$ to be consistent with values used in Volume II

The geologic unit being considered as the host rock is in the Topopah Spring Tuff (Tpt) of the Paintbrush Group The host rock is a densely welded, fractured, devitrified ash-flow tuff The Preliminary NFER reported estimates of fracture density ranging from 20 to 42 fractures per cubic meter based on information available at that time, which was obtained from surface outcrops and from boreholes (Macintyre et al , 1990; Scott and Castellanos, 1984; Dudley et al , 1990, Wilder, 1990) These data did not distinguish fracture spacing along any direction, although attempts to estimate fracture spacing in terms of fractures per meter were representative (see Volume 1 , Rev 0) Since the Preliminary NFER, the main drift of the Exploratory Studies Facility (ESF) has been excavated and mapped Results of mapping (Albin et al., 1997) more than 10,000 fractures within the middle nonlithophysal and lower lithophysal zones (upper repository horizon strata) indicate that there are four sets of fractures The first set is oriented at $120^{\circ} / 80^{\circ}$ (strike/dip) The second set is oriented $220^{\circ} / 80^{\circ} \mathrm{A}$ third set is oriented approximately $310^{\circ} / 30^{\circ}$ A fourth set was identified that has strike similar to sets 1 and 3 , ranging between $270^{\circ}$ and $330^{\circ}\left(90^{\circ}\right.$ to $150^{\circ}$ ), and dips intermediate between these sets at $40^{\circ}$ to $60^{\circ}$

The relative prominence of the fracture sets depends on location within the drift, however Set 1 is always, by far, the most prominent (from 47 to $74 \%$ of total fractures) Set 2 is the next most dominant of those sets that are associated with a particular orientation (as opposed to random) and varies from 5 to $22 \%$ of the fracture population These two sets comprise 61 to $79 \%$ of the fractures observed in the drift, as is clearly shown by the azimuth distribution histogram (Fig, 2-1) A correction for or ientation bias from drift ol ientation was made to evaluate Set 2 However, in the author's view, the drift and fracture Set 2 orientations were too similar (only $17^{\circ}$ from the edge of the distribution that starts at $200^{\circ}$ ), and the correction can be misleading (Yow and Wilder, 1983) Albin et al (1997) recognized this problem and used an averaging method to moderate the effect Albin et al (1997) interpreted four fracture domains within the drift These domains occur in separate intervals of the drift, as shown in Fig 2-2 As can be observed, the fracture frequency average--except in Domain 3, which was defined as a fracture zone-is about 25 fractures per meter. In the fracture zone, the average is about 5 fractures per meter

One of the critical NFE aspects of the fractures is the way the fractures are distributed Set 1 is dominant, and its spacing becomes critical, as will be discussed in Section 4 of this report The average spacing of Set 1 is 0.89 fractures per meter for domain 1, 1.1 fractures per meter for domain 2, 31 fractures per meter for domain 3 , and 12 fractures per meter for domain 4 Fracture aperture estimates range from 43 to $127 \mu \mathrm{m}$ (Buscheck, 1990) As discussed in greater detail in Volume II, this fracturing has a major impact on the NFE

\subsection{Geologic Framework}

The geologic framework was originally described in Chapter 1, Volume 1 of the Site Characterization Plan (SCP, DOE, 1988) The SCP pointed out that Yucca Mountain is in the southern part of the Great Basin, the northernmost subprovince of the Basin and Range 


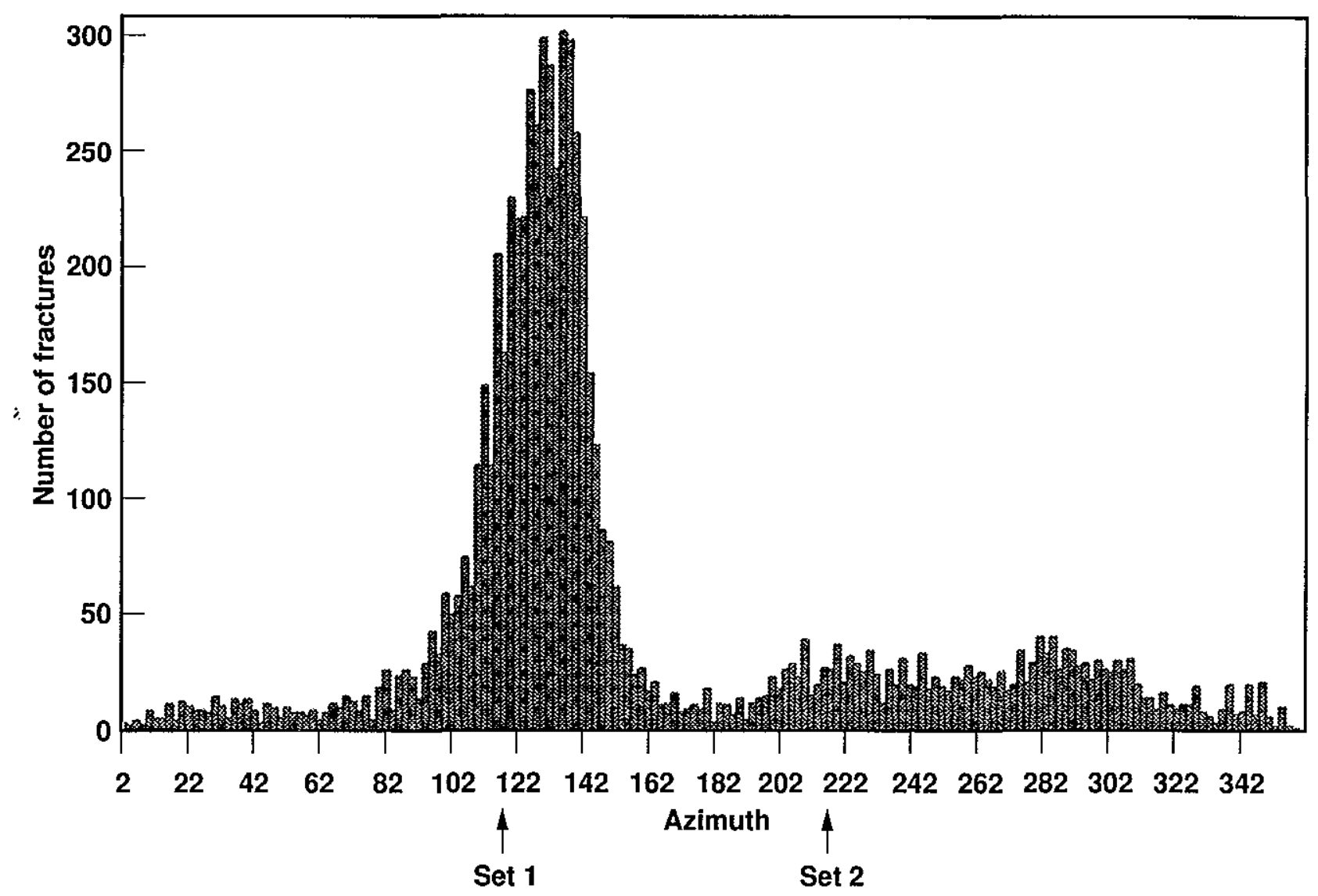

Figure 2-1. Distribution of fractures by azimuth in the main drift. Modified from Albin et al., (1997).

physiographic province. The overall structural features that characterize the Basin and Range province are more or less regularly spaced, subparallel mountain ranges and intervening intermontane sedimentary basins that are formed by extensional faulting

As noted in ISM2 0 (CRWMS M\&O, 1997), YM consists of several outflow volcanic sheets, the thickest of which are units within the Paintbrush Canyon Group, which includes the Topopah Spring Tuff (Tpt), which is the repository horizon unit Faulting at YM is typical of Basin and Range physiographic province The repository block as identified in the SCP is roughly defined by Solitario Canyon and Ghost Dance faults along the west and east boundaries, respectively, with possible fault bounding on the north Subsequent investigations have refined this understanding, but these refinements do not make significant changes in the impacts of the overall geologic structure on the NFE

The stratigraphy of the YM area, as defined in the $\mathrm{SCP}$, has been refined over the years and subdivided into units that are useful in performance analyses The Tpt is a formal stratigraphic unit and has been subdivided into more specific thermal/mechanical units, which are particularly useful for hydrologic analyses Both the formal and thermal/mechanical stratigraphic columns are shown in Fig 2-3 A complete listing of geologic units as reported in the ISM2 0 (CRWMS $\mathrm{M} \& O, 1997)$ is shown in Table 2-1 For the remainder of this report, the thermal/mechanical unit designation is used Figure 2-4 shows an east-west cross section through the repository site. The potential repository horizon is in the thermal/mechanical TSw2 unit (Ortiz et al, 1985) This unit is a devitrified, welded, rhyolitic tuff that is moderately to densely welded tuff It appears to consist of a mass of intact blocks separated by ubiquitous plana cooling fractures, which tend to be strata-bound, and by discrete tectonic fractures, which may not be planar but tend to be more extensive Price, Connolly, and Keil (1987) report that the majority of the rock is a fine-grained 


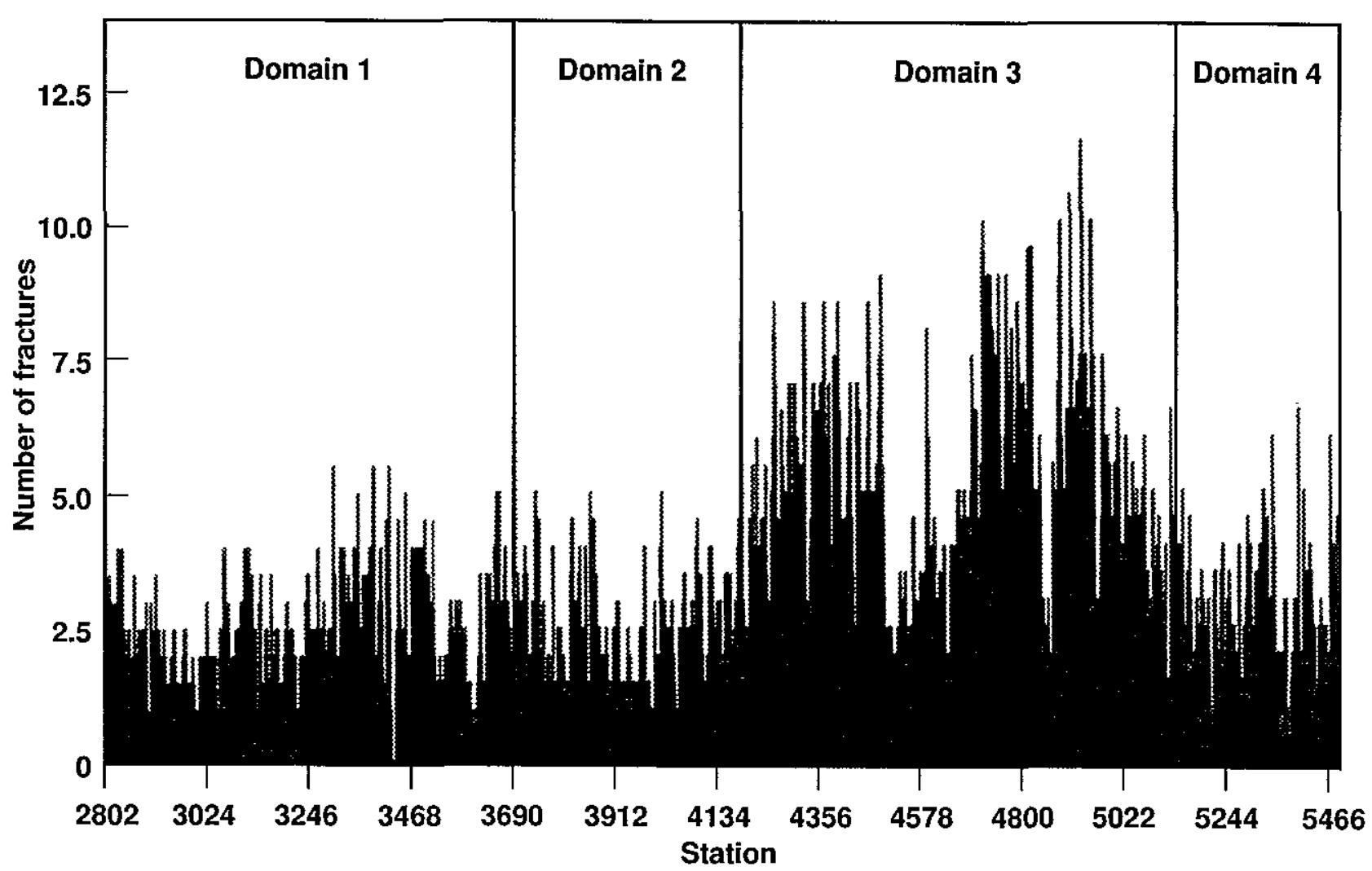

Figure 2-2. Fracture-density histogram plots of the number of fractures, cooling joints, and vapor-phase partings per meter in each 2-meter interval along the main drift. Modified from Albin et al., (1997).

matrix containing gray-colored regions of vaporphase-altered material that vary in size and are quite common. In addition to these main components, the rock contains small (open and closed) lithophysal and "healed" fractures filled with quartz or calcite.

A detailed, 3D, site-scale hydrological model has also been prepared by Bodvardsson and Bandurraga (1996). This model provides detailed descriptions of the hydrologic units and their properties

\subsection{Geochemistry}

Petrographic analysis shows that the repository horizon tuff consists of primary minerals, such as sanidine, plagioclase, quartz, biotite, iron-titanium oxides, allanite and zircon, that formed at temperatures in excess of $600^{\circ} \mathrm{C}$ in a magma chamber prior to eruption of the tuff It also contains secondary minerals, such as cristobalite, quartz, alkali feldspars, and smectite clays, that formed during cooling and later alteration of the tuff at temperatures less than $500^{\circ} \mathrm{C}$. The chemical composition of the rock is shown in Table 2-2 Because these values were determined from cores, they may not be representative of the composition of mineral coatings along fractures

Distinguished from the primary and secondary minerals are the minerals that formed on fracture surfaces [e g, calcite, smectite, quartz, cristobalite, alkali feldspar, and the zeolites mordenite, chabazite, clinoptilolite, and heulandite (Carlos, 1985, 1989, Lin and Daily, 1989)] These minerals form layers that possess physical properties distinct from those minerals in the rock matrix and are estimated to be a maximum of $5 \%$ of the total rock mass. The mineral assemblage along a fracture surface varies from one location to another, and appears to reflect, at least in part, the previous location of the saturated zone (Carlos, 1989) Based on X-ray diffraction (XRD) analyses, the mineral assemblage of a typical fracture surface within the repository horizon might consist of $7 \%$ smectite, $7 \%$ cristobalite, $12 \%$ quartz, $29 \%$ clinoptilolite, and $45 \%$ alkali feldspar (Carlos, 1985) 


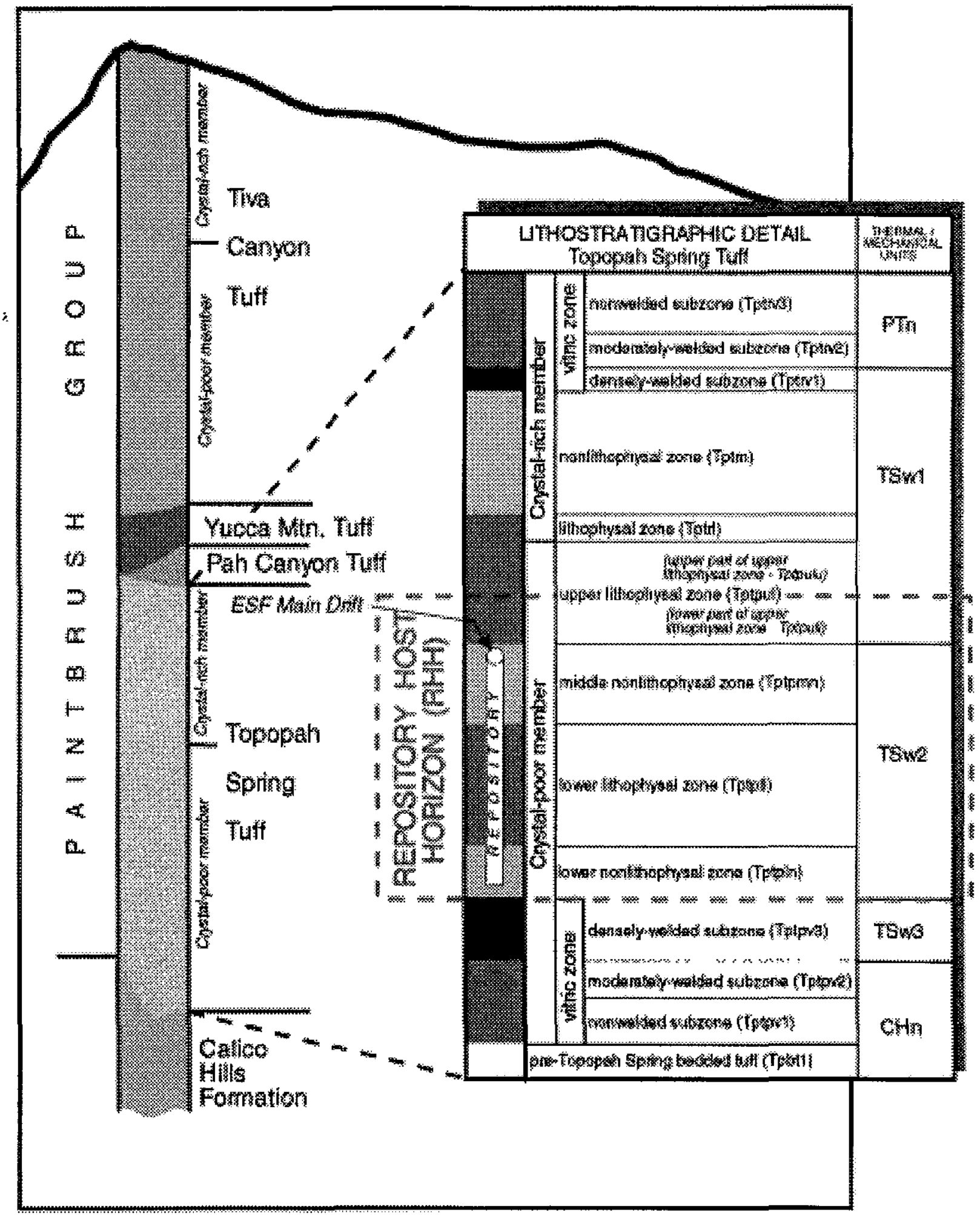

Figure 2-3. General stratigraphic column at Yucca Mountain. Modified from Elayer (1997). 
Table 2-1. Geologic units as reported in ISM2.0 (CRWMS M\&O, 1997).

\begin{tabular}{|c|c|c|}
\hline $\begin{array}{l}\text { Modeled units } \\
\text { (unit names are in column 2) }\end{array}$ & $\begin{array}{c}\text { Stratigraphy } \\
\text { (Buesch et al, 1996, } \\
\text { Sawyer et al , 1994) }\end{array}$ & $\begin{array}{c}\text { Thermal/ } \\
\text { mechanical units } \\
\text { (Ortiz et al , 1985) }\end{array}$ \\
\hline alluvium & NA & UO \\
\hline Rainier Mesa Tuff & Trm & UO \\
\hline rhylite of Comb Peak & Tpk & $\mathrm{N} / \mathrm{A}$ \\
\hline Tiva Canyon Tuff undiffer entiated & $\mathrm{Tpc}$ & $\mathrm{TCw}$ \\
\hline crystal-poor densely welded vitric subzone of Tiva Canyon Tuff & Tpcpv3 & TCw \\
\hline crystal-poor nonpartly welded vitric subzone of Tiva Canyon Tuff & Tpсpv1-2 & PTn \\
\hline Pre-Tiva Canyon Tuff bedded tuff & Tpbt4 & PTn \\
\hline Yucca Mountain Tuff & Tpy & PTn \\
\hline pre-Yucca Mountain Tuff bedded tuff & Tpbt3 & PTn \\
\hline Pah Canyon Tuff & Tpp & PTn \\
\hline pre-Pah Canyon Tuff bedded tuff & Tpbt2 & PTn \\
\hline Topopah Spring Tuff upper nonpartly-welded vitric subzones & Tptrv2-3 & PTn \\
\hline Topopah Spring Tuff upper densely welded vitric subzone & Tptrv1 & TSw1 \\
\hline Topopah Spring Tuff xl-rich nonlithophysal zone & Tptrn & TSw1 \\
\hline Topopah Spring Tuff xl-rich lithophysal zone & Tptrl & TSw1 \\
\hline Topopah Spring Tuff lithic rich member & Tptf & TSw1 \\
\hline Topopah Spring Tuff upper lithophysal zone & Tptpul & TSw1 \\
\hline Topopah Spring Tuff middle nonlithophysal zone & Tptpmn & TSw2* \\
\hline Topopah Spring Tuff lower lithophysal zone & Tptll & TSw2 \\
\hline Topopah Spring Tuff lower nonlithophysal zone & Tptpln & TSw2 \\
\hline Topopah Spring Tuff lower densely welded vitric subzone & Tptpv3 & TSw3 \\
\hline Topopah Spring Tuff nonpartly welded vitric subzones & Tptpv1-2 & $\mathrm{CHn} 1$ \\
\hline pre-Topopah Spring Tuff bedded tuff & Tpbt1 & $\mathrm{CHn} 1$ \\
\hline Calico Hills Formation undifferentiated & Tac & $\mathrm{CHn} 1$ \\
\hline pre-Calico Hills Formation bedded tuff & Tacbt & $\mathrm{CHn} 2$ \\
\hline Prow Pass Tuff upper nonwelded zone & Tcp [unw] & $\mathrm{CHn} 3$ \\
\hline Prow Pass Tuff welded zone & $\operatorname{Tcp}[w]$ & PPw \\
\hline Prow Pass Tuff lower nonwelded zone & Tcp $[\ln w]$ & CFUn \\
\hline pre-Prow Pass Tuff bedded tuff & {$[\mathrm{bt}]$} & CFUn \\
\hline Bullfrog Tuff upper nonwelded zone & Tcb [unw] & CFUn \\
\hline Bullfrog Tuff welded zone & $\mathrm{Tcb}[\mathrm{w}]$ & $\mathrm{BFw}$ \\
\hline Bullfrog Tuff lower nonwelded zone & $\mathrm{Tcb}[\ln w]$ & CFMn1 \\
\hline pre-Bullfrog Tuff bedded tuff & [bt] & CFMn2 \\
\hline Tram Tuff undifferentiated & Tct & CfFMn2, TRW \\
\hline Pre-Tram Tuff bedded tuff & [bt] & N/A \\
\hline lower Tertiary unit undifferentiated & $\mathrm{N} / \mathrm{A}$ & $\mathrm{N} / \mathrm{A}$ \\
\hline Paleozoic and older units & $\mathrm{N} / \mathrm{A}[\mathrm{pz}]$ & $\mathrm{N} / \mathrm{A}$ \\
\hline
\end{tabular}

${ }^{*}$ Top of TSw2 as used in repository design is above the top of Tptpmn (Elayer, 1995) 


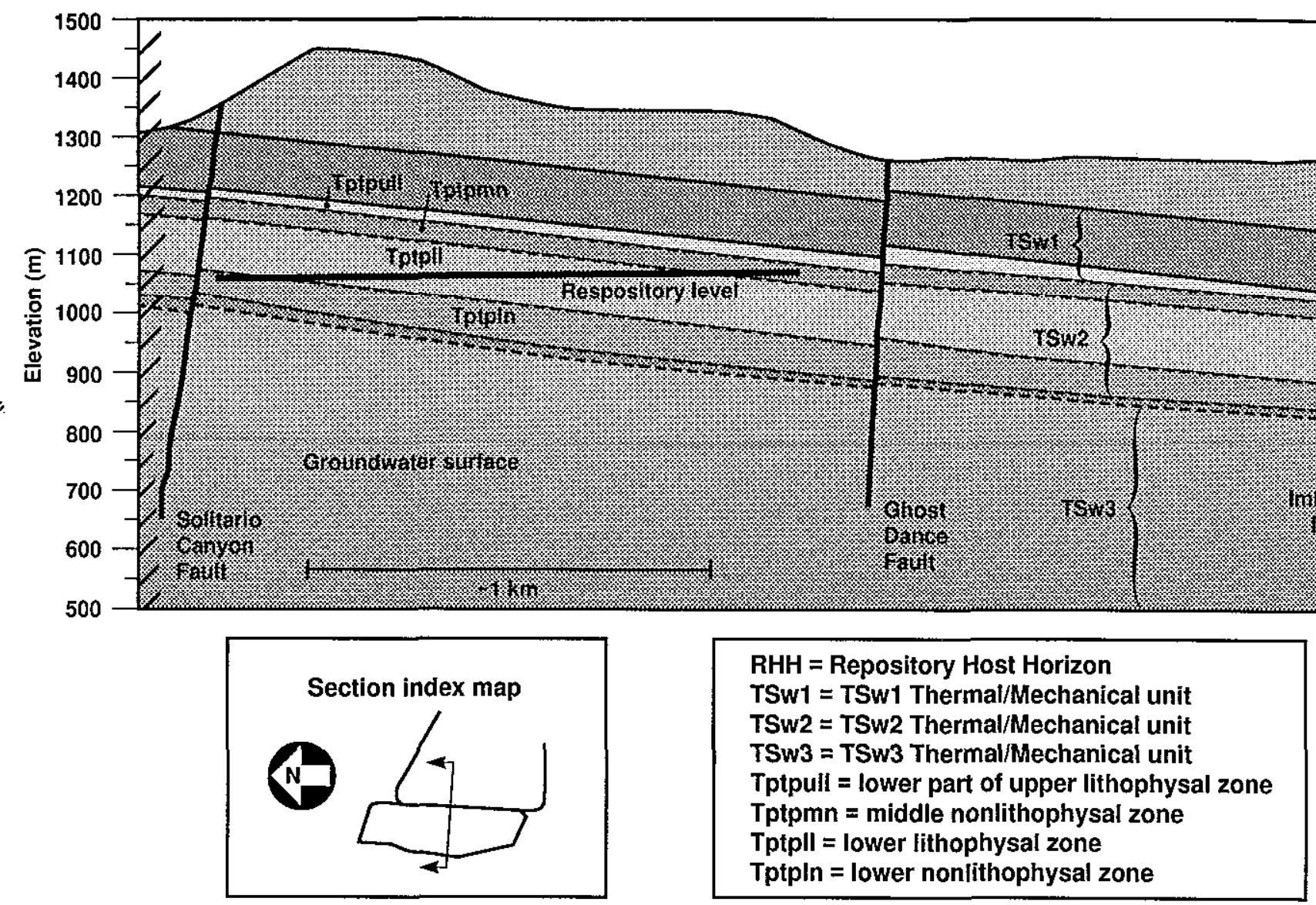

Figure 2-4. East-west cross section through the repository siting volume. Modified from Elayer (1997).

Table 2-2. Percentages of major constituents in Topopah Spring Tuff (core samples 60, 61, and 62 from drill hole USW G-3). $\mathrm{Fe}_{2} \mathrm{O}_{3}$ represents total iron. Data from Schuraytz et al. (1986).

\begin{tabular}{llllll}
\hline Constituent & $\mathbf{6 0}$ & $\mathbf{6 1}$ & $\mathbf{6 2}$ & Average & Standard deviation \\
\hline $\mathrm{SiO}_{2}$ & 784 & 789 & 789 & 7873 & 024 \\
$\mathrm{Al}_{2} \mathrm{O}_{3}$ & 120 & 123 & 122 & 1217 & 012 \\
$\mathrm{Fe}_{2} \mathrm{O}_{3}$ & 1016 & 0973 & 1000 & 0996 & 0018 \\
$\mathrm{CaO}$ & 0492 & 0451 & 0480 & 0474 & 0017 \\
$\mathrm{MgO}$ & 01217 & 01281 & 01126 & 0123 & 0007 \\
$\mathrm{TiO}_{2}$ & 01108 & 00927 & 00984 & 0101 & 0008 \\
$\mathrm{Na}_{2} \mathrm{O}$ & 407 & 392 & 4.25 & 408 & 013 \\
$\mathrm{~K}_{2} \mathrm{O}$ & 371 & 318 & 294 & 3.28 & 032 \\
$\mathrm{P}_{2} \mathrm{O}_{5}$ & 001 & 001 & 003 & 002 & 001 \\
$\mathrm{MnO}$ & 00624 & 00455 & 00488 & 0052 & 0007 \\
\hline
\end{tabular}


See Glassley (1986) for a more detailed discussion and a description of the mineralogic and chemical properties of the preemplacement environment

\subsection{Hydrology}

Because of the small pore size and the unsaturated conditions, a significant suction potential (matrix potential, capillary force, or suction) develops in the rock Recent measurements of saturation indicate higher saturations than originally estimated Samples from the ESF Single Heater Test indicate saturation ranges from 805 to $990 \%$, which compare with saturation values of $85 \pm 12 \%$ for the same interval from surface boreholes (CRWMS M\&O, 1996) LLNL evaluation of the Lawrence Berkeley Laboratory site scale model (Bodvarsson and Bandurraga, 1996) yields saturations ranging from 886 to $96 \%$ Thus, the suction potential may be less than previously anticipated

As noted in the Preliminary NFER, LLNL performed suction potential tests at room temperature and at elevated temperatures The results are shown in Figs 2-5(a) and 2-6

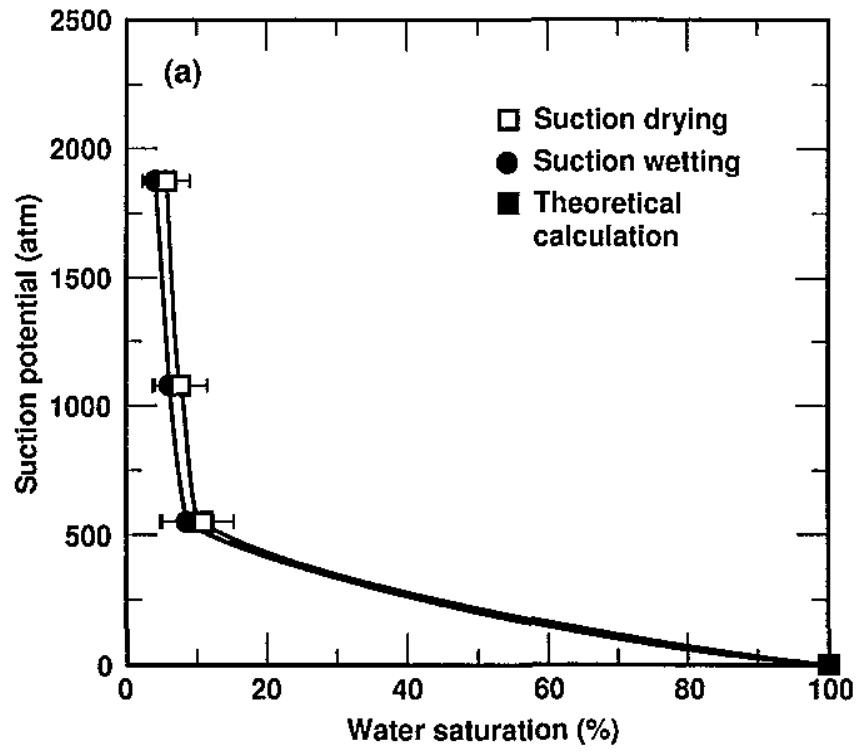

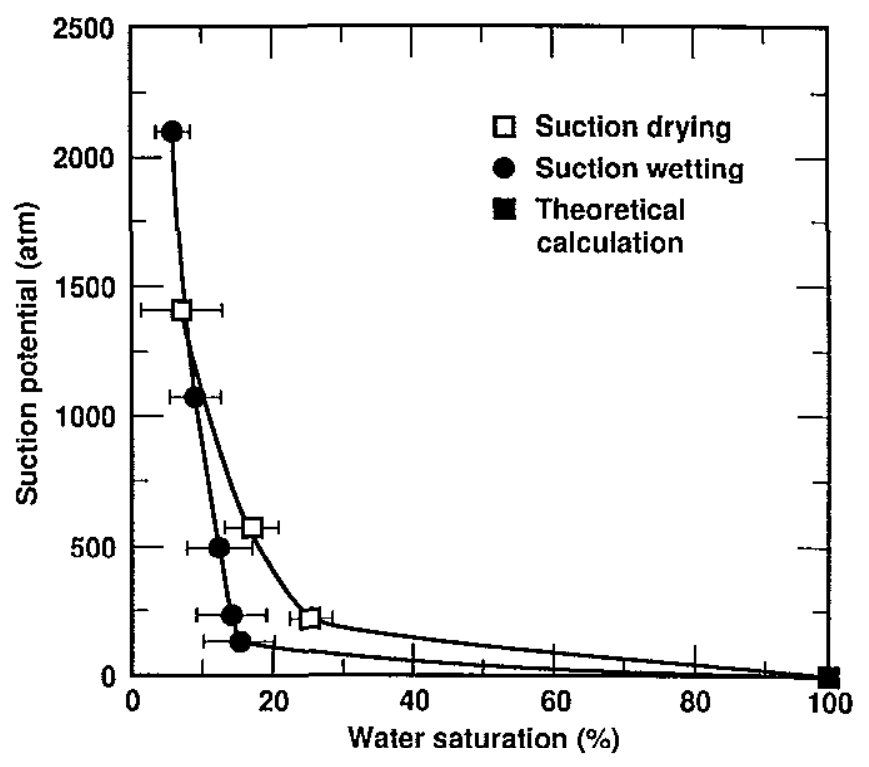

Figure 2-6. Suction potential as a function of water saturation at $70^{\circ} \mathrm{C}$ for Topopah Spring Tuff. Because suction potential cannot be measured at $100 \%$ saturation, this value is designated as a theoretical calculation.

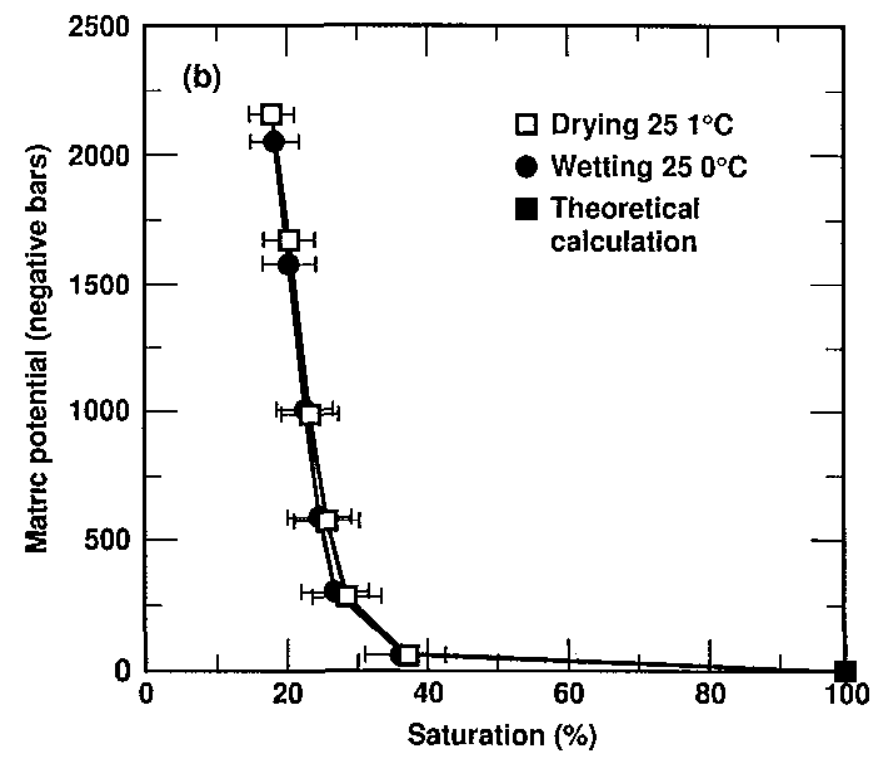

Figure 2-5. (a) Suction potential as a function of water saturation at $20^{\circ} \mathrm{C}$ for Topopah Spring Tuff. (b) Matric potential as a function of saturation from the Single Heater Test. Drying refers to the portion of the test cycle when moisture was being removed. Wetting refers to the portion of the test cycle when moisture was being added. Because suction potential cannot be measured at $\mathbf{1 0 0 \%}$ saturation, this value is designated as a theoretical calculation. 
Tests performed more recently have filled in the data gaps Based on these recent results, shown in Fig 2-5(b), the matric potential at the best current estimate for saturation (i e , about $90 \%$ ) is not greatly different than that for the assumed $65 \%$ saturation, both values are less than 100 bars (10 MPa)

Current data are significantly different from data reported in the Preliminary NFER Current data show the suction potential $>500$ bar up to 20 to $25 \%$ saturation compared to about $10 \%$ saturation in the Preliminary NFER This result probably reflects var iability of rock properties. The current tests were performed on samples from the ESF, whereas earlier tests relied on samples from surface boreholes It was noted in the Preliminary NFER that considerable variability was shown among these samples, implying a heterogeneity of suction properties in the Topopah Spring Tuff The earlier data showed approximately a factor of 3 difference in suction potential between samples 1 and 3 at $15 \%$ saturation Nevertheless, the room-temperature drying data of the earlier measurements were within the spread of corresponding psychrometer results of Klavetter and Peters (1987) The current data have not been analyzed sufficiently to determine how they compare with results from other tests

The saturated water permeability of an intact Topopah Spring Tuff sample at room temperature measured by LLNL is about $03 \mu \mathrm{D}$, although measurements by others (Moore et al , 1986) at room temperature ranged from 085 to $64 \mu \mathrm{D}$ The saturated water permeability of fractured Topopah Spring Tuff is at least 3 orders of magnitude greater than that of intact tuff At room temperature, cylindrical tuff samples containing a single natural hairline through-fracture have apparent water permeabilities ranging from 085 to $13 \mathrm{mD}$ (Daily et al , 1987) The water permeability of an intact Topopah Spring Tuff sample was virtually independent of temperature, time, and the dehydration and rehydration processes for these lab tests However, modifications of permeability were noted in the lab as a function of water flow at elevated temperatures for fractured samples

The matrix properties of the hydrostratigi aphic units at Yucca Mountain are summarized in Table 2-3 (Klavetter and Peters, 1988) As will be discussed in Section 4 , these properties may change in response to the emplacement of waste The initial properties assist in defining the evolution of the NFE Matrix property values are continuing to evolve (Bodvarsson and Bandurraga, 1996; Flint, 1997) The units generally fall into two categories (1) welded tuffs of very low permeability and low porosity (TCw, TSw1, TSw2, and TSw3), and (2) nonwelded vitric tuffs of high permeability and high porosity (PTn and CHnv) The zeolitized nonwelded $\mathrm{CHnz}$ has low permeability and inter mediate porosity, and the welded PPw has intermediate permeability and porosity The permeabilities of the nonwe1ded viti ic tuffs are 4 to 5 orders of magnitude gieater than those of the welded tuffs and the zeolitized nonwelded $\mathrm{CHnz}$

Physical properties including porosity, grain density, bulk density at in situ saturation, and dry bulk density have been determined from core samples, and values of these parameters are summarized in Table 2-4 Additional discussion can be found in Vol II, Sec 40

Table 2-3. Matrix properties of Yucca Mountain tuff (Klavetter and Peters, 1988).

\begin{tabular}{lcccccc}
\hline Unit & Sample code & Porosity & Permeability $\left(\mathbf{m}^{\mathbf{2})}\right.$ & $S_{\mathbf{r}}^{\mathbf{b}}$ & $\alpha^{\mathbf{c}}\left(\mathbf{1 0}^{\mathbf{- 2}} \mathbf{m}^{-\mathbf{1}}\right)$ & $\beta^{\mathbf{c}}$ \\
\hline TCw & G4-1 & 008 & $97 \times 10^{-19}$ & 0002 & 0821 & 1558 \\
PTn & GU3-7 & 040 & $39 \times 10^{-14}$ & 0100 & 1500 & 6872 \\
TSw1 & G4-6 & 011 & $19 \times 10^{-18}$ & 0080 & 0567 & 1.798 \\
TSw2 & G4-6 & 011 & $19 \times 10^{-18}$ & 0.080 & 0567 & 1798 \\
TSw3 & GU3-11 & 007 & $15 \times 10^{-19}$ & 0080 & 0411 & 2058 \\
CHnv & GU3-14 & 046 & $27 \times 10^{-14}$ & 0041 & 160 & 3872 \\
CHnz & G4-11 & 028 & $20 \times 10^{-18}$ & 0110 & 0308 & 1.602 \\
PPw & G4-18 & 024 & $45 \times 10^{-16}$ & 0066 & 141 & 2639 \\
\hline
\end{tabular}

aUnit designations $\mathrm{TC}=$ Tiva Canyon, $\mathrm{PT}=$ Paintbrush, $\mathrm{TS}=$ Topopah Spring, $\mathrm{CH}=$ Calico Hills, $\mathrm{PP}=\mathrm{Prow}$ Pass, $\mathrm{w}=$ welded, $\mathrm{n}=$ nonwelded, $\mathrm{v}=$ vitric, $\mathrm{z}=$ zeolitized

${ }^{b} S_{\mathrm{r}}$ is the residual liquid saturation (not in situ saturation)

$c_{\alpha}$ and $\beta$ are fitting parameters for capillary pressure and relative permeability curves, respectively 
Table 2-4. Physical and thermal properties of rock in the potential repository horizon.

\begin{tabular}{lc}
\hline Parameter & Value \\
\hline $\begin{array}{l}\text { Physical properties } \\
\text { Porosity }(\%)\end{array}$ & $12 \pm 4^{\mathrm{a}}$ \\
$\begin{array}{l}\text { Grain density }\left(\mathrm{g} / \mathrm{cm}^{3}\right) \\
\text { Bulk density at in situ saturation } \\
\left(\mathrm{g} / \mathrm{cm}^{3}\right)\end{array}$ & $255 \pm 003^{\mathrm{a}}$ \\
$\begin{array}{l}\text { Dry bulk density }\left(\mathrm{g} / \mathrm{cm}^{3}\right) \\
\end{array}$ & $230 \pm 09^{\mathrm{a}}$ \\
$\begin{array}{l}\text { Thermal properties } \\
\text { Dry matrix thermal conductivity } \\
\left(\mathrm{W} / \mathrm{m}^{\circ} \mathrm{K}\right)\end{array}$ \\
$\begin{array}{l}\text { Dry in situ thermal conductivity } \\
\left(\mathrm{W} / \mathrm{m}^{\circ} \mathrm{K}\right)\end{array}$ \\
$\begin{array}{l}\text { Saturated in situ thermal conductivity } \\
\left(\mathrm{W} / \mathrm{m}^{\circ} \mathrm{K}\right)\end{array}$ \\
$\begin{array}{l}\text { aDOE }(1995) \\
\text { bNimick (1990) }\end{array}$ \\
$\begin{array}{l}\mathrm{c}_{0} 65 \pm 019 \text { in situ saturation with lithophysical cavities and } \\
\text { fractures assumed dry }\end{array}$
\end{tabular}

On the basis of samples taken from sur face coring, the TSw 2 was expected to have $65 \%$ saturation $( \pm 19 \%)$ (although, as noted, measurements on ESF samples show saturations of approximately $90 \%$ ) and a porosity of $11 \%$ (DOE, 1990, Klavetter and Peters, 1986) Air in the unfilled voids is expected to be moist, although not always at $100 \%$ humidity For further discussion, see Vol. II, Sec 10

\subsection{Geomechanics}

A substantial number of laboratory measurements have been made to determine the mechanical strength of intact samples from the proposed repository horizon These data indicate that the intact rock is quite strong with a uniaxial strength of $155 \mathrm{MPa}( \pm 59 \mathrm{MPa})$ and a high Young's modulus Uncracked samples have stress-strain curves that show nearly linearly elastic behavior until failure Samples with cracks exhibit nonlinear stress-strain behavior as expected when stress is above $50 \%$ of the failure stress Typical stress-strain curves for 50 8-mm-diam saturated samples tested under drained conditions are shown in Fig 2-7 Most of the tests for compressive strength have been conducted on samples that were saturated with water and tested under drained conditions This represents a minimum

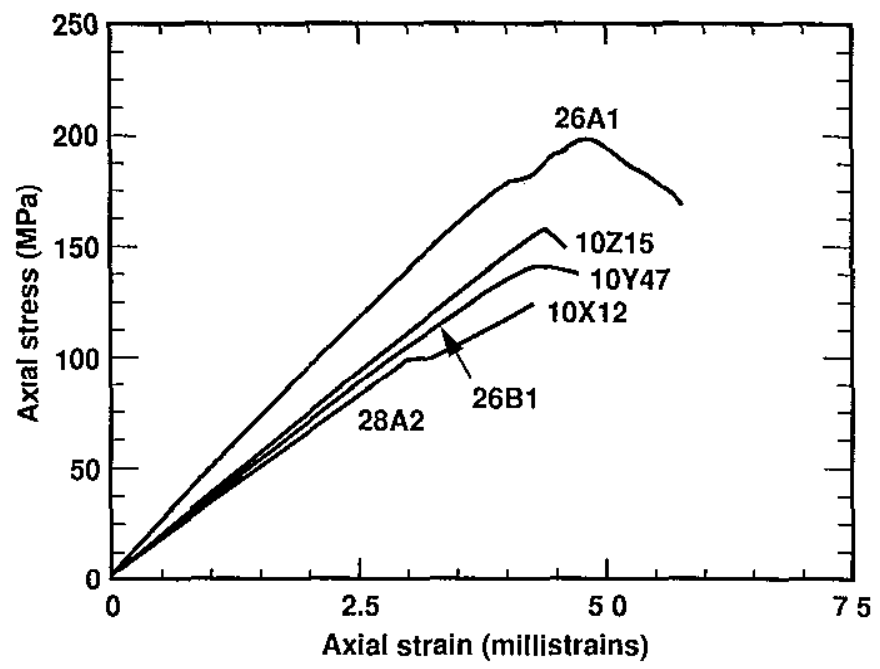

Figure 2-7. Plots of axial stress vs axial strain for uniaxial measurements on 50.8-mm saturated Topopah Spring Tuff samples at $22^{\circ} \mathrm{C}$. Measurements were taken at a strain rate of $10^{-5} \mathrm{~s}^{-1}$. Adapted from Price (1986).

value as rocks are generally weaker when saturated with water Furthermore, as noted by Biotnott (1997) the uniaxial stress path commonly used to infer elastic constants is strongly influenced by nonlinearities This becomes more critical when coupled to thermal and other processes, as will be discussed in the Section 4

The dynamic properties of the rock are also important, especially in the area of seismic design These properties include the compressional-wave ( $P$-wave) velocity $\left(C_{\mathrm{p}}\right)$, the shear-wave ( $S$-wave) velocity $\left(C_{\mathrm{s}}\right)$, the dynamic deformation (Young's) modulus $\left(E_{\mathrm{d}}\right)$, and the dynamic Poisson's ratio $\left(v_{d}\right)$ Recommended values of these parameters are given in item 222 of the Reference Information Base (RIB) (DOE, 1995) as $C_{p}=3400 \mathrm{~m} / \mathrm{s}$, $\mathrm{C}_{\mathrm{s}}=2040 \mathrm{~m} / \mathrm{s}, E_{\mathrm{d}}=235 \mathrm{GPa}$, and $v_{\mathrm{d}}=022$

Price (1986) studied the effect of sample size on mechanical properties of Topopah Spring Tuff and found that both the ultimate strength and axial strain at failure are inversely related to sample diameter, whereas Young's modulus and Poisson's ratio are independent of sample diameter The effect of sample size on ultimate strength is illustrated in Fig 2-8

Estimates of rock-mass strength are based on (1) the known behavior of intact rock, (2) the known joint characteristics, and (3) the presence of applied or confining stresses A rock-mass strength criterion of

$$
\left(\sigma_{1}\right)_{\text {ultimate }}=16.0+102\left(\sigma_{3}\right)^{0602},
$$


where $0<\sigma_{3}<25 \mathrm{MPa}$, is presented in item 126 of the RIB Equation (1) is based on an assumed rockmass rating (RMR) of 61 and an unconfined compressive strength of $160 \mathrm{MPa}$

In situ stress values for the potential repository horizon have been determined from measurements in drill holes USW G-1, USW G-2, and USW G-3 (Stock et al , 1984, 1985) Table 2-5 shows the average mean value and range for vertical stress, which is the maximum principal stress and is due to the overburden rock at the site, in addition to the ratios of minimum and maximum horizontal stresses to vertical stress, and the bearings of minimum and maximum horizontal stiesses

A stress profile for the in situ stress near the ESF has been estimated using two-dimensional finite-element analysis similar to those presented in Bauer et al (1985) The stress profile can be found in Vol II, Sec 40

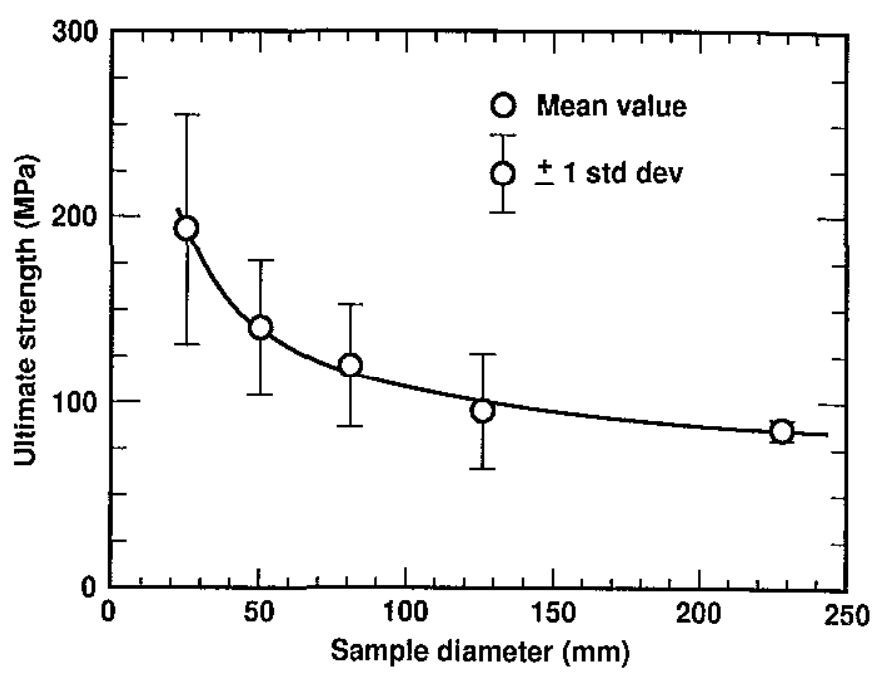

Figure 2-8. Plot of ultimate strength vs sample diameter for uniaxial measurements on saturated Topopah Spring Tuff samples at $22^{\circ} \mathrm{C}$. Measurements were taken at a strain rate of $10^{-5} \mathrm{~s}^{-1}$. Adapted from Price (1986).

Table 2-5. Values and ranges of principal stresses in the potential repository horizon at Yucca Mountain (Stock et al., 1984, 1985).

\begin{tabular}{lcc}
\hline \multicolumn{1}{c}{ Parameter } & Average value & Range \\
\hline Maximum principal stress (vertical) & $70 \mathrm{MPa}(1015 \mathrm{psi})$ & 50 to 10 \\
Ratio of minimum horizontal stress to vertical stress & 05 & 03 to 08 \\
Ratio of maximum horizontal stress to vertical stress & 06 & 03 to 10 \\
Bearing of minimum horizontal stress & $\mathrm{N} 57^{\circ} \mathrm{W}$ & $\mathrm{N} 32^{\circ} \mathrm{E}$ \\
Bearing of maximum horizontal stress & $\mathrm{N} 50^{\circ} \mathrm{W}$ to $\mathrm{N} 65^{\circ} \mathrm{W}$ \\
\hline
\end{tabular}

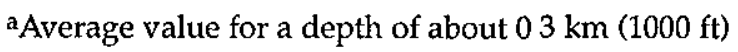




\subsection{Processes that form the NFE}

As discussed in Section 1, waste packages will inter act with a near-field environment that will be altered from the original Yucca Mountain conditions The NFE changes arise from several factors, including construction of the repository, emplacement of waste, and the possible backfilling of drifts All of these activities can cause chemical changes, possible mineralogical or basic rock-mass property changes, as well as hydrologic and thermal changes These alterations may be significant relative to the EBS design and performance Because NFE development is diven by coupled $\mathrm{T}-\mathrm{H}-\mathrm{M}-\mathrm{C}$ processes that are initiated by repository-related activities, the processes leading to the NFE related to those activities are discussed in this section The specific NFE conditions that may result are summarized in Section 4 The intention of this report is not to give all possible scenarios but, rather, to indicate the types of processes that can alter the environment so that the reader can consider the impacts on design options

\subsection{Construction}

The following discussion includes all activities involved in construction of the facilities that take place prior to emplacement of waste It does not include construction activities that will take place subsequent to waste emplacement (including closure activities)

\subsubsection{Excavation of Rock}

The most significant impacts assessed for excavation are the alteration of the stress field in the rock near drifts and changes in moisture due to exposure of surfaces to air. Moisture changes are discussed in Section 313 , below The changes in stress will result in an overall increase in hoop stresses, which will tend to close fractures, particularly during the period of increased temperature For further discussion, refer to the Preliminary NFER

\subsection{Fluids Introduced during Drilling and Mining}

As explained in the Preliminary NFER, the introduction of mining and drilling fluids may increase the matrix saturation surrounding the openings However, no evidence was found of significant moisture increases during constr uction of the 5-mile-long access drift, which should be representative of construction and emplacement drifts The Preliminary NFER contains discussions of possible impacts of drilling and mining, if they should occur

\subsubsection{Mine Ventilation}

The Preliminary NFER noted that mine ventilation may lead to drying of the matrix surrounding emplacement drifts, where ventilation of the shafts, ramps, and drifts will remove moisture from the rock via evaporation This appears to have been the case within the access drift No water has been observed to drip into the tunnels, except when the ventilation is shut off or when rock is isolated from ventilation Ions dissolved in the affected pore water will leave behind a small residue of soluble and insoluble salts as the pore watet evaporates No samples of such residue have been taken

\subsubsection{Introduction of Materials by Man}

Materials will be introduced, both intentionally and unintentionally, during construction of the facilities These materials may include such things as material added in the form of crushed rock, granular minerals, engine exhaust, rubber products and other polymers, metals, and concretes The major potential for perturbations of the environment due to manmade materials will exist after emplacement

\subsection{Emplacement of Waste}

When waste is emplaced, heat from the radioactive decay of the waste will cause changes in the environment, which will likely dominate the geochemical-hydrological-mechanical conditions Heat has the potential to drive water away from the WPs, to control the relative humidity, and to change the relative hydraulic conductivity, gas permeability, imbibition characteristics, and other propet ties of the rock mass

\subsubsection{Thermal Loading}

3.2.1.1 Dry Out. As reported in the Preliminary NFER, after waste emplacement, thermal loading will 
drive moisture away from waste emplacement openings Because of the large increase in vapor pressure, nearly all of the air will be driven away from the boiling zone (leaving the gas phase with $100 \%$ water vapor). Tests and analyses of matrix drying show that vapor transport preferentially occurs into openings and along fracture faces Upon reaching the fractures, most of the vapor is driven away from the boiling zone toward a condensation zone where it condenses and drains down fractures until it is either (1) entirely imbibed by the matrix, (2) enters the saturated zone, or (3) flows back into the boiling zone where it boils again forming a "heat pipe" by refluxing Low wetting sorptivity of TSw2 appears to facilitate drainage to great depths below the repository The extent to which condensate drains away from the emplacement zone depends on the competition between gravity drainage and imbibition by the rock matrix Results of field tests at G-Tunnel (Ramirez, et al , 1991, Nitao and Buscheck, 1995) and at the ESF Single Heater Test (Finley et al, 1997) indicate that condensate drainage can be significant

3.2.1.2 Rewetting. As the rock cools below boiling conditions, vapor and liquid will flow back into the dried region toward the drifts The flow will be dominantly along fractures Saturation gradients will also cause water redistribution in the matrix, however, the very low permeabilities will cause matrix flow to be slow Thus, flow along fractures will dominate rewetting of the dried-out zone

Studies show that rewetting occurs at a much slower rate than drying The details of emplacement configurations, fuel age, AMLs, and percolation flux will have profound effects on the time of dryout and return of moisture to the WP areas Design development must take these phenomena into account

3.2.1.3 Dissolution and Precipitation of Minerals. Strong coupling will take place between thermo-hydrologic and geochemical processes Within the NFE/AZ in the regions where rock is dried, the processes will be dominated by vapor flow and chemical exchanges associated with vapor flow In the portions of this region where temperatures are very near boiling, the rock will undergo drying with dissolved minerals left in the pores of the rock This zone may be fairly limited in extent, but the zone will move outward with time so that much of the rock mass may be in this zone at some time As water is removed, dissolved minerals will be deposited in the throats of pores, particularly the smaller ones This may result in fundamental changes of the matrix hydrologic properties Studies have shown that, in addition to salt deposition, considerable mineral changes can result from rock-water interactions at elevated temperatures This topic is discussed in detail in Sec 1044 , Volume II

The zone of rock where temperatures are elevated, but are below the boiling point, will be very active both hydrologically and geochemically with potential for very active dissolution and precipitation of minerals Numerous experiments have demonstrated that the chemical composition of the water is likely controlled by the solubility of mineral phases present in the rock (Knauss, 1987, Knauss and Peifer, 1986, Knauss et al , 1986) See Sec 1043 , Volume II

3.2.1.4 Increased Stress. The largest effect on the geomechanical behavior of the NFE is expected to be due to the thermal cycle in which the rock will be heated and then allowed to slowly cool Thermal loading of the NFE will alter the stress in the rock near the emplacement drift as a function of time During the period of temperature increase, stress in the nearfield rock will increase as the rock tries to expand However, due to geometry of the excavated drifts, the stress fields in the NFE will be complex, and some zones may even be put in tension for an extended period of time As the temperature decreases, the overall stress levels will decrease, and the entire stress will again be compressive

Deformations within the rock mass can impact the hydrologic flow system Many laboratory studies (Bandis et al , 1983, Barton et al , 1985) have documented that greater impact often results from shear rather than normal deformations This is especially true once stresses are removed, as would be the case for the repository once the thermal pulse has decayed Permanent changes in hydrologic properties or flow paths can result from stresses normal to fractures, but they tend to be smaller than those caused by shear displacements This has also been observed in field studies (Wilder, 1987) A "qualitative evaluation of the coupling complexity between mechanical behavior and void space evolution between the joint walls during shear displacement " has been suggested by Archambault et al (1997), but has not been applied to NFE evaluations

\subsubsection{Introduced Materials}

In addition to material introduced as part of construction, significant volumes of material will be brought in at the time of emplacement, including the container materials and EBS packing materials The significance of such materials (except for dust, coatings, 
lubricants, and so forth) is long-term once they interact (corrode) with the NFE As noted, the major potential for perturbations of the environment due to man-made materials will exist after emplacement, when heat and microbial activity will increase the chances for impact on geochemistry of the water It is anticipated that introduced material will dominate the WP or NFE chemistry, particularly if microbial activity becomes significant

\subsection{Backfilling}

Environmental conditions most likely to be impacted by backfilling include the hydrologic characteristics and an early, transient thermal effect of different heat conduction in the backfill compared with that of the rock mass Backfilling will also influence opening stability, but that is a design-related issue, not an environmental characteristic As is discussed in Section 4, backfill can have a significant effect on WP temperatures, on humidity, and on the potential for water to contact the WPs

As discussed in the Preliminary NFER, it is likely that backfill materials will be the tuff removed during excavation Excavated materials will either be temporarily stored in drifts, where it is assumed there would be some sort of dust control by ventilation, or on the surface The moisture in the excavated materials would be reduced because ventilation air and surface conditions are expected to be considerably drier than the in situ rock saturation conditions With handling and breaking of rock, this drying process would be facilitated Thus, backfill will likely have lower saturation than the original rock-mass saturation However, backfill will possibly have greater saturation than the dried-out rock mass that develops as a function of waste heat, unless the backfill materials have been stored in areas of drifts that were above the boiling point of the rock Once emplaced, the backfill will act as a porous medium that, depending on the material chosen, could disperse any episodic fracturedominated flow

Although crushed tuff is the most likely backfill material (it is readily available), significant advantages are associated with using backfill consisting of impervious grains (Wilder, 1990, Sec. 110 14, Vol II) rather than crushed tuff If such a granular backfill is used, there will be long-term flow diversion without wicking The thermal conduction of granular backfill will be lower than that of the rock mass because of its granular nature This will not only modify thermal conditions, but because of that modification, will also have dramatic impacts on relative humidity as well as evaporation and deposition of salt and its location

\subsection{Closure}

Major activities associated with closure that might impact the environmental conditions include (1) ceasing of ventilation, (2) emplacement of seals in openings, and (3) the introduction of construction materials Because the details of closure are yet to be determined, and fur ther field studies of hydrothermal-chemical-mechanical coupling will be conducted prior to those details being developed, closure effects will be discussed in subsequent revisions of this report

\subsection{Climate or Site Environment Changes with Geologic Time}

\section{Hydrologic discussions for the NFE included in} this report assume that conditions will remain unsaturated for the 10,000-y1 performance period The discussions do not address changes (e.g, climatic) that might take place during the 10,000 -yr time frame. However, preliminary information is included that addresses how sensitive the hydrologic response might be to differing flux conditions The flux at the depths of the NFE depends on the response of the overlying units

Current estimates suggest that the flux is considerably greater than values used at the time of the Preliminary NFER, and they are higher than those values addressed in Volume II, Rev 1 The information available at the time of preparing this report has not been updated to address the higher flux estimatesnamely, in the range of $10 \mathrm{~mm} / \mathrm{yr}$ The highest flux values evaluated in this report are in the range of 03 to $5 \mathrm{~mm} / \mathrm{yr}$ We are in the process of evaluating the hydrologic properties used in the higher flux estimates so that these analyses can be performed using internally consistent parameters In addition, analyses of whether the higher flux $(10 \mathrm{~mm} / \mathrm{yr})$ is representative of actual conditions are in progress Field measurements are likely to be available prior to the next update of the this report, and these values will allow an assessment to be made of the appropriate upper value of flux. Regardless of what value is deemed appropriate for upper ranges, the analysis contained in this report should be representative of the lower flux ranges If it is determined that the upper ranges are higher than those reported here, that information will be incorporated in subsequent revisions 


\subsection{Near-Field Environment}

Because the NFE is the environment that interacts with emplaced waste, it is, by definition, the postemplacement environment that develops through process interactions with the waste. The interactions that develop the NFE (as well as the AZ) are highly coupled processes To facilitate discussion in this report, the coupled processes are broken down either into singly coupled processes (see, for example, loop A-a in Fig 1-6) or into multiply coupled processes (see, for example, loop B-b in Fig 1-6), but with a limit on the number of processes analyzed separately

Figure 4-1 is a simplified model of the coupledprocess interactions that will develop the NFE Recall from Section 1 that entries along the diagonal of this matrix are the principal components-in this case, of the NFE Other entries in the matrix represent the processes Those interactions located to the right of the diagonal are the ones that are forward coupled; those to the left are back coupled

For example, waste emplacement generates heat that will mobilize water by boiling or evaporation Thus, to the right of the envir onmental parameter of temperature is the process of boiling, as indicated by the arrow Below this process is the changed moisture conditions of the NFE, shown on the diagonal The forward coupling indicates that the heat drives a change in moisture However, the changed moisture conditions may also result in changes in thermal conductivity and in removal of heat by convection These changes would result in a changed thermal regime Therefore, back-coupling from moisture conditions to temperature is shown by the arrow to the left from moisture conditions to the process box of latent heat and then up to the environmental condition of heat (temperature) The coupling matix shown in Fig. 4-1 is neither comprehensive nor definitive of all of the interactions that must be considered for the NFE It is simply provided to help understand the organization of technical discussions in this report and the coupling, which can be quite complex

Volume I of this report focuses only on those issues that are deemed to have direct impact on the design of the repository, or on the Total System Performance Analysis (TSPA) Many additional issues associated with the NFE and coupled processes must be considered when assessing the NFE, but they are not deemed critical to the design or to the PA abstraction These issues are discussed in Volume II of this report For example, one of the issues important to PA is changes in hydrologic properties Such changes are considered in the results reported in this volume, but the details of how those changes occur are of less direct interest and therefore are not specifically discussed in Volume I Volume I, Rev 0, of the Preliminary NFER discussed changes that can occur in rock properties (see Sec 421 of that report) Volume I, Rev 0 also discussed changes that can occur in hydrologic and geochemical properties (see Sec 42 2) Volume II, Rev 1 (Sec 17 and 20) discussed these effects in detail No attempt is made hele to repeat that information, only to summarize results for design and TSPA purposes

To aid the reader in locating a variety of issues discussed in greater detail in Volume II, Rev 1, see the tables in Section 4 4, below In addition, the discussions in this section are based on numerical models of an idealized system and should not be construed to reflect actual, detailed NFE and AZ conditions However, models with their inherent assumptions will always be the basis for understanding the evolving environment and for making decisions Even though some of the uncer tainties will be reduced with time, the conclusions need to be applied with care, realizing that the models are idealized and simplified abstractions of the real world

\subsection{Temperatures of the NFE}

The major contributor to development of the NFE is the coupling of heat to the hydrologic, chemical, and mechanical conditions of the ambient YM environment Thus, it is critical to determine temperature distributions within the NFE/AZ to address the prioritized design/ performance parameters of water, water chemistry, and many others 'This section begins with temperature regimes and then proceeds to the other prioritized topics that were identified in Tables 1-1 and 1-2

For this revision of the NFER, no effort has been made to back-couple geochemistry etc to the temper ature fields, although it is recognized that such backcoupling could alter the temperature fields, possibly in fundamental ways This will require an iteration of the alteration impacts back into the thermal conductivities. Such an iteration will be included in subsequent revisions of the NFER, once the design is more mature and laboratory and field test data are available on 


\begin{tabular}{|c|c|c|c|c|c|c|c|}
\hline (1) & $\begin{array}{l}\text { Kaporization } \\
\text { mobilization }\end{array}$ & $\begin{array}{l}\text { - Rock-water } \\
\text { interactions } \\
\text { - Manmade } \\
\text { material } \\
\text { interactions } \\
\text { (kinetics) }\end{array}$ & $\begin{array}{l}\text { Thermodyn } \\
\text { of vapor }\end{array}$ & $\begin{array}{l}\text { - Dehydration } \\
\text { - Rock-water } \\
\text { interactions } \\
\text { (kinetics) }\end{array}$ & $\begin{array}{l}\text { - Dehydration } \\
\text { - Rock-water } \\
\text { interactions } \\
\text { - Material } \\
\text { (kinetics) }\end{array}$ & $\begin{array}{l}\text { - Stress } \\
\text { changes } \\
\text { - Coefficient } \\
\text { impacts }\end{array}$ & $\begin{array}{l}\text { - Microbe } \\
\text { survival } \\
\text { - Metabolic } \\
\text { processes }\end{array}$ \\
\hline \multirow[t]{3}{*}{$\begin{array}{l}\text { - Latent heat } \\
\text { - Heat pipes. }\end{array}$} & Mosture & $\begin{array}{l}\text { Volumetrics } \\
\text { - Water } \\
\text { - Rock } \\
\text { - Materials }\end{array}$ & & & $\begin{array}{l}\text { - Volumetrics } \\
\text {-water } \\
\text {-rock } \\
\text { - Contact } \\
\text { modes }\end{array}$ & $\begin{array}{l}\text { Water } \\
\text { contribution } \\
\text { to crack } \\
\text { growth }\end{array}$ & Survival \\
\hline & & প. Water & $\begin{array}{c}\text { Vapor } \\
\text { partial } \\
\text { pressure }\end{array}$ & & $\begin{array}{l}\text { - Reaction } \\
\text { thermodyn } \\
\text { - Solubility } \\
\text { - Precipitation } \\
\text { - Carbonation }\end{array}$ & & $\begin{array}{l}\text { - Biomass } \\
\text { generation } \\
\text { - Nutrient } \\
\text { supply } \\
\text { - Metabolic } \\
\text { processes }\end{array}$ \\
\hline & & & $\begin{array}{l}\text { Retative } \\
\text { humidity } \\
\text { conditions: }\end{array}$ & $\begin{array}{l}\text { Vapor/rock } \\
\text { interactions }\end{array}$ & $\begin{array}{l}\text { Vaporirock/ } \\
\text { solid } \\
\text { interactions }\end{array}$ & & \\
\hline $\begin{array}{l}\text { Altered } \\
\text { flow } \\
\text { paths }\end{array}$ & $\begin{array}{l}\text { Altered } \\
\text { flow } \\
\text { paths }\end{array}$ & & $\begin{array}{l}\text { Changed } \\
\text { flow } \\
\text { conditions }\end{array}$ & $\begin{array}{l}\text { Hydrologic: } \\
\text { propertles. }\end{array}$ & $\begin{array}{l}\text { Water } \\
\text { contact }\end{array}$ & $\begin{array}{l}\text { - Healing of } \\
\text { fractures } \\
\text { - Changes } \\
\text { water avail } \\
\text { for cracking }\end{array}$ & \\
\hline \multirow[t]{2}{*}{$\begin{array}{l}\text { Thermal } \\
\text { conductivity } \\
\text { changes }\end{array}$} & $\begin{array}{c}\text { Water } \\
\text { release/ } \\
\text { consumpt } \\
\text { in reactions }\end{array}$ & $\begin{array}{l}\text { - Altered } \\
\text { minerals } \\
\text { - Rock-water } \\
\text { interactions }\end{array}$ & $\begin{array}{l}\text { Partial press } \\
\text { (salts) }\end{array}$ & $\begin{array}{l}\text { - Fracture/pore } \\
\text { plugging } \\
\text { - Fracture } \\
\text { healing } \\
\text { - Colloid } \\
\text { transport }\end{array}$ & $\begin{array}{l}\text { Mineraland } \\
\text { solid naterial } \\
\text { (changes) }\end{array}$ & $\begin{array}{l}\text { Volume } \\
\text { changes } \\
\text { (phase } \\
\text { transform } \\
\text { and mineral } \\
\text { changes) }\end{array}$ & \\
\hline & & & & $\begin{array}{l}\text { - Closing/ } \\
\text { opening } \\
\text { fractures } \\
\text { - Microcracks } \\
\text { - Coalescence } \\
\text { flow path }\end{array}$ & $\begin{array}{l}\text { - Stress } \\
\text { impacts } \\
\text { - Mineral } \\
\text { phase } \\
\text { - Microcracks } \\
\text { (new surfaces) }\end{array}$ & $\begin{array}{l}\text { Mechanica) } \\
\text { Conditions. } \\
\text { (changes) }\end{array}$ & \\
\hline N/A & $\begin{array}{l}\text { Blomass } \\
\text { water } \\
\text { consumpt } \\
\text { release }\end{array}$ & $\begin{array}{l}\text { Biomass } \\
\text { micro- } \\
\text { chemistry }\end{array}$ & $\begin{array}{c}\text { Biomass } \\
\text { control } \\
\text { of T/RH } \\
\text { relations }\end{array}$ & $\begin{array}{l}\text { Biomass } \\
\text { plugging }\end{array}$ & $\begin{array}{c}\text { Biomass } \\
\text { dissolution/ } \\
\text { mineralization }\end{array}$ & $\begin{array}{l}\text { - Biomass } \\
\text { microcracking } \\
\text { - Volume } \\
\text { changes }\end{array}$ & Microbiotic \\
\hline
\end{tabular}

Figure 4-1. Matrix of coupled processes in the NFE. 
impact of mineral changes and microfracturing on thermal conductivities and hydrologic properties.

Temperatures of the NFE are mainly determined by

- Thermal output of the waste

- Configuration of the waste

- Thermal conductivity of the rock

- Heat redistribution by moisture/vapor.

First, each of these parameters or processes is discussed, then the results of analyses that consider these factors is presented

\subsection{Thermal Output of the Waste}

The WPs being considered for emplacement have, for design analyses, been divided into six different classes based on heat outputs Heat output is a function of waste type, waste age, and amount of waste in any given package The WP types, in descending order of heat output, are

1 WPs with 21 PWR assemblies of 10-yr-old spent nuclear fuel (SNF), $179-\mathrm{kW}$ heat output

2 WPs with 21 assemblies of 26-yr-old PWR SNF with a total heat output of $92 \mathrm{~kW}$

3 WPs with 44 assemblies of 26-yr-old BWR SNF with $61-\mathrm{kW}$ heat output

4 WPs with 12 PWR assemblies of 40 -yr-old SNF with $32-\mathrm{kW}$ heat output

5 WPs with Defense High Level Waste (DHLW)

from Savannah River, $28-\mathrm{kW}$ heat output

6 WPs with DHLW from Hanford with $16-\mathrm{kW}$ heat output

Approximately $38 \%$ of the waste inventory consists of the 21 assembly PWRs The heat output will depend on the age of the SNF (as noted by comparing output of type 1 and 2 listed above). The 26-yr-old waste is considered to be more typical of the likely age of emplaced PWR waste than 10-yr-old SNF (see waste age discussion in Sec 1.2.3 of this report) Whereas the DHLW packages are the next most prevalent waste type, their heat output does not contribute significant amounts of heat The BWR SNF is the next most numerous WP type (about $26 \%$ ) The 12 PWR assemblies only represent about $6 \%$ of the WPs

Even though the US has other waste types, those listed are the ones that are currently being considered for disposal at YM if it were to become a repository If other waste types are later considered, the analyses that follow would need to take such wastes into account

Analyses of temperatures in the NFE/AZ have taken into account the heat outputs for the WP types, including their percentages and possible locations or distributions However, the details of WP distribution are of greater interest for individual WP temperatures and local NFE temperatures The AZ and average NFE temperatures are influenced more by the total AML and drift spacing than by details of emplacement distribution by WP type This is important because the distribution of the WPs shown on the design assumptions (see Figs 1-2 and 1-3) may not be the actual distribution of emplaced waste Final distributions will depend on several operational constraints

\subsubsection{Configuration (Layout) of the Waste}

This report only discusses the results in Volume II that are focused on two design cases, ACD and LL, both of which were performed for approximately $84 \mathrm{MTU} /$ acre loading These two cases should bound the conditions for those designs options currently being considered

One of the options common to all of the design cases is the incorporation (or lack thereof) of backfill From an NFE perspective, properly chosen backfill can have very positive performance aspects that derive from

1 Extending the duration of elevated WP temperatures

2 Establishment of strong ther mal gradients that result in significant $R H$ reductions (near the WPs) and lengthened duration of those reductions

3 Diversion of seepage flow that might enter drifts, thus moderating impacts of higher flux

4 Evaporation/boiling of any water that enters drifts during the thermal regime within the backfill rather than on WPs This has the significant benefit of preventing salts on WPs, which can lower the magnitude of the $R H$ at which corrosion becomes active.

Backfill is addressed in Volume I for the two reference design cases, the ACD and LL designs

Volume II considers many other design options, including variations in drift diameter, vat ious AMLs, and various waste ages Refer to Volume II for information on designs that may fall beyond the scope of those considered in the bounding calculations Tables 4-5 and 4-6 later in this section are provided to assist in locating the appropriate sections in Volume II for the various design options.

\subsubsection{Thermal Conductivity of the Rock}

Theoretically, the conductivity of the rock should be a strong function of its moisture conditions, although other factors such as microcracking and 
mineralogic changes can contribute to changes in conductivity As reported in the Preliminary NFER, the dry matrix thermal conductivity is $251 \pm 017 \mathrm{~W} / \mathrm{m}{ }^{\circ} \mathrm{K}$ The in situ measurements of thermal conductivity, both dry $\left(21 \pm 02 \mathrm{w} / \mathrm{m}^{\circ} \mathrm{K}\right)$ and at a saturation of $065\left(21 \pm 02 \mathrm{~W} / \mathrm{m}^{\circ} \mathrm{K}\right)$, showed that the thermal conductivity may not vary significantly That the dry and $65 \%$ saturation conductivities measured in situ are the same is not consistent with understanding based on intact sample measurements and may indicate that the presence of fractures has a mote significant or masking influence on conductivity than does saturation Recent measurements on intact TSw2 samples show that the thermal conductivity for dry samples is $150 \pm 044 \mathrm{~W} / \mathrm{m}^{\circ} \mathrm{K}$ and for saturated samples is $229 \pm 042 \mathrm{~W} / \mathrm{m}^{\circ} \mathrm{K}$ The calculations presented in this report use the Reference Information Base (RIB, Version 4) value of $21 \mathrm{~W} / \mathrm{m}^{\circ} \mathrm{K}$

\subsubsection{Heat Redistribution by Moisture and Vapor}

Hydrological conditions are the strongest coupledprocess determinants of temperatures that develop within the system, particularly where temperatures reach the boiling point Therefore, the coupling between heat output and hydrology is used to determine the temperature field of the NFE The calculations that will be presented consider these changes as well as the changes from convection/conduction to merely conduction as moisture is removed from rock zones Other processes (e g, geochemical and mineralogical) will then be coupled to the thermal and hydrological conditions Thus, coupling is discussed, first, based on an analysis of single coupling of hydrological conditions to the thermal output of the waste considering the design layout, configuration, and characteristics of the waste to determine the temperature field of the system Following that discussion, we describe the coupling of geochemistry and geomechanics to the coupled hydrothermal results

\subsubsection{Results: Temperatures in the NFE}

Temperatures that are of greatest interest for the NFE are those on the WP surfaces and on the surface of the rock For the AZ, the temperature distributions within the entire rock mass-at least to the point that they approach ambient temperatures-are important Because much of the information presented for the two regions comes from the same calculations, there is some overlap between the information in this section and in Section 5, which considers the $\mathrm{AZ}$

Several different analyses have been performed for temperatures in the NFE For consistency, the analyses reported in Volume II are the focus of this report More recent calculations are included in a Materials Research Society paper (Buscheck, 1996), which used a finer gridding as well as other model refinements Those results show peak temper atures that are 5 to $10 \%$ higher than the ones reported in Volume II Because this difference is well within the variation expected due to uncertainties in assumptions, it was decided that consistency between Volumes I and II is of greater value than incorporating more up-to-date information that was not as complete (less sensitivity analyses of other design options and of assumptions)

Another set of calculations sometimes referred to are those of TSPA95 These analyses assume that heat generated by WPs could be modeled as a line load As noted ear lier, this is only appropriate for the LL design option For the point loading typified by ACD and for the modified design, this is not as appropi iate as the analyses reported in Volume II that account for a large number of WP distributions/layouts Finally, several analyses have been performed using models that only account for heat flow by conduction These analyses are appropi iate in a limited number of applications and are particularly useful for details within the drifts or WPs, however, they are not generally appropriate to the NFE or AZE because they do not account for the potentially significant coupling with water For this reason, the analyses reported here will again be limited to those in Volume II, which include this coupling

Figures 4-2 and 4-3 show the calculated temperatures around the drifts and on the WP surface to illustrate the difference between the ACD and line-load approaches, respectively Two line-load options were considered one in which WPs are placed with only 0.1-m spacing between them, and one in which WPs are placed with $10-\mathrm{m}$ spacing In each scenario considered, the drift spacing was determined by equating the spacing of waste and drifts to the AML and then calculating the drift spacing for the given waste spacing that would yield $834 \mathrm{MTU} /$ acre

Drift-wall and waste package surface temperatures are critical parameters of the NFE. The peak temperatures are shown in Table 4-1, whereas the temperatures over time extending to 10,000 years are shown in Figs $4-2$ and 4-3. The very early time responses are not well defined in these plots, and those beyond 10,000 years are not shown The temperature data for these times can be found in 


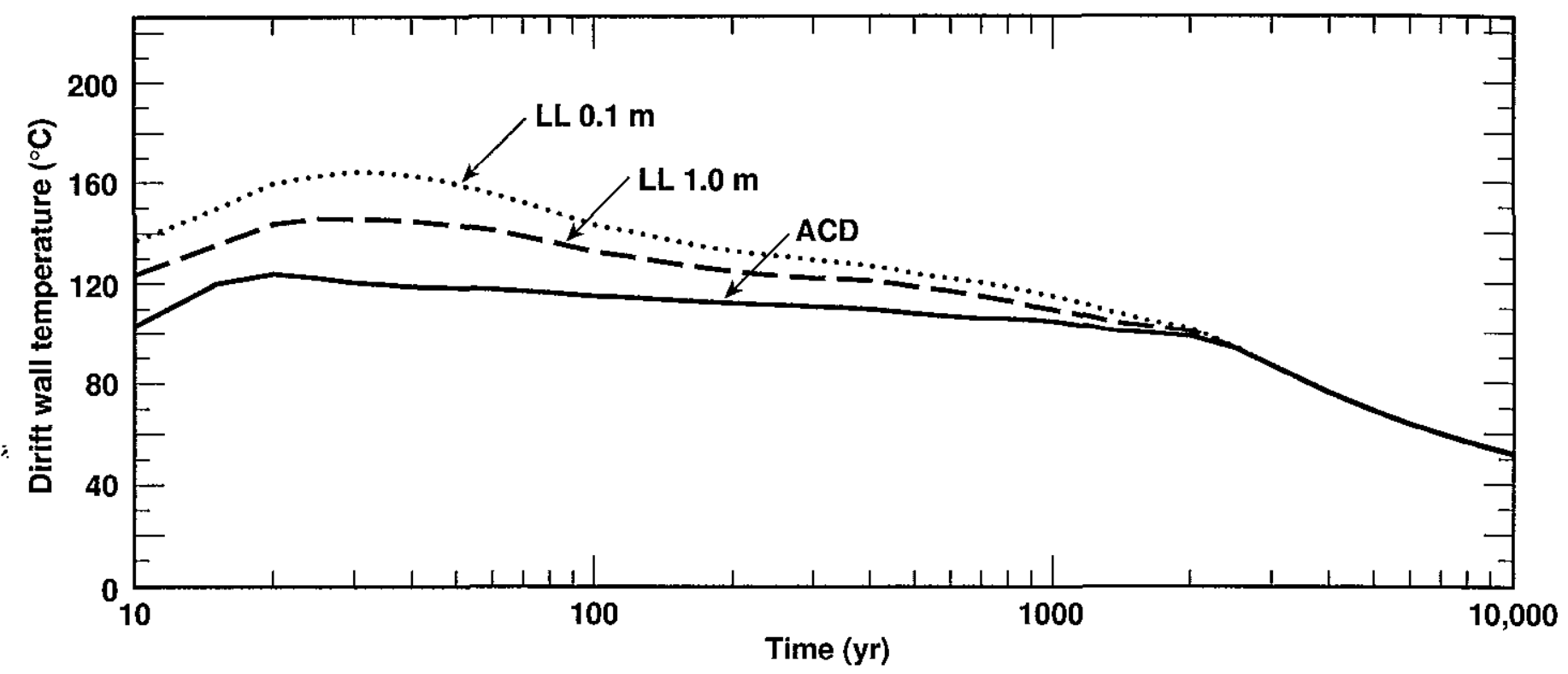

Figure 4-2. Calculated temperatures around the drifts for the ACD design, the LL design with 1.0-m spacing, and the LL design with $0.1-\mathrm{m}$ spacing. The calculations shown here are specific to WP placement and use WPs with 21 assemblies of 26-yr-old PWR SNF.

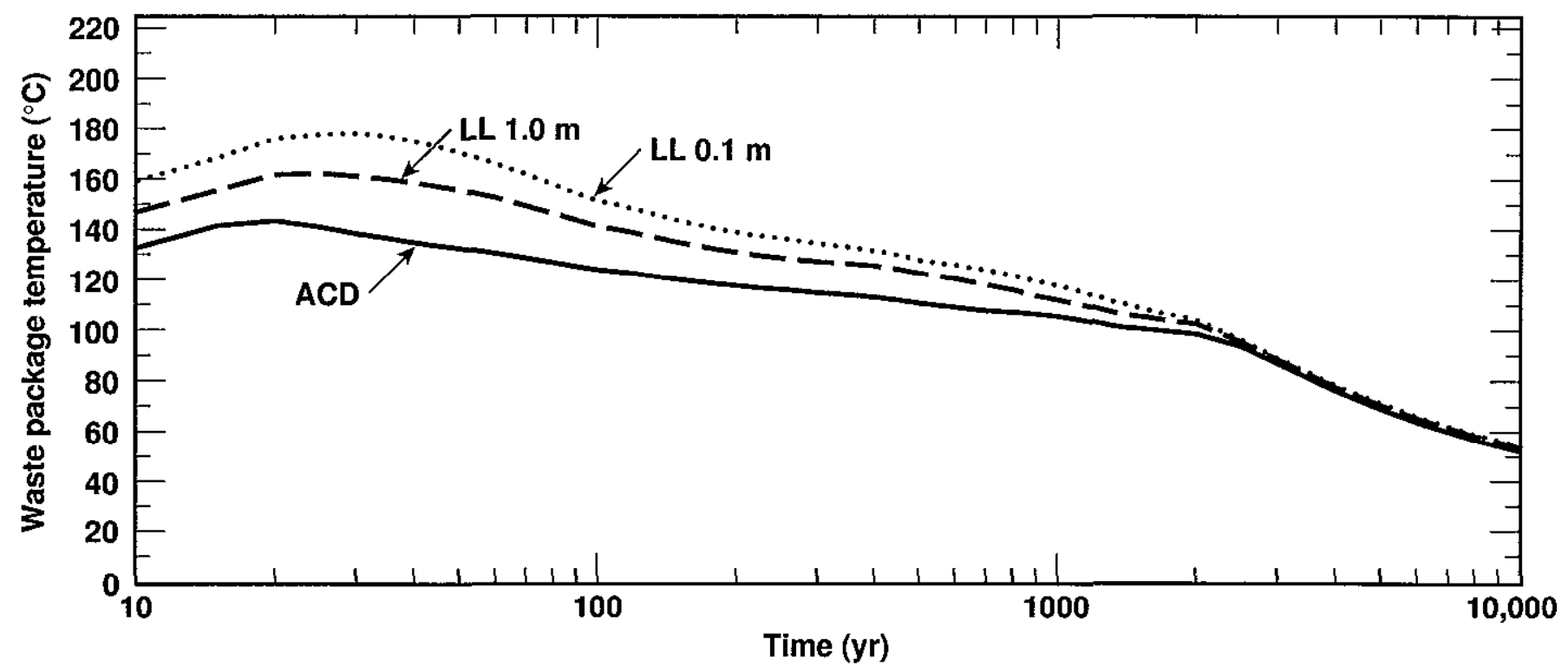

Figure 4-3. Calculated temperatures on the WP surface for the ACD design, the LL design with 1.0-m spacing, and the LL design with $0.1-\mathrm{m}$ spacing. The calculations shown here are specific to WP placement and use WPs with 21 assemblies of 26-yr-old PWR SNF. 
Table 4-1. Peak temperatures in rock at the upper drift wall and on the WP surface for ACD and line-load designs; percolation flux $=0.3 \mathrm{~mm} / \mathrm{yr}$.

\begin{tabular}{|c|c|c|c|c|}
\hline \multirow[b]{2}{*}{$\begin{array}{l}\text { Waste Package } \\
T_{\text {peak }}(t<100 \mathrm{yr}) \\
T_{\text {peak }}(t>100 \mathrm{yr})\end{array}$} & \multicolumn{2}{|c|}{ ACD Rev 00} & \multicolumn{2}{|c|}{ Line-load design, $0.1 \mathrm{~m}$ gap } \\
\hline & $\begin{array}{c}\text { Without backfill } \\
107-192^{\circ} \mathrm{C} \\
104-144^{\circ} \mathrm{C}\end{array}$ & $\begin{array}{c}\text { With backfill } \\
\text { same, no backfill yet } \\
117-353^{\circ} \mathrm{C}\end{array}$ & $\begin{array}{c}\text { Without backfill } \\
172-203^{\circ} \mathrm{C} \\
147-158^{\circ} \mathrm{C}\end{array}$ & $\begin{array}{c}\text { With backfill } \\
\text { same, no backfill yeta } \\
231-314^{\circ} \mathrm{C}\end{array}$ \\
\hline $\begin{array}{l}\text { Wall Rock } \\
T_{\text {peak }}(t<100 \mathrm{yr}) \\
T_{\text {peak }}(t>100 \mathrm{yr})\end{array}$ & $\begin{array}{l}100-165^{\circ} \mathrm{C} \\
100-129^{\circ} \mathrm{C}\end{array}$ & $\begin{array}{c}\text { same, no backfill yet } \\
104-144^{\circ} \mathrm{C}\end{array}$ & $\begin{array}{l}161-184^{\circ} \mathrm{C} \\
142-148^{\circ} \mathrm{C}\end{array}$ & $\begin{array}{c}\text { same, no backfill yeta } \\
135-137^{\circ} \mathrm{C}\end{array}$ \\
\hline
\end{tabular}

aBackfill is emplaced at $100 \mathrm{yr}$; therefore, there is no difference at $t<100 \mathrm{yr}$ between the backfilled and no-backfilled cases

Volume II (see Figs $110513,110516,11051.9$, and 1105113 )

The temperature responses of the ACD and LL designs are markedly different The axial WP spacing in the ACD design is large enough to thermally isolate WPs from each other, which results in a broader range of temperatures For the ACD case without backfill, peak drift-wall temperatures range from $100^{\circ}$ to $165^{\circ} \mathrm{C}$ (As shown in Table 4-1, the peak WP temperatures iange from $107^{\circ}$ to $192^{\circ} \mathrm{C}$ ) The average peak wall rock temperature (at $t<100 \mathrm{yr}$ ) is $1325^{\circ} \mathrm{C}$, and the average WP temperature is $1495^{\circ} \mathrm{C}$ There is a range of $65^{\circ}$ in wall rock temperatures and $85^{\circ}$ in WP temperatures This represents a range of $\pm 25 \%$ and $\pm 28 \%$ of the average wall rock and WP temperatures, respectively In contrast, the wall rock temperatures for the LL range from $161^{\circ}$ to $184^{\circ} \mathrm{C}$, and for the WPs the temperatures range from $172^{\circ}$ to $203^{\circ} \mathrm{C}$ This range represents $\pm 67 \%$ and $\pm 83 \%$ of the average temperature of $1725^{\circ}$ and $1875^{\circ} \mathrm{C}$ for wall rock and WPs respectively. As is apparent, the temperatures are much more uniform for the LL than for ACD case

The design option of backfilling the difts was evaluated for the ACD and LL cases It was assumed that backfilling was not emplaced until $100 \mathrm{yr}$ after waste emplacement The impact on WP and wall rock temperatures is also shown in Table 4-1 These analyses assumed complete backfilling around the WPs, including the gap between WPs In the LL case, leaving the gap open facilitates thermal communication between WPs and therefore would have performance advantages However, additional design features would be required to prevent backfill materials from filling (at least partially) the gap, and for that reason, the analyses reported are for the gap being filled A more complete analysis of impacts of gap filling is discussed in Volume II, Sec 11052 , and temperature information for the open gap can be found in Table 110522 of Volume II As can be seen, the peak temperature of the wall rock for backfilled versus nonbackfilled dr ifts are not significantly different (no change for $\mathrm{ACD}$ and 7 to $11^{\circ} \mathrm{C}$ greater temperatures for backfilled LL case) The greatest difference is for WP temperatures, where backfill increases temperature by 13 to $209^{\circ} \mathrm{C}$ for $\mathrm{ACD}$ and 84 to $156^{\circ} \mathrm{C}$ for the LL design As a result, when backfilled, the uniformity of the LL case compared to the ACD remains pronounced The average WP peak temperature after backfilling is $235^{\circ} \mathrm{C}$ with a range of $\pm 50 \%$ of the average for the ACD case, and is $2725^{\circ} \mathrm{C}$ with a range of $\pm 15 \%$ of the average for the LL design

Analyses of the current or modified design have been based on a modified ACD with $10-\mathrm{m}$ spacing for significant portions of the drifts Therefore, Figs 4-2 and 4-3 showing the line-load design with $10-\mathrm{m}$ spacing are more representative of portions of the current design than is the ACD design

As seen in Figs 4-2 and 4-3, the distinction between temperatures resulting from different designs is reduced with time This is also true for the distinction between wall rock and WP temperatures As can be seen in Fig 4-4, for times that extend beyond about 3000 years, there are only minor differences (about $5^{\circ} \mathrm{C}$ ) between the temperature on the WP surface and in the rock at the drift wall This plot was based on the TSPA95 reference case with $A M L=834 \mathrm{MTU} /$ acre The plot is included merely to illustrate that, at longer 


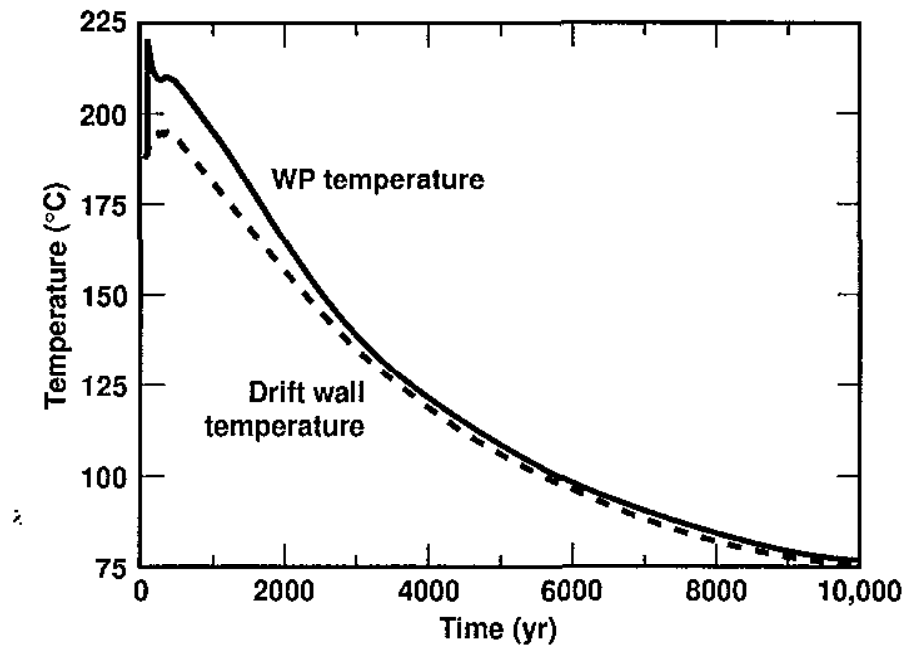

Figure 4-4. Temperature on the WP surface and in rock at the drift wall for the TSPA95 reference case with AML $=83.4 \mathrm{MTU} / \mathrm{acre}, \mathrm{LML}=0.47 \mathrm{MTU} / \mathrm{m}$, and drift spacing $=22.5 \mathrm{~m}$.

times, the temperature differences between WP and rock decrease Thus, the impacts of temperature differences between WPs and drift walls will be greatest during the first few thousand years after emplacement The TSPA95 case was essentially a line load, but it was judged sufficiently representative of the average response of the design cases to illustrate this point Therefore, the calculations were not redone to be more directly comparable with the ACD or LL cases
The preceding discussions were for average conditions Table 4-2 shows the temperature conditions for individual WPs by waste type based on the ACD and LL cases This table shows that there is considerably more variability in peak WP temperatures for the ACD design than for the LL design For the fir st 100 years, the average WP temperature for the ACD design is $134^{\circ} \mathrm{C}$, and the range of temperatures is equivalent to $64 \%$ of the average In contrast, the LL design has a higher average temperature of $180^{\circ} \mathrm{C}$ and much less variability, with a range of temper atures equivalent to $18 \%$ of the aver age The difference is even more pronounced for times beyond 100 years For $t>100 \mathrm{yi}$, the average ACD WP temperature is $212^{\circ} \mathrm{C}$, and the range is $111 \%$ of that value. The average LL WP temperature is $256^{\circ} \mathrm{C}$, and the range is only $6 \%$ of the average value

Figure $4-5$ shows the three-dimensional temperature distribution for the same amount of waste per acre (834 MTU/acre) at 100 and $500 \mathrm{yr}$ for the ACD and the line-load designs with $01-\mathrm{m}$ spacing and full sand backfill at $100 \mathrm{yr}$ Temperatures less than $112^{\circ} \mathrm{C}$ are transparent to emphasize the relatively hot regions in the NFE (For an ambient percolation flux of $03 \mathrm{~mm} / \mathrm{yr}$, rock temperatures above $105^{\circ} \mathrm{C}$ correspond to a reduction in relative humidity Therefore, the colored regions in the illustration are zones of superheated conditions where temperatures are hotter than the nominal boiling point $\left(96^{\circ} \mathrm{C}\right)$, and moisture conditions are drier than ambient Condensate drainage will generally occur around the colored regions )

Table 4-2 Temperature on the upper WP surface by waste type for the ACD versus LL design with 0.1-m spacing. Full sand backfill is used with $K_{\mathrm{th}}=0.6 \mathrm{~W} / \mathrm{m}^{\circ} \mathrm{C}$, and percolation flux $=0.3 \mathrm{~mm} / \mathrm{yr}$.

\begin{tabular}{lcccccc}
\hline Parameter & $\begin{array}{c}\text { Hanford } \\
\text { DHLW }\end{array}$ & $\begin{array}{c}\text { Savannah } \\
\text { DHLW }\end{array}$ & $\begin{array}{c}\text { 40-yr-old } \\
\text { PWR MPC }\end{array}$ & $\begin{array}{c}\text { 26-yr-old } \\
\text { BWR MPC }\end{array}$ & $\begin{array}{c}\text { 26-yr-old } \\
\text { PWR MPC }\end{array}$ & $\begin{array}{c}\text { 10-yr-old } \\
\text { PWR MPC }\end{array}$ \\
\hline $\begin{array}{l}\text { ACD } \\
T_{\text {peak }} \\
(t<100 \mathrm{yr})\end{array}$ & $106^{\circ} \mathrm{C}$ & $121^{\circ} \mathrm{C}$ & $112^{\circ} \mathrm{C}$ & $127^{\circ} \mathrm{C}$ & $145^{\circ} \mathrm{C}$ & $192^{\circ} \mathrm{C}$ \\
$\begin{array}{l}T_{\text {peak }} \\
(t>100 \mathrm{yr})\end{array}$ & $117^{\circ} \mathrm{C}$ & $136^{\circ} \mathrm{C}$ & $172^{\circ} \mathrm{C}$ & $222^{\circ} \mathrm{C}$ & $272^{\circ} \mathrm{C}$ & $353^{\circ} \mathrm{C}$ \\
$\begin{array}{l}\text { Line load } \\
T_{\text {peak }}\end{array}$ & & & & & \\
$(t<100 \mathrm{yr})$ & $171^{\circ} \mathrm{C}$ & $184^{\circ} \mathrm{C}$ & $171^{\circ} \mathrm{C}$ & $174^{\circ} \mathrm{C}$ & $178^{\circ} \mathrm{C}$ & $203^{\circ} \mathrm{C}$ \\
$\begin{array}{l}T_{\text {peak }} \\
(t>100 \mathrm{yr})\end{array}$ & $252^{\circ} \mathrm{C}$ & $258^{\circ} \mathrm{C}$ & $250^{\circ} \mathrm{C}$ & $251^{\circ} \mathrm{C}$ & $256^{\circ} \mathrm{C}$ & $266^{\circ} \mathrm{C}$ \\
\hline
\end{tabular}



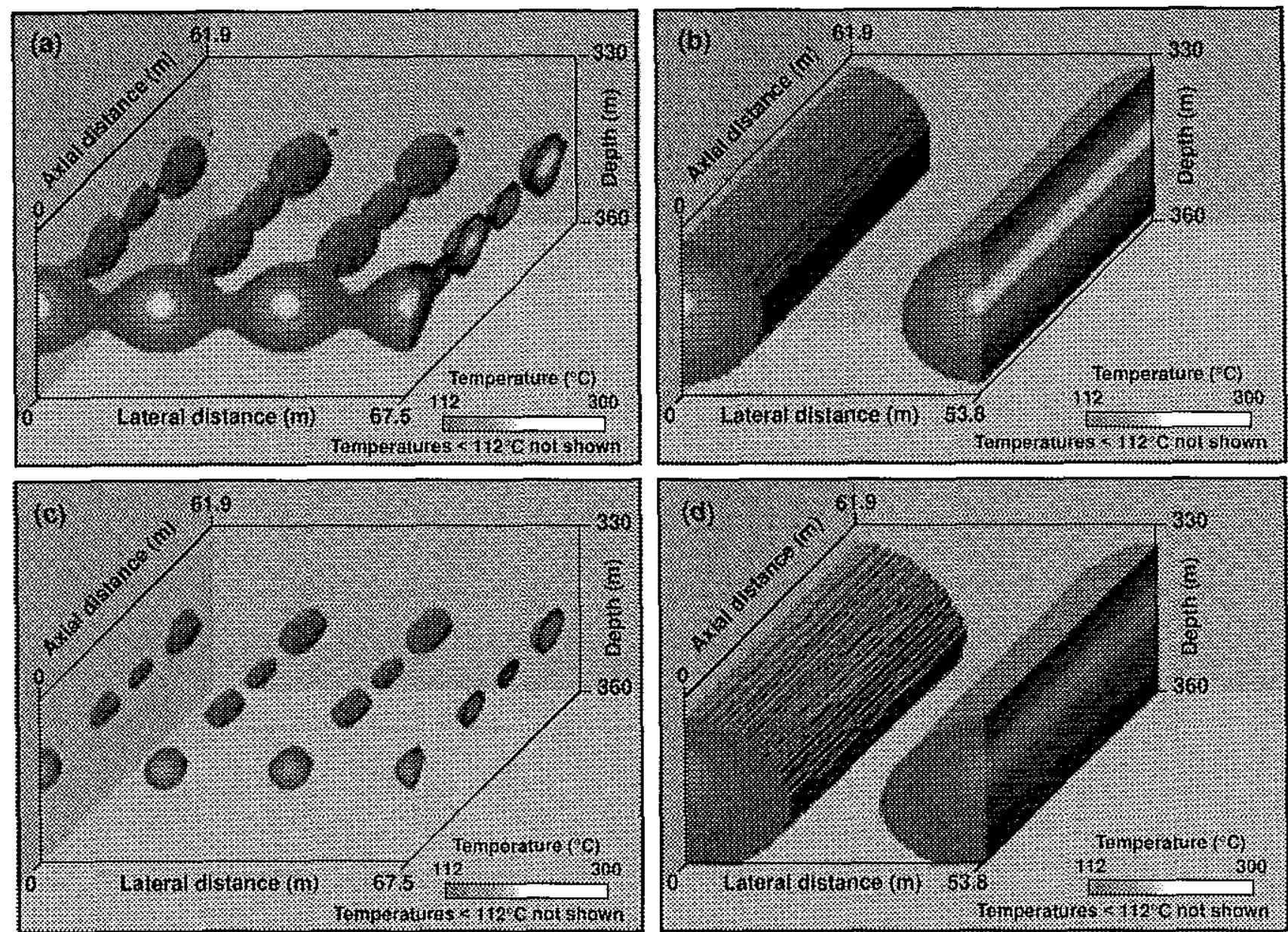

Figure 4-5. Temperature distribution for ( $a$ and c) ACD versus (b and d) line-load design with 0.1-m spacing between WPs. Temperatures are shown at ( $a$ and $b$ ) $100 \mathrm{yr}$ and at ( $\mathrm{c}$ and d) $500 \mathrm{yr}$. For all cases shown, AML $=83.4 \mathrm{MTU} /$ acre, fill sand backfill is present, drift diameter $=5.5 \mathrm{~m}$, and ambient percolation flux is $0.3 \mathrm{~mm} / \mathrm{yr}$. Emplacement drifts are parallel to the axial distance axis.

The large axial spacing in the ACD design thermally isolates WPs from one another, causing rock dryout and condensate shedding to occur in a spherical fashion The size of any spherically shaped superheated zone is directly correlated with the heat output of the WP in that zone. Only half of the WPs generate enough decay heat to develop a superheated zone at $100 \mathrm{yr}$ In addition, only a very small portion of the repository can be considered to be in a marginally superheated state at $500 \mathrm{yr}$ for the ACD design.

In contrast, for the line-load design, condensate shedding occurs in a cylindrical fashion, and condensate flux at the repository horizon only occurs in the rock pillars separating the emplacement drifts.

Consequently, the line-load design is associated with a much larger superheated volume that the ACD design, even though the two designs share the same AML

Refer to the tables in Section 44, below, for a list of cross references to Volume II, which considered many other parameters that can affect temperatures at the WP and drift wall

\subsection{Water (Liquid and Vapor) Fluxes in the NFE}

From the list of priorities identified in Section 1, a key consideration for nuclear waste isolation is whether (more precisely, when and how) water contacts a WP The manner in which decay heat 
influences the distribution of liquid saturation and liquid-phase flux in the NFE is the focus of this section

Water may contact a WP either by liquid-phase (advective or diffusive) flow or by condensation of water vapor that forms a liquid film on the WP (function of $\mathrm{RH}$ ) Water contact may arise in the following three ways

- Drift seepage Advective liquid-phase flow of water that enters the drift (and flows through the backfill if present) as a result of ambient percolation or decay-heat-driven condensate flow This seepage can include episodic, nonequilibrium fracture flow or steady weep

- Wicking Transport of moisture driven by matric potential gradients (i e capillary pressure gradients) This is considered to be primarily an advective liquid-phase transport process called imbibition, however, binary gas-phase diffusion can also play a role Because wicking can occur as two-phase flow, it does not necessarily require a continuous liquid phase

- Cold-trap effect. Axial water-vapor flow and condensation within the drift is driven by axial variations in temperature $(T)$ and vapor pressure $\left(P_{\mathrm{v}}\right)$ along the drift Water vapor is transported by gas-phase advection and diffusion from areas of higher $T$ and $P_{\mathrm{v}}$ to areas of lower $T$ and $P_{\mathrm{v}}$ where it condenses, which causes $R H$ to increase (to as high as $100 \%$ ) Large condensation rates can arise in the cooler areas if three conditions are met (1) high $R H$ in the rock at the drift wall, (2) WP heat output varies substantially from WP to WP, and (3) WPs are thermally isolated from one another It is important to note that this mechanism does not require liquid water to enter the drift

For all three of these effects, the most important thermal-management design factor is the WP layout rather than the overall AML of the repository itself (i e, high versus low AML)

Liquid-phase flux that may enter a drift is the result of ambient percolation flux and decay-heatmobilized vapor and condensate flow One of the issues that will be discussed in this report is whether (or under what conditions) decay heat decreases or increases the magnitude (or probability) of liquidphase flux entering a drift Depending on the AML, decay heat is capable of generating a zone of countercurrent, two-phase flow above the repository, which is sometimes called the refluxing zone or the heat-pipe zone (Nitao, 1988, Pruess et al, 1990, Buscheck and Nitao, 1994) This zone is associated with liquid-phase fluxes that are much larger than ambient If the AML is large enough, this zone can be displaced well above the repository horizon by the superheated (aboveboiling-temperature) zone. If the AML is not large enough or the ambient percolation flux is too large, it is possible for the heat-pipe zone to remain at the repository horizon A heterogeneous permeability distribution can also cause the heat-pipe zone to remain at the repository horizon in regions where condensate flow is focused (see Volume II, Sec 11025 )

Whether liquid-phase flux, arising from ambient percolation flux and decay-heat-mobilized condensate flux, may enter emplacement drifts depends on the magnitudes of the fluxes As noted earlier, this report considers ambient fluxes in the range between 0 to $5 \mathrm{~mm} / \mathrm{yr}$, with $03 \mathrm{~mm} / \mathrm{yr}$ as the reference value The value of $03 \mathrm{~mm} / \mathrm{yr}$ was chosen for convenience because of the amount of data available for this particular case. Current estimates, although not universally accepted, are much higher, in the range of 1 to $15 \mathrm{~mm} / \mathrm{yl}_{1}$ The overall magnitude of the condensate flux depends on AML, not layout configuration As shown in Fig 4-6, the total flux at the repository level that results from $834 \mathrm{MTU} /$ acre for percolation fluxes of $03 \mathrm{~mm} / \mathrm{yr}$ and $005 \mathrm{~mm} / \mathrm{yr}$ is less than $1 \mathrm{~mm} / \mathrm{yr}$, except between 3,000 to 6,000 yr, when fluxes peak at about $16 \mathrm{~mm} / \mathrm{yr}$ (at approximately 4,000 years) Moreover, liquid-phase flux in

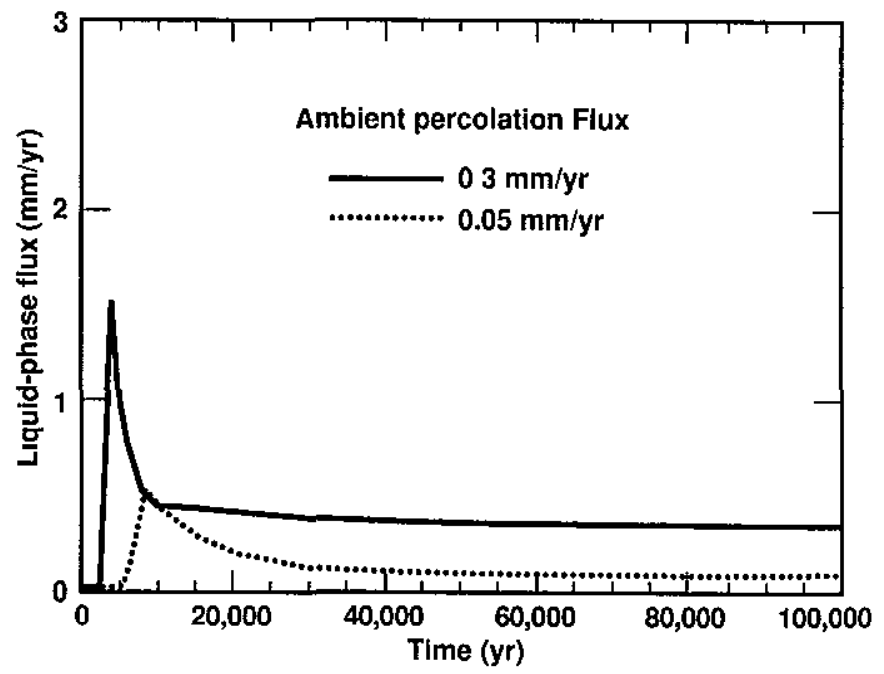

Figure 4-6. Liquid-phase flux at the repository horizon at a location midway between the repository center and the outer perimeter. AML = 83.4 MTU/acre, and repository area $=3.06 \mathrm{~km}^{2}$. 
the vicinity of an 834-MTU/acre repository is dominated by condensate flux for 2000 to $5000 \mathrm{yr}$ (see Buscheck, 1996, in Sec 1.10, Vol II) Thus, there is a potential total percolation/condensate flux of about $1 \mathrm{~mm} / \mathrm{yr}$ that theoretically could enter the drifts

Whether this amount of flux can actually enter the drifts depends on several factors. The first is how much of the condensate flux will be available to flow into the drifts and how much will be diverted away from drifts As noted by Wilder (1990), condensate will be driven away from the drifts in all directions (radially) and will tend to be deposited in the greatest volumes over the pillars between drifts rather than above the drifts (Although this analysis was made for the borehole emplacement case, the geometric conditions apply to current designs, so that this conclusion remains valid ) Thus, unless flow in pillars is restricted by processes such as fracture healing (see Section 5), it is not appropriate to combine both the average percolation and condensate fluxes to deter mine the potential flux into the drifts How large a percentage of the condensate would be deposited over the drifts will depend on the repository design or configurationspecifically drift spacing The assumption of uniform condensate buildup in the rock above the drifts gives an upper bound, since the condensate flux would be independent of location, and all of the focusing mechanisms would tend to focus condensate away from drifts rather than over them.

A second factor is whether condensate will leave the system before it can return to the drifts This depends on whether the condensate will be thermally perched so that it can reside in fractures/matrix in the condensate zone rather than flowing through the fractures and away from the condensate zone Laboratory studies by Roberts and Lin (1997) indicate that for a $25-\mu \mathrm{m}$ fracture, thermal perching is overcome once the condensate builds up a head exceeding $29 \mathrm{~m}$. At that point, the condensate would drain through fractures Of course, how far it can flow along the fracture is a function of length of flow path in the superheated zone, the heat flux, and the quantity of condensate available to continue to feed water into the fracture (Buscheck and Nitao, 1994) Because the heat flux is much higher near the drifts, the condensate would tend to drain preferentially through pillar areas If the condensate is thermally perched, the fractures have a very small storage volume for water to reside in Analyses of the relative volumes of available storage versus volumes of condensate generated indicate that more than $90 \%$ of the condensate generated will have to either flow laterally away from the repository drifts and/or down fractures to the saturated zone, or fill up the matrix pores, which would result in a thick zone of nearly saturated rock, or leave the system entirely

A third factor is whether the local heat flux, $q_{\mathrm{h}}$ is large enough to evaporate the local incoming liquidphase mass flux $q_{\text {liq }}$ Spatial variability can result in local regions where $q_{\text {liq }}$ will prevail Because $q_{\mathrm{h}}$ increases with proximity to the drift, it is more likely for $q_{\text {liq }}$ to prevail in the rock farther away from the drifts Near the drifts, $q_{\mathrm{h}}$ will be 24 times greater, on average, for the line-load design than for the pointload design.

Superheated conditions in the repository rock will occur as long as the local heat flux $q_{\mathrm{h}}$ is enough to evaporate the local incoming liquid-phase mass flux $q_{\text {liq }}$ The extent or rapidity at which the water that is within the pores of the matrix will be vaporized depends on the extent that $q_{\mathrm{h}}>q_{\text {liq }}$ If $q_{\text {liq }}$ is too large, then $q_{\mathrm{h}}$ is insufficient to generate superheated conditions Spatial variability can result in local regions where $q_{\text {lig }}$ will prevail Because $q_{\mathrm{h}}$ increases with proximity to the drift, it is more likely for $q_{\text {liq }}$ to prevail in the rock farther away from the drifts Near the drifts, $q_{\mathrm{h}}$ will be 24 times gieater, on average, for the lineload design than for the point-load design

Fourth, studies by Nitao (1997) indicate that for total percolation fluxes below $10 \mathrm{~mm} / \mathrm{yr}$, the water will not enter the drifts If the ambient percolation flux approaches $10 \mathrm{~mm} / \mathrm{yr}$, then during the thermal regime the issues of $q_{\mathrm{h}}$ versus $q_{\mathrm{liq}}$, as well as condensate drainage become very important After the waste and surrounding rock cools down $(2,000$ to $6,000 \mathrm{yr})$, then the condensate will not be added to the ambient percolation flux It will have either drained away or have been imbibed into the matrix Thus, for the longer time frames, the ambient percolation flux can be used to determine the water entry into drifts During this time, unless the percolation flux exceeds the $10-\mathrm{mm} / \mathrm{yr}$ value that is currently envisioned as the maximum value, then water would not enter the drifts

The above discussion assumes that there are no drift liners or other ground support systems to hinder water flow into the drifts The current design calls for emplacement of pre-cast concrete liner as ground support The liner will not be sealed at the joints but will interlock segments This will provide some additional resistance to flow into the drifts but will not be entirely tight Where fractures intersect the drift opening, the water would tend to be diverted around the liner segments, and if open fractures were available, 
much of the water would flow into those fractures This would not divert all of the water from the drift ,but it would result in reductions so that assessments based on the unrestricted flow into the drifts would be a conservative estimate Recent estimates of potential for flow into difts from the ambient percolation flux have concluded that no flow will enter the drifts (Bodvarsson and Bandurraga, 1996)

\subsection{Relative Humidity Conditions in the Drift and NFE}

One of the performance issues related to the NFE is the relation between relative humidity $(R H)$ and corrosion rates of candidate metals for the WP containers It has been observed that corrosion rates initiate, and kinetics become increased, at $R H$ values that are higher than about 70\% (McCright, 1997, see Van et al , 1994) Buscheck (1996) noted that one of the results of the heat output of the WPs is the lowering of the $R H$ on the surface of the WPs A temperature difference or gradient in the drift will result in lowering of the $R H$ in the drift, or more specifically, on the WP surface, to values below what they would be if the $R H$ was entirely determined by equilibrium with the humidity or water/moisture conditions in the rock Without a difference in temperature between the rock wall surface and the drift air or WP surfaces, the
$R H$ in the drift would be in equilibrium with humidity conditions in the rock, which are a function of saturation of the rock Except for very low rock saturations, this would mean that the $R H$ within the drifts would be very high Analyses have indicated that $\mathrm{RH}$ within the drifts will exceed $70 \%$ for rock saturation above $20 \%$. Thus, the rock would need to be reduced in saturation from its ambient state, currently estimated to be around $90 \%$ saturation, to below $20 \%$ saturation before there would be a sufficient reduction in $\mathrm{RH}$ to be out of the high-corrosion-potential regime of $R H$ equal to or exceeding $70 \%$ In contrast, the thermal gradient is highly effective at lowering the $R H$

Table 4-3 shows the calculated $R H$ conditions on the WP surface and on the emplacement drift wall (for average repository conditions) that would result from the two repository designs/layouts considered, i e , the ACD and LL 0 1-m-gap cases Because backfill has a strong influence on temperature gradients, the information is shown for both backfilled and open drifts

Comparison of the values in Table 4-3 shows that there is a reduction in $R H$ that results from emplacement of waste for both the WP and the drift wall The reductions are greater for the WP surfaces because the temperatures are higher there than on the drift walls Regardless of the design option considered, the RHs are considerably lower than the values of nearly 98 to $99 \%$ that are representative of the ambient conditions (the values for $t=10,000 \mathrm{yr}$ are essentially ambient)

Table 4-3. Relative humidity in rock at the upper drift wall and on the WP surface for ACD and line-load designs, assuming percolation flux $=0.3 \mathrm{~mm} / \mathrm{yr}$ and backfilling occurs at $100 \mathrm{yr}$.

\begin{tabular}{|c|c|c|c|c|}
\hline \multirow[b]{2}{*}{ Time of $R H$} & \multicolumn{2}{|c|}{ ACD Rev 00} & \multicolumn{2}{|c|}{ Line-load design } \\
\hline & Without backfill & With backfill & Without backfill & With backfill \\
\hline \multicolumn{5}{|l|}{ WP surface } \\
\hline$R H(t<100 \mathrm{yr})$ & $25-86 \%$ & Same ${ }^{a}$ & $16-21 \%$ & Same \\
\hline$R H(t=120 \mathrm{yr})$ & $29-85 \%$ & $1-57 \%$ & $18-23 \%$ & $1-4 \%$ \\
\hline$R H(t=2000 \mathrm{yr})$ & $86-97 \%$ & $43-98 \%$ & $72-76 \%$ & $44-57 \%$ \\
\hline$R H(t=10,000 \mathrm{yr})$ & $92-999 \%$ & $60-997 \%$ & $94-98 \%$ & $68-81 \%$ \\
\hline \multicolumn{5}{|l|}{ Rock Surface } \\
\hline$R H(t<100 \mathrm{yr})$ & $36-98 \%$ & Same ${ }^{a}$ & $21-25 \%$ & Same \\
\hline$R H(t=120 \mathrm{yr})$ & $36-97 \%$ & $45-99 \%$ & $23-27 \%$ & $31 \%$ \\
\hline$R H(t=2000 \mathrm{yr})$ & $90-97 \%$ & $92-99 \%$ & $76-77 \%$ & $78 \%$ \\
\hline$R H(t=10,000 \mathrm{yl})$ & $998-998 \%$ & $998-998 \%$ & $991-991 \%$ & $991 \%$ \\
\hline
\end{tabular}

aBackfill is emplaced at $100 \mathrm{yr}$; therefore, there is no difference at $\mathrm{t}<100 \mathrm{yr}$ between backfilled and nonbackfilled cases 
A significant difference between the $R H$ reductions resulting from the ACD and the LL designs ar ises because the axial WP spacing in the ACD design is large enough to thermally isolate WPs from each other However, the reductions are much more dramatic for the WPs when backfill is emplaced and the LL design option is used In this case, the humidities remain below the critical values for several thousand years Even after $10,000 \mathrm{yx}$, they are in the 70 to $80 \%$ range The difference between the ACD and LL case is not merely in the magnitude of the reduction, but also in the variability or range of the reduction This can be seen by comparing aver age values In the ACD case at $120 \mathrm{yr}$, the average $R H=29 \%$ and the range of values is $\pm 28 \%$ of the average, whereas for the LL case at $120 \mathrm{yr}$, the average $R H=25 \%$ and the range is only $\pm 15 \%$ of the average Likewise at 2,000 yr, the ACD RH $=705 \%$ and the range is $\pm 275 \%$ of the average, whereas the $\mathrm{LL}$ case $R H=505 \%$ and the range is only $\pm 65 \%$ of the average The range in $R H$ for the ACD case repiesents $\pm 97 \%$ and $\pm 39 \%$ of the average values at 120 and $2000 \mathrm{yl}$, respectively In contrast, the range of $R H s$ for the LL case represents $\pm 60 \%$ and $\pm 13 \%$ of the average values at 120 and $2000 \mathrm{yr}$, respectively The reductions in $R H$ for the wall rock ate not as significant for the backfill case as for the nonbackfilled case This reflects the temperature gradient that results when backfill is emplaced, which causes a much reduced WP relative humidity, but a less reduced wall-1ock relative humidity

The preceding discussions were for average conditions Table 4-4 shows the $R H$ conditions for individual WPs by waste type based on the ACD and LL cases This table shows that repository design can cause significant differences in the RHs that develop on the WP surfaces, particularly when the drifts are backfilled One way to consider this impact is to look at the range of $R H$ conditions that develop Prior to backfilling, the range of $R H$ s for the ACD case is fiom 25 to $86 \%$ The average $R H$ is $55 \%$, and the range is equivalent to $111 \%$ of the average value In contrast, the range of $R H$ s for the LL case is from 16 to $21 \%$, the average is $20 \%$, and the range is equivalent to $25 \%$ of the average value Thus, the $R H$ environment is much more uniform for the LL case prior to backfill

At $120 \mathrm{yr}$ ( $20 \mathrm{yr}$ after backfill is emplaced), the $R H$ range is from 1 to $57 \%$ for the ACD case, the aver age $\mathrm{RH}$ is $19 \%$, and the magnitude of the range of $\mathrm{RHs}$ is $300 \%$ of the average value For the LL case, the $R H$ range is from 2 to $3 \%$, the average $\mathrm{RH}$ is $3 \%$, and the range is equivalent to $35 \%$ of the average Similar differences are seen at 2,000 yr, where the ACD average value is $70 \%$, and the range is equivalent to $78 \%$ of the average value For the LL case, the average RH is $50 \%$, and the 1 ange is equivalent to only $6 \%$ of

Table 4-4. Relative humidity on the upper WP surface by waste type for the ACD versus LL design with 0.1-m spacing. Full sand backfill is used with $K_{\text {th }}=0.6 \mathrm{~W} / \mathrm{m}^{\circ}{ }^{\circ}$, and percolation flux $=0.3 \mathrm{~mm} / \mathrm{yr}$.

\begin{tabular}{|c|c|c|c|c|c|c|}
\hline Time of $R H$ & $\begin{array}{l}\text { Hanford } \\
\text { DHLW }\end{array}$ & $\begin{array}{l}\text { Savannah } \\
\text { DHLW }\end{array}$ & $\begin{array}{l}\text { 40-yr-old } \\
\text { PWR MPC }\end{array}$ & $\begin{array}{l}\text { 26-yr-old } \\
\text { BWR MPC }\end{array}$ & $\begin{array}{l}\text { 26-yr-old } \\
\text { PWR MPC }\end{array}$ & $\begin{array}{l}\text { 10-yr-old } \\
\text { PWR MPC }\end{array}$ \\
\hline \multicolumn{7}{|l|}{$\mathbf{A C D}$} \\
\hline$R H_{\max }(t<100 \mathrm{yr})$ & $86 \%$ & $61 \%$ & $65 \%$ & $50 \%$ & $42 \%$ & $25 \%$ \\
\hline$R H_{\max }(t=120 \mathrm{yr})$ & $57 \%$ & $34 \%$ & $13 \%$ & $5 \%$ & $2 \%$ & $1 \%$ \\
\hline$R H(t=2000 \mathrm{yr})$ & $98 \%$ & $97 \%$ & $71 \%$ & $62 \%$ & $50 \%$ & $43 \%$ \\
\hline$t(R H=65 \%)^{\mathrm{b}}$ & $160 y^{a}$ & $210 \mathrm{yr}^{\mathrm{a}}$ & $1590 \mathrm{yr}$ & $2250 \mathrm{yr}$ & 8480 yr & $13,660 y^{1}$ \\
\hline$t(R H=90 \%)^{\mathrm{b}}$ & $950 \mathrm{yr}$ & $860 \mathrm{yr}$ & $25,870 \mathrm{yr}$ & $35,690 \mathrm{yr}$ & 54,680 & $62,670 \mathrm{yr}$ \\
\hline \multicolumn{7}{|l|}{ Line load } \\
\hline$R H_{\max }(t<100 \mathrm{yr})$ & $21 \%$ & $21 \%$ & $21 \%$ & $21 \%$ & $19 \%$ & $16 \%$ \\
\hline$R H_{\max }(t=120 \mathrm{yr})$ & $3 \%$ & $3 \%$ & $3 \%$ & $3 \%$ & $3 \%$ & $2 \%$ \\
\hline$R H(t=2000 y r)$ & $51 \%$ & $52 \%$ & $50 \%$ & $51 \%$ & $49 \%$ & $49 \%$ \\
\hline$t(R H=65 \%)^{b}$ & $3930 \mathrm{yr}$ & $3730 \mathrm{yr}$ & $4250 \mathrm{yr}$ & $3960 \mathrm{yr}$ & $5430 \mathrm{yr}$ & $4600 \mathrm{yr}$ \\
\hline$t(R H=90 \%)^{b}$ & $33,320 \mathrm{yr}$ & $30,480 \mathrm{yr}$ & $36,800 \mathrm{yr}$ & $34,890 \mathrm{yr}$ & $39,920 \mathrm{yr}$ & $39,820 \mathrm{yr}$ \\
\hline
\end{tabular}

aRH is never less than $65 \%$ piior to backfill

bTime at which relative humidity reaches this value 
the average Similar differences are seen for the time at which the $R H$ returns to a value of $65 \%$

Figures 4-7 and 4-8 show the relative humidities over time extending to 10,000 years The very early time responses are not well defined in these plots, and those beyond 10,000 years are not shown The humidity data for these times can be found in Volume II (see Figs $110513,11051.6,1.10519$, and 1105113 ) Beyond about 2000 years, the WP RH is maintained at about $95 \%$, whereas the 1ock $R H$ returns to 99 to $100 \%$ The reason for this difference is that the decay heat flux is nearly constant, so that there is a sufficient

: difference in temperature between WP and rock wall to depress the WP RH by about $5 \%$

The forgoing discussion of $R H$ primarily considered a percolation flux of $03 \mathrm{~mm} / \mathrm{yr}$, consistent with Volume II However, the estimates of flux have been more recently revised to greater values, with $5 \mathrm{~mm} / \mathrm{yr}$ as the value that is recommended (Bodvarsson and Bandurraga, 1996) Values as high as 10 to $15 \mathrm{~mm} / \mathrm{yr}$ have been suggested. The effects of higher percolation were analyzed in Section 1106 of Volume II and are merely summarized here The relationship between relative humidity on the WP $\left(R H_{\mathrm{wp}}\right)$ and percolation flux $\left(q_{\text {perc }}\right)$ was found to fall into three ranges For $q_{\text {perc }}<03 \mathrm{~mm} / \mathrm{yr}$, the duration of reduced $R H_{\mathrm{wp}}$ increases strongly with decreasing $q_{\text {perc }}$ Fol $03<q_{\text {perc }}$ $<10 \mathrm{~mm} / \mathrm{yr}$, the duration of reduced $R H_{\mathrm{wp}}$ is relatively insensitive to $q_{\text {perc }}$ For $q_{\text {perc }}>10 \mathrm{~mm} / \mathrm{yr}$, the duration of reduced $R H_{w p}$ decreases with increasing $q_{\text {perc }}$ Increasing $q_{\text {perc }}$ from 1 to $5 \mathrm{~mm} / \mathrm{yr}$, reduces the period during which $R H_{\text {wp }}$ is less than $65 \%$ from 1660 to $1200 \mathrm{yr}$ Because the decay-heat-driven liquid-phase flux is much greater than $q_{\text {perc }}$ for the first $1000 \mathrm{yr}$, it is not surprising that $R H_{\mathrm{wp}}$ was found to be only moderately sensitive to $q_{\text {perc }}$ for $03<q_{\text {perc }}<5 \mathrm{~mm} /$ yr Even if $q_{\text {perc }}$ is as large as 10 to $20 \mathrm{~mm} / \mathrm{yr}$, the decay-heatdriven liquid-phase flux is much larger than $q_{\text {perc }}$ during the fir st $500 \mathrm{yr}$

Other studies (e g, Bodvarsson and Bandurraga, 1996) suggest that much less reduction of $R H_{w p}$ would occur at higher $q_{\text {perc }}$ (such as $5 \mathrm{~mm} / \mathrm{yr}$ ) However, those studies used hydrological properties that result in much stronger capillary-driven rewetting of the dryout zone (both the fracture and matrix continua) than are predicted using the hydrological proper ties in Volume II of this report $A n$ important distinction between the percolation-flux sensitivity study conducted in Volume II

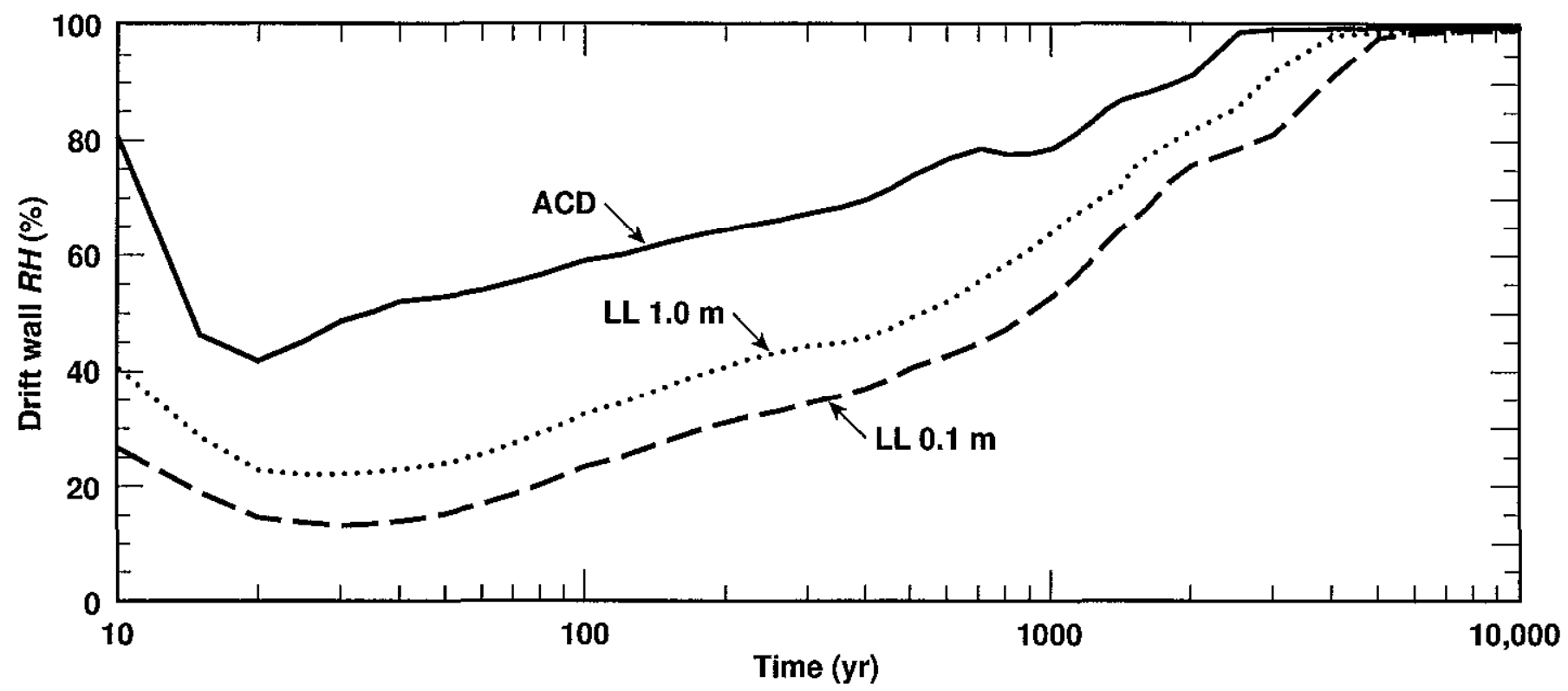

Figure 4-7. Calculated relative humidities on upper drift wall for the ACD design, LL design with 1.0-m spacing, and LL design with $0.1-\mathrm{m}$ spacing (no backfill). The calculations shown here are specific to WP placement and use WPs with 21 assemblies of 26-yr-old PWR SNF. 


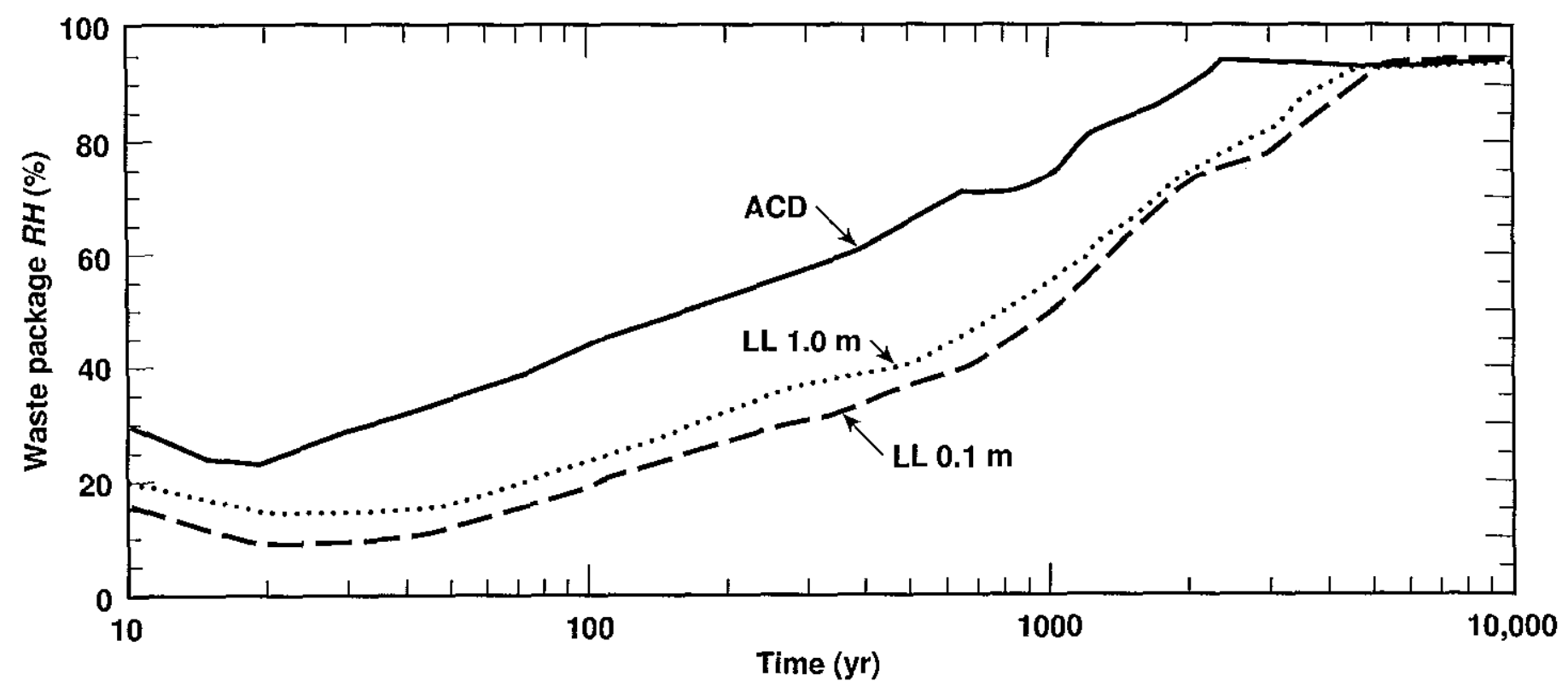

Figure 4-8. Calculated relative humidities on the WP surface for the ACD design, LL design with 1.0-m spacing, and LL design with $0.1-\mathrm{m}$ spacing (no backfill). The calculations shown here are specific to WP placement and use WPs with 21 assemblies of 26-yr-old PWR SNF.

and the other sensitivity studies is whether the intrinsic hydrological proper ties of the rock were simultaneously varied along with percolation flux In Volume II, the hydrological properties of the fracture and matix continua were held constant while percolation flux was varied Other studies (e $g$, Bodvarsson et al 1996) simultaneously var ied percolation flux and the intrinsic hydrological properties, which makes it difficult to discern the influence of individual factors

Post-test analyses of the Single-Heater Test (Buscheck et al , 1997) show that the use of recent hydrological property sets calibrated to percolation fluxes of 36 and $62 \mathrm{~mm} / \mathrm{yr}$ predicted much lower temperatures than those measured in the superheated zone surrounding the heater The $36-$ and $62-\mathrm{mm} / \mathrm{yr}$ property sets resulted in unreasonably high rates of capillary-driven rewetting of the dryout zone around the heater, preventing the temperatures at many of the thermocouple locations around the heater from $x$ ising above the nominal boiling point This calculated temperature behavior differed markedly from the obsei ved behavior, which rose sharply past the nominal boiling temperatures An important finding was that the 36 - and $62-\mathrm{mm} / \mathrm{yr}$ property sets hampered the predicted dryout for the Single-Heater Test more as a result of the extremely high rates of capillary-driven rewetting than as a result of high percolation flux Similanly, the greatly hampered dryout around emplacement drifts that has been attributed to high percolation flux is more the result of extremely high (and probably uniealistic) capillarydriven rewetting than high percolation flux itself This finding illustrates the importance of using thermal tests to calibrate hydrological properties that are required for drift-scale thermal-hydrological modeling

\subsection{Guide to Temperature and $R H$ Data in Volume II}

Volume II considers many design details that can affect temperature and relative humidity, in addition to the ones discussed in this report The variations assessed include different values for WP spacing, drift diameter, percolation flux, emissivity, and backfill thermal conductivity As an aid to the reader, the following tables contain cross references, by topic, to the approptiate sections, tables, and illustrations in Volume II 
Table 4-5. Guide to temperature and relative humidity data in Volume II, Rev. 1 by section number.

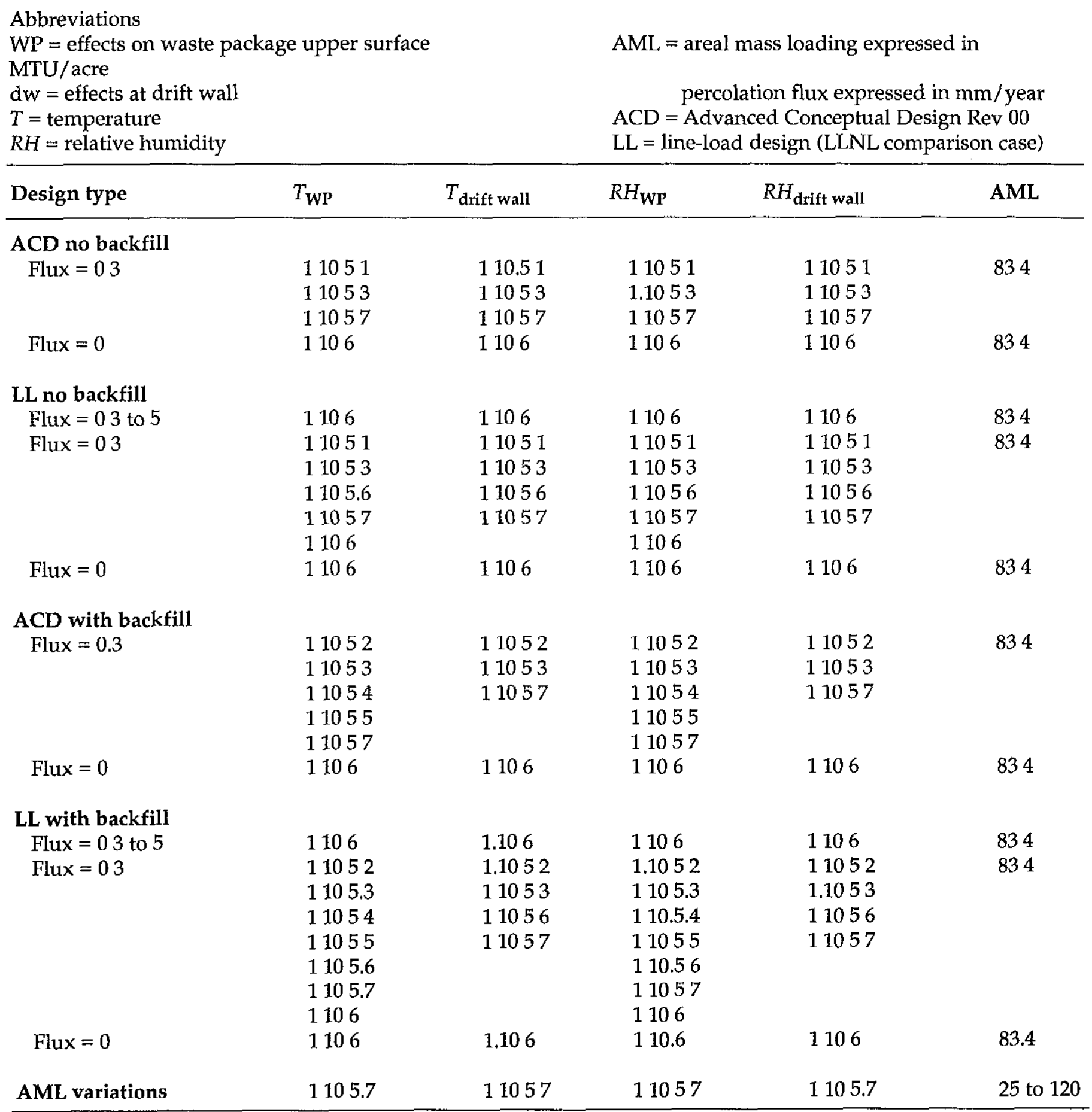


Table 4-6. Guide to Figures and Tables in Volume II, Rev. 1, Section 1-10.

Abbreviations'

$\mathrm{WP}=$ effects on waste package upper surface

$\mathrm{d} w=$ effects at drift wall

$\mathrm{T}=$ temperature

$\mathrm{RH}=$ relative humidity thermal conductivity $K_{\text {th }}$ expressed in $\mathrm{W} / \mathrm{m}^{\circ} \mathrm{C}$

$\Delta \mathrm{T}_{\text {drift }}=$ temp difference between WP and $\mathrm{dw}$

$\mathrm{RH}_{\mathrm{wp} / \mathrm{dw}}=$ relative humidity difference for waste package and drift wall
$\mathrm{AML}=$ areal mass loading expressed in MTU/acre

$\mathrm{LML}=$ lineal mass loading expressed in $\mathrm{MTU} / \mathrm{m}$ (WP spacing) percolation flux expiessed in $\mathrm{mm} /$ year

TSPA95 = Total Systems Performance Assessment (Andrews, 95) $\mathrm{ACD}=$ Advanced Conceptual Design rev 00 (Reference case)

$\mathrm{LL}=$ line-load design (LLNL comparison case) \begin{tabular}{l}
$\begin{array}{l}\text { Figure or } \\
\text { Table No. }\end{array} \quad \begin{array}{l}\text { Variable } \\
\text { studied }\end{array}$ Where $\begin{array}{l}\text { When } \\
\text { (years) }\end{array}$ \\
\hline $\begin{array}{ll}1.10 .2 \text { Localized and extended dryout regimes } \\
\text { F1 } 1021 & \text { Dryout, T for various WP agesvaries }\end{array}$
\end{tabular}

F1 1022 AML for various WP agesvaries

F1 1023 T, RH WP 10,000 varies

1.10.3 Performance of engineered backfill

$\begin{array}{lllrllllll}\text { T1 10.31 } & \text { T, RH } & \text { WP, dw } & 100,000 & \text { varies } & 24,80 & 063 & 0 & 03 & \text { yes, } K_{\text {th }}=03 \\ \text { F1 1031 } & \text { T, RH } & \text { WP, dw } & 10,000 & \text { varies } & 24,80 & 063 & 0 & 03 & \text { yes vs no }\end{array}$

1.10.4 Engineered backfill scenarios

$\mathrm{T} 1104$

F1.10 41

F1 1042

F1 1043

F1 1044

F1 1045

$\mathrm{RH}$ calc

$\mathrm{T}, \Delta \mathrm{T}_{\text {drift }} \mathrm{WP}$

$\mathrm{RH}_{\mathrm{wp} / \mathrm{dw}}$

$\mathrm{T}, \mathrm{RH}, \Delta \mathrm{T}_{\mathrm{drift}}$

$\mathrm{T}, \mathrm{RH}, \Delta \mathrm{T}_{\mathrm{drift}}$

$\mathrm{RH}_{\mathrm{wp} / \mathrm{dw}} \mathrm{WP} / \mathrm{dw}$

$\mathrm{RH}_{\mathrm{wp} / \mathrm{dw}} \mathrm{WP} / \mathrm{dw}$

$\begin{array}{rr} & \text { TSPA95 } \\ 10,000 & \text { TSPA95 } \\ 10,000 & \text { TSPA95 } \\ 10,000 & \\ 10,000 & \\ 10,000 & \\ 100,000 & \end{array}$

0 to 100

varies 063,125

$40 \quad 026-125$

Perc.

LML flux Emiss. Backfill

Notes

F1 1046

$047-053$

$834 \quad 047$

834 varies

$80 \quad 063$

$24 \quad 063$

80

063

063

0 to 03

0 to 03

0 to 03

various model assumptions rectangular vs circular drift varies backfill, LML, drift diam yes, $K_{\text {th }}=03$ to 04

yes, $K_{\text {th }}=03$ to 04

24

0 to 03

yes, $K_{\text {th }}=03$ to 04

yes, $K_{\text {th }}=03$ to 04

\subsubsection{Influence of axial WP spacing and drift spacing}

T1.10511 $\mathrm{T}, \mathrm{RH}$ drift wall varies $\mathrm{ACD}$

T1 10512 T, RH WP varies ACD, LL

T1.10513 T, RH different waste types

T1.10514 T, RH different waste types

T1 10515 T, RH different waste types

F1.10511 T 3 b view 100 vs 500

F1 10.512 Liq flux dw $\quad 100,000$

F1 10513 T, RH dw $\quad 100$

F1 10514 T, RH dw 2000

F1 105.1.5 T, RH $\quad d w \quad 10,000$

F1 10516

10,000 ACD, LL

834

834

F1 10.51 .8

I, RH

100

2000

F1 10519

$\mathrm{T}, \mathrm{RH}$

WP

10,000

1.10 .5110

$\mathrm{T}, \mathrm{RH}$

WP

100,000

1.105111

$\mathrm{T}, \mathrm{RH}$

WP

1.10 .5112

$\mathrm{T}, \mathrm{RH}$

$W P, d w$

2000

LL

834

varies

03

08

$\begin{array}{lll}\text { varies } & 03 & 08\end{array}$

no

111

0

08

no

LL

834

111

03

094

834

varie

03

08

no

ACD, LL

ACD

834

046

03

08

no

$A C D, L L$

834

046,111

03
03

0.8

no

no

ACD, LL 834

$046,1.11$

08

no

834

046,111

03

ACD, LL

834

046,111

03

0.8

no

ACD, LL

834

$0.46,111$

0.3

0.8

no

$A C D, L L$

83.4

046,111

03

0.8

no

$A C D, L L$

834

046,111

03

08

no

no

834

094

03
03

08

no

10,000

LL

834

094

03

08

no

1105113

$\mathrm{T}, \mathrm{RH}$

WP, dw

100,000

834

094

$03 \quad 08$

no

no 
Table 4-6. Guide to Figures and Tables in Volume II, Rev. 1, Section 1-10-continued.

\begin{abstract}
Abbreviations
$\mathrm{WP}=$ effects on waste package upper surface

$\mathrm{dw}=$ effects at drift wall

$\mathrm{T}=$ temperature

$\mathrm{RH}=$ relative humidity thermal conductivity $K_{\mathrm{th}}$ expressed in $\mathrm{W} / \mathrm{m}^{\circ} \mathrm{C}$
\end{abstract}

$\mathrm{AML}=$ areal mass loading expressed in MTU/acre

$\mathrm{LML}=$ lineal mass loading expressed in $\mathrm{MTU} / \mathrm{m}$ (WP spacing) percolation flux expressed in $\mathrm{mm}$ /year

$\mathrm{ACD}=\mathrm{Advanced}$ Conceptual Design rev 00 (Reference case)

$\mathrm{LL}=$ line-load design (LLNL comparison case)

\begin{tabular}{|c|c|c|c|c|c|c|c|c|c|c|}
\hline $\begin{array}{l}\text { Figure or } \\
\text { Table No. }\end{array}$ & $\begin{array}{l}\text { Variable } \\
\text { studied }\end{array}$ & Where & $\begin{array}{l}\text { When } \\
\text { (years) }\end{array}$ & $\begin{array}{c}\text { Design } \\
\text { type }\end{array}$ & AML & LML & $\begin{array}{l}\text { Perc. } \\
\text { flux }\end{array}$ & Emiss. & Backfill & Notes \\
\hline \multicolumn{11}{|c|}{ 1.10.5.2 Influence of engineered backfill } \\
\hline T1 10521 & $\mathrm{~T}, \mathrm{RH}$ & $d w$ & varies & ACD, LL & 834 & varies & 03 & 08 & yes & $K_{\text {th }}=06$ \\
\hline T1 10522 & $\mathrm{~T}, \mathrm{RH}$ & WP & varies & $\mathrm{ACD}, \mathrm{LL}$ & 834 & varies & 03 & 08 & yes & $K_{\mathrm{th}}=06$ \\
\hline $\mathrm{T} 110523$ & $\mathrm{~T}, \mathrm{RH}$ & different $w$ & te types & $\mathrm{ACD}$ & 834 & 046 & 03 & 08 & yes & $K_{\text {th }}=06$ \\
\hline $\mathrm{T} 1.10524$ & $\mathrm{~T}, \mathrm{RH}$ & different $w$ & te types & LL & 834 & 111 & 03 & 08 & yes & $K_{\mathrm{th}}=06$ \\
\hline T1 10525 & $\mathrm{~T}, \mathrm{RH}$ & different & te types & LL & 834 & 111 & 03 & 08 & \multirow{2}{*}{\multicolumn{2}{|c|}{$\begin{array}{l}\text { yes, also fills WP gaps } \\
\text { yes }\end{array}$}} \\
\hline F1 10521 & $\mathrm{~T}$ & $3 \mathrm{D}$ view & 100,500 & ACD, LL & 834 & 046,111 & 03 & 08 & & \\
\hline F1 10522 & $\mathrm{~T}, \mathrm{RH}$ & WP, dw & 10,000 & LL & 834 & 111 & 03 & 08 & no vs yes & varies $K_{\mathrm{th}}$ \\
\hline F1 10523 & $\mathrm{~T}, \mathrm{RH}$ & $d w$ & 2000 & $\mathrm{ACD}, \mathrm{LL}$ & 834 & 046,111 & 03 & 0.8 & yes & varies $W P$ \\
\hline F1 10524 & $\mathrm{~T}, \mathrm{RH}$ & $d w$ & 10,000 & ACD, LL & 834 & 046,111 & 03 & 08 & yes & varies WP \\
\hline F1 10525 & $\mathrm{~T}, \mathrm{RH}$ & $\mathrm{WP}$ & 2000 & $\mathrm{ACD}, \mathrm{LL}$ & 834 & 046,111 & 03 & 08 & yes & varies $W P$ \\
\hline F1 10526 & $\mathrm{~T}, \mathrm{RH}$ & WP & 10,000 & ACD, LL & 834 & 046,111 & 03 & 08 & yes & varies WP \\
\hline F1 10527 & $\mathrm{~T}, \mathrm{RH}$ & WP & 100,000 & $\mathrm{ACD}, \mathrm{LL}$ & 834 & 046,111 & 03 & 08 & yes & varies WP \\
\hline F1 10528 & $\mathrm{~T}, \mathrm{RH}$ & $\mathrm{WP}, \mathrm{dw}$ & 2000 & LL & 834 & 111 & 03 & 08 & yes & varies WP \\
\hline F1 105.29 & $\mathrm{~T}, \mathrm{RH}$ & $\mathrm{WP}, \mathrm{dw}$ & 10,000 & LL & 834 & 111 & 03 & 08 & yes & varies WP \\
\hline 1105210 & $\mathrm{~T}, \mathrm{RH}$ & WP, & 100,000 & LL & 834 & 111 & 03 & 08 & yes & varies WP \\
\hline 1105211 & $\mathrm{~T}, \mathrm{RH}$ & WP, dw & 2000 & $L L$ & 834 & 094 & 03 & 08 & yes & varies WP \\
\hline 1105212 & $\mathrm{~T}, \mathrm{RH}$ & WP, & 10,000 & LL & 83.4 & 094 & 03 & 08 & yes & varies WP \\
\hline 1105213 & $\mathrm{~T}, \mathrm{RH}$ & $\mathrm{WP}, \mathrm{dw}$ & 100,000 & LL & 834 & 094 & 03 & 08 & yes & varies $W P$ \\
\hline \multicolumn{11}{|c|}{ 1.10.5.3 Influence of waste package emissivity } \\
\hline $\mathrm{T} 110531$ & $\mathrm{~T}, \mathrm{RH}$ & $d w$ & varies & $\mathrm{ACD}, \mathrm{LL}$ & 834 & ues & 03 & 03 & no & \\
\hline $\mathrm{T} 110532$ & $\mathrm{~T}, \mathrm{RH}$ & WP & varies & $A C D, L L$ & 834 & 3 values & 03 & 03 & no & \\
\hline T1 10533 & $\mathrm{~T}, \mathrm{RH}$ & WP & varies & $\mathrm{ACD}$ & 83.4 & 046 & 03 & 03 & no & varies $W P$ \\
\hline T1 105.3 .4 & $\mathrm{~T}, \mathrm{RH}$ & WP & varies & LL & 834 & 111 & 03 & 03 & no & varies $W P$ \\
\hline $\mathrm{T} 1.10535$ & $\mathrm{~T}, \mathrm{RH}$ & WP & varies & LL & 83.4 & 094 & 03 & 0.3 & no & varies $W P$ \\
\hline T1 10536 & $\mathrm{~T}, \mathrm{RH}$ & $d w$ & varies & $\mathrm{ACD}, \mathrm{LL}$ & 834 & 3 values & 03 & 03 & yes & \\
\hline T1 10537 & $\mathrm{~T}, \mathrm{RH}$ & WP & varies & $\mathrm{ACD}, \mathrm{LL}$ & 834 & 3 values & 03 & 03 & yes & \\
\hline T1 10.538 & $\mathrm{~T}, \mathrm{RH}$ & WP & varies & $\mathrm{ACD}$ & 834 & 046 & 03 & 03 & yes & varies $W P$ \\
\hline T1 10.5.39 & $\mathrm{T}, \mathrm{RH}$ & WP & varies & LL & 834 & 111 & 03 & 03 & yes & varies $W P$ \\
\hline 1.105310 & $\mathrm{~T}, \mathrm{RH}$ & WP & varies & LL & 834 & 094 & 03 & 03 & yes & varies WP \\
\hline $\mathrm{F} 110.5 .31$ & $\mathrm{~T}$ & $W P, d w$ & & varies & 834 & 04 to 12 & 03 & & no & \\
\hline
\end{tabular}


Table 4-6. Guide to Figures and Tables in Volume II, Rev. 1, Section 1-10-continued.

Abbreviations

$W P=$ effects on waste package upper surface

$\mathrm{AML}=$ areal mass loading expressed in MTU/acre

$\mathrm{dw}=$ effects at drift wall

$\mathrm{T}=$ temperature

$\mathrm{RH}=$ relative humidity

emissivity expressed in $\mathrm{mm}$ /year

ther mal conductivity $K_{\mathrm{th}}$ expressed in $\mathrm{W} / \mathrm{m}^{\circ} \mathrm{C}$

$\mathrm{LML}=$ lineal mass loading expressed in MTU/m (WP spacing) percolation flux expressed in $\mathrm{mm} /$ year

$\mathrm{ACD}=$ Advanced Conceptual Design rev 00 (Reference case)

$\mathrm{LL}=$ line-load design (LLNL comparison case)

\begin{tabular}{|c|c|c|c|c|c|c|c|c|c|c|}
\hline $\begin{array}{l}\text { Figure or } \\
\text { Table No. }\end{array}$ & $\begin{array}{l}\text { Variable } \\
\text { studied }\end{array}$ & Where & $\begin{array}{l}\text { When } \\
\text { (years) }\end{array}$ & $\begin{array}{c}\text { Design } \\
\text { type }\end{array}$ & AML & LML & $\begin{array}{l}\text { Perc. } \\
\text { flux }\end{array}$ & Emiss. & Backfill & Notes \\
\hline \multicolumn{11}{|c|}{ 1.10.5.4 Influence of waste package and backfill } \\
\hline T1 10541 & \multicolumn{4}{|c|}{$\%$ drift occupied } & varies & 834 & & & & varies \\
\hline T1 10542 & $\mathrm{~T}, \mathrm{RH}$ & WP & varies & $\mathrm{ACD}$ & 834 & 047 & 03 & 03 & varies & \\
\hline T1 10543 & $\mathrm{~T}, \mathrm{RH}$ & WP & varies & LL & 834 & 094 & 03 & 03 & varies & \\
\hline T1 10544 & $\mathrm{~T}, \mathrm{RH}$ & WP & varies & $\mathrm{ACD}$ & 83.4 & 046 & 03 & 08 & yes & varies $W P$ \\
\hline T1 10545 & $\mathrm{~T}, \mathrm{RH}$ & WP & varies & LL & 834 & 111 & 03 & 08 & yes & varies $W P$ \\
\hline F1 10541 & \multicolumn{3}{|c|}{ 2D RH distribution } & 120 & $\mathrm{ACD}$ & 834 & 046 & 03 & 03 & varies \\
\hline F1 10542 & \multicolumn{3}{|c|}{ 2D RH distribution } & 120 & LL & 834 & 094 & 03 & 03 & varies \\
\hline F1 10543 & $\mathrm{~T}, \mathrm{RH}$ & WP & 10,000 & LL & 834 & 094 & 03 & 03 & varies & off-center \\
\hline F1 10544 & $\mathrm{~T}, \mathrm{RH}$ & WP & 10,000 & LL & 834 & 094 & 03 & 03 & yes & center \\
\hline F1 10545 & $\mathrm{RH}$ & WP & 100,000 & $\mathrm{ACD}$ & 83.4 & 047 & 03 & 03 & yes & \\
\hline F1 10546 & $\mathrm{RH}$ & WP & 100,000 & $A C D$ & 834 & 047 & 03 & 03 & partial s & ing backfill \\
\hline F1 10547 & $\mathrm{RH}$ & WP & 100,000 & $\mathrm{ACD}$ & 834 & 047 & 03 & 03 & no backfi & \\
\hline
\end{tabular}

1.10.5.5 Influence of engineered backfill thermal conductivity

\begin{tabular}{|c|c|c|c|c|c|c|c|c|c|c|}
\hline T1 10551 & $\mathrm{~T}, \mathrm{RH}$ & $\mathrm{dw}$ & varies & ACD, LL & 834 & 3 values & 03 & 08 & yes & $K_{\mathrm{th}}=03$ \\
\hline T1 10552 & $\mathrm{~T}, \mathrm{RH}$ & WP & varies & ACD, LL & 834 & 3 values & 03 & 08 & yes & $K_{\text {th }}=03$ \\
\hline T1 10553 & $\mathrm{~T}, \mathrm{RH}$ & \multicolumn{2}{|c|}{ different waste types } & $\mathrm{ACD}$ & 834 & 046 & 03 & 08 & yes & $K_{\mathrm{th}}=03$ \\
\hline T1 10554 & $\mathrm{~T}, \mathrm{RH}$ & \multicolumn{2}{|c|}{ different waste types } & LL & 834 & 111 & 03 & 08 & yes & $K_{\mathrm{th}}=03$ \\
\hline T1.10555 & $\mathrm{T}, \mathrm{RH}$ & \multicolumn{2}{|c|}{ different waste types } & LL & 834 & 0.94 & 03 & 08 & yes & $K_{\text {th }}=03$ \\
\hline F1 10551 & $\mathrm{~T}, \mathrm{RH}$ & WP & 2000 & $\mathrm{ACD}, \mathrm{LL}$ & 834 & 046,111 & 03 & 08 & yes & $K_{\mathrm{th}}=03$ \\
\hline 110552 & $\mathrm{~T}, \mathrm{RH}$ & WP & 10,000 & $\mathrm{ACD}, \mathrm{LL}$ & 83.4 & $0.46,111$ & 03 & 08 & yes & $K_{\mathrm{th}}=03$ \\
\hline 110553 & $\mathrm{~T}, \mathrm{RH}$ & WP & 100,000 & $\mathrm{ACD}, \mathrm{LL}$ & 834 & 046,111 & 03 & 08 & yes & $=03$ \\
\hline
\end{tabular}

\subsubsection{Influence of drift diameter}

\begin{tabular}{|c|c|c|c|c|c|c|c|c|c|}
\hline $\mathrm{T} 110561$ & T, RH & $\mathrm{dw}$ & LL & 834 & 111 & 03 & 08 & no & diam 3-65 \\
\hline T1 10.562 & $\mathrm{~T}, \mathrm{RH}$ & WP & LL & 834 & 111 & 03 & 08 & no & diam 3-65 \\
\hline T1 10.5.63 & $\mathrm{T}, \mathrm{RH}$ & $\mathrm{dw}$ & LL & 834 & 111 & 03 & 08 & yes & diam 3-65 \\
\hline $\mathrm{T} 1105.64$ & $\mathrm{~T}, \mathrm{RH}$ & WP & LL & 834 & 111 & 03 & 08 & yes & diam 3-65 \\
\hline T1 10565 & $\mathrm{~T}, \mathrm{RH}$ & different waste types & LL & 83.4 & 1.11 & 03 & 08 & yes & $\operatorname{diam} 3 \mathrm{~m}$ \\
\hline T1 105.6 .6 & $\mathrm{~T}, \mathrm{RH}$ & different waste types & LL & 834 & 111 & 03 & 08 & yes & $\operatorname{diam} 4 \mathrm{~m}$ \\
\hline T1 10.5.67 & $\mathrm{T}, \mathrm{RH}$ & different waste types & LL & 834 & 111 & 0.3 & 08 & yes & diam $65 \mathrm{~m}$ \\
\hline F1 10561 & peak $\mathrm{T}$ & $\mathrm{WP}, \mathrm{dw}$ & LL & 83.4 & 111 & 03 & 08 & no & diam 3-6 \\
\hline
\end{tabular}


Table 4-6. Guide to Figures and Tables in Volume II, Rev. 1, Section 1-10-continued.

\section{Abbreviations}

$\mathrm{WP}=$ effects on waste package upper surface $d w=$ effects at drift wall

$\mathrm{T}=$ temperature

$\mathrm{RH}=$ relative humidity

$\Delta \mathrm{T}_{\text {drift }}=$ temp difference between WP and $d w$

$\Delta \mathrm{T}_{\text {pillar }}=$ temp difference, $\mathrm{dw}$ vs rock centerline
$\mathrm{AML}=$ areal mass loading expressed in MTU/acre

$\mathrm{LML}=$ lineal mass loading expressed in $\mathrm{M}^{\top} \mathrm{TU} / \mathrm{m}$ (WP spacing) percolation flux expressed in $\mathrm{mm}$ /year emissivity expressed in $\mathrm{mm} /$ year

$\mathrm{ACD}=$ Advanced Conceptual Design rev 00 (Reference case)

$\mathrm{LL}=$ line-load design (LLNL comparison case)

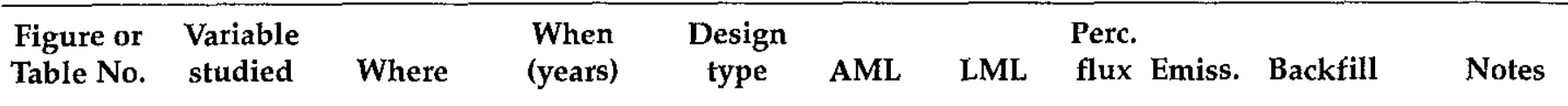

\begin{tabular}{|c|c|c|c|c|c|c|c|c|c|c|}
\hline \multicolumn{11}{|c|}{ 1.10.5.7 Influence of areal mass loa } \\
\hline $\mathrm{T} 110.571$ & $\mathrm{~T}, \mathrm{RH}$ & $d w$ & varies & $\mathrm{ACD}$ & $25-83.4$ & 046 & 03 & 08 & no & diam 55 \\
\hline T1 10572 & $\mathrm{~T}, \mathrm{RH}$ & WP & varies & ACD & $25-834$ & 046 & 03 & 08 & no & diam 55 \\
\hline T1 10573 & $\mathrm{~T}, \mathrm{RH}$ & WP & varies & $A C D$ & 25 & 046 & 0.3 & 0.8 & no & diam 55 \\
\hline T1 10574 & $\mathrm{~T}, \mathrm{RH}$ & WP & varies & ACD & 45 & 046 & 03 & 0.8 & no & diam 55 \\
\hline Т1 10575 & $\mathrm{~T}, \mathrm{RH}$ & dw & varies & LL & $25-120$ & 111 & 03 & 08 & no & diam 55 \\
\hline T1 105.76 & T, RH & WP & varies & LL & $25-120$ & 111 & 03 & 08 & no & diam 55 \\
\hline T1 10577 & $\mathrm{~T}, \mathrm{RH}$ & WP & varies & LL & 25 & 111 & 03 & 08 & no & diam 55 \\
\hline T1 10578 & $\mathrm{~T}, \mathrm{RH}$ & WP & varies & LL & 45 & 111 & 03 & 08 & no & diam 55 \\
\hline T1 10.579 & $\mathrm{~T}, \mathrm{RH}$ & WP & varies & LL & 100 & 1.11 & 03 & 08 & no & diam 55 \\
\hline 1105710 & $\mathrm{~T}, \mathrm{RH}$ & WP & varies & LL & 120 & 111 & 03 & 08 & no & diam 55 \\
\hline 1105711 & $\mathrm{~T}, \mathrm{RH}$ & $\mathrm{dw}$ & varies & $\mathrm{ACD}$ & $25-834$ & 0.46 & 03 & 08 & yes & $K_{\mathrm{th}}=06$ \\
\hline 11057.12 & $\mathrm{~T}, \mathrm{RH}$ & WP & varies & $A C D$ & $25-834$ & 046 & 0.3 & 08 & yes & $K_{\mathrm{th}}=06$ \\
\hline 1105713 & $\mathrm{~T}, \mathrm{RH}$ & WP & varies & $\mathrm{ACD}$ & 25 & 046 & 0.3 & 08 & yes & $K_{\text {th }}=06$ \\
\hline 1105714 & $\mathrm{~T}, \mathrm{RH}$ & WP & varies & $\mathrm{ACD}$ & 45 & 046 & 03 & 08 & yes & $K_{\text {th }}=06$ \\
\hline 1105715 & $\mathrm{~T}, \mathrm{RH}$ & $d w$ & varies & LL & $25-120$ & 111 & 03 & 08 & yes & $K_{\mathrm{th}}=06$ \\
\hline 1105716 & $\mathrm{~T}, \mathrm{RH}$ & WP & varies & LL & $25-120$ & 111 & 03 & 08 & yes & $K_{\mathrm{th}}=06$ \\
\hline 1105717 & $\mathrm{~T}, \mathrm{RH}$ & WP & varies & LL & 25 & 111 & 03 & 08 & yes & $K_{\mathrm{th}}=06$ \\
\hline 1105718 & $\mathrm{~T}, \mathrm{RH}$ & $W P$ & varies & LL & 45 & 1.11 & 03 & 08 & yes & $K_{\mathrm{th}}=06$ \\
\hline 1105719 & T, RH & WP & varies & LL & 100 & 111 & 03 & 08 & yes & $K_{\mathrm{th}}=06$ \\
\hline 1105720 & $\mathrm{~T}, \mathrm{RH}$ & WP & varies & LL & 120 & 111 & 03 & 08 & yes & $K_{\text {th }}=06$ \\
\hline F1 10571 & \multicolumn{3}{|c|}{ Liquid fluxdifferent waste types } & $\mathrm{ACD}, \mathrm{LL}$ & 83.4 & $046,1.11$ & 0.3 & 08 & no & \\
\hline F1 10572 & \multicolumn{3}{|c|}{ Liquid fluxdifferent waste types } & ACD, LL & 25 & $0.46,1.11$ & 03 & 08 & no & \\
\hline F1 1057.3 & $\Delta \mathrm{T}_{\text {drift }}$ & \multirow{2}{*}{\multicolumn{2}{|c|}{$\begin{array}{l}\text { different waste types } \\
\text { different waste types }\end{array}$}} & LL & $25-120$ & 111 & 03 & 08 & no & \\
\hline F1 10.5 7.4 & $\Delta \mathrm{T}_{\text {drift }}$ & & & LL & 25,834 & 111 & 0.3 & 08 & no & \\
\hline F1 10.575 & $\mathrm{RH}$ & WP & varies & LL & $25-120$ & 111 & 0.3 & 08 & no & \\
\hline F1 10.576 & $\mathrm{RH}$ & WP & varies & LL & $25-120$ & 111 & 0.3 & 08 & yes & $K^{\text {th }}=06$ \\
\hline F1 10577 & $\Delta \mathrm{T}_{\text {pillar }}$ & Pwr WP & varies & LL & $25-120$ & 111 & 0.3 & 08 & yes & $K^{\text {th }}=06$ \\
\hline F1 1057.8 & $\Delta \mathrm{T}_{\text {pillar }}^{\mathrm{r}}$ & DHLW & varies & LL & $25-120$ & 111 & 03 & 08 & yes & $K^{\text {th }}=06$ \\
\hline F1 10579 & $\Delta \mathrm{T}_{\text {drift }}$ & $W P, d w$ & varies & LL & $25-120$ & 111 & 03 & 0.8 & yes & $K^{\text {th }}=06$ \\
\hline 1105710 & $\Delta \mathrm{T}_{\mathrm{drift}}$ & different & types & LL & 25,834 & 111 & 03 & 08 & yes & $K^{\mathrm{th}}=06$ \\
\hline
\end{tabular}


Table 4-6. Guide to Figures and Tables in Volume II, Rev. 1, Section 1-10-continued.

\section{Abbreviations}

$\mathrm{WP}=$ effects on waste package upper surface

$\mathrm{d} w=$ effects at drift wall

$\mathrm{T}=$ temperature

$\mathrm{RH}=$ relative humidity emissivity expressed in $\mathrm{mm}$ /year thermal conductivity $K_{\mathrm{th}}$ expressed in $\mathrm{W} / \mathrm{m}^{\circ} \mathrm{C}$
$\mathrm{AML}=$ areal mass loading expressed in MTU/acre

$\mathrm{LML}=$ lineal mass loading expressed in $\mathrm{MTU} / \mathrm{m}$ (WP spacing) percolation flux expressed in $\mathrm{mm}$ /year

$\mathrm{ACD}=$ Advanced Conceptual Design rev 00 (Reference case)

$\mathrm{LL}=$ line-load design (LLNL comparison case)

\begin{tabular}{|c|c|c|c|c|c|c|c|c|c|c|}
\hline $\begin{array}{l}\text { Figure or } \\
\text { Table No. }\end{array}$ & $\begin{array}{l}\text { Variable } \\
\text { studied }\end{array}$ & Where & $\begin{array}{l}\text { When } \\
\text { (years) }\end{array}$ & $\begin{array}{c}\text { Design } \\
\text { type }\end{array}$ & AML & LML & $\begin{array}{l}\text { Perc. } \\
\text { flux }\end{array}$ & Emiss. & Backfill & Notes \\
\hline \multicolumn{11}{|c|}{ 1.10.6 Influence of ambient percolation flux and edge effects on $T-H$ behavior } \\
\hline T1 1061 & \multicolumn{2}{|c|}{ Liquid fluxdw } & 100,000 & $\mathrm{ACD}, \mathrm{LL}$ & 834 & 046,111 & 03 & 08 & no & \\
\hline T1 106.2 & \multicolumn{2}{|c|}{ Liquid fluxdw } & 100,000 & ACD, LL & 83.4 & 046,111 & 005 & 08 & no & \\
\hline T1 1063 & $\mathrm{~T}, \mathrm{RH}$ & $d w$ & varies & $\mathrm{ACD}$ & 834 & 046 & $0-03$ & 08 & no & \\
\hline T1 1064 & $\mathrm{~T}, \mathrm{RH}$ & WP & varies & $A C D$ & 834 & 046 & $0-0.3$ & 08 & no & \\
\hline T1 10.6.5 & $\mathrm{T}, \mathrm{RH}$ & different & te types & $\mathrm{ACD}$ & 834 & 046 & 0 & 08 & no & \\
\hline T1 1066 & $\mathrm{~T}, \mathrm{RH}$ & different & te types & $\mathrm{ACD}$ & 834 & 046 & 005 & 08 & no & \\
\hline T1 106.7 & $\mathrm{~T}, \mathrm{RH}$ & different & te types & $\mathrm{ACD}$ & 834 & 046 & 03 & 08 & no & \\
\hline T1 1068 & $\mathrm{~T}, \mathrm{RH}$ & $\mathrm{dw}$ & varies & $\mathrm{LL}$ & 834 & 1.11 & $0-5$ & 08 & no & \\
\hline T1 106.9 & $\mathrm{~T}, \mathrm{RH}$ & WP & varies & LL & 834 & 111 & $0-5$ & 08 & no & \\
\hline T1 10610 & $\mathrm{~T}, \mathrm{RH}$ & different & te types & LL & 834 & 111 & 0 & 08 & no & \\
\hline T1 10611 & $\mathrm{~T}, \mathrm{RH}$ & different & te types & LL & 834 & 111 & 005 & 08 & no & \\
\hline T1 10612 & $\mathrm{~T}, \mathrm{RH}$ & different & te types & $\mathrm{LL}$ & 834 & 111 & 03 & 08 & no & \\
\hline T1 10613 & $\mathrm{~T}, \mathrm{RH}$ & different & te types & LL & 834 & 111 & 10 & 08 & no & \\
\hline T1 10614 & $\mathrm{~T}, \mathrm{RH}$ & different & te types & LL & 834 & 111 & 50 & 0.8 & no & \\
\hline T1 10615 & $\mathrm{~T}, \mathrm{RH}$ & $\mathrm{dw}$ & varies & $\mathrm{ACD}$ & 834 & 046 & $0-03$ & 08 & yes & $K_{\mathrm{th}}=06$ \\
\hline T1 10616 & $\mathrm{~T}, \mathrm{RH}$ & $\mathrm{WP}$ & varies & $\mathrm{ACD}$ & 834 & 0.46 & $0-03$ & 08 & yes & $K_{\mathrm{th}}=06$ \\
\hline T1 10617 & $\mathrm{~T}, \mathrm{RH}$ & different & te types & ACD & 834 & 046 & 0 & 08 & yes & $K_{\mathrm{th}}=06$ \\
\hline T1 10618 & $\mathrm{~T}, \mathrm{RH}$ & different & te types & $\mathrm{ACD}$ & 834 & 046 & 005 & 0.8 & yes & $K_{\mathrm{th}}=06$ \\
\hline T1 10619 & $\mathrm{~T}, \mathrm{RH}$ & different & te types & $\mathrm{ACD}$ & 834 & 046 & 03 & 08 & yes & $K_{\text {th }}=06$ \\
\hline T1 106.20 & $\mathrm{~T}, \mathrm{RH}$ & $d w$ & varies & LL & 834 & 111 & $0-5$ & 08 & yes & $K_{\text {th }}=0.6$ \\
\hline T1 10621 & $\mathrm{~T}, \mathrm{RH}$ & $W P$ & varies & LL & 834 & 111 & $0-5$ & 0.8 & yes & $K_{\mathrm{th}}=06$ \\
\hline T1 10622 & $\mathrm{~T}, \mathrm{RH}$ & different & te types & LL & 834 & 111 & 0 & 08 & yes & $K_{\text {th }}=06$ \\
\hline T1 10623 & $\mathrm{~T}, \mathrm{RH}$ & different & te types & LL & 834 & 111 & 005 & 08 & yes & $K_{\text {th }}=06$ \\
\hline T1 10624 & $\mathrm{~T}, \mathrm{RH}$ & different & te types & LL & 834 & 1.11 & 0.3 & 08 & yes & $K_{\text {th }}=0.6$ \\
\hline T1 106.25 & $\mathrm{~T}, \mathrm{RH}$ & different & te types & LL & 834 & 111 & 1.0 & 08 & yes & $K_{\mathrm{th}}=06$ \\
\hline T1 10626 & $\mathrm{~T}, \mathrm{RH}$ & different & te types & LL & 834 & 111 & 50 & 08 & yes & $K_{\text {th }}=06$ \\
\hline 'T1 10627 & $\mathrm{~T}, \mathrm{RH}$ & different & te types & LL & 834 & 111 & 0.3 & 0.8 & no & near center \\
\hline T1 10628 & $\mathrm{~T}, \mathrm{RH}$ & different & te types & LL & 834 & 111 & 0.3 & 08 & no & outer edge \\
\hline T1 10629 & $\mathrm{~T}, \mathrm{RH}$ & different & te types & LL & 834 & 1.11 & 03 & 08 & yes & near center \\
\hline T1 10630 & $\mathrm{~T}, \mathrm{RH}$ & different & te types & LL & 834 & 111 & 03 & 08 & yes & outer edge \\
\hline
\end{tabular}


Table 4-6. Guide to Figures and Tables in Volume II, Rev. 1, Section 1-10-continued.

\begin{tabular}{|c|c|}
\hline \multicolumn{2}{|l|}{ bbreviations } \\
\hline$W P=$ effects on waste pack & areal mass loading expressed in MTU/acre \\
\hline $\begin{array}{l}\text { IW = effects at drift wall } \\
=\text { temperature }\end{array}$ & $\mathrm{ML}=$ lineal mass loading expressed in $\mathrm{MTU} / \mathrm{m}$ (WP line spacing) \\
\hline $\mathrm{H}=$ relative humidity & $\mathrm{ACD}=$ Advanced Conceptual Design rev 00 (Reference case) \\
\hline $\begin{array}{l}\text { percolation flux expr } \\
\text { bulk permeability } k_{\mathrm{b}}\end{array}$ & $\mathrm{LL}=$ line-load design (LLNL comparison case) \\
\hline
\end{tabular}

\begin{tabular}{lllccccc}
\hline $\begin{array}{l}\text { Figure or } \\
\text { Table No. }\end{array}$ studiable & Where & $\begin{array}{c}\text { When } \\
\text { (years) }\end{array}$ & $\begin{array}{c}\text { Design } \\
\text { type }\end{array}$ AML LML flux Emiss. Backfill & $\begin{array}{c}\text { Perc. } \\
\text { flutes }\end{array}$ \\
\hline
\end{tabular}

\begin{tabular}{|c|c|c|c|c|c|c|c|c|c|c|}
\hline F1 1061 & Liquid flux & $51 \mathrm{~m} \mathrm{a}$ & rift & $A C D, L L$ & 83.4 & $046,1.11$ & varies & 0.8 & no & \\
\hline F1 1062 & flux, RH & $51 \mathrm{~m} \mathrm{a}$ & rift & LL & 834 & 111 & $0-5$ & 08 & no & \\
\hline F1 1063 & Liquid flux & varies & 100,000 & mtn scale & 834 & & $03-05$ & & & \\
\hline F1 10.64 & Liquid flux & varies & 2000 & mtn scale & 834 & & $03-05$ & & & \\
\hline$F 1.1065$ & $\mathrm{RH}$ & varies & 10,000 & mtn scale & 834 & & $0-03$ & & & \\
\hline F1 1066 & $\mathrm{RH}$ & varies & 100,000 & mtn scale & 834 & & $0-03$ & & & \\
\hline F1.1067 & $\mathrm{RH}$ & WP & 100,000 & $\mathrm{ACD}$ & 834 & 046 & $0-03$ & 08 & no & \\
\hline F1 1068 & $\mathrm{RH}$ & WP & 100,000 & LL & 834 & 111 & $0-5$ & 08 & no & \\
\hline F1 10.69 & $\mathrm{RH}$ & WP & 100,000 & $\mathrm{ACD}$ & 834 & 046 & $0-03$ & 08 & yes & $K_{\mathrm{th}}=06$ \\
\hline $\mathrm{F} 110610$ & $\mathrm{RH}$ & WP & 100,000 & LL & 834 & 111 & $0-5$ & 08 & yes & $K_{\mathrm{th}}=06$ \\
\hline $\mathrm{F} 110611$ & $\mathrm{~T}, \mathrm{RH}$ & WP & 100 & LL & 834 & 111 & 03 & 08 & no & \\
\hline F1 10.612 & $\mathrm{~T}, \mathrm{RH}$ & WP & 2000 & LL & 83.4 & 111 & 03 & 08 & no & \\
\hline F1 10.613 & $\mathrm{~T}, \mathrm{RH}$ & WP & 10,000 & LL & 834 & 111 & 03 & 08 & no & \\
\hline F1 106.14 & $\mathrm{~T}, \mathrm{RH}$ & WP & 100,000 & LL & 834 & 111 & 0.3 & 0.8 & no & \\
\hline F1 10615 & $\mathrm{~T}, \mathrm{RH}$ & WP & 2000 & LL & 834 & 111 & 03 & 08 & yes & $K_{\mathrm{th}}=06$ \\
\hline F1 10616 & $\mathrm{~T}, \mathrm{RH}$ & WP & 10,000 & LL & 83.4 & 111 & 03 & 08 & yes & $K_{\mathrm{th}}=06$ \\
\hline F1 10617 & $\mathrm{~T}, \mathrm{RH}$ & WP & 100,000 & LL & 834 & 111 & 03 & 08 & yes & $K_{\mathrm{th}}=06$ \\
\hline $1.10 .7 \mathrm{C}$ & npart & & tout & & $c 0$ & & & & & \\
\hline F1 1071 & Liq saturat & ion at 5 & 00 yrs & & 48 & & & & & $k_{\mathrm{b}}=280$ \\
\hline F1 1072 & Liq. saturat & ion at 1 & 000 yrs & & 48 & & & & & $k_{\mathrm{b}}=280$ \\
\hline
\end{tabular}

\subsection{Geochemistry of the NFE}

The chemistry of water entering drifts and contacting WPs will depend not only on the chemistry of water as it moves through the rock mass and interacts with the rock, but also on the chemical interactions of that water with introduced materials and microbial communities that exist within the drifts These topics are discussed separately In addition, performance of the system will depend on the mineralogy of zones within the natural system that are perturbed as a result of the emplacement of waste, specifically the thermal pulse that results from emplacement Mineralogy is discussed in Section 5 of this report
Figure 4-9 is a matrix showing the main components of the NFE associated with water chemistry on the diagonal and the coupled processes off-diagonal

To determine the composition of water that might contact the WPs, the evolution of water compositions over a range of scenarios must be determined The chemistry of the initial water is probably only of concern during the early time prior to the thermal pulse within the rock exceeding the boiling point of water. After boiling, the water is mobilized, and any water that retums into the drifts subsequently will be a combination of meteoric and condensate water The condensate would be very dilute, essentially distilled, water but would have strong interaction with the rock because it 


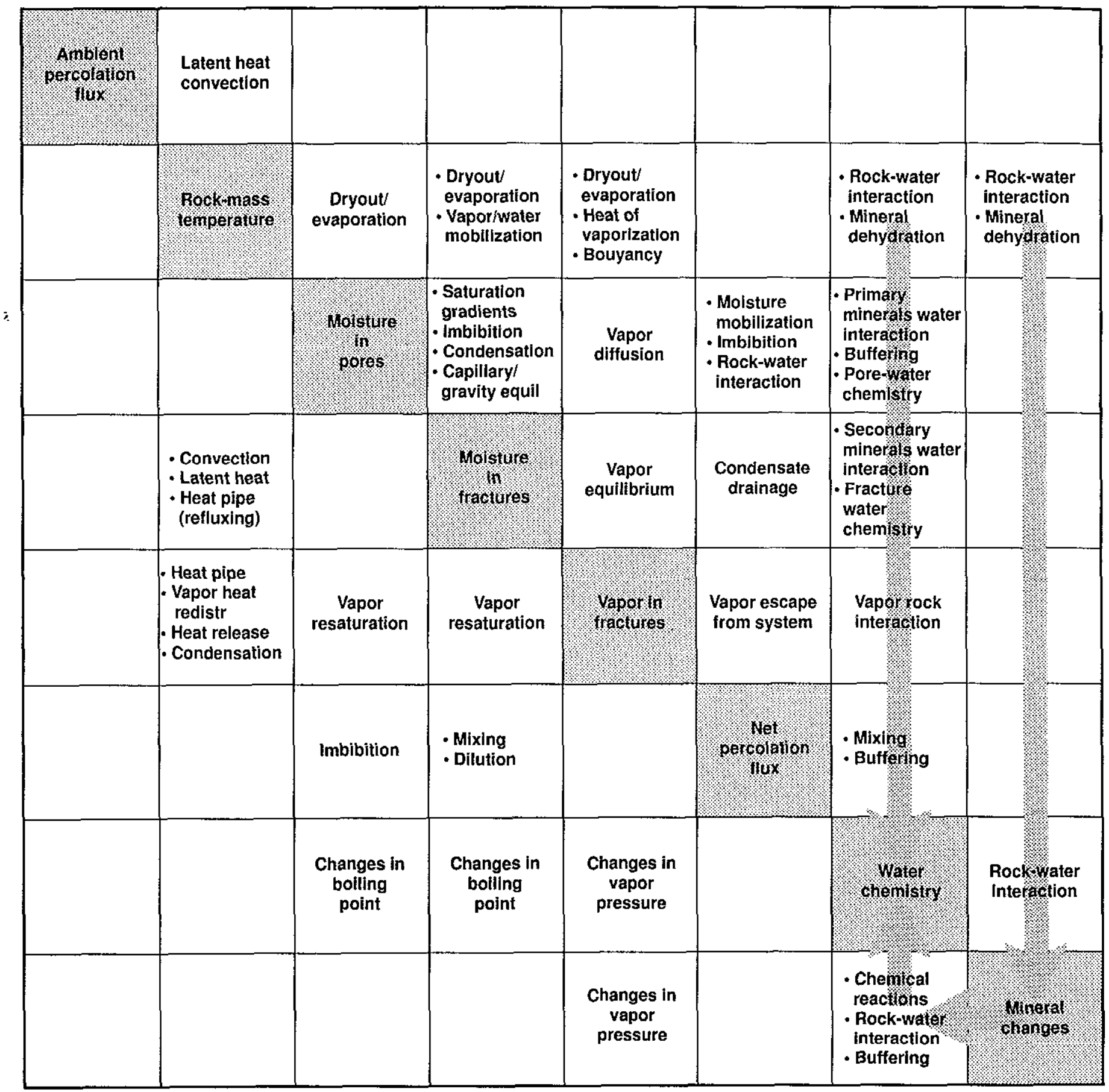

Figure 4-9. Matrix of coupled processes in the NFE related to water chemistry. 
would be condensing at elevated temperatures The extent of rock-water interaction will be a function of the temperatures, the duration of contact, whether the rock is unaltered, or whether it had already interacted with other water (typical of the more stable condensate zone of later time frames) The meteoroic waters may have been exposed to elevated temperatures, but such would only be the case for the first few thousand years after emplacement The mixture of meteoric and condensate waters would then interact strongly with the materials within the drift that had been introduced into the system Such materials will include significant volumes of cementitious materials, irons or steel, and various construction-related materials An exhaustive list of these materials is available in Volume II, Sec 6

Water contacting the EBS would also interact with any minerals or salts left by the water that had been removed from the NFE during the thermal pulse The likely result will be that between the introduced material interactions, dissolution of precipitated minerals, as well as the microbial interactions The water chemistry will be largely determined by interactions in the very near field regardless of what the water chemistry might have been in the condensate or meteoric waters Therefore, water chemistry within the $A Z$ is not discussed here (see Volume II for more information), and is only discussed in Section 50 (AZ) as it determines the chemistry of reactions

As noted, water might drip into the drifts and contact the WPs in the period prior to water removal by boiling Such contact is less likely because this is also the period during which the ground-support system should be essentially intact and would tend to inhibit water influx into the drifts This is especially the case if continuous concrete liners are used as ground support However, the liner segments are not intended to be sealed, and water can enter through the joints between segments. During early elevated temperatures prior to boiling, evaporation of water is an important consideration in determining the water chemistry as well as in establishing the nature of secondary precipitates that may be deposited along fracture surfaces or rock pores In such regions, secondary precipitates could be dissolved later by the percolation of meteoric and condensate waters It is also important to determine the nature of precipitates deposited on the WPs directly as water is evaporated or boiled, thus leaving behind the mineral salts The deposition on WPs is important not only in determining future water chemistries but also in relative humidity corrosion interactions because salt depositions can facilitate corrosion at much lower $R H$
The specific precipitates that may develop will reflect the initial water composition and that which evolves as evaporation takes place

The chemical consequences of evaporation are distinct from those of boiling The distinction arises from the contrast in behavior of dissolved gases during evaporation and boiling The material reported here does not consider the role of rock-water interaction, or the role of boiling in development of water compositions Rock-water interactions are discussed in Section 5 of this volume and are reported in detail in Volume II Boiling impacts have been discussed in TSPA workshops, but the impacts have not been reported elsewhere and were not available at the time this volume was prepared

\subsubsection{Results}

Simulations of the evolving water chemistry due to evaporation of water with chemistry of J-13 water were reported in Volume II Water from J-13 well, thus called J-13 water, is considered to be representative of the pore water chemistries and thus was used as the chemistry of water that would be evaporated from around the emplacement drifts In Volume II, it was noted that results are sensitive to whether limits were placed on gas-phase control or on mineral availabilities As shown in Fig 4-10, the pH that evolves as

$\mathrm{O} \mathrm{CO}_{2} \& \mathrm{O}_{2}$ fugacities not fixed

$\square \mathrm{CO}_{2} \& \mathrm{O}_{2}$ fugacities fixed at atmospheric Black circles and squares indicate precipitation of solids was unrestricted White circles and squares indicate quartz, tridymite, and talc suppressed

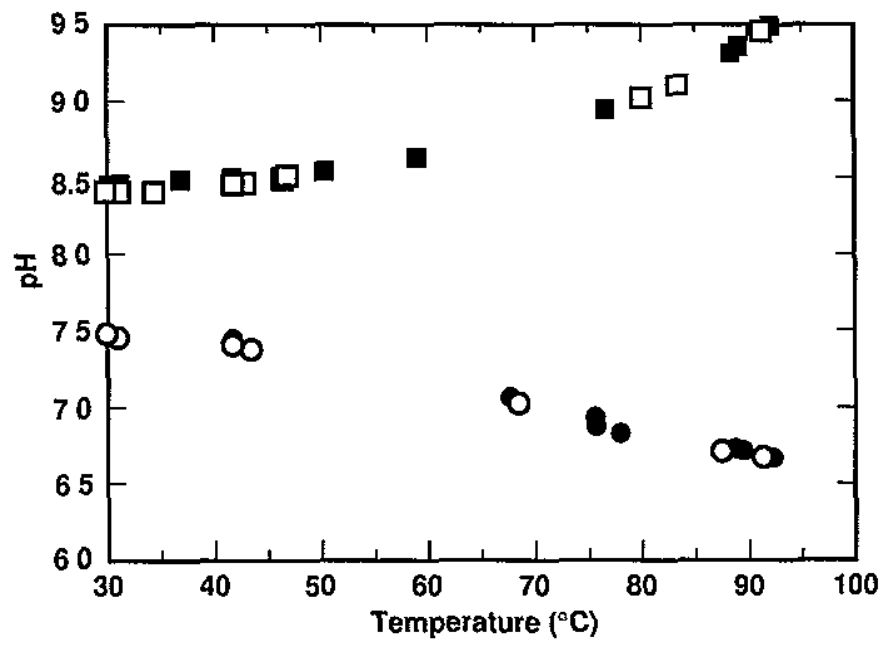

Figure 4-10. Evolving $\mathrm{pH}$ as a function of temperature. 
temperature increases will tend towards slightly acidic $(\mathrm{pH}=65)$ for an open system or towards moderately alkaline $(\mathrm{pH}=95)$ if $\mathrm{CO}_{2}$ and $\mathrm{O}_{2}$ were held at atmospheric levels In Fig 4-10 and all subsequent illustrations in this section, square symbols are used to denote cases in which gas-phase controls were implemented $\left(\mathrm{CO}_{2}\right.$ and $\mathrm{O}_{2}$ fugacities were fixed at atmospheric values throughout the runs), circles denote values computed with no gas-phase controls Filled symbols denote runs in which precipitation of solids was not restricted, open symbols denote runs in which quart $z$, tridymite, and talc were suppressed

Because of the overall gas exchange in the mountain (e $g$, breathing wells), it might be assumed that the $\mathrm{CO}_{2}$ and $\mathrm{O}_{2}$ would always approach atmospheric values However, several factors may create a limit on these compounds First, barometric pressure responses in the Topopah Spring unit were suppressed until the tunnel was opened into this unit This suppression would indicate that the gas exchange is restricted to the overlying units Second, during the heatup and particularly when boiling is active, water vapor will displace the oxygen However, the evaporation chemistry is only of concern when temperatures are below boiling and probably occur during emplacement operations when ventilation would replenish the oxygen If ventilation is maintained beyond the time of emplacement, then the

$O \mathrm{CO}_{2} \& \mathrm{O}_{2}$ fugacities not fixed

$\square \mathrm{CO}_{2} \& \mathrm{O}_{2}$ fugacities fixed at atmospheric Black circles and squares Indicate preclpitation of solids was unrestricted

White circles and squares indicate quartz, tridymite, and talc suppressed

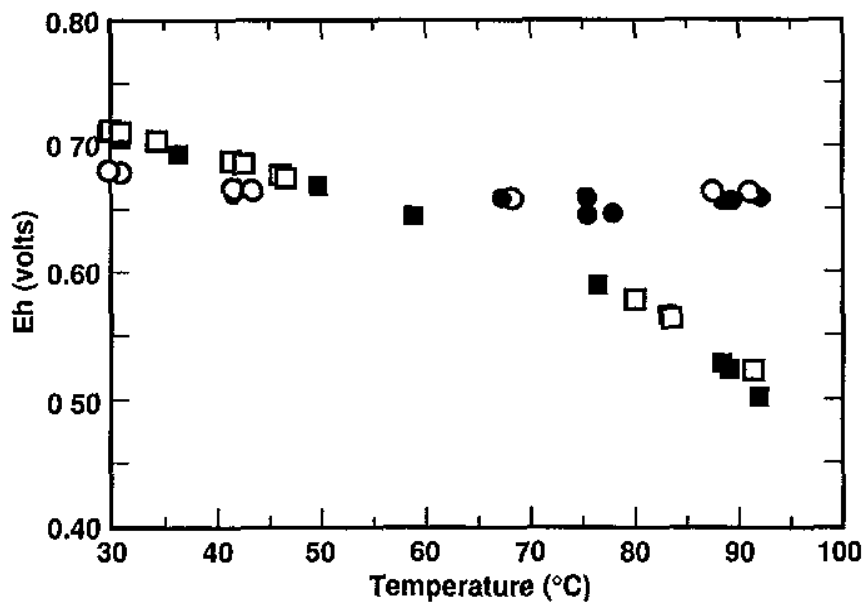

Figure 4-11. Eh, in volts, as a function of temperature. atmospheric $\mathrm{CO}_{2}$ and $\mathrm{O}_{2}$ fixed conditions would probably be the more appropriate

Figure 4-11 shows the simulation results for Eh Evaporation that occurs in the absence of controls on coexisting gases results in water compositions that remain near neutral, and the Eh slightly oxidizing

Figures 4-12 through 4-15 show that $\mathrm{Na}, \mathrm{S}, \mathrm{Cl}$, and $\mathrm{F}$ concentrations, respectively, increase linearly as the activity of $\mathrm{H}_{2} \mathrm{O}$ decreases (as temperature increases) Figures 4-16 through 4-22 show the results for $\mathrm{Ca}, \mathrm{P}, \mathrm{Si}$, calcite, dolomite, saponite, and stilbite, respectively

The type of salt deposits, as well as their volumes, can be estimated from the amount of water estimated to enter the drift prior to moisture displacement by the thermal pulse and the temperature of the drift wall, which would determine the chemistry of the water based on the amount of evaporation that would have taken place at that temperature Such estimates are highly dependent on the designs selected.

However, regardless of the design, water will begin to evapor ate in response to heat as the waste is emplaced Initially, water in the NFE will be similar in composition to water in the pores and fractures, although it may also include water used in construction, e g; excess water in concrete The composition within the rock is not determined in detail at present

$\mathrm{O} \mathrm{CO}_{2} \& \mathrm{O}_{2}$ fugacities not fixed

$\square \mathrm{CO}_{2} \& \mathrm{O}_{2}$ fugacities fixed at atmospheric Black circles and squares indicate precipitation of solids was unrestricted White circles and squares indicate quartz, tridymite, and talc suppressed

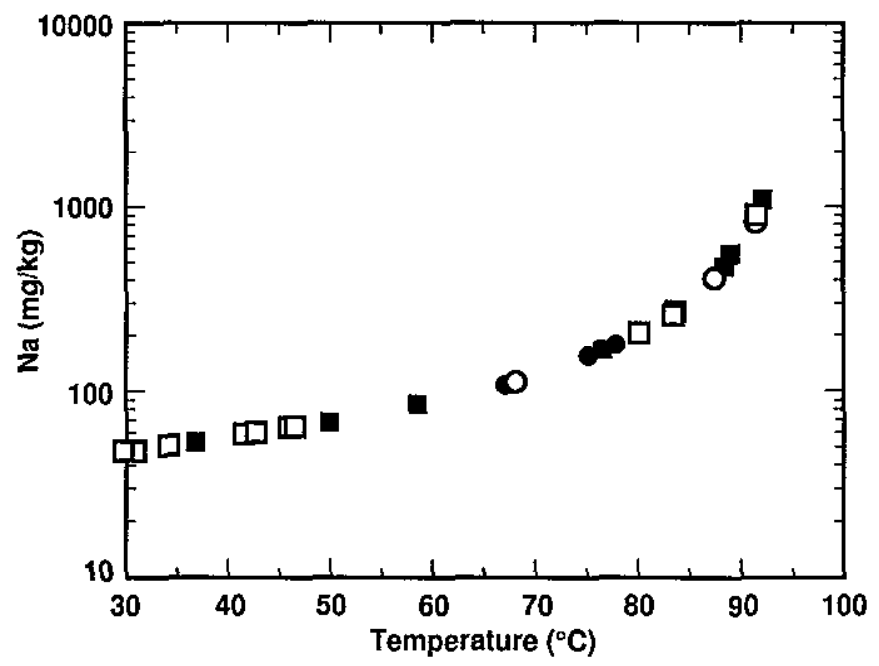

Figure 4-12. Total $\mathrm{Na}$ in solution, in $\mathrm{mg} / \mathrm{kg}$, as a function of temperature. 
$\mathrm{O} \mathrm{CO}_{2} \& \mathrm{O}_{2}$ fugacities not fixed

$\square \mathrm{CO}_{2} \& \mathrm{O}_{2}$ fugacities fixed at atmospheric Black circles and squares indicate precipitation of solids was unrestricted

White circles and squares Indicate quartz, tridymite, and talc suppressed

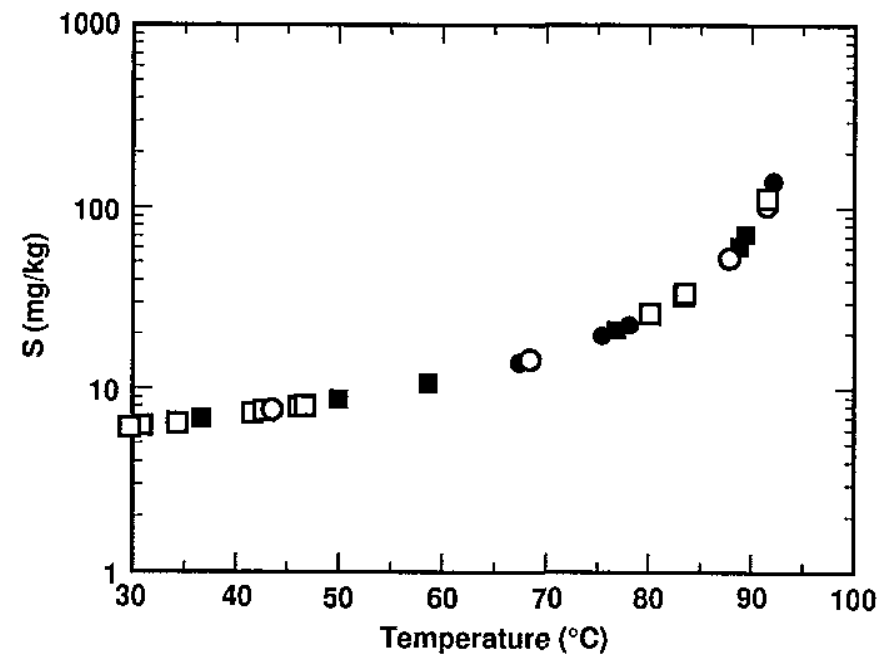

Figure 4-13. Total $\mathrm{S}$ in solution, in $\mathrm{mg} / \mathrm{kg}$, as a function of temperature.

$\mathrm{O} \mathrm{CO}_{2} \& \mathrm{O}_{2}$ fugacities not fixed

$\square \mathrm{CO}_{2} \& \mathrm{O}_{2}$ fugacities fixed at atmospheric Black circles and squares indicate precipitation of solids was unrestricted

White circles and squares indicate quartz, tridymite, and talc suppressed

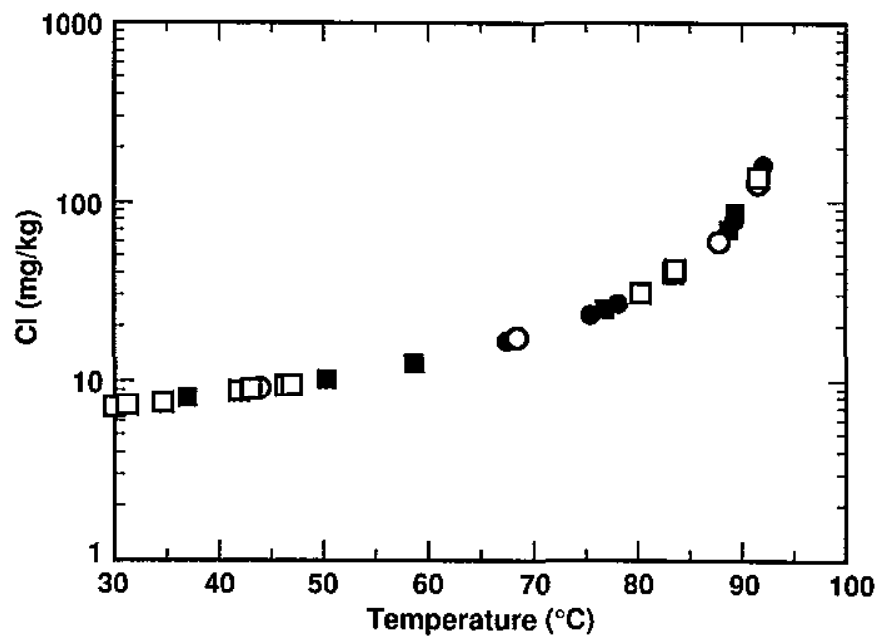

Figure 4-14. Total $\mathrm{Cl}$ in solution, in $\mathrm{mg} / \mathrm{kg}$, as a function of temperature.
$\mathrm{O} \mathrm{CO}_{2} \& \mathrm{O}_{2}$ fugacities not fixed

$\square \mathrm{CO}_{2} \& \mathrm{O}_{2}$ fugacities fixed at atmospheric

Black circles and squares indicate precipitation of solids was unrestricted

White clrcles and squares indicate quartz, tridymite, and talc suppressed

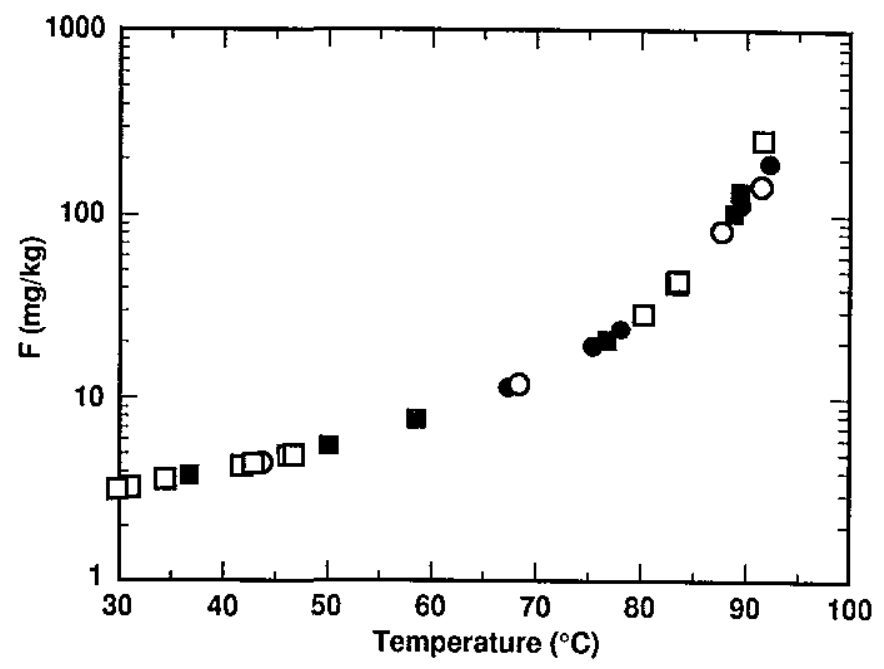

Figure 4-15. Total $\mathrm{F}$ in solution, in $\mathrm{mg} / \mathrm{kg}$, as a function of temperature

$\mathrm{O} \mathrm{CO}_{2} \& \mathrm{O}_{2}$ fugacities not fixed

$\square \mathrm{CO}_{2} \& \mathrm{O}_{2}$ fugacities fixed at atmospheric Black circles and squares indicate precipitation of solids was unrestricted

White circles and squares Indicate quartz, tridymite, and talc suppressed

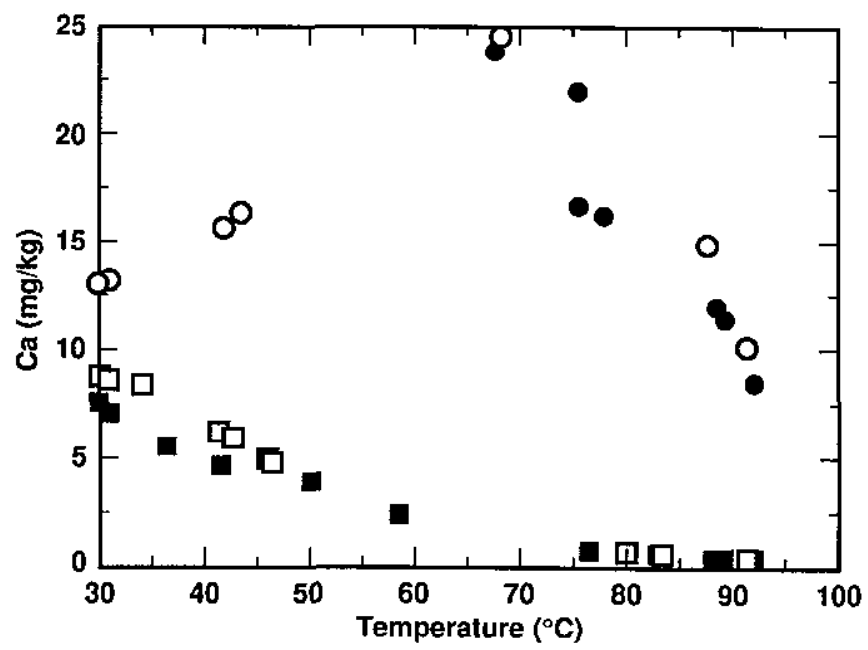

Figure 4-16. Total $\mathrm{Ca}$ in solution, in $\mathrm{mg} / \mathrm{kg}$, as a function of temperature. Peak concentration for the uncontrolled $\mathrm{CO}_{2}$ and $\mathrm{O}_{2}$ case corresponds to calcite saturation. 
$\mathrm{O} \mathrm{CO} 2 \& \mathrm{O}_{2}$ fugacities not fixed

$\square \mathrm{CO}_{2} \& \mathrm{O}_{2}$ fugacitles fixed at atmospheric Black circles and squares indicate precipitation of solids was unrestricted White circles and squares indicate quartz, tridymite, and talc suppressed

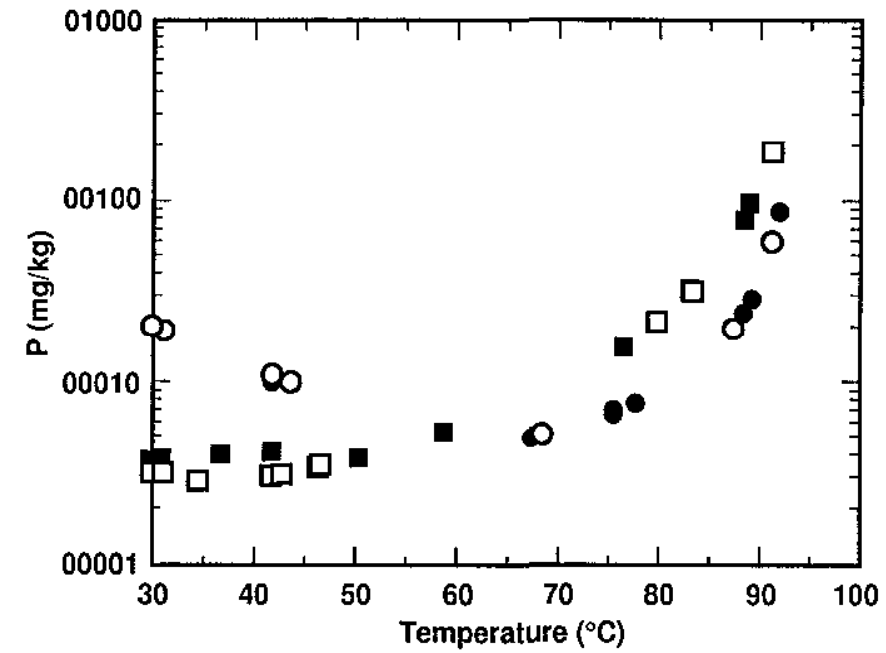

Figure 4-17. Total $P$ in solution, in $\mathrm{mg} / \mathrm{kg}$, as a function of temperature.

$\mathrm{O} \mathrm{CO}_{2} \& \mathrm{O}_{2}$ fugacities not fixed

$\square \mathrm{CO}_{2} \& \mathrm{O}_{2}$ fugacities fixed at atmospheric Black circles and squares indicate precipltation of solids was unrestricted

White circles and squares indicate quartz, tridymite, and talc suppressed

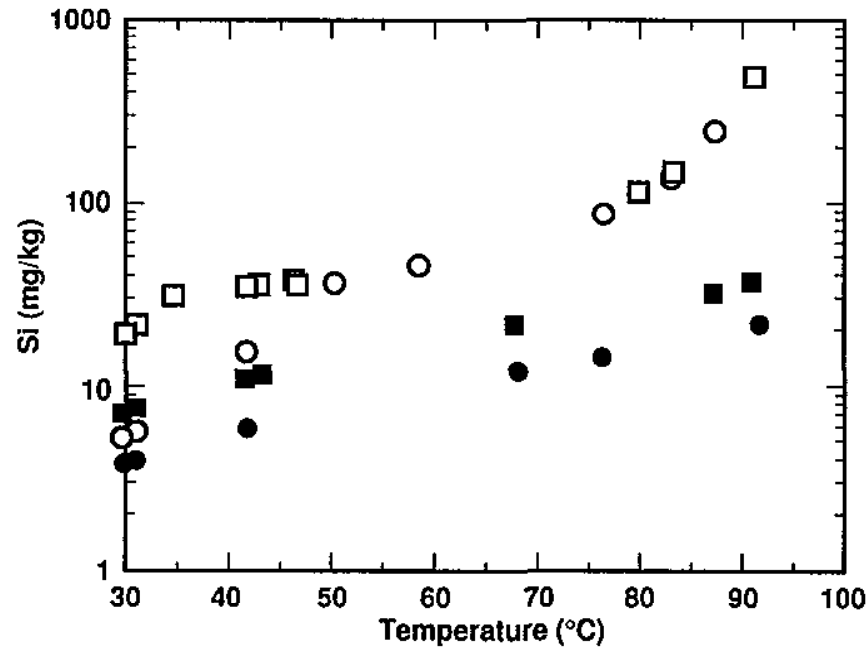

Figure 4-18. Total $\mathrm{Si}$ in solution, in $\mathrm{mg} / \mathrm{kg}$, as a function of temperature.
$\mathrm{O} \mathrm{CO}_{2} \& \mathrm{O}_{2}$ fugacities not fixed

$\square \mathrm{CO}_{2} \& \mathrm{O}_{2}$ fugacities fixed at atmospheric Black circles and squares indicate precipitation of solids was unrestricted White circles and squares indicate quartz, tridymite, and talc suppressed

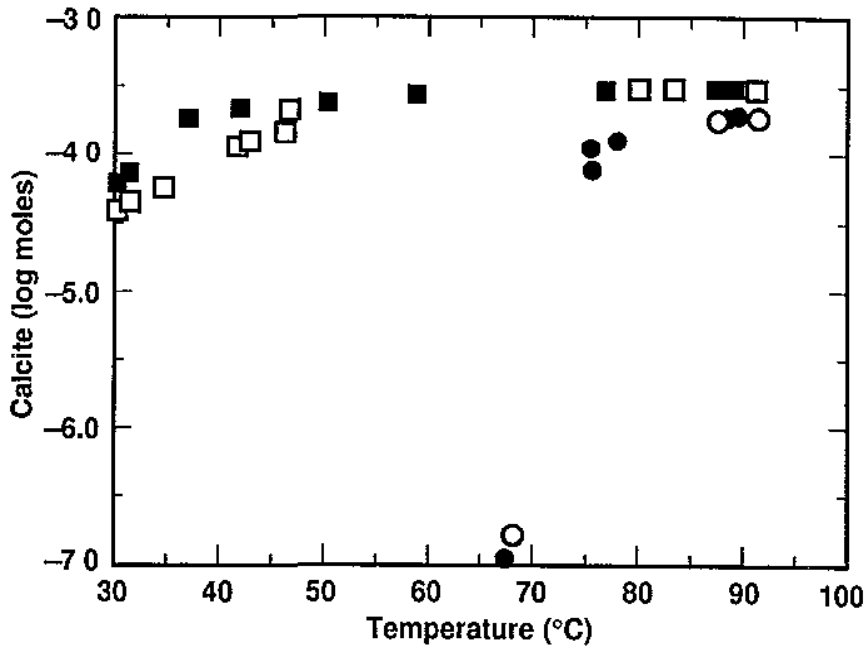

Figure 4-19. Log of the number of moles of calcite precipitated as a function of temperature.

$\mathrm{O} \mathrm{CO}_{2} \& \mathrm{O}_{2}$ fugacities not fixed

$\square \mathrm{CO}_{2} \& \mathrm{O}_{2}$ fugacities fixed at atmospheric Black circles and squares indicate precipitation of solids was unrestricted White circles and squares indicate quartz, tridymite, and talc suppressed

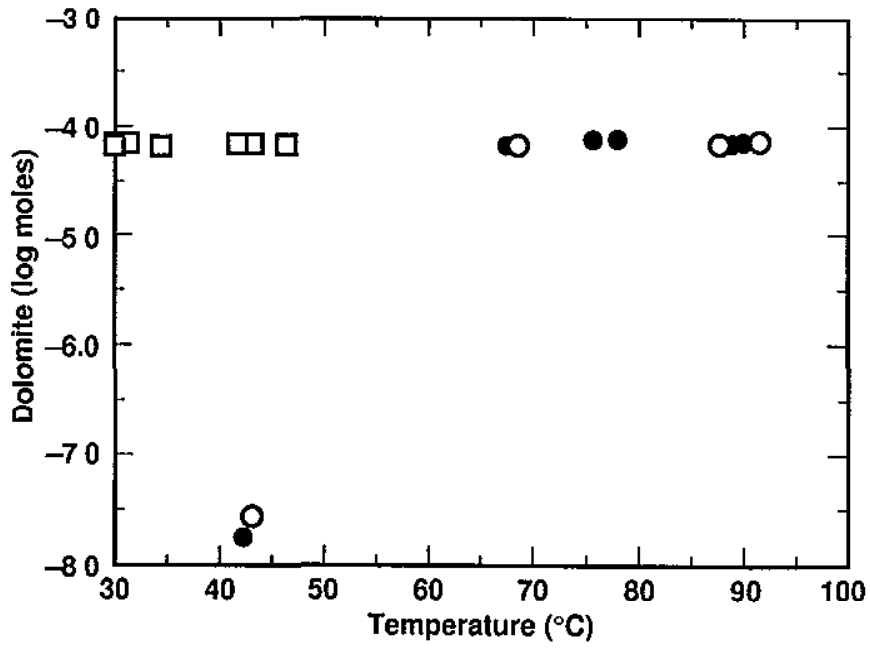

Figure 4-20. Log of the number of moles of dolomite precipitated as a function of temperature. 
$O \mathrm{CO}_{2} \& \mathrm{O}_{2}$ fugacitles not fixed

$\square \mathrm{CO}_{2} \& \mathrm{O}_{2}$ fugacities fixed at atmospheric

Black circles and squares indicate precipitation of solids was unrestricted

White circles and squares indicate quartz, tridymite, and talc suppressed

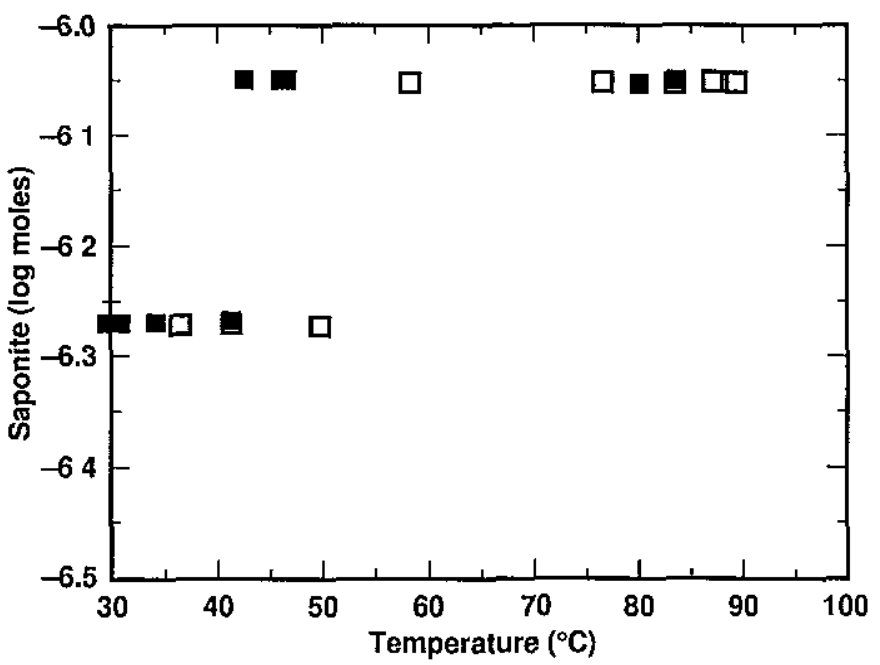

Figure 4-21. Log of the number of moles of saponite precipitated as a function of temperature.

$\mathrm{O} \mathrm{CO}_{2} \& \mathrm{O}_{2}$ fugacities not fixed

$\square \mathrm{CO}_{2} \& \mathrm{O}_{2}$ fugacities fixed at atmospheric Black circles and squares indicate precipitation of solids was unrestricted

White circles and squares indicate quartz, tridymite, and talc suppressed

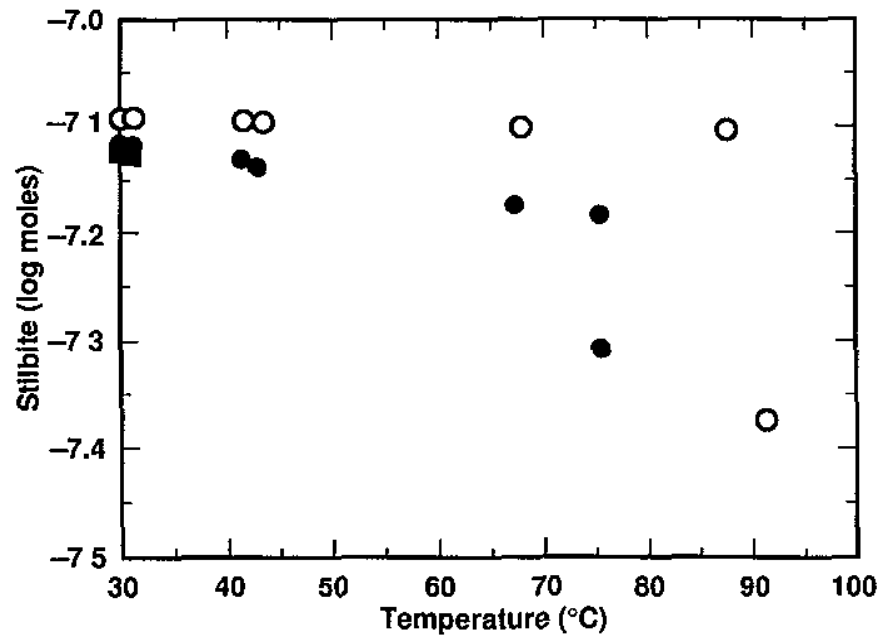

Figure 4-22. $\log$ of the number of moles of stilbite precipitated as a function of temperature. but will be somewhat similar to that from J-13. As noted earlier, evaluations of the chemical evolution of water as it evaporates indicate that water compositions will change as the water evaporates such that the composition will be near neutral $\mathrm{pH}$, slightly oxidizing, with increased $\mathrm{Na}, \mathrm{S}, \mathrm{Cl}$, and $\mathrm{F}$ Sodium approaches $1,000 \mathrm{mg} / \mathrm{kg}$ at temperatures of about $95^{\circ} \mathrm{C}$, extrapolation to near total evaporation is not accurate but would indicate in excess of $10,000 \mathrm{mg} / \mathrm{kg}$ water Similar increases are seen for $\mathrm{S}, \mathrm{Cl}$, and $\mathrm{F}$, from about 6,8 , and $3 \mathrm{mg} / \mathrm{kg}$, respectively, for ambient conditions to about 100,150 , and $200 \mathrm{mg} / \mathrm{kg}$, respectively, at 90 to $95^{\circ} \mathrm{C}$ In contrast, Ca nearly disappears, whereas $\mathrm{Si}$ increases from about $20 \mathrm{mg} / \mathrm{kg}$ to in excess of $500 \mathrm{mg} / \mathrm{kg}$ at about $90^{\circ} \mathrm{C}$ As water is evaporated and boiled in the region of rock that exceeds the boiling point, the salts will be left behind, and the vapor will migrate to cooler portions of the rock mass, where it will condense The water chemistry of the condensate will approach that of distilled water

After temperatures exceed the boiling point, water will not enter the drift until the temper atures decay, or if the combined volume of meteoric and condensate fluxes exceed the capacity for the heat flux to drive off that water After the thermal pulse decays, the chemistry of the condensate will likely be dominated by rock-water interactions because of the long residence times at elevated temperatures so that the water would tend to be in equilibi ium with the rock Thus, the initial chemistry of water entering the drift will be a combination of meteoric and dilute water If the fluxes exceed the heat-flux capacity, then it is likely that the percolation fluxes will be high so that initial water chemistry of water entering the drifts will be dominated by the fast-fracture flow of meteoric water with some condensate that has not come into equilibrium with the rock

Any water entering the drifts will flow through the $\mathrm{AZ}$ and through the dried zone, where it can pick up the residual salts that had been left when the water was driven out of the dried zone Water initially entering the near-field will contain relatively elevated concentrations of a var iety of salts and other highly soluble species, which will be present because of evaporation of water during heating and dryout of the rock near emplacement drifts With time, if flow of water continues along the same pathway, the concentrations of these species will decrease as the salts are 
dissolved These relatively high-ionic-strength solutions will then interact with emplaced materials that have been altered in response to repository conditions The alteration is expected to evolve over time It is anticipated that the result of these interactions will be a solution of moderately high $\mathrm{pH}$ ( 9 to 11), with an ionic strength greater than that of the present ambient pore waters Regardless of the starting chemistry, the final chemistry of water that contacts the waste during this time will be strongly, if not dominantly, influenced by the interactions with materials within the drifts themselves, including the rock support system

\subsubsection{Introduced Materials}

Volume II provides extensive accountings of possible materials and volumes that will be used during construction However, considerable uncertainty remains as to the materials that will be used In addition, the design is evolving, and at the time of publication of Volume II, the most likely ground support system (other than steel sets, which are still being evaluated) was considered to be pre-cast concrete or cast-in-place concrete or shotcrete The techniques to make a detailed analysis are in development Therefore, determination of likely water chemistry remains for subsequent revisions of this report Once the materials are emplaced, the chemical and mineralogical evolution of the repository would be fixed to a specific path and would be hypothetically predictable. One of the uncertainties at present in making such determinations is the role of chemical processes that are biotic, or mediated by living organisms, in contrast to those that are abiotic At present, the abiotic processes are more easily determined, as is discussed below.

4.5.2.1 Abiotic Chemistry. One of the first evaluations of the impact of introduced materials on chemistry considered the impacts of diesel fuels. Although a decision was made not to use diesel underground, the results remain applicable because the experiments that incorporated other materials (tuff and shotcrete) were performed both with and without diesel fuels The results of these experiments also underscored the potential significance of microbial activity because it is clear that in an abiotic environment, diesel fuel would remain indefinitely under repository conditions We know from experience, however, that organic compounds, such as diesel fuel, do degrade far more quickly than that, because of microbial activity The interactions measured were between water and Fibercrete ${ }^{\mathrm{TM}}$ The results indicated that, although some components of diesel fuel are soluble or volatile, most of the inorganic abiotic interactions were independent of the presence of diesel fuel That is, diesel components do not degrade and do not affect the inorganic species in solution As shown in Figs 6-6 through 6-8 of Volume II, solution $\mathrm{pH}$ at $200^{\circ} \mathrm{C}$ decieases from approximately 88 to 84 and was approaching a steady state Similarly, total sulfur concentrations increased to approximately $15 \mathrm{mM}$, and initial inorganic carbon decreased to near the detection limit. Aqueous $\mathrm{Si}$ concentrations increased to about $5 \mathrm{mM}$, and aqueous Al concentrations decreased to $1 \mathrm{mM}$ Concentrations of $\mathrm{Ca}$ increased with time without diesel present Aqueous $\mathrm{Fe}$ and $\mathrm{Mg}$ concentrations hovered around $1 \mathrm{mM}$ (near detection limits) At $200^{\circ} \mathrm{C}$, the system quickly reached an equilibrium that is stable over the lifetime of the repository The cementitious material used in these experiments was Fibercrete ${ }^{\mathrm{TM}}$, which may be analogous to the cast-in-place design option for mechanical support

Insight into the long-term performance of cements (a likely component of ground support systems) has been gained from rocks containing minerals that are expected in concrete exposed to elevated temperatures Water with $\mathrm{pH}$ as high as 125 has been collected from these rocks These data are consistent with preliminary calculations of phases in equilibrium with water (Atkins et al , 1992, 1994) It is concluded that the presence of cementitious material may greatly alter the chemistry of water moving through the repository by providing a large reservoir of unstable Ca-silicate phases, which will affect the corrosion of the WP, the dissolution of the waste form, and the solubility of repository rock

At YM, the impact of temperature must be considered in these chemical interactions Clearly, temperature will cause an evolution in the construction materials so that water returning to the post-thermal repository will contact significantly altered materials However, it is also likely that the cementitious materials will have dehydrated and transformed to a more crystalline mineral assemblage As a consequence, chemical reactions can affect not only water chemistry, but the relative humidity of the repository if there are 
large volumes of cement present This coupling was not considered in the earlier discussion of relative humidity (Section 43 ) An iteration with the analyses in Section 43 will be included in a subsequent revision of this report when the design has matured and the amount of cement is better determined

Recent results from the Single Heater Test (SHT) raise the issue of excess $\mathrm{CO}_{2}$, which not only impacts the rock-water interaction results, but also the evolutionary history of cement. As noted in Volume II, at partial pressures of $\mathrm{CO}_{2}$ greater than ambient, compositional and microstructur al changes are expected in the cement phases The data from the SHT indicate that excess $\mathrm{CO}_{2}$ is generated by rock-water interaction and release from water Thus, much of the cementitious material could evolve into $\mathrm{CaCO}_{3}$ phases plus $\mathrm{SiO}_{2}$ phases The consequences to the $\mathrm{pH}$ are significant in that a calcite-water-dominated system would have a significantly lower $\mathrm{pH}$ than that of the cement-water systems discussed, which have $\mathrm{pH}$ values of 11 to 12 As discussed in Volume II, water in contact with portland cement can attain extremely high $\mathrm{pH}$ However, the effects of microbes, heating, $\mathrm{CO}_{2}$ partial pressure above ambient, and other factors can all impact those pHs and tend to lower them In addition to the influence on chemistry, cementitious materials may contain zeolites as aggregate or pozzolana, which would also contribute to sorbing radionuclides

4.5.2.2 Biotic Chemistry. The impact of biotic chemistry cannot be ignored There is a growing awareness that biotic factors could affect the integrity of the repository by several processes. They include microbially induced corrosion (MIC) of the WP, degradation of construction materials (including concrete), and alteration of the chemical environment Evaluations of microbial populations at $\mathrm{YM}$ indicate that microbes are both present and capable of growth under repository conditions (see Volume II). Some microbes are capable of producing slime under low nutrient conditions and could therefore play a role in corrosion of WP materials Some of the microbes can produce acids, and some may alter the pore water chemistry (Horn et al , 1996) The impacts of biotic factors on chemistry will be included in subsequent revisions of this report

Microbial activities are subject to bounds To a certain extent, heat will promote microbial activity, but at temperatures greater than $130^{\circ} \mathrm{C}$, microbial activity is expected to cease (and to reinitiate when temperatures drop below $130^{\circ} \mathrm{C}$ ). Similarly, we expect relative humidity to limit microbial activity. The exact bounds will be discussed in subsequent revisions of this report For further discussion of this topic, see Horn and Meike (1996)

\subsubsection{Conclusions}

Chemistry within the near-field will be dominated by the interaction of emplaced materials with the repository atmosphere and liquid water The emplaced materials, in turn, are affected by heat and relative humidity Hence, the chemical conditions that develop within the near field will be dominated by the alteration products of cementitious materials and metals, which appear to be the majority of introduced materials, and how these materials affect the composition of incoming water It is expected that the water chemistry interactions will occur in a solution of moderately high $\mathrm{pH}$ (9 to 11) with an ionic strength greater than that of present ambient pore water

Specifically, the results demonstrate that evaporation of pore waters similar to that of J-13 will lead to the development of concentrated solutions and associated secondary salts Waters percolating into this environment will be ent iched in chlorides, carbonates, and other species The extent of enrichment will depend on the total volume of water entering the region, enrichments in $\mathrm{Cl}^{-}$, for example, may be many times higher than that typical of ambient pore waters, for small volumes of percolating water Regardless of the amount of enrichment, these results show that the first waters entering drifts and interacting with emplaced materials will not be similar to J-13 pore water but will, instead, be more concentrated waters reflecting the interaction of J-13-like pore waters with the residues of evaporation

One of the impacts of introduced materials that needs to be considered during repository design is that chemical potentials, concentrations, and temperatures can be extremely heterogeneous This heterogeneity is the basis for gradients in factors that influence chemical interactions 'The gradients are the basis of thermodynamic driving forces and, as such, cause substances to dissolve and precipitate in a manner that is not predicted by using average values Thus, those design options that tend toward more homogeneous conditions (e g , end-to-end emplacement, uniform ground support systems, etc ) will be more desirable when making performance assessments

In addition to the physical-chemical processes, it is also likely that microbial activity will play a role in establishing the near-field conditions, given the ability of microbes to adapt to extreme environments, to sporulate, migrate, and become dormant Microbial 
activity can alter local chemistry significantly, plug fractures to modify hydrology, and create a vehicle for radionuclide sorption Once sorbed, radionuclide transport depends on the attachment and detachment characteristics of the microbes Work is currently underway to bound the conditions under which microbial activity may be significant, and to define those locations and times for which microbial activity is likely to have no significant influence on near-field conditions

\subsection{Geomechanics}

\subsubsection{Ambient Mechanical Rock Properties}

To properly characterize the mechanical behavior of the NFE, it is necessary to know the mechanical properties of the rock mass forming the NFE The mechanical properties of a rock mass are difficult to measure directly and depend on the properties of both intact rock and the fractures making up the rock mass The information presented here includes rock mass properties measured in situ to the extent such data are available, however, if not available, properties of intact rock samples are discussed Because most of the intact properties are available in the YMP Reference Information Base (RIB) (DOE, 1995) and are discussed in Section 2, that information is not duplicated here This section focuses only on rock properties when either the thermal influence or the rock mass variability in those properties is known

Information on physical properties is available in the RIB (refer also to Sec 4211 and Table 4-4 of Volume II) Information on thermal properties, including conduction and expansion, is also included in the RIB (refer to Sec 4.212 of Volume II for additional data on changes in properties due to temperature and confinement and to Sec. 444 of Volume II for more discussion)

\subsubsection{Ambient Joint/Fracture Properties}

Mapping of the Exploratory Studies Facility (ESF) at Yucca Mountain, which is within the Topopah Spring Tuff, identified three major fracture sets. Two are subvertical, while the third is subhorizontal These fractures will dominate much of the geomechanical behavior of the rock in the NFE, and it is important to have a basic knowledge of the properties of the fractures MacDougall et al (1987) reported joint cohesion $=01 \mathrm{MPa}$ and joint friction angle $=284^{\circ}$. Olsson $(1987,1988)$ found that the strength of a joint may increase with the time of stationary contact and that joint properties are dependent on stress history These findings need to be considered for the long-term repository analyses since the stress history will include a thermal pulse followed by cooldown The times of stationary contact will be much longer after the thermal pulse and major portions of cooldown are completed

The constitutive properties of fractures and joints in the potential repository horizon are also impor tant for assessment of the thermal-mechanical and thet mal-hydrologic behavior of the rock Olsson and Brown (1994) measured constitutive properties of seven fractures from drill holes NRG-4 and NRG-6 using a rotary shear apparatus They found that the peak friction 1 anged from 0.89 to 111 , and residual friction ranged from 0.76 to 100 . They also reported that dilation angle ranged from 529 to $1128^{\circ}$ and that the roughness characteristics for the fracture surfaces are in qualitative agreement with the mathematical model of Brown (1994) Olsson examined the effect of sliding velocity on the mechanical response of an artificial joint in Topopah Spring Tuff to determine the velocity dependence of shear strength Olsson found that different initial conditions affected the character of the stress-slip curve In particular, slide-hold-slide tests exhibited time-dependent strengthening, whereas hold-slide tests produced slip weakening No joint creep was observed in these tests

Blair and Berge (1996) found that imposing low levels of compressive stress on 05 -m-scale blocks caused time-dependent, nonrepeatable behavior to occur for existing cracks Under long-term loading, cracks/vugs oriented perpendicular to the applied stress showed significant closure, and pre-existing hairline cracks oriented parallel to the applied stress opened Based on their observations Blair and Berge postulated that some properties of the rock mass may become increasingly anisotropic with time. Additional data are currently being collected from the ESF; however, the data were not available at the time this report was prepared.

\subsubsection{Ambient Rock Mass Properties}

A major issue associated with measuring physical properties is scale effects One of the reasons for this is the ability, or lack thereof, to test fractures Blair and Berge (1996) monitored deformation of a fiacture zone in a $05-\mathrm{m}$ block of Topopah Spring Tuff and found that deformation is nonlineal with increasing stress, and modulus increases as normal stress increases above $4 \mathrm{MPa}$ They determined the modulus value to be $\sim 4 \mathrm{GPa}$ below 4-MPa normal stress, and $\sim 6 \mathrm{GPa}$ above 
4-MPa confinement These values are considerably lower than measured values on core samples They interpreted the increase in modulus to above $4 \mathrm{MPa}$ to be due to closure of fractures and vugs Based on hysteretic behavior, they postulate that during the cooldown period, when stresses are released, opening of fractures will increase permeability of the NF region

Uncracked samples exhibited quite high uniaxial strength of about $155 \mathrm{MPa}$ for Topopah Spring Tuff However, as expected, samples with cracks exhibit nonlinear stress-strain behavior when stress is above $50 \%$ of the failure stress (see Fig 4-2 of Volume II for stress-strain curves) The implications for the rock mass is that, except in localized areas without fractures present, the use of linearly elastic models must be used with caution Furthermore, work of Martin et al $(1993,1994,1995 a)$ reported in Volume II (p 4-6) indicates that the Topopah Spring Tuff is quite heterogeneous in porosities and in strength-some tested samples were much weaker than would be indicated by the values shown in the RIB, having failed at pressures well below $100 \mathrm{MPa}$ Brechtel et al (1995) analyzed the rock-mass strength based on empirical methods (see p 4-11, Volume II) and found that the estimated rock-mass strengths are substantially lower than those deter mined from intact rock samples They estimated that the compressive strength for TSw2 is $188 \mathrm{MPa}$, which is about $10 \%$ of the value determined from intact core samples

Tests performed on one $05-\mathrm{m}$ block that contained fractures indicate that the Young's modulus is about 6 GPA (Blair and Berge, 1996). This is approximately $16 \%$ of the modulus determined from intact rock Therefore, the values of Young's modulus reported in Table 4-4 (Volume II) may be untealistically high for application to repository conditions This lower modulus may serve to decrease stress levels predicted for the NFE

\subsubsection{Time-Dependent Rock Properties}

The thermal properties of rock samples from the proposed repository horizon have been the subject of several laboratory and field studies Results, as reported in the RIB and included in the Preliminary NFER, indicate that the dry matrix thermal conductivity is $251 \pm 017$ $\left(\mathrm{W} / \mathrm{m}^{\circ} \mathrm{K}\right)$. The in situ thermal conductivity has been measured both dry $\left(2.1 \pm 02 \mathrm{~W} / \mathrm{m}^{\circ} \mathrm{K}\right)$ and at a saturation of $065\left(21 \pm 02 \mathrm{~W} / \mathrm{m}^{\circ} \mathrm{K}\right)$ Brodsky et al (1997) indicate that recent data are consistent with previous values reported by Nimick (1989) However, they found that saturation had an effect For unit TSw2, the thermal conductivity for dry samples was $1.50 \pm 044 \mathrm{~W} / \mathrm{m} \cdot{ }^{\circ} \mathrm{K}$, and for satur ated samples, the value was $229 \pm 042 \mathrm{~W} / \mathrm{m}^{\circ} \mathrm{K}$

The effect of temperature on the strength of nearfield rock is not well defined at this time Rock strength, however, generally decreases with increasing temperature Price et al (1987) report that for samples from the potential repository horizon, Young's modulus decreases an average of $16 \%$ as temperature is raised from 22 to $150^{\circ} \mathrm{C}$ The mean ultimate strength also decreases $16 \%$ as temperature is raised from 22 to $150^{\circ} \mathrm{C}$ at both 0 - and 5-MPa confining pressures

Measurements of linear thermal expansion have been made on samples from unit TSw2 and are reported in the RIB (see summary Table 4-2 in Volume II) At temperatures below $100^{\circ} \mathrm{C}$, the coefficient of thermal expansion was in the range of 7.7 to $108 \times 10^{-6{ }^{\circ}} \mathrm{C}^{-1}$ As temperature was increased to near $250^{\circ} \mathrm{C}$, the values increased to between 142 and $206 \times 10^{-6}{ }^{\circ} \mathrm{C}^{-1}$ Cautions in the Preliminary NFER regarding the use of these values to estimate processes in the very near field and for simulation of cooling still apply Recent measurements (Brodsky et al, 1997) indicate that the coefficients are highly temperature-dependent and that there is a hysteresis between heating and cooling Furthermore, they observed some permanent elongations Because the coefficients are strongly temperature-dependent, single ranges are not useful Table 4-7 gives the coefficient of thermal expansion at different temperatures Whereas the values for $T<100^{\circ} \mathrm{C}$ are similar to those reported in the Preliminary NFER, the values for higher temperatures are significantly different

In general, the coefficient of thermal expansion increases with increasing temperature Work by Martin et al (1996) indicated that confining pressure has little effect on the coefficient of thermal expansion The increase with temperature is attributed to local distortions and formation of microcracks due to mismatch of expansion coefficient of constituent grains Brodsky et al (1997) attributed the hysteresis observed at temperatures near $200^{\circ} \mathrm{C}$ to phase changes in trydimite and cristobalite. Phase changes in some minerals can cause step changes in the rock volume Cristobalite exhibits a few percent volume increase in transition from alpha to beta phase at temperatures around $200^{\circ} \mathrm{C}$ However, cristobalite is expected to represent only about $30 \%$ of rock mass volume, and depending on design, a small percentage of the rock volume will be elevated to temperatures approaching $200^{\circ} \mathrm{C}$ The phase change, if it does occur, is reversible so that a volume decrease may occur upon cooling below $200^{\circ} \mathrm{C}$ 
Table 4-7. Coefficient of thermal expansion in TSw2 unit at different temperatures, from Brodsky et al. (1997).

\begin{tabular}{|c|c|c|c|c|c|c|c|c|c|c|c|c|}
\hline \multirow{2}{*}{$\begin{array}{l}\text { Saturation } \\
\text { state }\end{array}$} & \multicolumn{10}{|c|}{ Mean coefficient of thermal expansion $\left(\times 10^{-6}\right.$ per $\left.{ }^{\circ} \mathrm{C}\right)$ during heatup } & \multirow[b]{2}{*}{$250-275^{\circ}$} & \multirow[b]{2}{*}{$275-300$} \\
\hline & Statistic & $25-50^{\circ} \mathrm{C}$ & $50-75^{\circ} \mathrm{C}$ & $75-100^{\circ}$ & $100-125^{\circ}$ & $125-175^{\circ}$ & $150-175^{\circ}$ & $175-200^{\circ}$ & $200-225^{\circ}$ & $225-250^{\circ}$ & & \\
\hline Saturated & Mean & 714 & 747 & 746 & 907 & 998 & 1174 & 1309 & 1547 & 1903 & 2528 & 3713 \\
\hline Saturated & Std $\operatorname{dev}^{\mathrm{a}}$ & 065 & 151 & 121 & 241 & 077 & 128 & 140 & 175 & 309 & 687 & 1427 \\
\hline Saturated & Count & 19 & 19 & 19 & 19 & 19 & 19 & 19 & 16 & 16 & 16 & 16 \\
\hline Dry & Mean & 667 & 831 & 887 & 937 & 1010 & 1096 & 1222 & 1454 & 2079 & 2513 & 3513 \\
\hline Dry & Std dev & 120 & 042 & 040 & 055 & 088 & 116 & 150 & 257 & 1703 & 1007 & 1456 \\
\hline Dry & Count & 40 & 40 & 40 & 40 & 40 & 38 & 38 & 35 & 35 & 35 & 35 \\
\hline \multicolumn{13}{|c|}{ Mean coefficient of thermal expansion $\left(\times 10^{-6}\right.$ per $\left.{ }^{\circ} \mathrm{C}\right)$ during cool-down } \\
\hline Saturated & Mean & 2189 & 2783 & 2655 & 2138 & 1731 & 1406 & 1249 & 1152 & 1027 & 948 & 881 \\
\hline Saturated & Std dev & 616 & 1036 & 1001 & 570 & 307 & 138 & 132 & 200 & 062 & 063 & 062 \\
\hline Saturated & Count & 16 & 16 & 16 & 16 & 19 & 19 & 19 & 19 & 19 & 19 & 19 \\
\hline Dry & Mean & 2057 & 2431 & 2420 & 2116 & 1845 & 1434 & 1174 & 1051 & 954 & 887 & 748 \\
\hline Dry & Std dev & 488 & 755 & 808 & 624 & 936 & 423 & 303 & 226 & 179 & 156 & 199 \\
\hline Dry & Count & 35 & 35 & 35 & 35 & 38 & 38 & 40 & 40 & 40 & 40 & 40 \\
\hline
\end{tabular}

aStandard deviation

\subsubsection{Time-Dependent Joint /Rock Mass Properties}

Microcracking and subcritical growth in the nearfield rock over long time periods is of concern because the formation, growth, and coalescence of microcracks in the rock at or near excavations could lead to excavation damage and the formation of rock chips or blocks The chips or blocks might passively load the container and form transport pathways The formation of microcracks may also change the physical and geochemical properties of rock in the NFE Little work has been done in this area Kemeny and Cook (1990) however used a probabilistic approach that included time-dependent crack growth to examine borehole emplacement They estimated that, over the lifetime of the repository, slabbing would be likely to occur in a significant portion of emplacement boreholes, were they to be used

\subsubsection{Mechanical Loading Conditions on WPs}

4.6.6.1 Block Failures. The rock-mass failure mechanisms that could lead to loading of the container include

1 Block failures Blocks could fall into open spaces left by a collapsed ground support system Block failures are the most credible loading scenario

2 Rock burst failures Such failures are unlikely, even if ground support fails

3 Creep Openings close, forcing ground support segments onto the package or backfill
4 Sloughing of rock materials into openings created by failed ground support systems

The type of loadings that would result from these failures will be different and are assessed separately in the following sections Thermal loading is the most likely cause of ground support failures and associated loading of the WPs

Two types of loading are possible point loads and uniform loads. The type of loading that is most likely is strongly influenced by engineering design For instance, nonuniform loading of WPs can be mitigated by engineered alternatives, such as backfilling the drifts at the time of closure Drift backfill should remain effective against drift collapse indefinitely Even if settlement of backfill occurred, the amount of rock motion would be limited Therefore, loading conditions must be discussed relative to design assumptions

Under assumed conditions, rock loading on the WPs by block failures or by sloughing can be bounded The rock support system currently envisioned consists of pre-cast segmental liner, which will be emplaced immediately behind the tunnel boring machine (TBM) If this support system maintains its integrity, there will be no rock loading on WPs The issue of mechanical loading on the rock support system is beyond the scope of the NFER If the drift collapses with time, then the WPs can be loaded by contact with the failed concrete support system that, in turn, would be loaded by either blocks of rock or bulked rock rubble If backfill is used, the contact 
would not be directly with the concrete, and the potential for point loading would disappear Presumably smaller blocks of rock would be able to mobilize because of the smaller open volume for the rock to move into Unless a different ground support system is used than that currently envisioned, there is no likelihood that blocks could fall directly onto WPs More likely, the liner_segments, if the wedging or keyblock failed, could fall onto the WPs, and then blocks of rock could fall into the opening left by the liner segments Unless the liner segments failed by crumbling, they would not occupy the space in a densely packed fashion, and, therefore, there would be a limit on the magnitude of rock movement that would occur

A probabilistic approach could be used to estimate the stability of drifts over time Kemeny and Cook (1990) used this approach to evaluate the stability of boreholes over time in conjunction with a repository design that employed borehole emplacement They estimated that, over the lifetime of such a repository, slabbing would be likely to occur in a significant portion of the emplacement boreholes This analysis, although performed for boreholes, could be applied to drifts It should be recognized that other processes might apply to drifts, and furthermore, that in a rock mass where vertical fractures dominate, the potential for slabbing or for block failures into a large horizontal opening may be significantly greater than into a vertically oriented borehole such as was used by Kemeny and Cook Slabs could place either uniform or point loading on the ground support system liners, etc, but would not likely impact directly on WPs except through failed support system components

4.6.6.2 Uniform Loading. Without backfill, uniform loading of the WPs could only result from creep closure of openings being imposed on a uniformly failed and completely crumbled support system. This, in turn, would impose the loading on the WPs In the case of backfill, creep closure could be imposed through the backfill If sufficient long-term creep takes place to entirely close the openings around the WPs, then the full lithostatic load might be imposed Whereas data are not available to address creep over long time frames $(10,000 \mathrm{yr})$, there is no indication that full lithostatic loading is likely to be imposed. Natural openings in other rock types have remained open over long periods (e $g$, limestone caves and lava tubes), but no study has been made as to whether these natural analogs apply to Yucca Mountain
A third mechanism for uniform loading is hydrostatic loading. No hydrostatic loading is anticipated because the repository horizon is unsaturated Any water that might be introduced inadvertently into the system will likely drain away before any appreciable head can develop Therefore, no hydrostatic loads need be provided for.

4.6.6 3. Point Loading. If pre-cast liners are used for ground support, the only means of creating point loadings on WPs would be from the concrete liner itself The rock load could be imposed on a failed, but not crumbled ground-support system, which in turn transferred that load to WPs, or by rock blocks directly if portions of the ground-support system fell to the sides of the WPS The rock loading could be from block failures behind the liner or from creep closure

The size of blocks that could enter the space left by a collapsed liner depend on the fracture spacing and, ultimately, the opening dimensions that result from the ground support failure The ultimate bound on this opening dimension would be the full drift diameter, but the actual dimension should be somewhat smaller because total failure of the ground support is unlikely In the Preliminary NFER, it was noted that for horizontal emplacement, it is conceivable that vertical_joints with different orientations could form a block with about $1 \mathrm{~m}^{2}$ horizontal dimension that could extend for a considerable distance vertically Given the dry bulk density of $222 \mathrm{~g} / \mathrm{cm}^{3}$, this would be equivalent to $\sim 2000 \mathrm{~kg} /$ vertical $\mathrm{ft}$ of block A reasonable estimate for point loadings by a tabular block can be made by using a ratio of 101 vertical to horizontal dimensions for the block. (At vertical dimensions greater than 101 , an estimate of the locking into the overall fracture/block system needs to be made )

An estimate for a tabular block was based on constraining the horizontal dimension of blocks by the borehole diameter and by fracture spacing (see Table 4-8) A similar approach can be taken for the drift emplacement Given the orientation of fracture Set 1 (about $18^{\circ}$ to drift orientation), theoretically tabular blocks with dimensions up to $16 \mathrm{~m}$ long (the length of the fracture trace in a 5-m-diameter drift) could fall with the drift However, a more realistic value can be estimated by using the average fracture spacing of the three prominent Sets 1,2 , and 3 (realizing that when fracture spacing is different, blocks of quite different dimensions can form). These sets would intersect to form blocks with one side oriented 
Table 4-8. Fracture spacing by domain.

\begin{tabular}{|c|c|c|c|c|}
\hline & Domain 1 & Domain 2 & Domain 3 & Domain 4 \\
\hline \multicolumn{5}{|l|}{ Set 1} \\
\hline Fractures & 798 & 540 & 2851 & 428 \\
\hline Drift length (m) & 900 & 500 & 950 & 350 \\
\hline Fractures $/ \mathrm{m}$ & 089 & 108 & 311 & 122 \\
\hline Spacing between fractures $(\mathrm{m})$ & 113 & 093 & 032 & 082 \\
\hline \multicolumn{5}{|l|}{ Set 2} \\
\hline Fractures & 230 & 134 & 215 & 168 \\
\hline Drift length $(\mathrm{m})$ & 900 & 500 & 950 & 350 \\
\hline Fractures $/ \mathrm{m}$ & 026 & 027 & 023 & 048 \\
\hline Spacing between fractures (m) & 391 & 373 & 442 & 208 \\
\hline \multicolumn{5}{|l|}{ Set 3} \\
\hline Fractures & 86 & 51 & 21 & 26 \\
\hline Drift length (m) & 900 & 500 & 950 & 350 \\
\hline Fractures $/ \mathrm{m}$ & 010 & 010 & 002 & 007 \\
\hline Spacing between fractures $(\mathrm{m})$ & 105 & 980 & 452 & 135 \\
\hline \multicolumn{5}{|l|}{ Set 4} \\
\hline Fractures & 62 & 0 & 0 & 0 \\
\hline Drift length (m) & 900 & 500 & 950 & 350 \\
\hline Fractures/m & 0.07 & 0 & 0 & 0 \\
\hline Spacing between fractures $(\mathrm{m})$ & 145 & NA & NA & NA \\
\hline
\end{tabular}

approximately $120^{\circ}\left(300^{\circ}\right)$ with a length of about 2 to $4 \mathrm{~m}$ (that is, $2 \mathrm{~m}$ in domain 4 , and $44 \mathrm{~m}$ in domain 3 ) and width ranging from about $03 \mathrm{~m}$ to $11 \mathrm{~m}$ for domains 3 and 1, respectively The vertical extent of the blocks would be roughly the spacing of Set 3, which varies from about $10 \mathrm{~m}$ in domains 1 and 2 to about $45 \mathrm{~m}$ in domain 3 (see Table 4-8) Domain 3 will represent a large portion of the repository. Therefore, if a single block were to fall into the drift, it could range in weight from 360,000 to $20,000 \mathrm{~kg}$ for domains 3 and 1 , respectively It is less likely that a single block $45 \mathrm{~m}$ high would fail; therefore, the $360,000-\mathrm{kg}$ block represents a bounding value that is unlikely. If multiple blocks fell into the drift, then a block of this dimension would be more plausible.

4.6.6.4 Seismic Loading. Information contained in Rev 0 of the Preliminary NFER remains relevant (refer to Sec 413 of that document) An earthquake with focus at Little Skull Mountain has been studied, and damage to underground structures was evaluated. This information is available in (Anderson et al , 1993)
The current design with large WPs emplaced within drifts and resting on pedestals results in different potential seismic impacts Specifically, the thick packages within a large opening should allow for much greater fault creep and fault offsets without exposing the WPs to excessive shearing loads or large deformations due to fault offsets than a borehole emplacement Since the drift diameter is approximately $5 \mathrm{~m}$, and the WPs are about $3 \mathrm{~m}$ with a length of about $6 \mathrm{~m}$, offsets that are less than $2 \mathrm{~m}$ (for fault perpendicular to drifts, which is the worst case) will merely cause the WP to rotate or be offset (knocked off) the supporting pedestals without having the ends of the WP touch the ribs of the drifts Only the very large offsets associated with major earthquake events (usually less than $8 \mathrm{~m}$ ) would have enough offset to shear the WPs Furthermore, the WPs are sufficiently strong that the rock in a sheared zone associated with faulting could be expected to break around the fairly short WP rather than shearing the WP itself However, the WP could be dislodged from the pedestals and could be thrown against the rib of the drift 


\subsubsection{Predictive Modeling}

No predictions of the geomechanical component of the NFE are currently available Analyses of stresses resulting from waste heat generation have been made and are included in the Design Review Document (Repository Ground Support Analysis for Viability Assessment), which is in review However, predictive modeling for heater tests compare favorably with deformation responses measured by Finley et al , 1997 Thus, macroscopic geomechanical behavior can probably be modeled by existing techniques However, the real focus of geomechanics for the NFE involve how it back couples with hydrology and geochemistry The major issues involve

1 Modification of hydrologic pathways due to opening and closing of existing fractures as well as creation of new fractures (microcracking) It should be noted that deformations of the rock mass can have a strong influence on permeability, and these deformation effects may be permanent (Wilder, 1986)

2 Creation of newly exposed surfaces for geochemical rock-water interactions

3 Long-term creep or crack propagation that could alter the coupling
All of these issues will be address in subsequent revisions of the NFER based on models, testing, and technique development that are the focus of current work

The focus of LLNL's geomechanics work in the past was to evaluate subcritical crack growth over long time frames as it would produce deformations equivalent to long-term creep Model development to address the potential for crack propagation has been the focus of geomechanical studies Crack growth as a mechanism of long-term creep behavior has been studied and reported by Martin et al (1997) and Yang and Daemen (1997) This work will be reported in the forthcoming Synthesis Report on Thermally Driven Coupled Processes (Hardin and Chesnut, 1997) Martin et al (1997) report that there is not only similarity between the creep curve and that of time-dependent crack growth, but also that there is a theoretical basis for relating creep to crack growth They note that data for crack growth in single-crystal quartz is similar to that observed in creep experiments Whereas the focus of their work was on drift stability, it also has application to the NFE in that crack growth provides the surface exposure as well as modified hydrologic paths and stress concentrations for increased rock-water inter actions Yang and Daemen (1997) observed that creep of tuff increases with temperature, thus, this issue will have direct application to the NFE 


\subsection{Altered Zone Environment}

\subsection{Introduction}

\subsubsection{Definitions and Organization}

At Yucca Mountain, many processes or inter actions associated with the potential repository can potentially cause significant proper ty changes extending for considerable distances into the rock mass or natural system The altered zone (AZ) is defined as the region of the natural system wherein fundamental changes to hydrologic, mineralogical, or chemical conditions take place The changes are generally a result of increased temperature in the presence of water or water vapor Alteration can also take place with increased temperature in the dryout zone where water exists as vapor rather than liquid phase However, the alterations are greatest where both liquid water and elevated temperatures exist The $A Z$ conditions do not interact directly with the WPs, rather, they interact with the NFE The AZ, with associated conditions, differs from the FFE, where ambient conditions tend to prevail Many of the same processes occur in the NFE, AZ, and to some extent FFE However, the processes that dominate the system in the $\mathrm{AZ}$ are not necessarily the same as the ones that dominate either the NFE or the FFE Except for the coupling with introduced materials that occurs in the NFE, the AZ processes are the most fully coupled

The fact that coupled processes dominate the $A Z$, and that the processes are coupled in complex ways, makes understanding difficult To facilitate explanations, the multiply coupled processes are discussed in this report as being singly or, where necessary, multiply coupled but without evaluating all the interactions at the same time Thus, the fully coupled processes are broken down into component parts Figure 5-1 is the basis for organizing the discussion The way to read this chart is discussed in Section 1 Simply put, components of the NFE and AZ environments are identified on the diagonal, and processes are shown off-diagonal Forward coupling is shown to the right, and backward coupling is shown to the left

For example, when thermal-mechanical unit TSw2 is exposed to water at elevated temperatures, the rock-water interaction will form new mineral assemblages, including carbonates and silica depositions. These, in turn, will heal fractures and plug the original pore spaces resulting in an overall reduction in permeability This example of coupling is shown in Fig 5-1, where the arrows extending to the right from temper atures and moisture conditions to processes of kinetics, rock-water interactions, mineral dissolution, and so for th, indicate the interaction leading to a change in development of mineral assemblages Moreover, once the mineralogy changes, the permeability changes, the coefficient of thermal conduction is modified, moisture conditions (involved in reactions) change, and the convection within the system is hindered This type of back-coupling is indicated by the arrows pointing to the left from changed mineralogy and upward to changed hydrologic properties, and through the backcoupling of those processes to the thermal regime As is apparent, the coupling can be quite complex However, such forward and backward coupling is important to repository performance In this example, the changes in heat flow due to changed conduction and convection conditions could lead to vastly different temperatures within the NFE and drifts Each main topic in Section 5 is organized by identifying on a similar chart the coupling that is most dominant The multiple back-coupling will be implied on the matrix However, the multiple coupling pathways are not fully identified at this time and will be included in future revisions of this report

\subsubsection{Background}

The environmental conditions that impact WPs and radionuclides will be strongly perturbed by the heat of decay from the waste for many hundreds or thousands of years As the thermal pulse moves further into the rock mass, the rapidity of movement of the thermal isotherms slows down, and equilibrium conditions begin to dominate Thus, to some degree, the distinction between the NFE and AZ is the transition from dominance of kinetics to equilibrium, although both processes will occur to some degree in each zone For any given emplacement scenario, the rate at which temperature changes occur depends, in general, on the distance from the heat source the greater the distance, the slower the change of temperature This temperature behavior provides one basis for defining or distinguishing the NFE from the AZ 


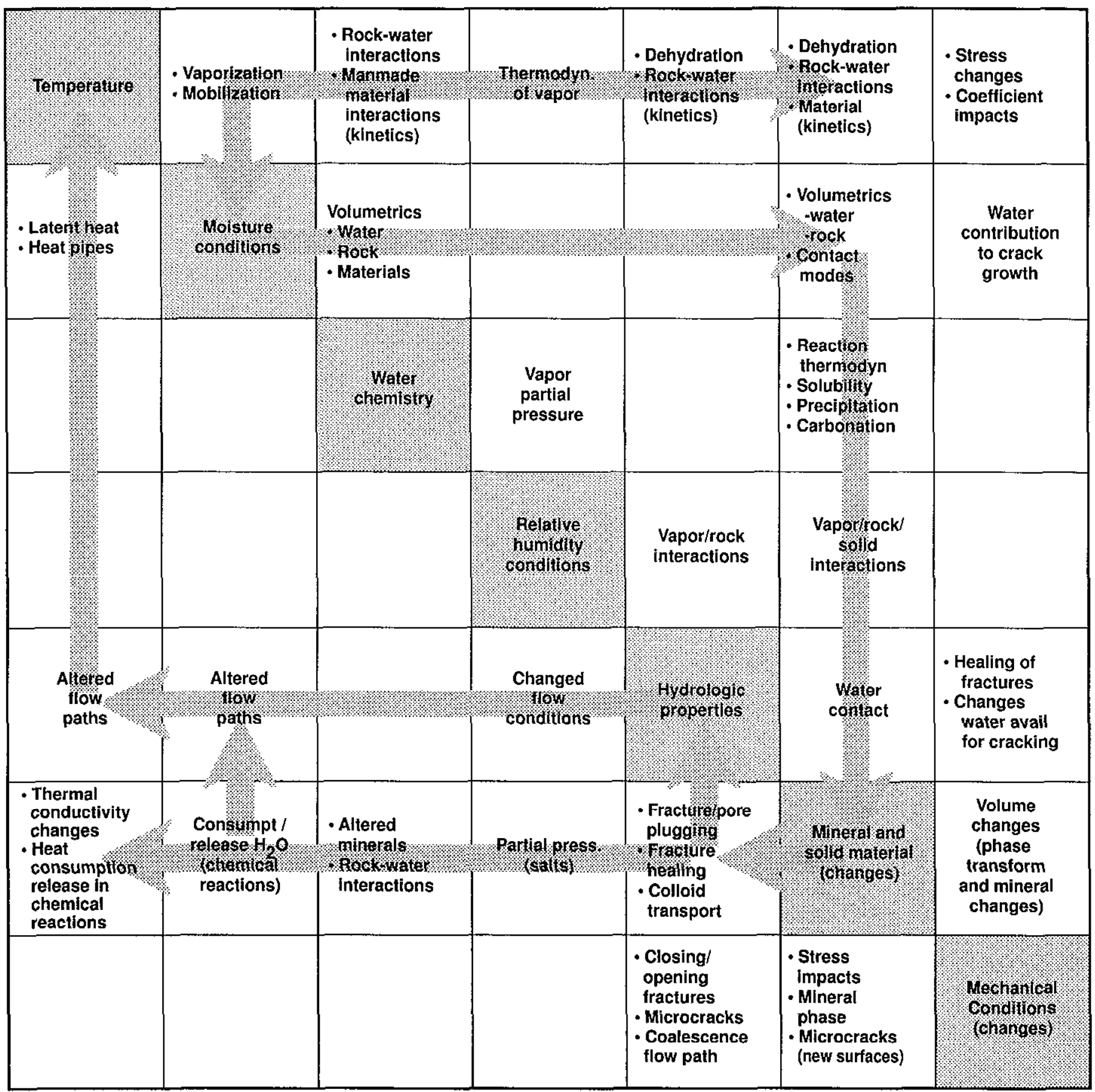

Figure 5-1. Model of coupled processes in the AZ. Entries on the diagonal denote components of the environment. Arrows to the right denote forward coupling; arrows to the left denote backward coupling. 
In the near-field region, strong thermal gradients will exist for the first $1000 \mathrm{yr}$. These regions will be dominated by kinetic effects, and hydrological processes will be dominated by water vaporization, water movement by means of gas-phase transport, and condensation in those outer regions of the NFE where temperatures are below the boiling point Geochemical processes will be dominated by evaporation and boiling, mineral dehydration, and solid-vapor interactions The system will be a highly dynamic one in which the dryout regions will continue to increase in size and therefore incorporate what had been zones of condensation Because of the dynamics, coupling between hydrology and geochemistry may not be well developed (water removed before geochemical reactions change the system in significant or fundamental ways)

In the $\mathrm{AZ}$, hydrologic processes will be dominated by an increase in water availability and increased saturation, associated with vapor condensation There will be a gener al elevation of temperatures by several tens of degrees centigrade The geochemical processes will be dominated by fluid-rock interactions and reactive transport The AZ will tend to be less dynamic than the NFE in that the residence times for water will be much longer, and the dryout zone will not incorporate the condensation zones until long after geochem$\mathrm{ical} / \mathrm{mineralogic}$ changes have occurred, if at all Within the AZ, these interactions will result in significant coupling between hydrological and geochemical processes, such that fluid pathways and geochemical conditions will evolve in a synergistic way

Although the geochemical processes (e g, recrystallization, hydration/dehydration of mineral phases, dissolution/precipitation, rock-water interaction involving water in pores and fractures, cation exchange, sorption, etc ) in both regions are the same, their impact on rock properties will be different The differences are due to contrasts in heating and cooling rates, in the abundance and temperature of liquid water, in whether kinetics or equilibrium dominate, and in the duration of reactions These differences will be expressed as differences in the magnitude and nature of chemical and mineralogical changes As a result, repository performance will be affected differently in the two regions because of water-mineral interactions. In this report, the NFE is considered to be those regions that achieve temperatures well above the boiling point, thus contact times for rock-water interactions are shorter The $A Z$ is considered to be those regions that maintain temperatures low enough to allow liquid water to exist in pores and fractures This distinction has the advantage of focusing attention on the dominant processes that may affect performance in different regions of the repository

Because hydrothermal conditions are strongly coupled with geochemical processes, the hydrothermal conditions will be determined first, then coupling with geochemical processes will be discussed Figure 5-2 shows the various decay-heat-driven hydrological processes and ambient site conditions that may significantly affect moisture balance in and development of the AZ In general, decay heat will result in regions of dryout and condensate buildup in the unsaturated zone (UZ) Modeling studies (Buscheck and Nitao, 1993a, Buscheck and Nitao, 1993b, Buscheck and Nitao, 1994a, Buscheck et al , 1994) have indicated that decayheat-driven changes in the saturation distribution can persist for more than 100,000 years These effects, along with temperature changes, can alter the hydrological, geochemical, and geomechanical properties that influence fluid flow and radionuclide th ansport

\subsection{Thermal-Hydrology in the Unsaturated Zone}

This discussion focuses on those thermal-hydrologic processes shown within the shaded areas of Fig 5-2 and as the off-diagonal process in Fig 5-3, which essentially define the $\mathrm{AZ}$ The processes are dryout/boiling-driven vapor flow, condensate buildup and flow (including downward drainage), vapor diffusion, and buoyancydriven vapor flow Refluxing or gravity-driven heat pipes are included in these processes but are mentioned specifically because of their significance

Fluid flow in the UZ at Yucca Mountain involves liquid- and gas-phase flow through the fractures and through the rock matrix Under ambient conditions, the gas phase contains about $985 \%$ air and $15 \%$ water vapor Except for regions with a perched water table or during transient recharge episodes, capillary/gravity forces cause most fractures to be drained of liquid water Matrix permeability is extremely low for most of the hydrostratigraphic units in the UZ, so liquid-phase flow will primarily occur in fractures rather than in the matrix. Liquid-phase flow in fractures may arise from three origins:

1 Ambient infiltration and percolation of rainfall and snowmelt

2 Condensate generated under boiling conditions

3 Condensate generated under sub-boiling conditions 


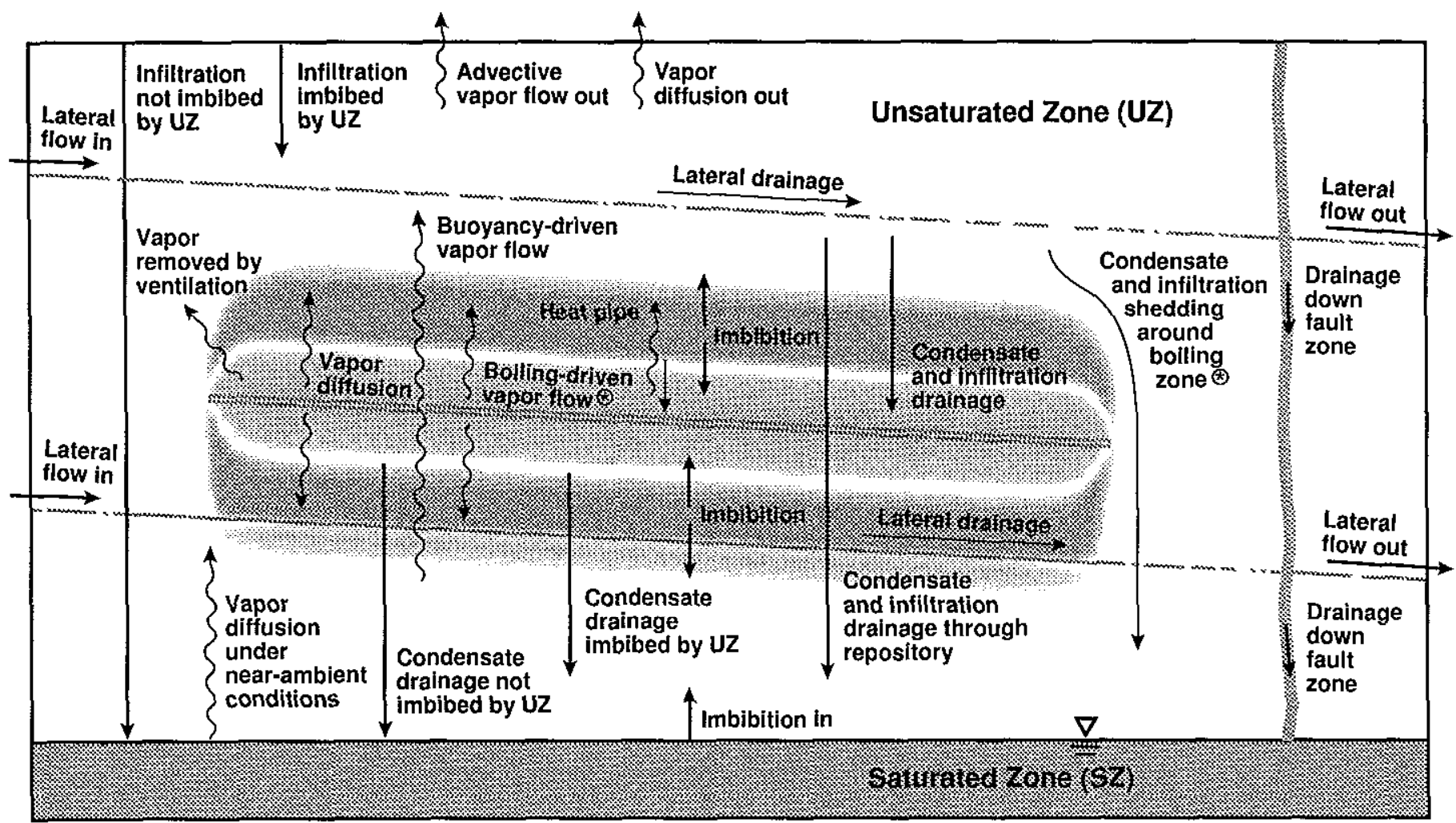

Figure 5-2. Moisture balance in the UZ (and above the repository) is affected by both ambient and decay-heatdriven processes. The two processes labeled with an asterisk are applicable only to above-boiling conditions. All other processes can occur under both sub-boiling and above-boiling conditions.

The first source arises from the ambient system, the second and third are generated by radioactive decay heat Decay-heat-driven, buoyant vapor flow may play an important role in generating the second and third sources of liquid water Decay-heat-driven binary diffusion of water vapor and air may also play important roles in condensate generation (Buscheck and Nitao, 1994a)

Because of the large bulk permeability of fracture networks, gas-phase pressures in the fractures remain very close to atmospheric, even during boiling Consequently, as temperatures reach the nominal boiling point $\left(\sim 96^{\circ} \mathrm{C}\right)$, boiling first occurs along fractures (Fig 5-4) and proceeds into the matrix blocks Accordingly, dry-out due to boiling is more suppressed in sparsely fractured regions (with large matrix blocks) and less suppressed in intensely fractured regions

Most of the water vapor reaching the fracture network is eventually driven away from the emplacement drift by higher gas-phase pressures in the boiling zone to where cooler temperatures cause it to condense along fracture walls (Fig 5-4) Buoyant, gasphase convection can cause more of the vapor flow to be driven upward to where it condenses above the dry-out zone In general, regardless of where the condensate is generated, three things can happen to it

1 It can drain away from the boiling zone

2 It can drain back toward the boiling zone

3 It can be imbibed by the matrix

Because the small matrix permeability limits the rate at which the matrix can imbibe condensate by capillary suction, condensate can drain for considerable distances down fractures before being completely imbibed Below the boiling zone, condensate drainage is away from the boiling zone (Fig 5-4), enhancing the dry-out rate Above the boiling zone, condensate tends to drain back toward the boiling zone, where it reboils, creating a gravity-driven heat pipe This creates asymmetry in the boiling zone around the drift, as is illustrated in Fig 5-4, where the dryout or elevated temperature zone is larger below the drift 


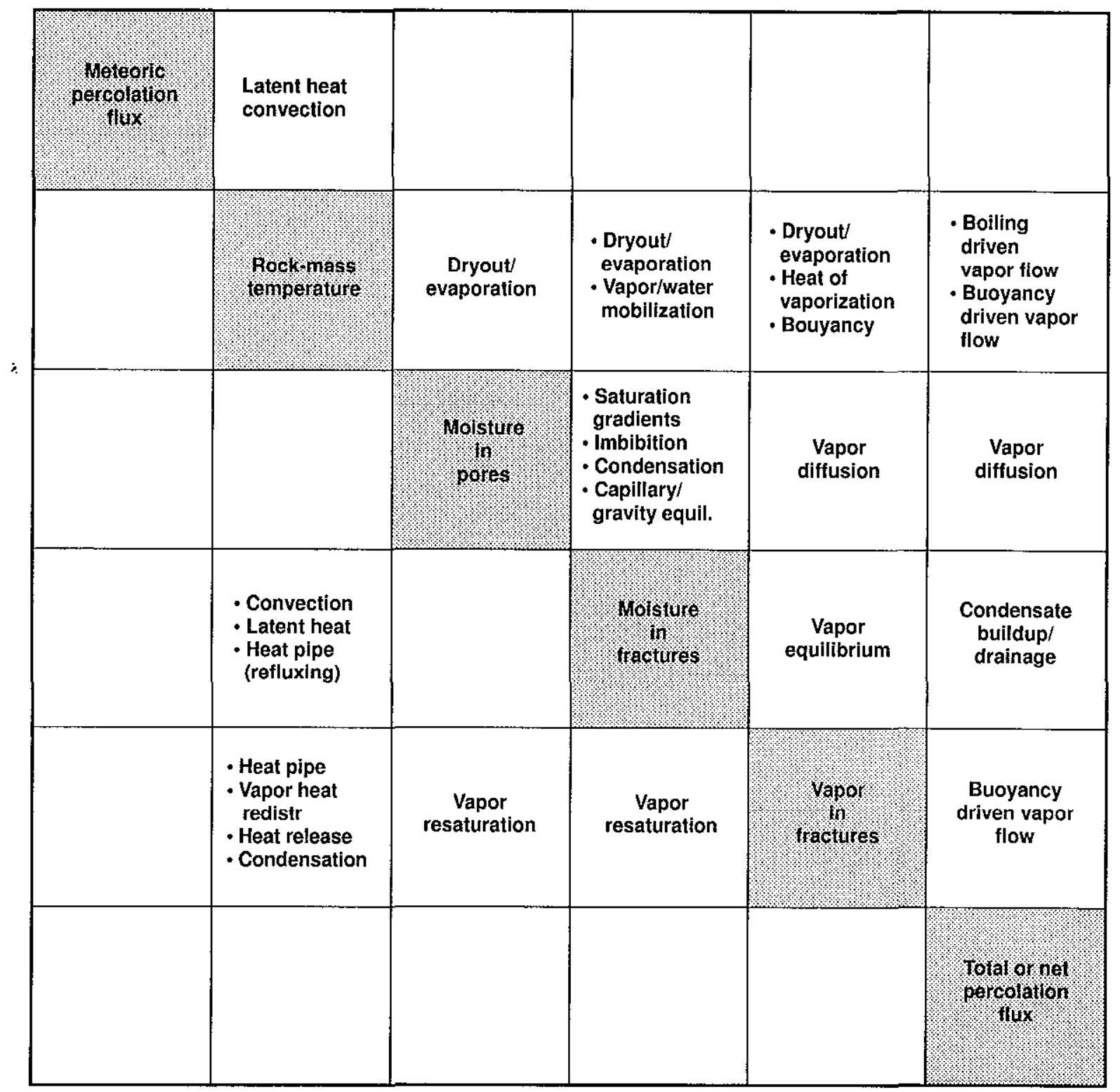

Figure 5-3. Thermal-hydrologic coupling matrix.

This effect has been observed in field experiments at G-Tunnel (Ramirez et al., 1991), at the Exploratory Studies Facility (Lin, 1997), and at the Large Block Test at Fran Ridge.

Refluxing does not require boiling conditions (Buscheck and Nitao, 1994a) Heat-driven, buoyant gas-phase flow can drive refluxing under sub-boiling conditions; however, the heat transfer is greater under boiling conditions Refluxing results in a heat transfer mechanism (driven by the convection of latent heat) called the heat-pipe effect Heat pipes are capable of sustaining a given heat flux with a much flatter temperature gradient than is associated with heat conduction Consequently, heat pipes are manifested by a flat temperature profile, with temperatures close to the nominal boiling point

The zone of two-phase refluxing overlying the boiling zone (the heat-pipe zone) is of particular interest because the liquid saturation and relative humidity $R H$ remain high in this zone, increasing the likelihood of aqueous reactions and aqueous-transport processes occurring Refluxing can also generate a 


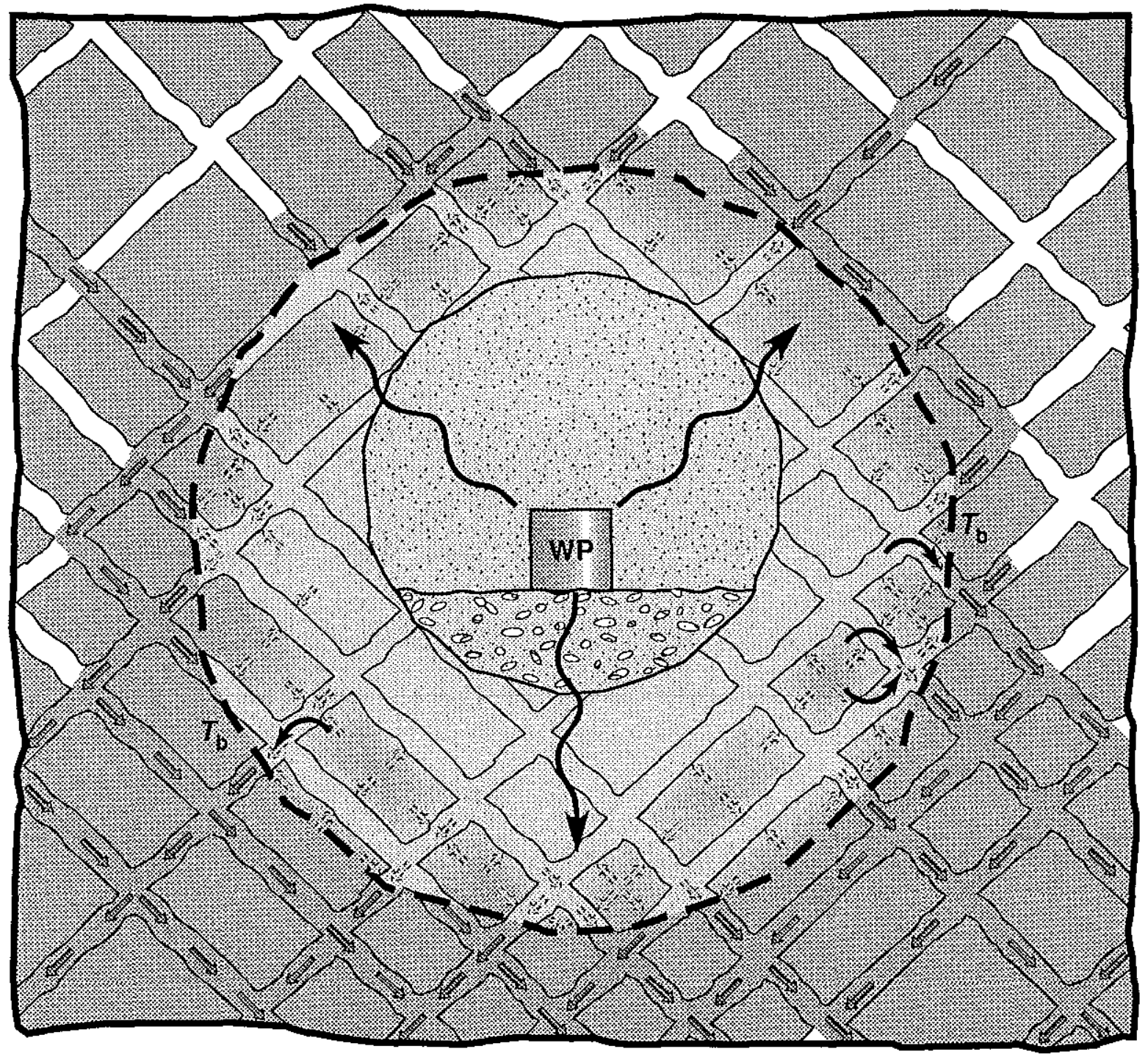

Figure 5-4. Schematic of hydrothermal flow near the emplacement drift. Water held in pores (blue) will be mobilized by heat (wavy arrows) from WPs. Rock dryout (yellow) occurs as boiling drives water vapor out of the rock matrix (small black arrows). On reaching the fracture network, vapor is driven away from the boiling zone to where cooler temperatures cause it to condense along fracture walls. This condensate will flow through the fracture network (green). Because the small matric permeability limits the rate of matrix imbibition, condensate drainage can persist for considerable distances down fractures.

very high liquid-phase flux in fractures, which can result in significant dissolution and precipitation of minerals along the fracture walls The heat-pipe zone is typically manifested by temperatures that are very close to the nominal boiling point of water at the repository elevation $\left(96^{\circ} \mathrm{C}\right)$ and a liquid saturation that is very close to $100 \%$
Figure 5-5 summarizes the time and length scales involved in how repository heat influences the three major sources of fracture flow Mountain-scale effects depend on the overall heating conditions for the entire repository The most useful macroscopic thermal loading parameter quantifying the time-integrated heat content of the waste in the repository is the areal 

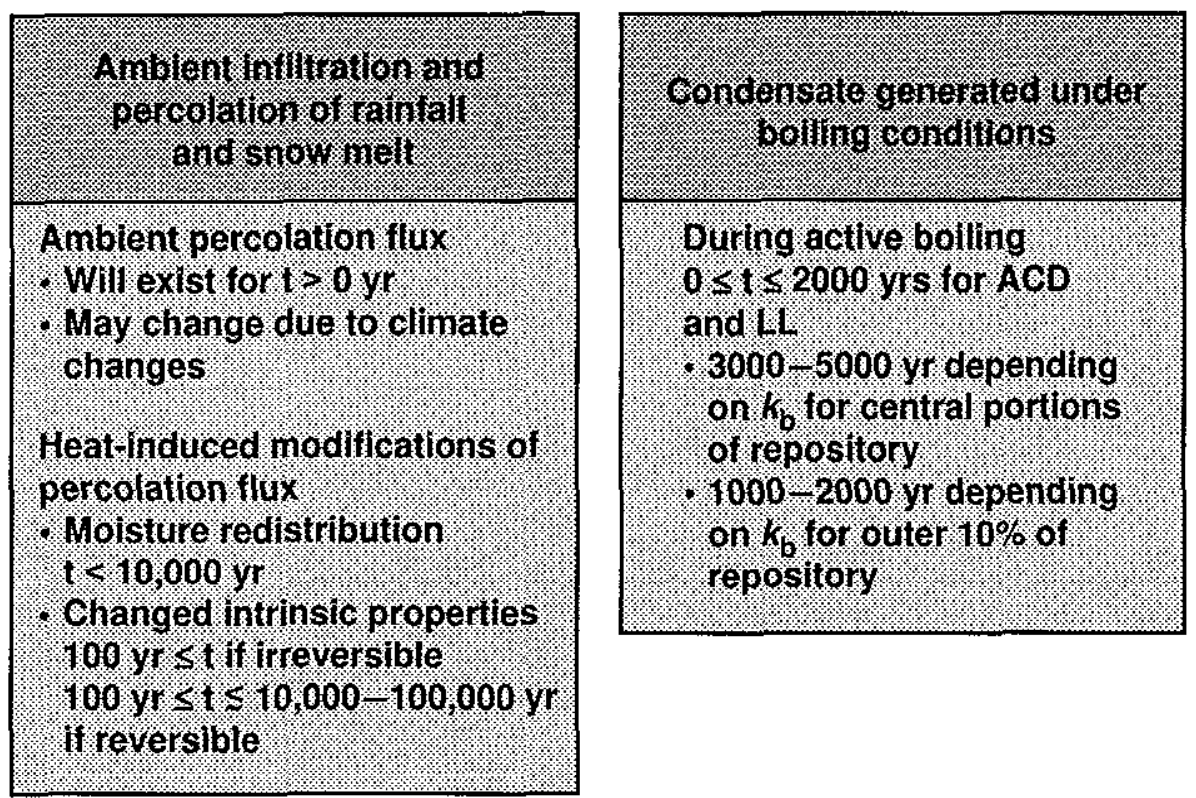

\begin{tabular}{|c|}
\hline 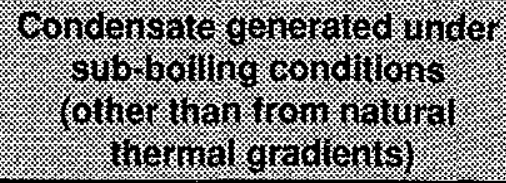 \\
\hline 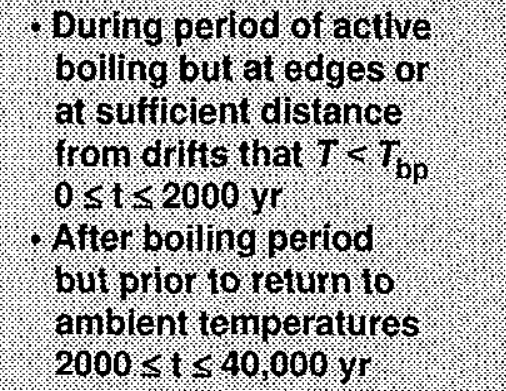 \\
\hline
\end{tabular}

Figure 5-5. Various time (t) and length scales involved in how decay heat influences the three major sources of liquid water flow. Bulk permeability is denoted by $k_{\mathrm{b}}$, temperature by $T$, and the boiling point of water by $T_{\mathrm{bp}}$.

mass loading (AML, expressed in metric tons of ur anium per acre, MTU/acre) Mountain-scale effects depend primarily on the AML of the entire repository, and they are insensitive to the details of WP emplacement, such as WP size and spacing, and spent nuclear fuel (SNF) age

\subsubsection{Assumptions and Calculations}

The discussions in this section are based on numerical models of an idealized system and, as discussed in $\operatorname{Sec} 13$, should not be construed to reflect actual, detailed NFE and AZ conditions However, models with their inherent assumptions will always be the basis for understanding the evolving environment and for making decisions Even though some of the uncertainties will be reduced with time, the conclusions need to be applied with care, realizing that the models are idealized and simplified abstractions of the real world.

For a detailed discussion of the property values and boundary conditions used in the calculations reported here, refer to Secs 101.1 .3 and 10114 of Volume II All major hydrostratigraphic units in the UZ at Yucca Mountain were included in the models The wet and dry thermal conductivity $\left(K_{\mathrm{th}}\right)$ data were obtained from the Reference Information Base (RIB) (DOE, 1990) A steady-state liquid saturation profile obtained for a net percolation flux of $0 \mathrm{~mm} / \mathrm{yr}$, yielding a repository horizon saturation of $68 \%$ was used in calculations Other studies (Buscheck and Nitao, 1992, Buscheck and Nitao, 1993a, Buscheck and Nitao, 1993c) also considered the steady-state saturation profile obtained for percolation fluxes of 0045 and $0132 \mathrm{~mm} / \mathrm{yr}$, resulting in repository horizon saturations of 85 and $95 \%$, respectively For the reference case, we used the matrix hydrological properties given in the RIB and in Klavetter and Peters (1986) Updated physical properties are currently being incorporated and will be included in subsequent revisions of this report We also considered the impact of more recent matrix hydrological properties reported by Pruess and Tsang (1994)

The reference case assumed a bulk permeability $k_{\mathrm{b}}$ of $2.8 \times 10^{-13} \mathrm{~m}^{2}$ ( 280 millidarcy), equivalent to three $100-\mu \mathrm{m}$ fractures per meter The sensitivity of buoyant, gas-phase convection, boiling and dryout behavior to $k_{\mathrm{b}}$ was examined (see Sec 10113 , Volume II)

The initial vertical temperature distribution $T$ in the models corresponded to the nominal geothermal gradient in the region The initial temperature and saturation at the repository horizon in the UZ model are $233^{\circ} \mathrm{C}$ and $68 \%$, respectively The atmosphere at the ground surface was represented by a constantproperty boundary, with $T$ and gas-phase pressure 
fixed at $13^{\circ} \mathrm{C}$ and $086 \mathrm{~atm}$, respectively The relative humidity $\mathrm{RH}$ at the ground surface was also fixed at $100 \%$. Therefore, under initial (ambient) saturation and temperature conditions, there is no mass flux of water vapor between the atmosphere and upper $\mathrm{TCW}$ We also assumed that the water table has a fixed depth $(z=5681 \mathrm{~m})$ and $\mathrm{a}$ constant temperature $\left(31^{\circ} \mathrm{C}\right)$, this causes the water table to act as a heat sink For the first 1000 years, repository temperatures are insensitive to the treatment of heat flow at the water table (Buscheck and Nitao, 1993, Buscheck and Nitao, 1993c)

Calculations that use a fixed-depth constanttemperature boundary at the water table substantially underpredict mountain-scale temperature rise as well as the overall magnitude of decay-heat-altered $\mathrm{T}-\mathrm{H}$ effects in the UZ (see Sec. 102 1, Volume II) We assumed that the Prow Pass welded unit (PPw) data were applicable to the upper $1000 \mathrm{~m}$ of the saturated zone (SZ) (down to the lower boundary of the UZ-SZ model) The lower boundary of the UZ-SZ model has a constant temperature of $535^{\circ} \mathrm{C}$ and a fixed pressure corresponding to the hydrostatic pressure and temperature profile of the upper $1000 \mathrm{~m}$ of the SZ The repository was assumed to be at a depth of $3431 \mathrm{~m}$

Because it areally averages the thermal load and represents the repository as a planar heat source, the mountain-scale model cannot represent differences in temperature and saturation behavior within the pillars, the emplacement drifts, or the WPs themselves The drift-scale model is useful in representing details of thermal-hydrological behavior at the drift scale and, thus, AZ scale

Heterogeneity that occurs at a larger scale was represented by a third model, called the cross-sectional uniform heat flow (CSUHF) model Like the drift-scale model, the CSUHF model assumes an infinite repository, thereby enabling it to take advantage of symmetry The CSUHF model represents an infinite series of vertical, uniformly spaced, 10 -m-wide, high $-k_{b}$ zones We considered high- $k_{\mathrm{b}}$ zone spacings of 100 and $1000 \mathrm{~m}$ For the high- $k_{\mathrm{b}}$ zones, we considered $10,84,414$, and 840 darcy

\subsubsection{Influence of Fracture Permeability Distribution}

\subsubsection{Temperature and Liquid Saturation}

Distribution. The vertical temperature and saturation profiles in Sec 10.121 of Volume II are given for three different repository locations (1) the center of the repository, (2) the perimeter that encloses the central $50 \%$ of the repository area (representative of "average" conditions because half of the WPs are inside this area), and (3) the perimeter that encloses $95 \%$ of the repository area (representative of the repository edge) The following discussion focuses on the repository average conditions

Figure 5-6 shows the vertical temperature and saturation profiles at a radial distance enclosing $50 \%$ of the repository for the 83 4-MTU/acre case at various times after emplacement The thermal and dryout behavior are very similar for the center and average repository locations for the first thousand years (The percentage of the repository that is influenced by edge-cooling effects increases with time) The flattening of the temperature profile at the nominal boiling temperature $T_{\mathrm{b}}\left(\sim 96^{\circ} \mathrm{C}\right)$, corresponds to the two-phase flow refluxing zone (the heat-pipe zone) This zone is of particular interest because the liquid saturation and $R H$ remain high, increasing the likelihood of aqueous reactions and aqueous-transport processes Refluxing also generates a very high liquidphase flux in fractures, which can result in significant dissolution and precipitation of minerals along the fracture walls This is the zone where significant coupling with geochemistry takes place and where conditions are maintained for sufficient times to allow reactions to achieve equilibrium

Figure 5-6 shows significant zones wherein the saturation remains above $60 \%$ (blue color) and temperatures are between $60^{\circ}$ and $96^{\circ} \mathrm{C}$ (pink color) The zones where both conditions are present, shown as yellow bands, represent where coupling will be strong, thus forming the $\mathrm{AZ}$ As shown, the $\mathrm{AZ}$ will be maintained for thousands of years (still operating at $10,000 \mathrm{yr})$ for the case shown here Factors such as higher percolation flux could modify the spatial and temporal extent of the AZ, but it will nonetheless be substantial In actuality, the AZ encompasses the entire region of rock extending from the repository to the highlighted regions in Fig. 5-6. However, once water is removed from the system, the coupling processes are greatly reduced Thus, the $A Z$ analyses and discussions are focused on the highlighted zones

Boiling results in a 150 - to 200 -m-thick dryout zone for the inner $50 \%$ of the repository The low liquid saturation in the dryout zone decreases the likelihood of aqueous reactions and aqueous-transport processes altering the flow and transport properties in this zone However, as noted earlier, the regions closer to the drifts are highly dynamic, and, as shown in Fig 5-6, approximately $100 \mathrm{~m}$ of this 150 - to $200-\mathrm{m}$ dryout zone is part of the $\mathrm{AZ}$ at 100 years Depending on the kinetics, it is possible that part of this zone 


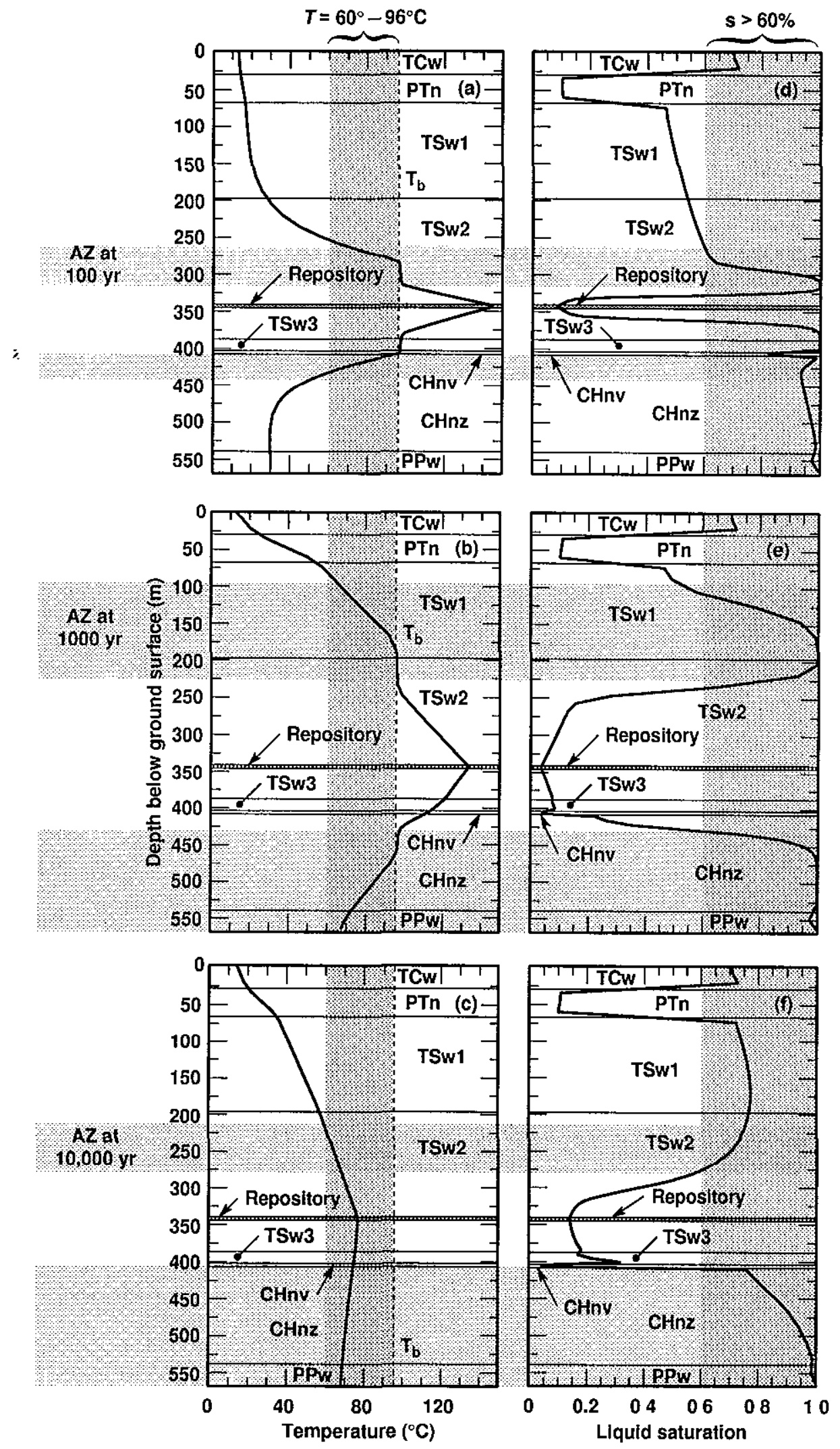

Figure 5-6. Vertical temperature profiles at a radial distance enclosing $50 \%$ of the repository for $A M L=83.4 \mathrm{MYU} / \mathrm{acre}$ at (a) $100 \mathrm{yr}$, (b) $1000 \mathrm{yr}$, and (c) 10,000 yr. Vertical liquid saturation profiles for the same times are shown in (d) through (f). The AZ, defined as the regions where temperature ranges from $60^{\circ}$ to $96^{\circ} \mathrm{C}$ and saturation is $>60 \%$, is identified by the yellow bands at the three time periods. 
would experience chemical/mineralogical alterations that would then be exposed to further alteration (at a minimum, dehydration) as the thermal pulse envelopes this region above boiling temperatures.

Refer to Volume II, Sec 1012 for nonreference case calculations (other AMLs) as well as discussion of edge effects Volume II (Fig 101211) indicates that edge-cooling effects substantially reduce the vertical extent of dryout in the outer region of the 1epository Temperatures in the outer edge of the repository only rise to $98^{\circ} \mathrm{C}$, while at the centel of the repository, $T_{\text {peak }}=146^{\circ} \mathrm{C}$ Temperatures decline to below $T_{b}$ within $5000 \mathrm{yr}$, however, a zone of less-than-ambient saturations persists after that. The outer $5 \%$ of the repository rewets back to ambient saturation within $10,000 \mathrm{yr}$, whereas the repository center remains below ambient saturation for more than 30,000 yr Edgecooling/rewetting/shedding effects will probably have less of an impact on the edge of a high-AML repository Wide drift spacing will encourage more drift-scale condensate shedding, which will decrease the amount of condensate that can be displaced to the edge of the repository This would lessen the contribution of edge-shedding to the liquid-phase flux at the edge of the repository, thereby lessening the impact of heat pipes at the repository edge
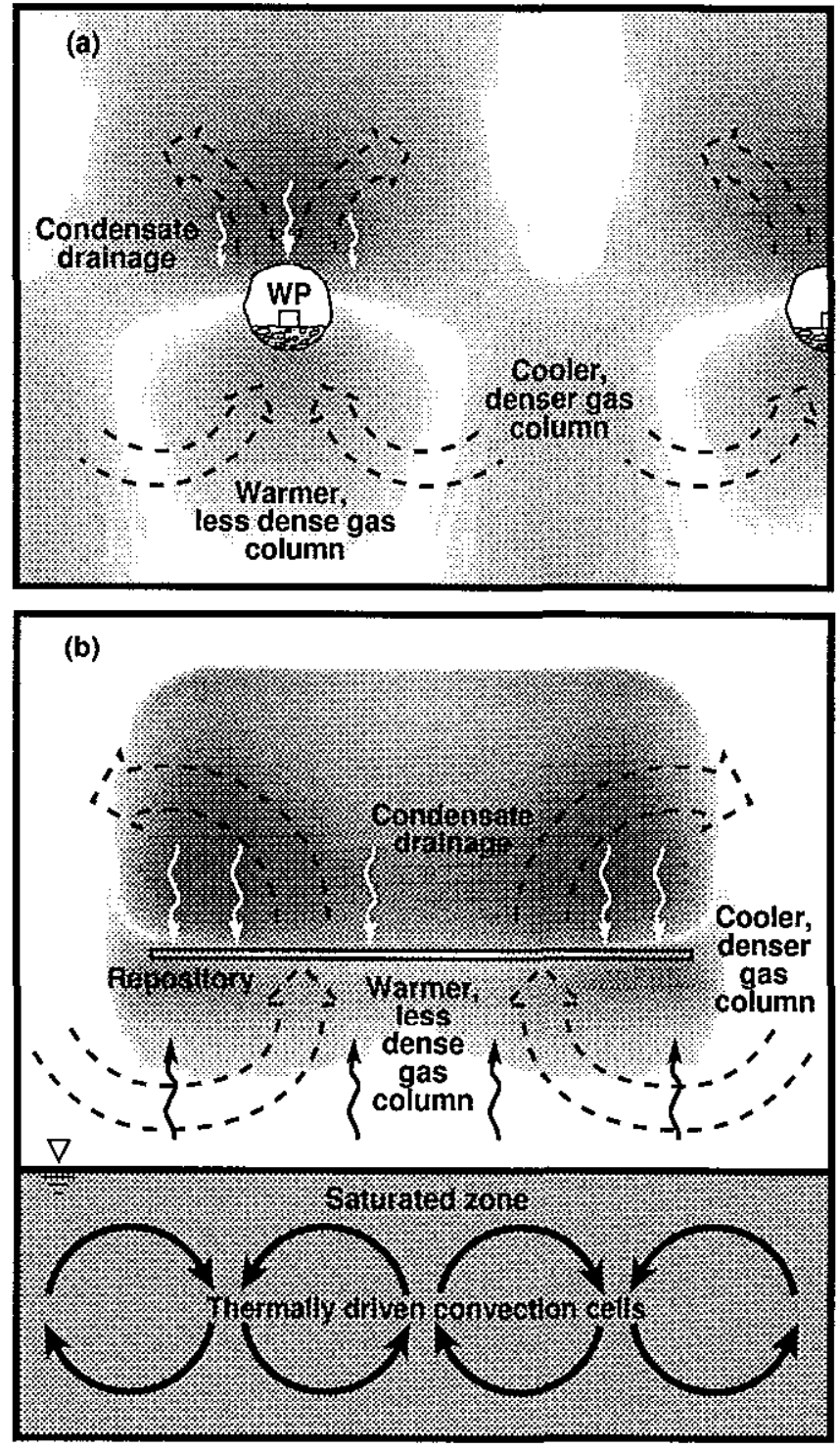

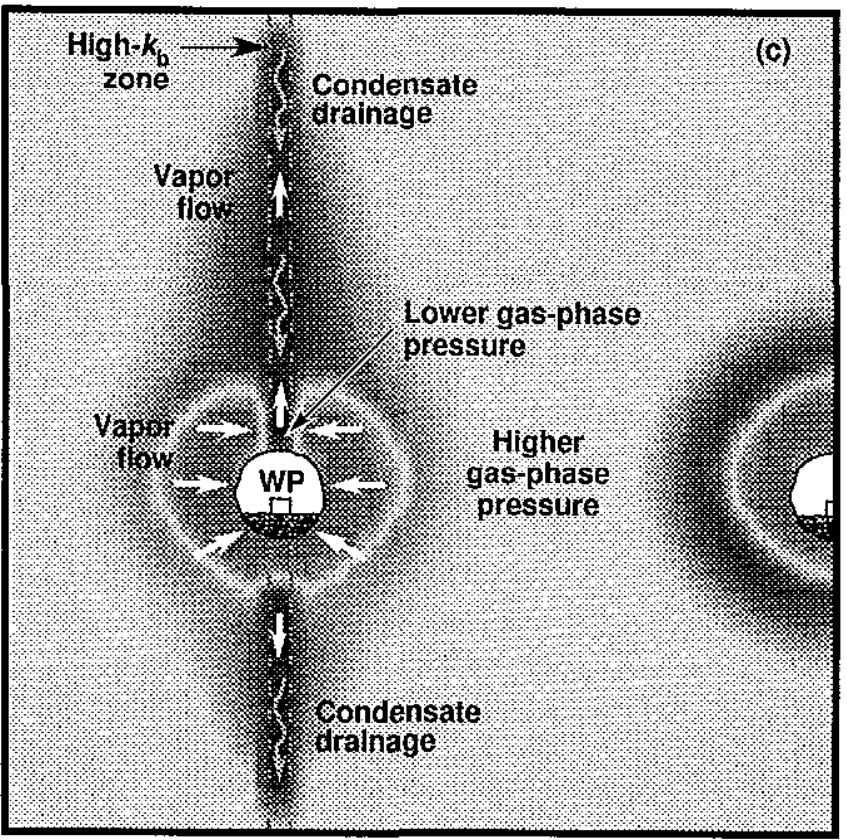

Figure 5-7. Illustration of model calculations of repository-heat-driven vapor and condensate flow. Buoyant vapor flow occurring on the (a) nearrepository or (b) mountain scale moves moisture from below to above the repository. (c) Zones of contrasting bulk permeability result in gas-phase pressure differentials that drive vapor flow into a hypothetical high-bulk-permeability zone, where it condenses and drains, possibly causing persistent two-phase refluxing (heat pipes) near WPs. 
If the bulk permeability, $k_{\mathrm{b}}$, of the fractured rock mass is large enough, repository heat can lead to the development of large-scale, buoyant convection cells transporting water vapor from regions below the repository to regions above These cells also have the potential to redistribute heat within the mountain and reduce temperatures in the repository as well as in the altered zone

Mountain-scale, buoyant, gas-phase convection occurs within fracture networks having a connectivity with length scale comparable to the UZ thickness and repository width As repository heat propagates into the rock, a column of warmer, less-dense gas develops that encompasses the repository area (Fig 5-7) The result is that gas from outside the repository footpint is drawn into the region below the repository and flows upward through the repository, in a fashion similar to the updraft in a chimney Buoyant, gasphase convection cells develop as the warmer, lessdense column of gas within the repository footprint is displaced by the cooler, denser gas from outside the repository footprint As the initially cooler gas is heated, its relative humidity is lowered, causing it to evapor ate water from the rock matrix below the repository This warm moist air is convected upward to where it cools above the repository, generating condensate that drains down fractures back toward the repository and/or is imbibed by the matrix, causing a saturation buildup above the repository Because water removed below the repository may be replenished by water imbibed from the $\mathrm{SZ}$, this process can result in a net buildup of liquid water in the UZ For sufficiently large $k_{\mathrm{b}}$, mountain-scale, buoyant, vapor flow can dominate moisture movement on the order of 100,000 yr (see Fig 5-5) The analyses indicate that if $k_{\mathrm{b}}$ is sufficiently large (greater than 10 darcy) and well connected over a sufficiently large volume, then the fluxes are large enough to alter the saturation distribution for thousands of yearswell beyond the thermal period This indicates that the magnitude would be greater than the natural percolation flux

Under sub-boiling conditions, this phenomenon always occurs and is significant unless the $k_{\mathrm{b}}$ is very small Under boiling conditions, steam generation causes a gas pressure buildup that can dominate the buoyancy forces, thereby suppressing large-scale buoyant convection cells

Figure 5-8 shows the duration of the boiling period, $t_{\mathrm{bp}}$, as a function of the percentage of the repository included within the calculations and bulk

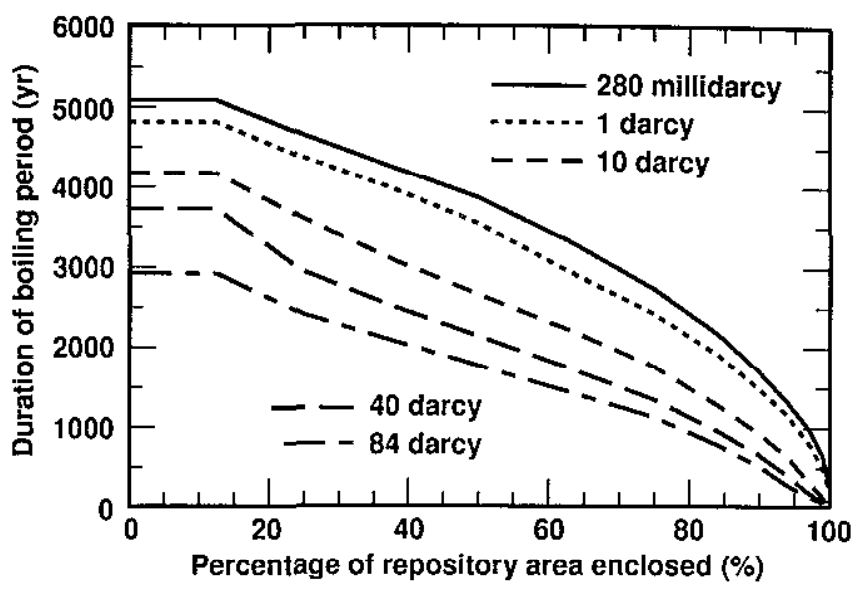

Figure 5-8. Duration of boiling period versus percentage of repository area enclosed, for different bulk permeabilities.

permeability for the 83.4-MTU/acre case The influence of edge cooling is evident Mountain-scale, buoyant, gas-phase convection begins to significantly reduce repository temperatures for $k_{\mathrm{b}}>1$ darcy For $k_{\mathrm{b}}$ $\leq 1$ darcy, duration of boiling is less sensitive to $k_{\mathrm{b}}$ as illustrated by the similar durations for 1 darcy and for 280 millidarcy ( 028 darcy)

For $k_{\mathrm{b}} \geq 10$ darcy, a very early peak in the net buildup of liquid water $\Delta V$ occurs at 500 to $800 \mathrm{yr}$ Fig 5-9(c-e), coinciding with the maximum extent of boiling conditions After the initial peak, $\Delta V$ declines for the high- $k_{\mathrm{b}}$ cases, with a trough occuring at $3000 \mathrm{yr}$, coinciding with the maximum vertical extent of dryout The trough is less pronounced as $\Delta V$ stays well above zero After the trough occurs, the increase in $\Delta V$ resumes until a second peak in $\Delta V$ occurs at around 20,000 to $30,000 \mathrm{yr}$

If the large-scale connected $k_{\mathrm{b}}$ is small enough, mountain-scale, buoyant, gas-phase convection does not result in a liquid water buildup above the repository For intermediate $k_{\mathrm{b}}\left(k_{\mathrm{b}}<1-10\right.$ darcy), for which buoyant gas-phase convection does not dominate vapor flow, the cumulative effects of vapor flow and condensate buildup depend on the magnitude of boiling effects

It is likely that the $k_{\mathrm{b}}$ distribution at Yucca Mountain will be highly variable Some of that variability will be random, while some may be correlated with discrete hydrological features such as fault zones or hydrostratigraphic units like the nonwelded vitric tuff units (PTn) If the $k_{b}$ distribution spans a significant 

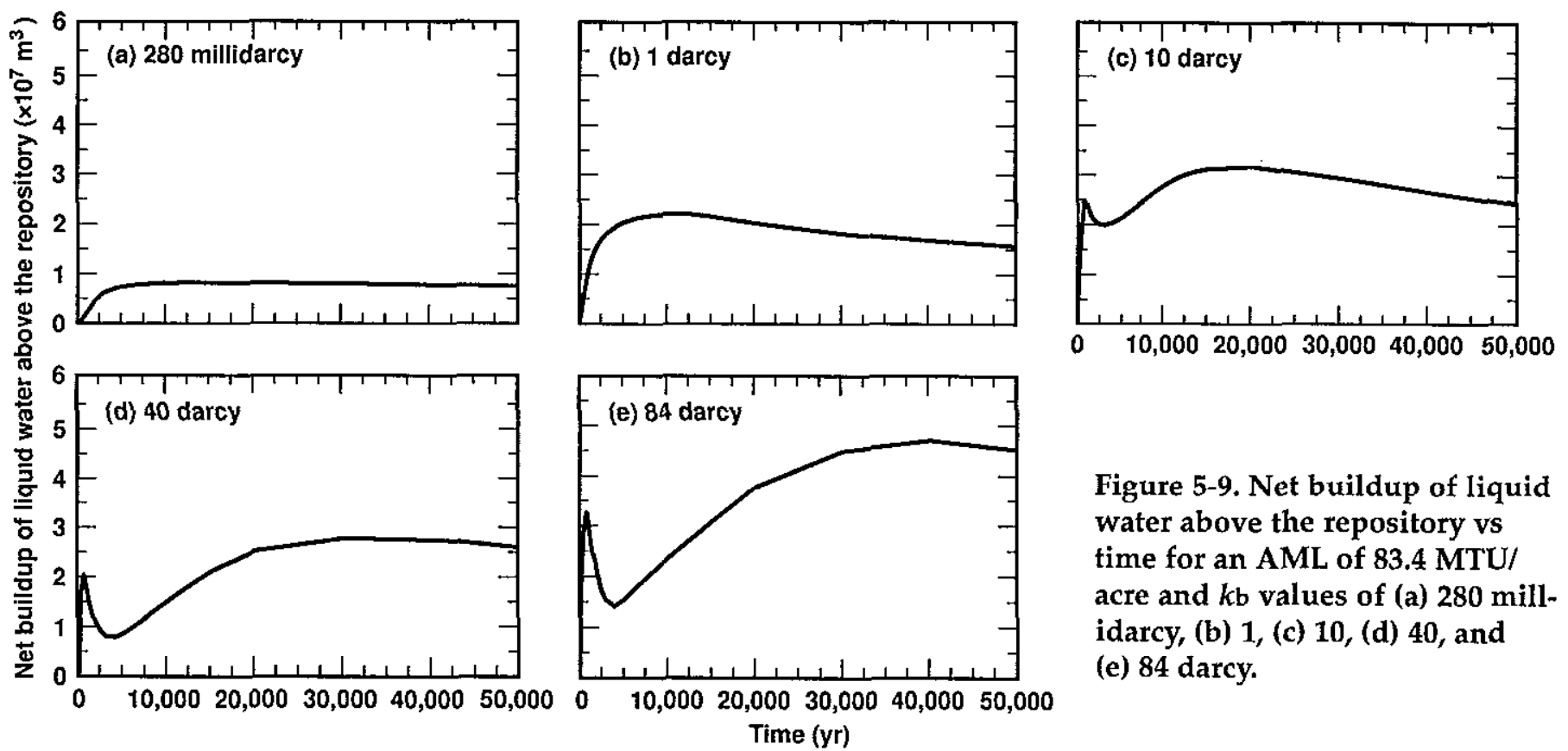

Figure 5-9. Net buildup of liquid water above the repository vs time for an AML of 83.4 MTU/ acre and $k b$ values of (a) 280 millidarcy, (b) 1, (c) 10, (d) 40, and (e) 84 darcy.

Time (yr)

fraction of the range shown in Fig 5-10 (including regions in which $k_{\mathrm{b}}>10$ darcy), then mountain-scale hydrothermal behavior will be more variable for lowto-intermediate AMLs than for high AMLs. If the $k_{\mathrm{b}}$ distribution only spans the lower end of the $k_{\mathrm{b}}$ range $\left(k_{\mathrm{b}}<1\right.$ darcy), then mountain-scale hydrothermal behavior will be less variable for all AMLs The ECM cannot represent nonequilibrium fracture-matrix flow It underpredicts the condensate drainage flux and, consequently, overpredicts $\Delta V_{1}$

5.2.2.2 Heat-Pipe Behavior. Refluxing, or the heatpipe effect, is important to consider because it can affect coupled T-H-M-C processes (that may alter flow and transport properties) in two ways First, refluxing maintains local temperatures near the boiling point, making it more difficult to dry the rock out Consequently, the liquid saturation and relative humidity $R H$ remain high, increasing the likelihood of coupled processes, specifically rock-water interactions. Second, refluxing can generate a very high liquid-phase flux in fractures, which can result in significant dissolution and precipitation of minerals along the fracture walls.

The magnitude and duration of refluxing depend on four factors

- First, there must be a fracture or set of fractures that allow76s vapor from boiling to move above the boiling zone [The classical heat pipe involving porous media will not develop at YM because the matrix permeability Kmatrix is so small that (1) flow

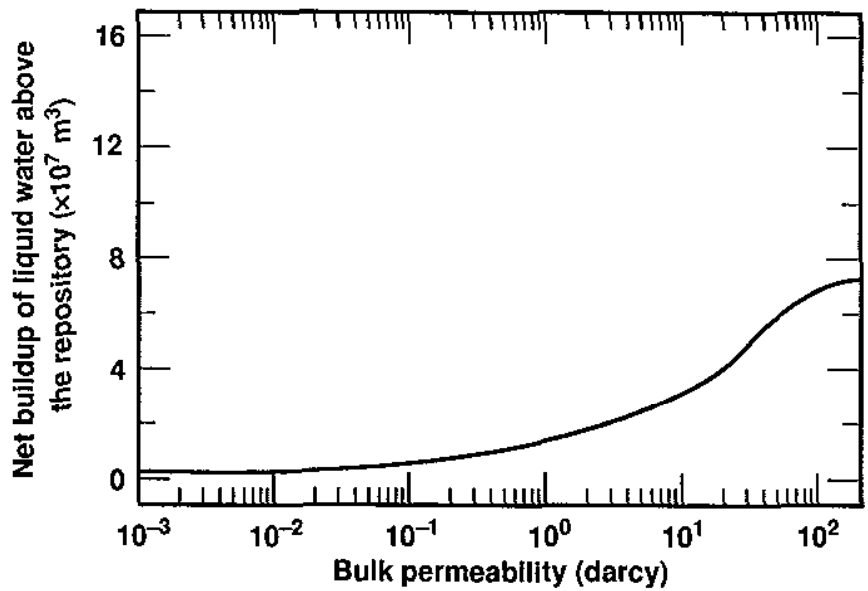

Figure 5-10. Maximum net buildup of liquid water above the repository as a function of bulk permeability for an AML of 83.4 MTU/acre.

will preferentially occur in fractures, (2) the time scale for flow through the matrix would exceed that of the boiling process, and (3) imbibition rates are too low ] Therefore, saturation-gradientinduced flow that would be required for flow through the boiling zone, except as driven by gravity, would not allow for development of a heat pipe This report uses the term gravity-driven heat pipe to make this distinction Thus, the only potential heat-pipe zone is above the boiling zone 
- Second, $\mathrm{kb}$ in the nominally fractured zone must be large enough not to significantly throttle the rate of vapor generation due to boiling (or due to evaporation under sub-boiling conditions)

- Third, a large contrast in $\mathrm{kb}$ between the high- and nominal-kb zones results in a gas-phase pressure differential between these zones that preferentially drives vapor flow into the high-kb zone [Fig 5-7(c)] This is based on the observation that the rock mass contains ubiquitous fractures that are open to vapor flow, but would not support significant liquid flow (Chesnut, 1992) It has been observed that the spacing of the more permeable fractures is greater than that of the smaller and tighter fractures Thus, it would be necessary for a fracture or fractures to exist that would allow vapor to preferentially collect and flow in them so that condensate could return as fracture flow

- Fourth, there must be sufficient spacing between the high-kb zones to drive enough water vapor into these zones to result in the local condensate drainage flux being substantially greater than the mean condensate flux Effectively, the high- $\mathrm{kb}$ zones are competing for a finite quantity of vapor flow and condensate generation Consequently, there is a trade-off between the duration of refluxing and the number of locations where it can occur in the repository If there are too many such zones, there will be insufficient condensate focusing to cause persistent refluxing at the repository horizon The degree of focusing necessary to cause persistent refluxing limits the number of locations where it can occur Therefore, it is unlikely that refluxing can dominate the overall thermal behavior in the repository (or throughout the AZ) See Volume II, Sec 10125 for a more detailed discussion

Heat pipes farther away from the WP heat sources are more likely to persist longer than heat pipes that are closer The reason is that close in, the heat is more influenced by single WP; farther out, the heat is contributed from many WPs Similarly, heat pipes closer to cold WPs in a thermal design in which the WPs are thermally isolated from one another (such as in the ACD design) will be more persistent than those close to hot WPs This variability in the likelihood or duration of heat pipes could lead to a highly heterogeneous distribution of decay-heat-driven alteration in the near field and $\mathrm{AZ}$ At $200 \mathrm{yr}$, the manifestation of focused vapor and condensate flow on the dryout zone is no longer evident, and the two design cases have nearly identical dryout zones (see Fig 101251 , Volume II)

Because heat pipes are manifestations of heterogeneities, they are influenced by the repository design Figure 5-11 shows the total flux calculated to be present in the zone $51 \mathrm{~m}$ above the repository where heat pipes can exist Heat pipes are more likely to exist at early times, as shown in this figure by the shortduration peak in total fluid flux that occurs at about $100 \mathrm{yr}$ Furthermore, the volume of liquid flux for the ACD case is approximately $103 \mathrm{~mm} / \mathrm{yr}$, whereas for the LL case, it is approximately $57 \mathrm{~mm} / \mathrm{yr}$ Thus, there is a potential for significant fluid flux to be present in the reflux zone Figure 5-12 shows the impact of percolation flux for the LL case There is very little impact on the peak fluxes at $100 \mathrm{yr}$ Beyond about $200 \mathrm{yr}$, except for zero ambient percolation flux, there is no real difference between total flux for percolation fluxes from 05 to $50 \mathrm{~mm} / \mathrm{yr}$ other than the magnitude of the percolation flux itself

Based on experience with geothermal reservoirs, some have suggested that heat-pipe zones, spaced every $100 \mathrm{~m}$, have the potential of convecting enough heat away from the repository to prevent its temperature from $x$ ising above the boiling point However, we found for a wide range of AMLs, that the heat-pipe zone could not prevent the temperature exceeding the boiling point beyond about $28 \mathrm{~m}$ from the heat pipe Convection-dominated heat flow occurs in the heatpipe zone, whereas in the neighboring rock, heat flow

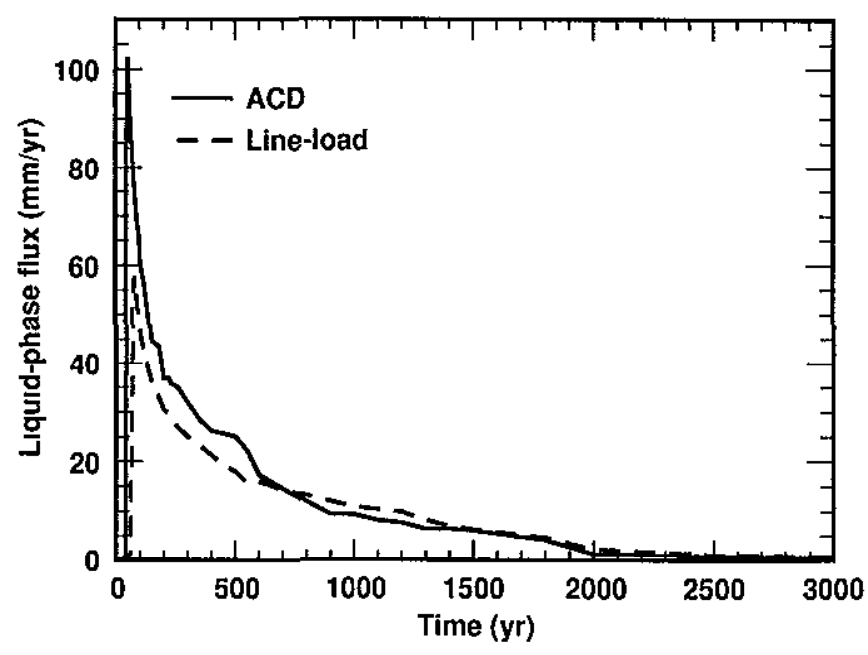

Figure 5-11. Liquid-phase flux $51 \mathrm{~m}$ directly above the emplacement drift for an AML of 83.4 MTU/acre. Curves are shown for Hanford DHLW waste packages. 

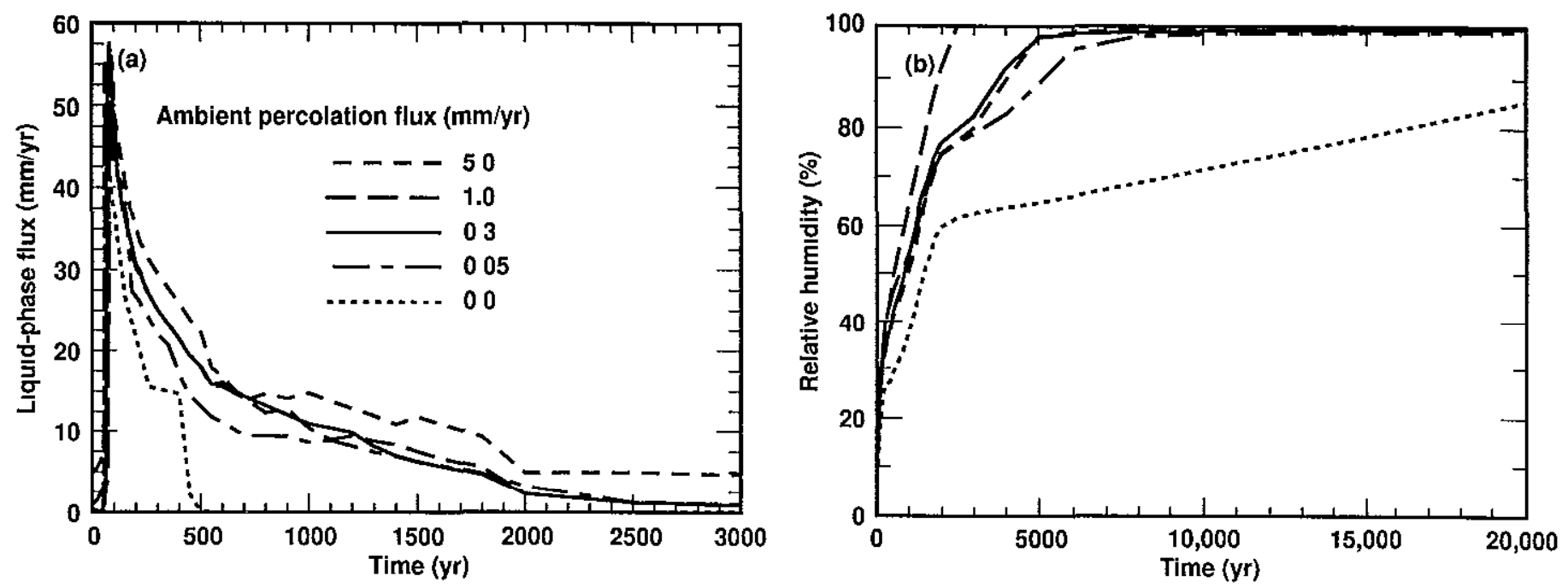

Figure 5-12. (a) Liquid-phase flux $51 \mathrm{~m}$ above the repository horizon and (b) relative humidity in rock at the upper drift wall for the LL design with an AML of 83.4 MTU/acre. Curves are shown for conditions above Hanford DHLW waste packages.

primarily occurs as heat conduction Heat must be conducted from the heat sources (the WPs) to the heatpipe zone for that zone to significantly influence repository temperatures Heat cannot be conducted in relatively low-thermal-conductivity rock unless a significant temperature gradient is established Such a thermal gradient would cause temperatures away from the heat-pipe zone to be elevated above the boiling point

\subsubsection{Influence of Water Vapor and Relative Humidity}

Coupled processes in the $\mathrm{AZ}$ do not require liquid water, they can also occur if water vapor is present. A measure of the availability of water is the relative humidity in the rock mass As noted in Section 102, under ambient conditions, the gas phase in fractures consists of about $985 \%$ air and $15 \%$ water vapor The mole fraction $n_{v}$ of water vapor under conditions of local thermodynamic equilibrium within the rock is a function of liquid saturation $S_{1}$, absolute temperature, $T$, and gas-phase pressure, $P_{\mathrm{g}}$ The mole fraction of water vapor is considerably greater at the repository in response to higher temperatures there

As temperatures rise in the repositoly, the equilibrium amount of water vapor in the gas phase increases because of the increase in $\mathrm{P}_{\text {sat }}(T)$ As temperatures reach the boiling point of water, $P_{\text {sat }}$ approaches $P_{\mathrm{g}}$ and the mole fraction of water vapor approaches unity (i e the gas phase becomes $100 \%$ water vapor)
Gas-phase advection (advective transport of water vapor will occur as long as steam is generated) is likely to be the dominant mechanism transporting water vapor from the boiling zone to the condensation zone except for a rock mass where $k_{\mathrm{b}}$ is sufficiently small $\left(k_{\mathrm{b}}<1-10\right.$ millidarcy) to substantially throttle gas-phase advection and the rate of boiling Beyond the condensation zone, vapor diffusion is the dominant mechanism of vapor movement except where $k_{\mathrm{b}}$ is sufficiently large $\left(k_{\mathrm{b}}>1-10\right.$ darcy) for buoyant gasphase convection to dominate Because temperatures in the vicinity of the condensation zone are close to the boiling point, the water vapor mole fraction is nearly unity, whereas beyond the condensation zone, the temperatures are cooler and the mole fractions are much less (approximately $2 \%$ at ambient conditions) This gradient in mole fraction leads to diffusive fluxes that transport water vapor away from the condensation zone Diffusive vapor fluxes can dominate over convective vapor fluxes around the repository if the vapor generation rate is very low or if temperatures are close to, but below, the boiling point

The amount of water calculated to be involved in (or mobilized by) convection is orders of magnitude larger than any estimates of later al flow. Therefore, the ignoring of advective heat removal by lateral flow is not considered to be a significant issue

As the repository heat generation decays, water vapor continues to diffuse away from the repository because of the higher temperatures there This diffusion 
of water vapor contributes to latent heat transport In general, water vapor diffuses away from the repository until repository temperatures have decreased to the point that the temperature effect (that drives water vapor away from the repository) can no longer overcompensate for the vapor-pressure lowering effect This "vapor-pressure lowering" effect is significant only at $S_{1}<20-30 \%$ Consequently, vapor diffusion will only significantly contribute to rewetting the dryout zone for $S_{1}<20-30 \%$ For $S_{1}>20-30 \%$, rewetting of the dryout zone will be dominated by liquidphase advection driven by matric potential gradients and gravity The length of time during which diffusive vapor transport dominates rewetting behavior depends on

- How dry the dryout zone becomes

- The range of Sl that is associated with high matric potential.

- How quickly repository rock temperatures decline

The longer that the dryout zone remains dry, the higher the value of $S_{1}$ limit for which vapor-pressure lowering dominates rewetting behavior The faster repository temperatures decrease while still in the high-matric-potential (i e , dry) regime, the longer the duration of significant gas-phase diffusion of water vapor back to the dryout zone

\subsubsection{Overburden Thickness}

For a discussion of the effects of overburden, refer to Sec 1014 of Volume II

\subsection{Thermal-Hydrology in the Saturated Zone}

For $t>1000 \mathrm{yr}$ (after repository temperatures have peaked), the saturated zone (SZ) begins to heat up significantly, as shown in Fig 5-13 These calculations do not account for advective transport of heat by lateral flow of water within the SZ Thus, the predicted temperatures and convection reported here are upper bounds Consequently, the duration of boiling $t_{\mathrm{bp}}$ substantially increases, particularly for higher AMLs $\left(t_{\mathrm{bp}}\right.$ " $1000 \mathrm{yr}$ ) More importantly for AZ considerations, the temperatures are sufficiently elevated above ambient that issues of rock-water interactions arise As noted, the duration of the elevated temperatures is long

Because water has been present for long periods, and the water mobilized by emplacement will not necessarily elevate the water table, the rock-water interactions that have been occurring in the past repiesent those that will occur in the future Heat affects the kinetics, not the reactions themselves, at the temperatures shown in Fig 5-13 To date, the analyses of coupling in the AZ have not considered the saturated zone to any real extent Preliminary results indicate that, in gener al, changes are small, but there could be significant changes (up to $30 \%$ ) in porosity in some units Analyses of $A Z$ effects in the saturated zone will be incorporated in subsequent revisions of this report

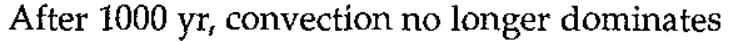
heat flow in the SZ However, heat flow continues to dominate vapor and, as vapor condenses, fluid flow This dominant influence of decay-heat-driven flow was found to occur for all AMLs investigated As the SZ temperatures (below the repository footprint) rise, the accompanying decrease in mass density results in

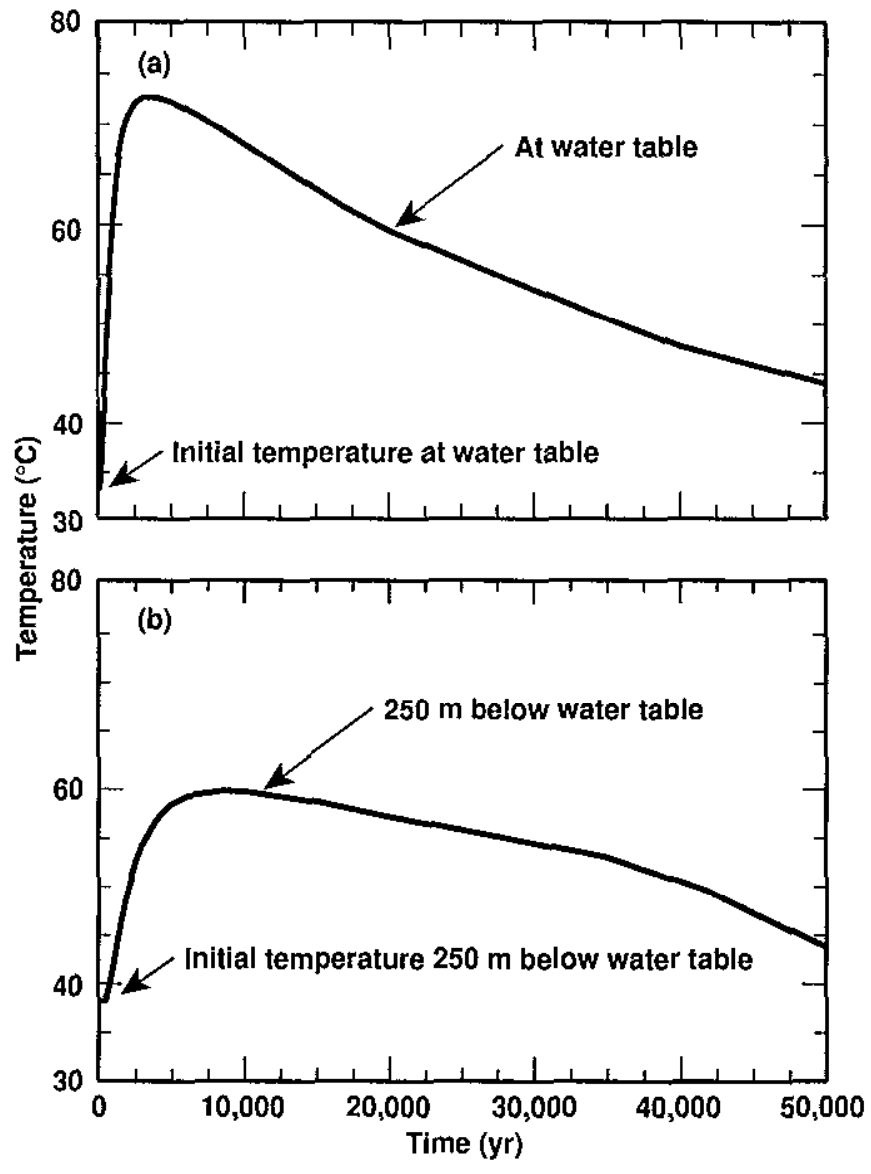

Figure 5-13. Temperature history at locations below the center of the repository (a) at the water table and (b) $250 \mathrm{~m}$ below the water table. AML = 83.4 MTU/acre. 
significant upward component of flow from considerable depth, generating buoyant convection cells This, of course, depends on the hydrologic continuity with depth If the strata prevent continuity, then convection will not occur to the same depth or extent, and smaller convection cells will result.

Decay-heat-driven convection cells in the $\mathrm{SZ}$ require tens of thousands of years to fully develop As the thermal pulse from the repository propagates both vertically and radially into the SZ, the region over which decay-heat-driven convection occurs continues to expand during at least the first 20,000 yr (Fig 5-14) As this region expands, additional parallel convection cells are added to the convective system After $1000 \mathrm{yr}$, multiple (two distinct) convection cells (one on each side of the symmetry axis) have developed (in cross section), extending radially $\sim 2$ to $3 \mathrm{~km}$ from the repository center After $5000 \mathrm{yr}$, the radial extent of repository-heat-driven convection is $\sim 5 \mathrm{~km}$ [Fig 5-14(a)]. After $10,000 \mathrm{yr}$, the radial extent of the convection cells is $\sim 8$ to $10 \mathrm{~km}$ After $20,000 \mathrm{yr}$, the radial extent of the convection cells exceeds $10 \mathrm{~km}$ from the repository center [Fig 5-14(b)] Because the matrix permeability of the $\mathrm{SZ}$ is presumably quite small, these large-scale, buoyant convection cells require large-scale connectivity within the fracture system Because the temperatures will be elevated, significant alteration is possible through rock-water interactions This could impact the connectivity and interrupt convection In addition, the convection shown is based on uniform hydrologic properties with depth below the water table In reality, the YM system is dominated by strata with greatly differing hydrologic properties, including strata-determined fracture patterns and extent. Therefore, the more likely case will be a series of smaller convection cells However, the temperature increases will be significant, and convection will not dominate heat flow in the $S Z$, thus the temperatures shown in Fig. 5-14 would be representative regardless of the convection patterns

\subsection{Altered Zone Geochemistry and Mineralogy}

The purpose of the research summarized in this section is to establish the accuracy of long-term simulations of geochemical processes expected to take place in the AZ The approach has been to evaluate the parameters that influence uncertainty in simulations, which are
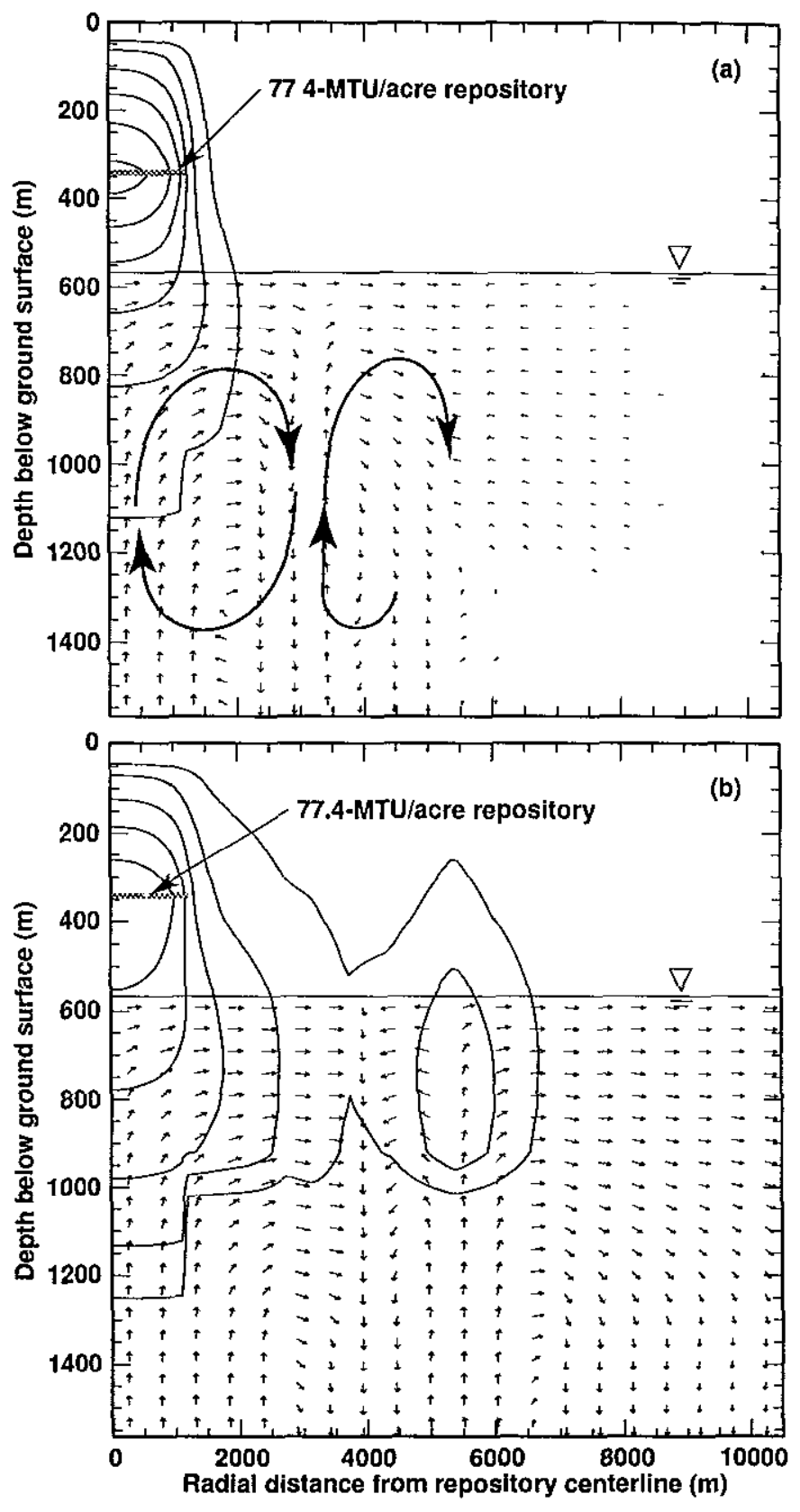

Figure 5-14. Contours of temperature rise above ambient and velocity vectors for liquid-phase flow in fractures in the SZ for AML = 77.4 MTU/acre, 30-yr-old SNF, 1118-acre repository area, and ambient percolation flux $=0 \mathrm{~mm} / \mathrm{yr}$ at (a) 5000 and (b) $20,000 \mathrm{yr}$. Temperature contour interval is $5^{\circ} \mathrm{C}$. Liquid-phase velocity vectors are scaled logarithmically from 0.03 to $1600 \mathrm{~m} / \mathrm{yr}$. Larger arrows in (a) denote the convection cells described in text. 
primarily error in reaction rate constants and thermodynamic properties This has been done by conducting simulations using the extreme values for rates of dissolution of certain minerals, by comparing field- and laboratory-based measurements of precipitation rates for silica polymorphs, and by conducting plug flow reactor experiments and comparing the results with simulations using the reactive transport simulator GIMRT

The results of the rate studies indicate that the uncertainty in dissolution kinetics will have a more significant affect on numerical simulation results than will the much faster precipitation rates This conclusion assumes that nucleation effects are not rate limiting.

Given knowledge of the uncertainty in reaction rate constants, it is then possible to conduct simulations that are constrained to use rates that fall within these uncertainty envelopes The results of this effort demonstrate an excellent correspondence between experiments and simulations, indicating that the conceptual models of reaction process are accurate

On this basis, it is then possible to develop with some confidence first-generation descriptions of the long-term mineralogical evolution of the $\mathrm{AZ}$ The accuracy of these results is directly dependent on numerical representation of the thermal-hydrological regime Further refinements of these simulations will be developed as the ability to couple thermal-hydrological models with reactive transport models improves

Geochemical processes that will occur as a result of emplacement of waste will depend on the heat transferred into the rock surrounding the emplacement drifts and the hydrological regime associated with that heat As shown in Fig. 5-15, elevated temperatures couple (see yellow arrows) to mineralogy and solid material conditions by several geochemical processes The processes include dehydration, rock-water and material interactions, and changes in the volume and chemistry of water that is available for geochemical reactions The consequences of geochemical effects will depend on the rate of temperature change, the maximum temperature reached, and the flux of water and vapor through the rock For any given emplacement scenario, the rate at which temperature changes occur depends, in general, on the distance from the heat source The further the distance, the slower the heating rate Such temperature behavior has led to the conceptual model in which NFE effects are distinguished from $\mathrm{AZ}$ effects by whether dominant processes are kinetic or equilibrium reactions

\subsubsection{Summary of Recent Studies}

This section summarizes four studies that considered the geochemical and mineralogical evolution of the $\mathrm{AZ}$ More detailed information is provided at the end of the summary

- Hydrothermal alteration of vitric tuff. Vitic material typical of the TSw3 unit and the vitric Calico Hills lithology, as a function of time, is sensitive to temperature (as expected from well-established models of reaction kinetics), and to the extent of prior alteration

- Amorphous silica precipitation. Rate measurements show that the field-based rates are 10 to 300 times faster than those measured in the laboratory Observations suggest that these differences are sensitive to temperature, and may be influenced by the presence of other chemical species in solution The precipitation mechanism in the field may be controlled by surface defects

- Preliminary bounds on the water composition and secondary mineral development. This study considered the effect of temperature and uncertainty in reaction kinetics to place limits on fluid composition for devitrified and vitric tuffs interacting with a J-13-like water over a 1 ange of temper atures The simulations assumed that fluid was in equilibrium with atmospheric gases The results indicate that water compositions remain mildly oxidizing and slightly to mildly alkaline ( $\mathrm{pH}$ between 75 and 88 ) for most conditions The exception was that in which very large water volumes interacted with small volumes of vitric material In that case, the buffering effect of atmospheric gases was overwhelmed, and the solution became acidic This may be the case for large volumes of condensate draining, however, the only way for condensate to drain is by fast fracture flow Thus, the large volumes of water relative to rock volumes would not remain within the UZ and could only exist in SZ or ponded areas if imbibed into the matrix The fracture volume is too small relative to the rock However, on a local basis, the water volume in fractures versus the fracture coating volume might be considered high Secondary minerals that formed were sensitive to the extent of reaction and temperature In most cases, zeolites and clays were formed, with minor to trace amounts of other minerals Uncertainty in the time at which secondary minerals form can be as great as hundreds to thousands of years 


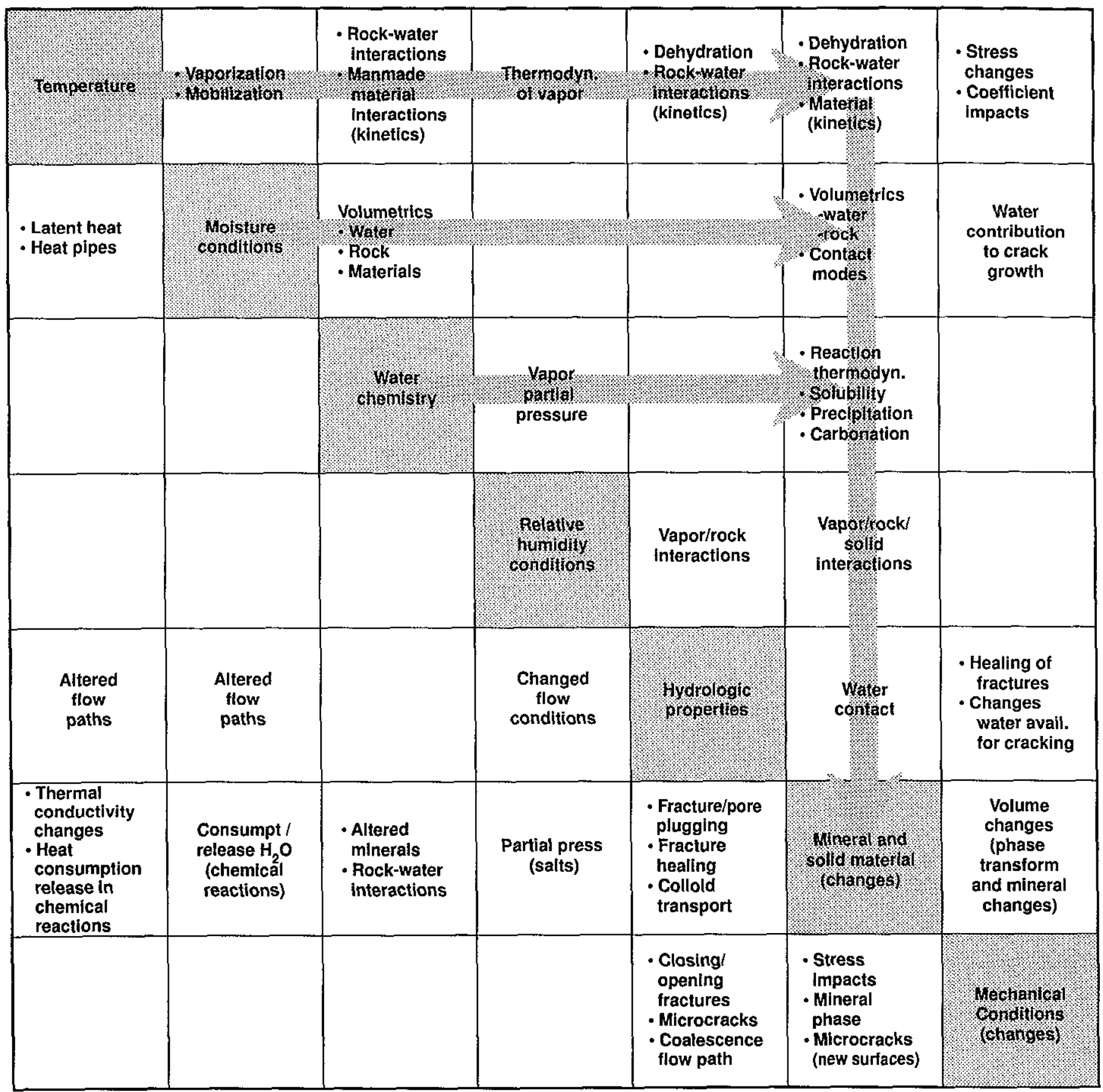

Figure 5-15. Matrix of coupled geochemical and mineralogical processes. 
- Reactive transport simulations. Porosity modification was monitored during dissolution and precipitation of a wide range of silicates along a flow path similar to that expected for water condensed from steam generated in the NFE The results show that porosity may more than double in devitrified and welded tuff, due to the dissolution of cristobalite in the regions immediately adjacent to the condensation front As these waters migrate along and across isotherms, the dissolved constituents eventually precipitate as complex silicates, reducing porosity, and forming altered regions composed of zeolites, clays, and hydrated alumino-silicates The complex coupling of fluid flow and reactive chemical transport demonstrates that large changes in bulk rock hydrological properties may occur within a few hundred years of repository operation As was noted in Section 52.21 and on Fig 5-6, the condensation zone may remain in place for thousands of years, therefore this change in hydrologic properties may be quite significant.

These results are expected to be the foundation upon which refined estimates of mineral facies would be developed for specific repository scenarios of waste emplacement strategies, infiltration fluxes, and rock properties These scenarios have yet to be developed Future work will focus on developing these mineralogical and chemical scenarios, and on reducing the uncertainties in key thermodynamic and kinetic data to better bound the behavior of the repository

\subsubsection{Hydrothermal Alteration of Vitric Tuff}

Alteration of the basal vitrophyre of the Topopah Spring Tuff (TSw3 unit) represents a potentially profound modification of the lithologic units that compose the potential repository block at Yucca Motuntain The results of earlier hydrothermal alteration experiments, in which the devitrified (repository-equivalent) $\mathrm{TS} w$ was reacted with well $\mathrm{J}-13$ water at $150^{\circ}$ and $250^{\circ} \mathrm{C}$, showed that the primary alteration products were the $\mathrm{Ca}$-rich, mordenite-type zeolite, dachiardite, and mordenite itself (Knauss et al, 1987) Aqueous $\mathrm{SiO}_{2}$ activity was controlled by cristobalite saturation. Fluid chemistry was in accord with the production of these zeolites In contrast, results of earlier hydrothermal alteration experiments, in which the vitric airfall/ashflow at the base of the TSw was reacted with well J-13 water at $250^{\circ} \mathrm{C}$, showed production of the zeolite clinoptilolite, exclusively (Knauss, 1987)
Knauss continued the series of runs using vitric airfall/ashflow from the base of the TSw and found that even after 6 months at $150^{\circ} \mathrm{C}$, the $\mathrm{SiO}_{2}$ activity remained below amorphous silica saturation, and no zeolites precipitated However, at $350^{\circ} \mathrm{C}$, amorphous silica saturation was quickly reached, and the glass was completely consumed by the end of the run Because the temperatures generated by waste disposal are well below $250^{\circ} \mathrm{C}$, this would imply that zeolites and clays would be formed at the base of the TSw, but their exact compositions remain to be established

Hydrothermal alteration of TSw vitrophyre in well J-13 water was also studied(Knauss, 1987) Although compositionally identical to the vitric basal airfall/ashflow material, the vitrophyre has a much smaller specific surface area At $250^{\circ} \mathrm{C}$, it is clear from SEM/EMP analyses that early in the run the dominant product was a clay, but as the run progressed, the zeolite clinoptilolite became the major product Given sufficient time and reaction progress, one would expect the vitrophyre to result in mostly zeolite alteration

Knauss also studied hydrothermal alteration of naturally zeolitized TSw in well J-13 water at $90^{\circ}$ and $150^{\circ}$. No new run products were identified in either run, and there was no obvious evidence of dissolution

Preliminary results from the three experiments to study the hydrothermal alter ation of vitric Calico Hills Tuff (Tchnv) at $90^{\circ}, 150^{\circ}$, and $250^{\circ} \mathrm{C}$ contrast with those from the other experiments Whereas the basal airfall/ashflow and vitrophyric TSw samples were largely fresh (unaltered) glass, the vitric Tch material contained a significant amount of smectite. The smectite was observed to coat the matrix shards and pumice lapilli These results demonstrate that the presence of secondary minerals in the vitric tuffs may accelerate, relative to rates of formation in "pristine" vitric materials, the formation of a new generation of minerals under repository conditions. By implication, this leads to the conclusion that alteration of the underlying vitric material will not be rate limited by nucleation effects or alteration minerals

\subsubsection{Amorphous Silica Precipitation}

To ascertain how quickly alteration of the nearfield and altered zone will occur, it is necessary to rigorously determine the dissolution and precipitation rates of minerals that are present in the mountain in its ambient state, and which may form at future times 
Some laboratory measurements have been conducted using pure mineral phases and simple, controlled solutions. However, it has often been noted that inferences of rates from field measurements are not consistent with laboratory measurements Therefore, experiments were conducted in the field to measure the precipitation rate of amorphous silica, a mineral that may play an important role in the evolution of the mountain system

Dissolution of silica in response to water movement at elevated temperatures and subsequent ptecipitation of silica on cooling may affect local porosity and permeability Changes in porosity and permeability will, in turn, affect flow pathways, imbibition, and heat transfer A study was conducted to measure rates of precipitation in natural and laboratory settings as the first stage of an effort to place bounds on kinetic effects over a range of humidities (Carroll et al , 1996, in Sec 104.2 , Vol II, Johnson and Glassley, 1996, in Sec 104.4 , Vol II)

This study confirmed the need of complementary laboratory and field studies to determine the factors that control mineral-water interactions in tuff Amorphous silica precipitation rates appear to be controlled by distinct mechanisms in laboratory versus field studies Rates from a field study are 10 to 300 times higher than those predicted from laboratory experiments The deviation in rates increases as temperature decreases and solution composition increases, and may be influenced by the presence of other chemical species in solution The precipitation mechanism in the field may be controlled by surface defects, such as dislocation or impurities

These results indicate that laboratory measurements of precipitation rates may significantly underestimate the rates at which alteration minerals will form in the natural system when perturbed by repository heat Mineral precipitation rates may be considered instantaneous for modeling purposes, and the primary rate-limiting step in alteration processes will be the dissolution kinetics of mineral phases

\subsubsection{Bounds on Water Composition and Secondary Mineral Development in the AZ}

Heat-driven evaporation, boiling, and condensation processes will lead to movement of water vapor away from the repository, resulting in increased saturation of some rocks within some parts of the repository block (Nitao, 1988, Buscheck and Nitao, 1992,

1993) The saturation may approach $100 \%$ under some operation scenarios after waste is emplaced. During cool down, or as a result of fracture flow or dehydration of hydrous minerals, it is possible that liquid water may return to or enter the NFE, or may affect rock units bounding the repository horizon. Most of the minerals currently present in the rock making up the potential repository horizon are not in thermodynamic equilibrium with water at elevated temperatures, nor is the glassy material preserved within the PTn or the TSw3 units As a result, water will interact with existing minerals and glass, causing new minerals to form, existing minerals to change their compositions or dissolve, and modifying the water chemistry in the process Therefore, a range of simulations were conducted to establish how the mineralogy and water chemistry will evolve as a function of time To account for uncertainty in the rates at which reactions may procede, as described in Section 54.3 , simulations were conducted assuming that the rate constants of dissolution and precipitation reactions could have a plus or minus error of an order of magnitude

The extent to which reactions will progress in the near-field and AZ systems may be limited by water availability In such cases, the natural systems will only progress part way along the reaction paths suggested by the modeling described here In these studies, the initial water composition reacting with the rock materials was assumed to be that of J-13 water The composition used was the average composition reported in Harrar et al (1990)

5.4.4.1 Results. The water compositions and secondary mineralogies obtained at steady-state conditions, at a given temperature, for the tuffs are constrained by the fixed composition of the starting material, and the solubilities of the starting phases For vitric material, however, dissolution is treated as though it is congruent, hence, the amount of material dissolved (or, in other words, the extent of reaction progress) will determine the mineralogical products and water chemistry In this case, therefore, a steadystate composition will not be achieved, except under extreme conditions in which very high absolute amounts of glass are dissolved

The mineral suites described here must be considered representative "facies" of the assemblage of minerals that may form, and not absolute descriptions of the specific identities of minerals that will be present In particular, the occurrence of zeolites, such as mesolite, clinoptilolite, and stilbite, or the occurrence of muscovite in simulations must be taken to indicate that a zeolite(s) and a sheet silicate are 
expected to form, but the specific composition of those phases will depend on local effects that cannot be accounted for a priori

Throughout reaction progress, saponite (a clay), carbonate, and fluorapatite are present at low abundances at all temperatures These phases are joined by clays (celadonite and smectite), authigenic feldspar (microcline), and zeolites (clinoptilolite at low temperature, stilbite at $50^{\circ}$ and $75^{\circ} \mathrm{C}$, with mesolite present throughout the temperature range), relatively early in the reaction progress period, and they persist to steady-state conditions The actual time of appearance of specific phases depends on temperature At $40^{\circ} \mathrm{C}$, impor tant secondary alumino-silicate phases do not appear until after approximately 100 days of reaction progress At temperatures greater than $50^{\circ} \mathrm{C}$, important alumino-silicates appear within a few days However, in all cases, steady-state conditions with relatively high abundances of secondary minerals are not approached until thousands of days have elapsed In all cases, one of the last phases to appear is a silica polymorph (in this case, chalcedony), but it quickly becomes the most abundant secondary phase At high temperatures $\left(90^{\circ} \mathrm{C}\right)$, garnet and tremolite appear in the secondary mineral assemblage These phases probably would not be the stable phases that would form under these conditions, given evidence from metamorphic petrology in low-temperature systems. Their presence in the simulations attests to the limitations of the thermodynamic data currently available

The initial water composition reflects equilibration of J-13 water at the temperature of the simulation At all temperatures, this initial composition is moderately alkaline (pH of $\sim 85$ ), oxidizing ( $\mathrm{Eh}$ between 580 and 680 millivolts), and has a low ionic strength ( 0.0028 molal). Concentrations of the dissolved elements are low

Water composition remains relatively constant at a given temperature, until reaction progress reaches approximately 100 days At that point, the composition changes significantly due to formation of secondary mineral phases, and dissolution of significant quantities of the rock components. Calcium and magnesium are both largely removed from solution due to precipitation of carbonates and, to a lesser extent, a variety of silicates Thus, as long as the system is changing and dynamic, we would not expect significant changes in secondary mineral phases; however, once conditions become stable (e g , $50 \mathrm{yr}$ after emplacement), it will only take a few years to experience significant changes
$\mathrm{Na}, \mathrm{Si}$, and $\mathrm{Al}$ increase significantly, because the amount added to solution by dissolution of the solids is much greater than the amount removed by precipitation Nevertheless, the final concentration reached for these elements is controlled by the solubilities of the major secondary phases Silica, for example, is buffered at chalcedony saturation, at steady-state conditions Therefore, in the $\mathrm{AZ}$, where temperature and saturation remain relatively stable for long times, it is expected that silica will be in equilibrium with chalcedony saturation

The redox state is effectively determined by the assumption that the solution is in equilibrium with atmospheric gases Although this may not be the case within the drifts at early times, it is most likely to be the case in the AZ Hence, total oxygen is assumed to be maintained at approximately $20 \%$ of the coexisting gas phase

Variation in $\mathrm{pH}$ is strongly controlled by the fact that $\mathrm{CO}_{2}$ fugacity is fixed in these simulations These results differ somewhat from those described in Sec 341 of Volume II, where water evaporation was modeled In the latter study, the effect of including rock interaction with the water was not considered The $\mathrm{pH}$ remains relatively alkaline when $\mathrm{CO}_{2}$ is controlled by atmospheric gases Results of the single heater test (SHT) indicate that within the active boiling regime, excess $\mathrm{CO}_{2}$ is generated by rock-water interactions This would change the $\mathrm{pH}$ conclusions However, it is unknown whether excess $\mathrm{CO}_{2}$ will be generated within the $A Z$ That generated in the boiling zone could flow into the $A Z$, but after the initial thermal perturbation, the excess $\mathrm{CO}_{2}$ should decrease

The conservative elements $\mathrm{Cl}, \mathrm{F}, \mathrm{Li}$, and $\mathrm{P}$ showed no significant variation during reaction progress because they are not incorporated into any secondary phases that form in significant quantities

For dissolution of relatively small volumes of glass, the secondary phases that form during reaction progress are similar to those formed in the tuffs (pyrolusite, clays, and zeolites), except for the respective amounts of secondary phases These results are qualitatively consistent with the description of glass alteration (Levy, $1984 a, b)$ in the vicinity of Yucca Mountain The main exception is calcite, which persists to the end point of the calculations for all temperatures except $40^{\circ} \mathrm{C}$

Dissolution of large volumes of glass rather quickly achieves a state in which the only secondary phases that are present are pyrolusite, chalcedony, and hematite In none of the simulations with vitric material was muscovite or microcline present as reaction products at any temperature 
Water composition in simulations involving small degrees of glass dissolution reached end points that were nearly identical to those for the tuff-water system The simulations involving large volumes of glass ultimately achieved much higher total concentrations of all elements except $\mathrm{Si}$, which dropped to very low values controlled by large volumes of precipitated chalcedony In addition, at high degrees of glass dissolution, pH drops, reaching acidic values $(\sim 38)$ in the low temperature simulations and slightly alkaline $(\sim 78)$ at the $90^{\circ} \mathrm{C}$ simulation This $\mathrm{pH}$ behavior primarily reflects the effects of temperature, the glass chemistry components, and the solubility of C-bearing aqueous species (e.g, $\mathrm{HCO}^{3-}$ ) and solids on $\mathrm{pH}$ In these simulations, total dissolved elemental carbon decreased by three orders of magnitude, which will profoundly influence alkalinity

To evaluate the effects of uncertainty in reaction rate constants on mineral development, simulations were conducted in which sanidine dissolution rate was varied by an order of magnitude, plus or minus This was done to document the effect of this uncertainty on time predictions of when specific minerals will appear or vanish during the reaction progress The results shown in Fig 5-16 for sanidine abundance demonstrate that the propagated error increases with time, until sanidine vanishes The error bars represent uncertainty regarding the amount of the mineral present at any given time. The error in predicting when a phase appears or disappears from the model can be substantially greater than the prediction of the amount made For example, the maximum uncertainty in the amount of sanidine produced is about $50 \%$, but

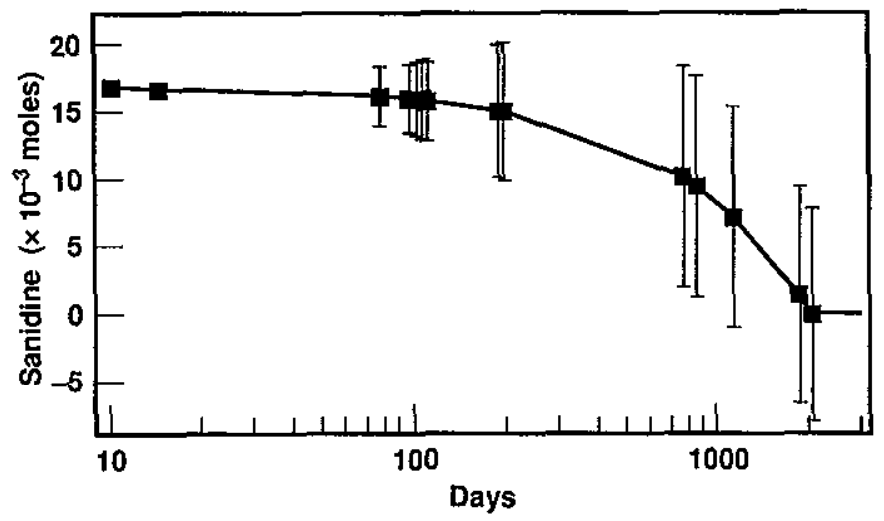

Figure 5-16. Estimates of sanidine abundance over time. the uncertainty of when it is consumed is from about $-60 \%$ to $+2100 \%$

5.4.4.2 Conclusions. These simulations were designed to be preliminary for bounding water compositions that could evolve within the $\mathrm{AZ}$ and migrate into the NFE, and for bounding the mineralogy that could evolve in the $A Z$ The key constraints upon which the simulations were based and details of the uncertainties are discussed in Sec 10434 of Volume II The results provide bounds on secondary mineralogy and water chemistry and are a baseline from which further refinements in simulation strategies can be developed

The results document that the timing of mineral development is most sensitive to dissolution kinetics Precipitation kinetics are sufficiently fast that they do not significantly influence mineral development for most mineral phases This knowledge allows uncertainty limits to be quantified for projections of mineral development based mainly on dissolution kinetics

These results also complement studies of the thermodynamic properties of mineral phases (Bruton, 1996, in Sec 342 , Vol II) documenting that specific types of minerals (facies) can be accurately predicted during evolution of the repository However, the development of individual mineral compositions is less accurately predicted The studies also provide quantitative descriptions of the uncertainty expected in simulations of the evolution of the $\mathrm{AZ}$

Retardation of radionuclides passing through the AZ is directly related to the identity and abundance of minerals along the flow path These results show that an analysis of radionuclide transport must consider the effects of water chemistry as well as the impact of dissolution kinetic and thermodynamic properties on the models

\subsubsection{Formation of Flow and Transport Barriers in the $\mathrm{AZ}$}

Thermal gradients and resultant advective mass transport within the $\mathrm{AZ}$ will invariably lead to porosity evolution as a consequence of reactioncontrolled mineral dissolution and precipitation both along fractures and within bounding matrix blocks (Fig 5-17) Preliminary reactive transport modeling conducted in FY 1995 suggested that these processes might result in significant modification of flow porosity both above and below the repository (Glassley, 1995) 


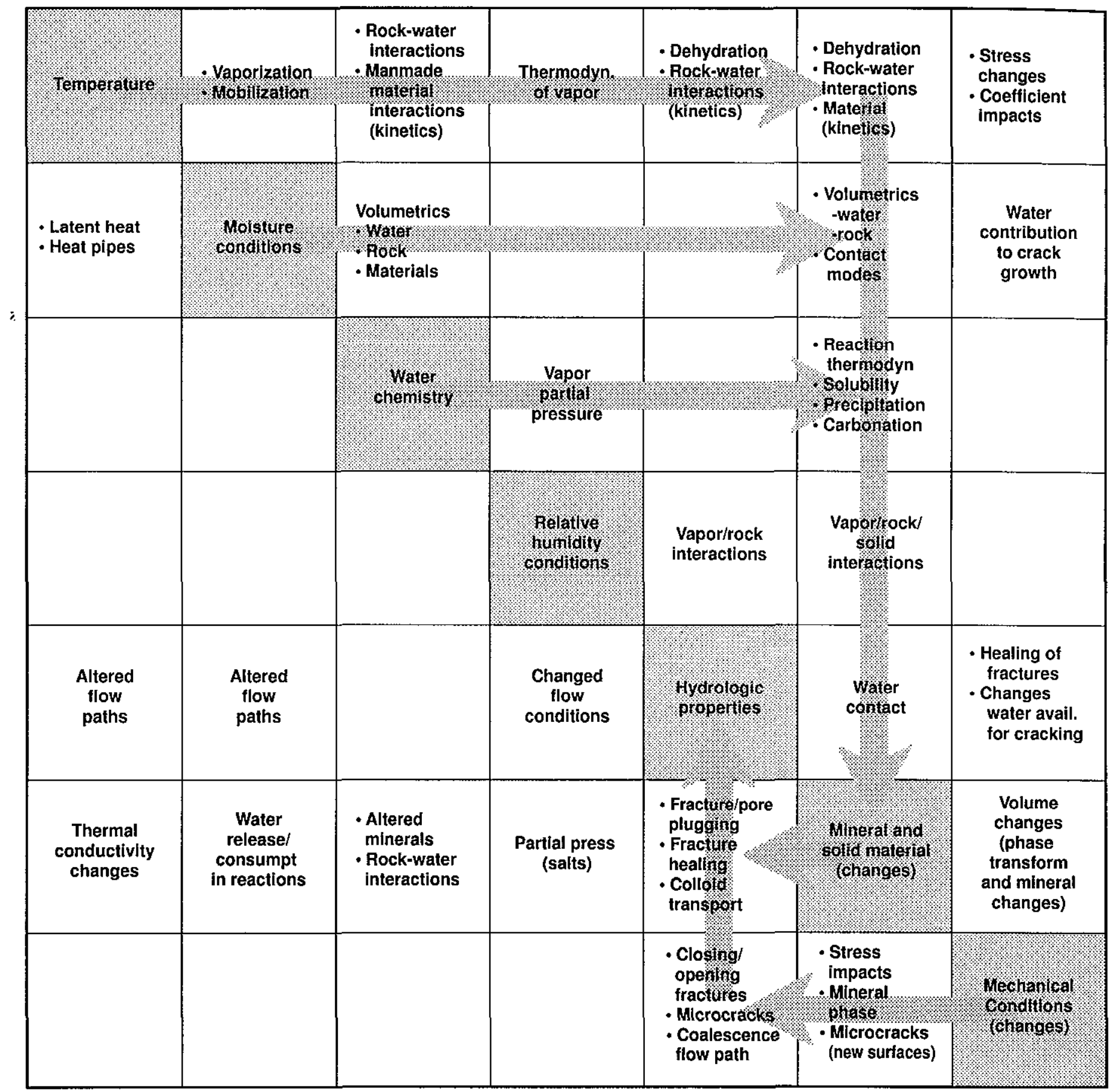

Figure 5-17. Matrix of coupled processes. 
Reactive transport simulations can be viewed as an iterative, five-stage process, in which the steps are 1 Precise specification of the initial chemical and hydrologic state of the fluid-rock system

2 Translation (which often includes approximation) of the specifications into the analogous model parameters of the software

3 Specification of cer tain system-independent numerical parameters

4 Successful execution of the software

5 Interpretation of calculated results

Using this five-stage process, the approach taken in this study was to first establish the validity of the software-encoded numerical model by successfully predicting the outcome of two well-characterized, experimentally verifiable "benchmark" problems Next, increasingly complex, yet still experimentally verifiable problems having some relevance to porosity evolution in the backfill zone were addressed Finally, a critical simulation that cannot be addressed directly by physical experiment was carried out modeling of long-term porosity evolution in the AZ. These benchmark comparisons are reported in more detail in Sec 10441 of Volume II and provide some confidence that the results of the verification are realistic, if not exact Only those simulations that apply to the $\mathrm{AZ}$ are reported here

\subsubsection{Compositional Specifications and} Parameterization of the AZ. The composition and relative abundance of mineral phases in the potential repository host rock, the Topopah Spring Tuff of the Paintbrush Group (TSw2), have been determined experimentally by Warren et al. (1984), and translated into model compositions/abundances by Delany (1985) for use in EQ3/ 6 calculations Because GIMRT, unlike EQ3/6, is not yet configured to account for solid solutions, it is necessary to further approximate Delany's (1985) model TSw2 mineralogy by resolving its alkali feldspar and plagioclase compositions into the corresponding end-member $\mathrm{K}$-feldspar, albite, and anorthite components $\mathrm{Mg}$-beidellite and biotite compositions compose only 11 volume\% of the TSw2, and they represent the only $\mathrm{Mg}$ - and Fe-bearing phases in the system In these preliminary simulations, $\mathrm{Mg}$-beidellite and biotite were eliminated from the model TSw2 composition

The fluid phase anticipated to form within, and react with, the TSw2 in the $A Z$ is derived from condensation of a vapor phase moving radially outward from the repository (Buscheck et al , 1993)
This condensate is likely to be a highly dilute, neutral$\mathrm{pH}$ fluid The fluid was modeled to initially contain very low concentrations of aqueous ions and complexes augmented by the additional component $\mathrm{CO}_{2}$, which is necessary owing to the presence of atmospheric gases Again, a cautionary note regarding $\mathrm{CO}_{2}$ beyond atmospheric is made The initial fluid composition, specified as the log molal concentration of basis species and given in Table 5-1, is much more dilute than J-13, reflecting its condensation from a vapor phase.

We employed the thermodynamic data base typically used with both the original and our modified ves sion of GIMRT, mastertemp data, which is a reformatted version of the "composite" data base distributed with the EQ3/6 software package (Wolery, 1992) Two distinct AZ environments were addressed with GIMRT The first was the localized, interior backfill environment The second was the much largerscale, relatively outlying condensation zone (Buscheck et al., 1993), where gravity-driven flow of vaporexsolved fluid represents the most likely catalyst for significant, long-term porosity evolution in the $\mathrm{AZ}$

5.4.5.2 Backfill Simulations. We used crushed TSw material having an initial porosity of $40 \%$, where a constant outlet flux of $2667 \mathrm{~m}^{3} / \mathrm{m}^{2} / \mathrm{yr}$ was maintained over six months Because the porosity of actual backfill material and especially the in situ fluid flux are likely to be lower than the adopted values, the simulations provide an upper bound to the potential magnitude of porosity evolution

In the first TSw2-backfill simulation, the system was maintained in isothermal equilibrium at $90^{\circ} \mathrm{C}$ Steady-state saturation indices for all primary and

Table 5-1. Summary of infiltrating fluid composition used in this study. In the simulations, $\mathrm{Ca}^{+2}$ and $\mathrm{HCO}^{3-}$ represent the mass- and charge-balancing species, respectively.

\begin{tabular}{cc}
\hline Basis species & Log activity \\
\hline $\mathrm{H}^{+}$ & -7 \\
$\mathrm{~K}^{+}$ & -10 \\
$\mathrm{Na}^{+}$ & -10 \\
$\mathrm{Ca}^{+2}$ & -5 \\
$\mathrm{SiO}_{2}(\mathrm{aq})$ & -10 \\
$\mathrm{HCO}^{3-}$ & -5 \\
\hline
\end{tabular}


potential secondary minerals were achieved within one hour As shown in Fig 5-18, the fluid remains undersaturated with respect to all primary and potential secondary minerals at this inlet node throughout the simulation Hence, at this location, all primary phases will dissolve to varying degrees controlled by the encoded kinetic rate law, and no secondary minerals will precipitate At the outlet node (Fig 5-19), mineral saturation indices reach steady-state values in about 9 hours Here again the fluid remains undersaturated with respect to all primary minerals, but in contrast to : the initial node, several secondary phases (kaolinite, gibbsite, diaspore, boehmite, and muscovite) achieve steady-state supersaturation with the fluid

At $90^{\circ} \mathrm{C}$, kinetic dissolution rates for the undersaturated primary phases are on the order of $-10^{-1}$ volume $\% / \mathrm{yr}$ for cristobalite and albite, $-10^{-2}$ volume\%/yr for quartz, and $<-10^{-3}$ volume $\% / y 1$ for K-feldspar and anorthite As a result, over six months, the aggregate dissolution of primary minerals will be $<025$ volume\% Some of this minute volume loss will be filled by precipitation of secondary phases following their sequential supersaturation along the flowpath Specifically, gibbsite will precipitate first (at

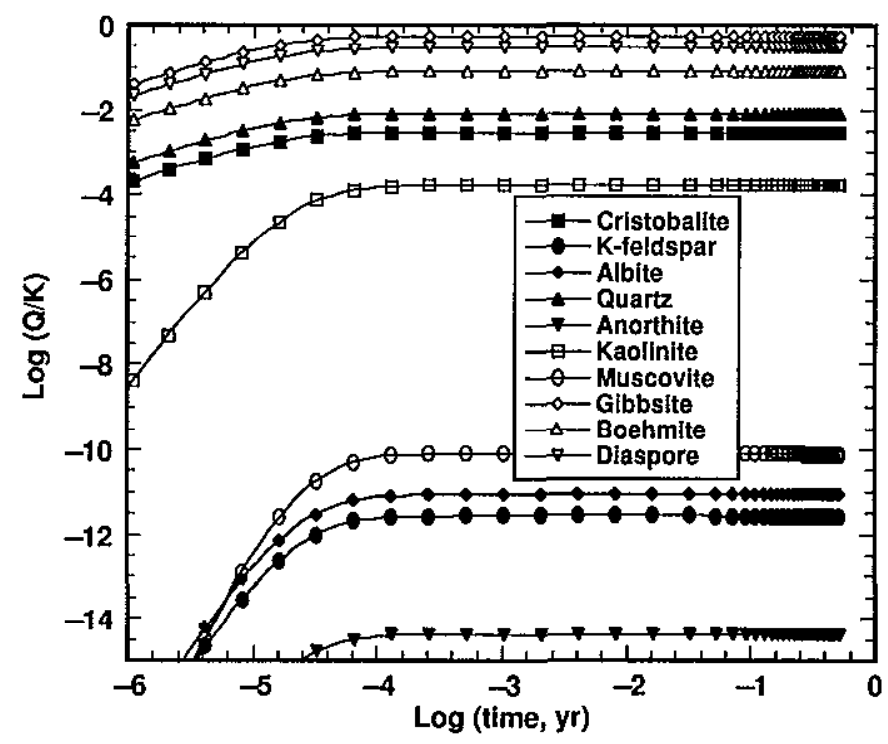

Figure 5-18. Mineral saturation indices $(\log Q / K)$ vs time at the inlet node of a GIMRT simulation at $90^{\circ} \mathrm{C}$, where initial composition of the 31-cm, 1-D, fluid-rock system is given in Table 5-1. Solid symbols denote primary minerals; open symbols denote secondary minerals.

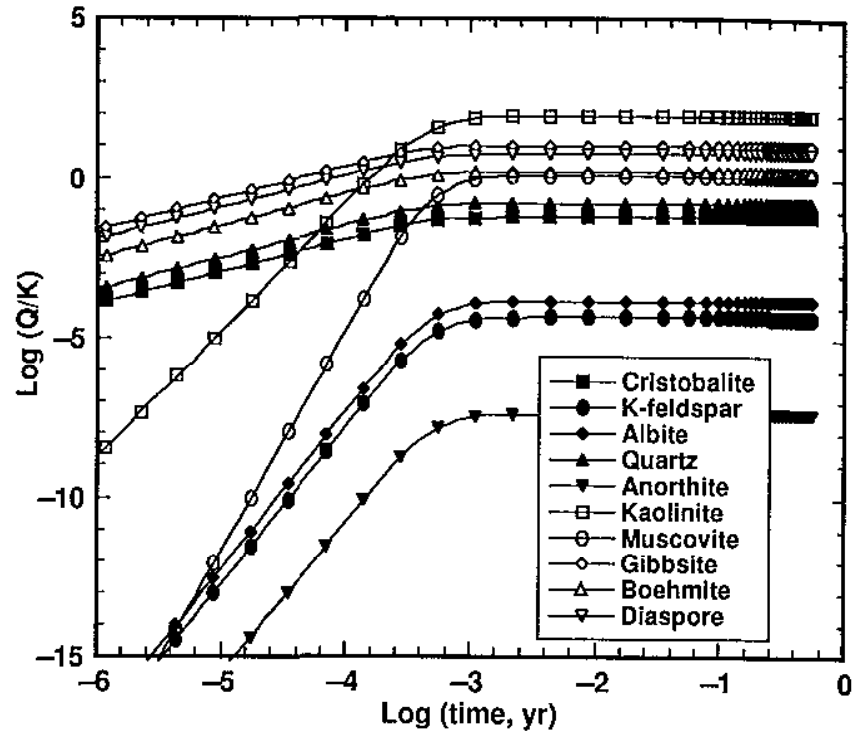

Figure 5-19. Mineral saturation indices $(\log Q / K)$ vs time at the outlet node of a GIMRT simulation at $90^{\circ} \mathrm{C}$.

node 2 , nodes were located at each $\mathrm{cm}$ along the flowpath), subsequently joined by diaspore (node 4), kaolinite (node 9), boehmite (node 14), and finally muscovite (node 29) However, because maximum precipitation rates for these phases are so slow at $90^{\circ} \mathrm{C}$ (ranging from $10^{-11}$ volume\%/yr for kaolinite to $10^{-14}$ volume\%/yr for muscovite and boehmite), the aggregate precipitation of secondary minerals is $<25\left(10^{-3}\right)$ volume/yr throughout the domain, i e, negligible. As a consequence, six months of reactive flow through crushed TSw at $90^{\circ} \mathrm{C}$ results in a relatively uniform but minute increase in porosity (from 40 to $\sim 4025 \%$ ) as a function of minor dissolution of primary phases and trace precipitation of alteration minerals (Figs 5-20 and 5-21) Although the changes are very small, when considering the times of concern for repository performance $(10,000 \mathrm{yr}$ or longer), the changes can be significant At about $3000 \mathrm{yr}$, the aggregate is $10 \%$; at $100,000 \mathrm{yr}$, it could be significant It is unknown whether these rates continue or if they decrease with time

A second GIMRT simulation was performed identical to the first except for the temperature, which was increased to $250^{\circ} \mathrm{C}$ Although this temperature exceeds the maximum likely to be attained in the near-field rock, depending on emplacement configuration, it may be realistic and is within the plausible temperature ranges in the backfill close to drifts These 
temperatures are probably unrealistic for the $\mathrm{AZ}$, which will be in the temperature range closer to $100^{\circ}$ to $150^{\circ} \mathrm{C}$. Thermodynamic and kinetic considerations suggest that $250^{\circ} \mathrm{C}$ will lead to readily observable porosity evolution and alteration-phase precipitation

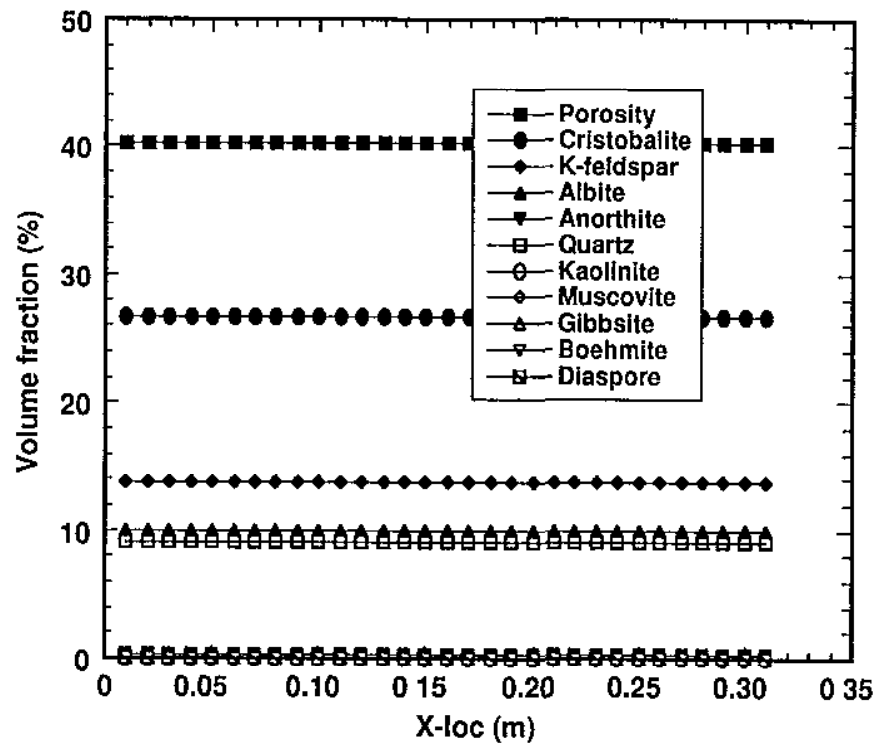

Figure 5-20. Porosity and volume fractions of primary and secondary minerals as a function of distance at six months for a GIMRT simulation at $90^{\circ} \mathrm{C}$. Solid symbols denote primary minerals; open symbols denote secondary minerals.

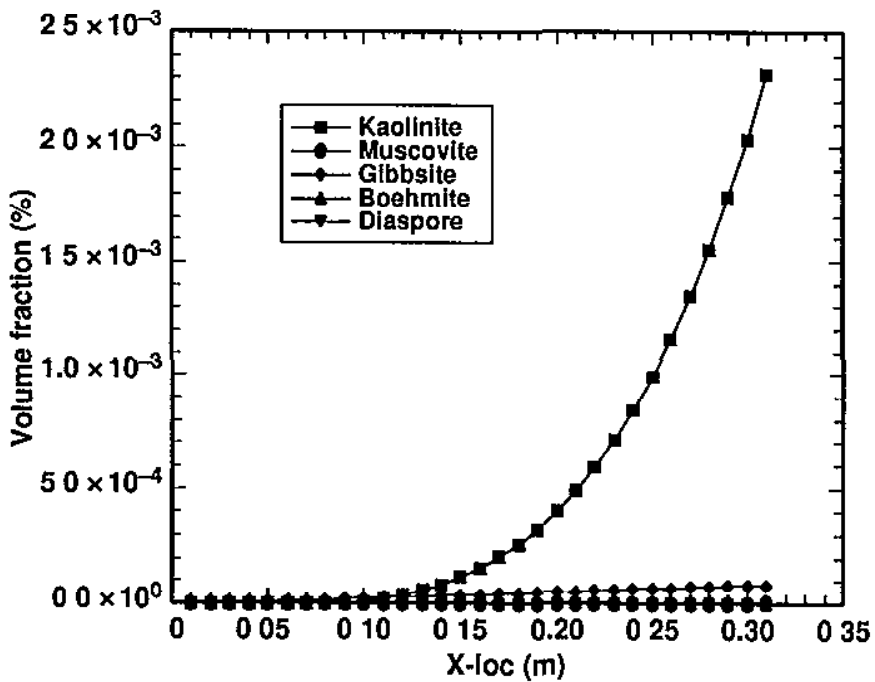

Figure 5-21. Porosity and volume fractions of trace secondary minerals as a function of distance after six months for a GIMRT simulation at $90^{\circ} \mathrm{C}$.
We know that similar changes to those observed at $250^{\circ} \mathrm{C}$ would apply to lower temperatures (especially at long time frames), but in a qualitative sense We do not have sufficient information at present to be more quantitative

Although the time scale for attainment of steadystate saturation indices is similar for the $90^{\circ} \mathrm{C}$ and $250^{\circ} \mathrm{C}$ simulations, the enhanced solubilities and faster reaction rates of primary TSw 2 minerals at the higher temperature and their effect on dissolution (and secondary phase precipitation) are readily apparent Despite concomitant precipitation of kaolinite, whose reaction rate and volume fraction ultimately attain 50 volume \%/yr and 14 volume\%, respectively, this near-complete consumption of cristobalite, albite, and quartz causes porosity to increase from 40 to $70 \%$ at the initial node (Fig 5-22), and, of course, results in the late marked decline in saturation indices for these and all other silicabearing phases (Fig 5-23) Because the differences between the $90^{\circ} \mathrm{C}$ and $250^{\circ} \mathrm{C}$ cases are impacted by reaction kinetics, except for those products that are in thermodynamic equilibrium, the long time frames of elevated temperatures expected in the $\mathrm{AZ}$ will probably result in mineralogy/chemistry similar to the $250^{\circ} \mathrm{C}$ case by the time the thermal pulse decays

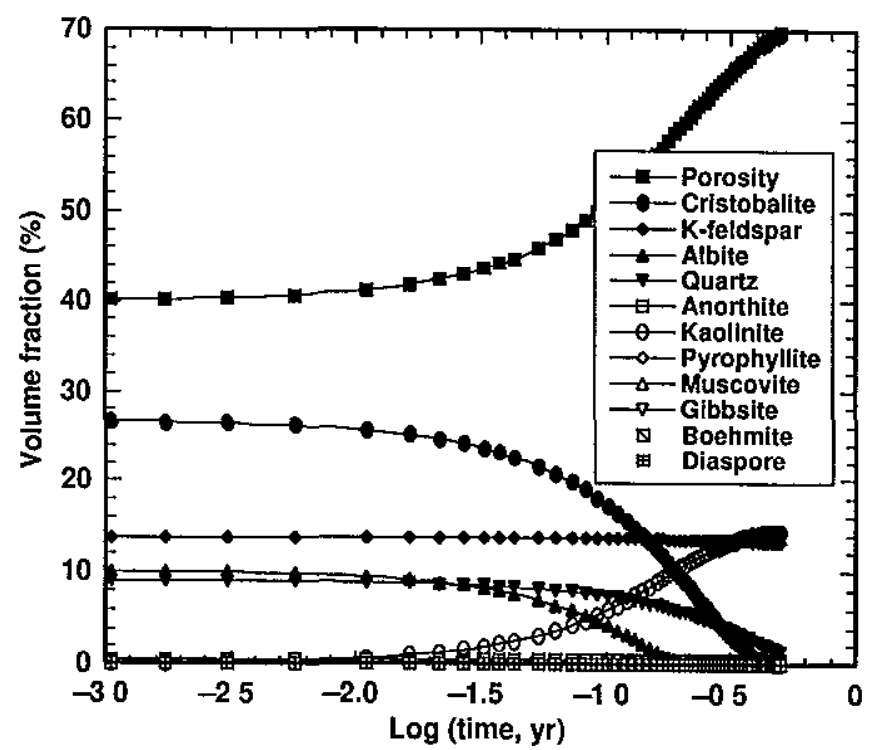

Figure 5-22. Porosity and volume fractions of primary and secondary minerals as a function of time at the inlet node of a GIMRT simulation at $250^{\circ} \mathrm{C}$. 
As shown in Fig 5-24, the fluid is supersaturated with not only the same six secondary minerals that characterize the inlet node, but also with albite and quartz

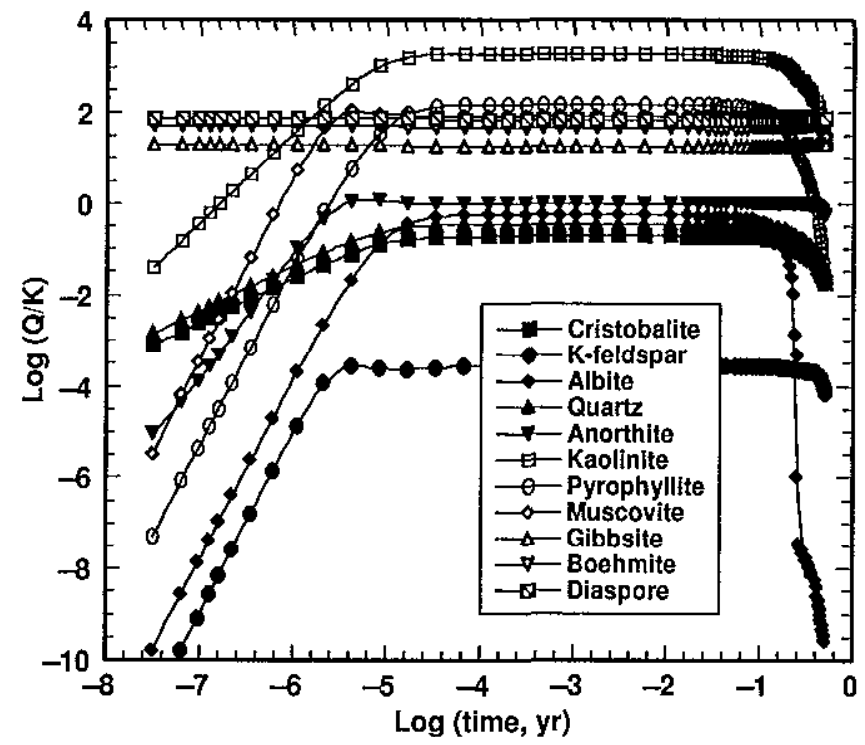

Figure 5-23. Mineral saturation indices $(\log Q / K)$ vs time at the inlet node $(1 \mathrm{~cm})$ of a GIMRT simulation at $250^{\circ} \mathrm{C}$, where initial composition of the $31-\mathrm{cm}, 1-\mathrm{D}$, fluid-rock system is given in Table 5-1. Solid symbols denote primary minerals; open symbols denote secondary minerals.

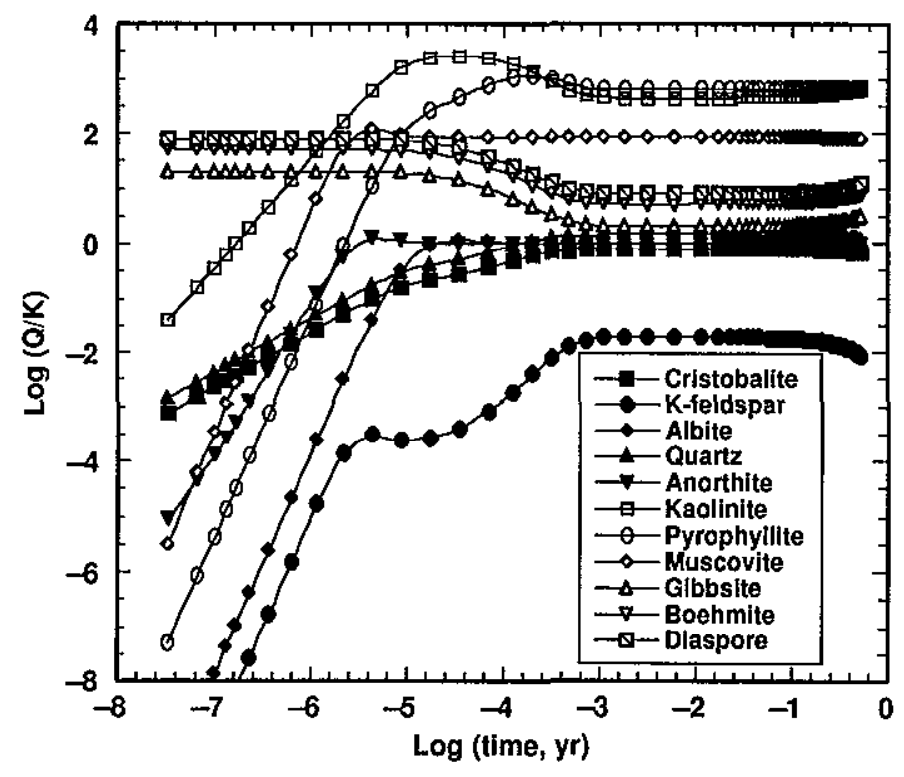

Figure 5-24. Mineral saturation indices $(\log Q / K)$ vs time at the outlet node of a GIMRT simulation at $250^{\circ} \mathrm{C}$.
Primary albite ceases to dissolve, and secondary albite begins to precipitate within 20 minutes, quartz follows suit about 40 minutes later, and within nine hours the cristobalite dissolution rate has dropped to and essentially leveled off at about $20 \%$ of its original magnitude As a result, after six months, total quartz and albite volume fractions have actually increased (Fig 5-25), and the net volume fraction of cristobalite, albite, and quartz has only declined from $459 \%$ to $372 \%$ (versus the inlet node) Hence, despite slightly reduced precipitation of secondary kaolinite relative to the inlet ( $102 \%$ versus $152 \%$ ), the six-month outlet porosity has actually decreased from 40 to $388 \%$ (Fig 5-25)

One would expect the gradient in dissolution/ precipitation behavior to be sharpest across the first few nodes, where the fluid concentration gradient is steep This is exactly the case, as illustrated by the time-integrated spatial distribution of saturation indices and porosity/volume fractions (Figs 5-26 and 5-27) Thus, gradients that develop during initial $\mathrm{AZ}$ development close to the WP environment may not experience complete chemical reactions However, the rapidity of growth in the dryout zone and its associated condensate zone will slow as a function of decreasing rate and increased diameter as the spherical volumes increase In addition, the kinetics are sufficiently high that reactions can be essentially fully developed in a relatively short time Therefore, the products of the $250^{\circ} \mathrm{C}$ case should be representative of the majority of the $\mathrm{AZ}$ Note that

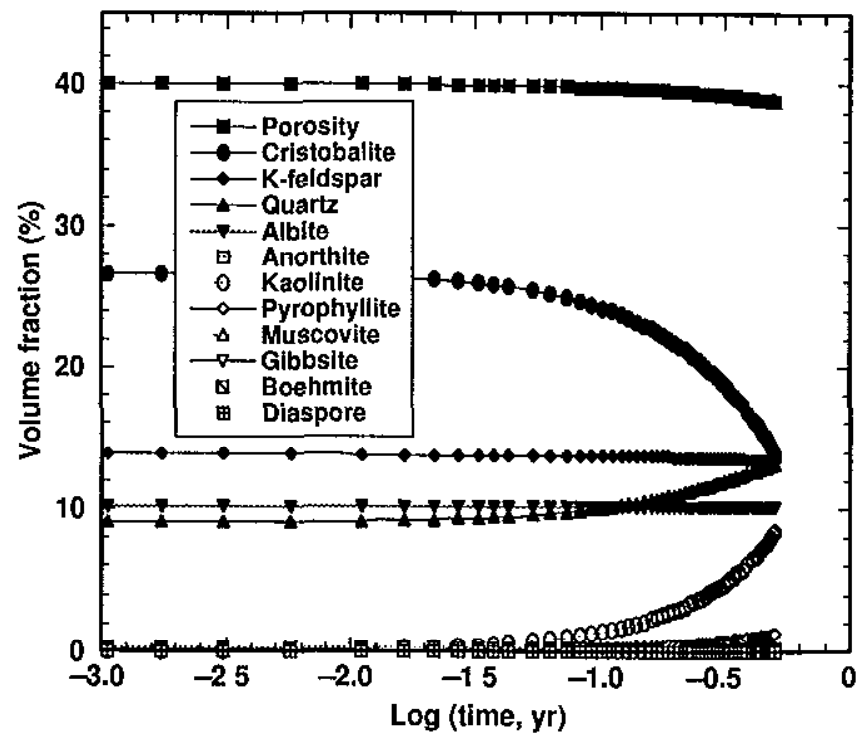

Figure 5-25. Porosity and volume fractions of primary and secondary minerals as a function of time at the outlet node of a GIMRT simulation at $250^{\circ} \mathrm{C}$. 


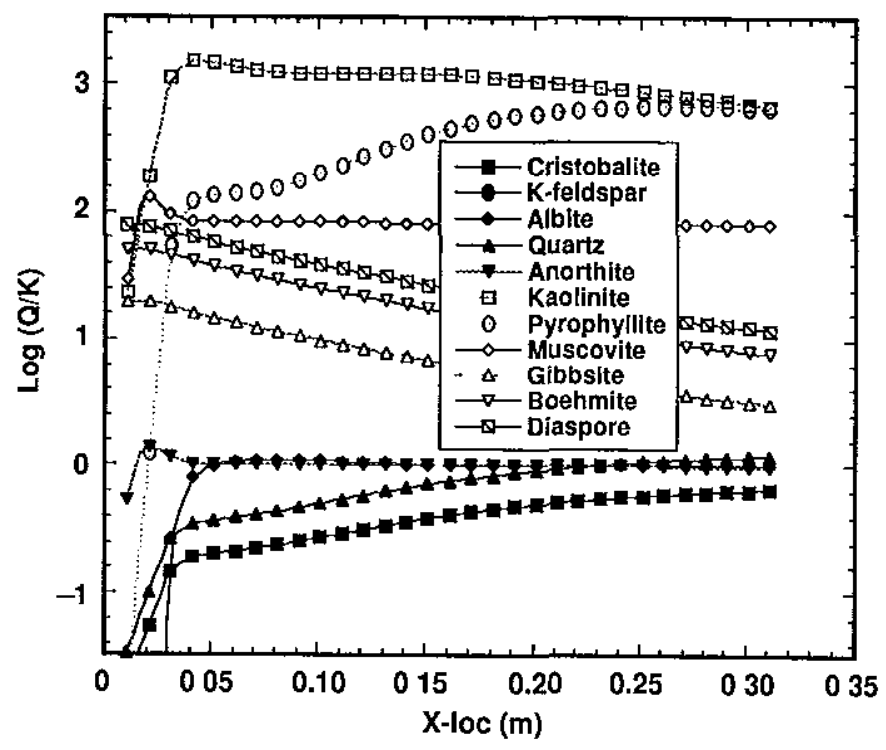

Figure 5-26. Mineral saturation indices $(\log Q / K)$ as a function of distance after six months for a GIMRT simulation at $250^{\circ} \mathrm{C}$.

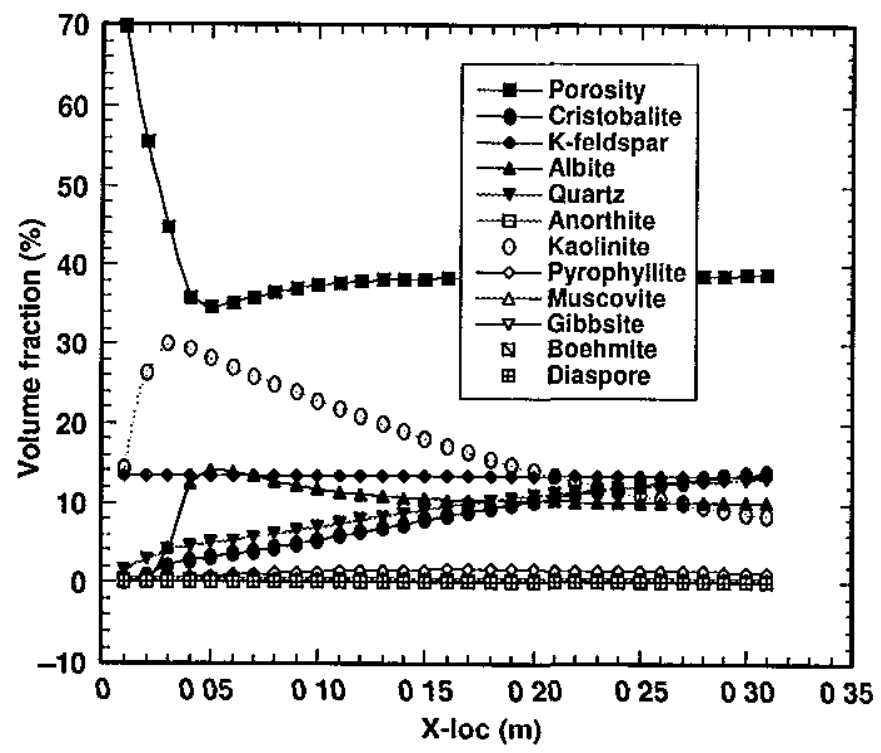

Figure 5-27. Porosity and volume fractions of primary and secondary minerals as a function of distance after six months for a GIMRT simulation at $250^{\circ} \mathrm{C}$.

the region of enhanced porosity is restricted to the first few nodes and is characterized by very steep gradients, whereas the region of reduced porosity accounts for roughly $90 \%$ of the reaction domain and is characterized by much subtler variations
Significant porosity evolution in the $90^{\circ} \mathrm{C}$ backfill zone will not be realized for at least $100 \mathrm{yr}$ Moreover, recalling the likely overestimation of initial porosity, this time frame must be considered extremely conservative Because accurate values for the initial porosities and flow rates relevant to the potential crushed-TSw2 backfill environment are currently unavailable, a more detailed, longer time-scale simulation addressing porosity evolution here cannot be pursued at this time Current information indicates that if pre-cast or cast-inplace concrete liners are used, the watel chemistries $(\mathrm{pH})$ would be affected, and the fluid would be more reactive Therefore, the extent of alteration of the backfill would be increased However, no quantitative studies of this topic have been performed to date

The potential repository horizon lies well above the present-day water table within the welded, devitrified section, which is characterized by low porosity (11\%) and extremely low, fiacture-controlled permeability $\left(10^{-18} \mathrm{~m}^{2}\right)$ (Klavetter and Peters, 1988) As described by Buscheck et al (1993), hydrology of the post-emplacement NFE may be characterized by a boiling zone, where vapor moves radially outward from the EBS/WP and an outer but partially over lapping condensation zone, where temperature-dependent condensation of the vapor leads to primarily gravity-driven flow of a fluid phase In the vicinity of emplacement drifts, average calculated trajectories indicate that the condensate may flow along path lines characterized by an initial isother mal segment (at $90^{\circ}$ to $100^{\circ} \mathrm{C}$ ) of several meters and subsequent cooling segment $\left(-1^{\circ}\right.$ to $\left.-3^{\circ} \mathrm{C} / \mathrm{m}\right)$, also of several meters

The temporal evolution of mineral saturation indices at the inlet $(025 \mathrm{~m})$, center $(5 \mathrm{~m})$, and outlet $(10 \mathrm{~m})$ nodes are shown in Figs $5-28$ through 5-30 Initial steady-state mineral saturation indices are attained after about 1 month, during which time the fluid obtains supersaturation with quartz and the secondary phases kaolinite and pyrophyllite, but remains undersaturated with respect to cristobalite (and the primary feldspars) throughout the reaction domain. As a result, over the entire reactive flowpath, cristobalite (and the feldspars) will dissolve, whereas quartz, kaolinite, and pyrophyllite will precipitate Given the relatively sluggish dissolution rates of the feldspars at $90^{\circ}$ to $95^{\circ} \mathrm{C}$, dissolution of these primary aluminous phases and dependent precipitation of kaolinite and pyrophyllite will be very minor Hence, the fundamental mechanism of porosity evolution in this environment is expected to be metasomatic replacement of cristobalite by quartz 


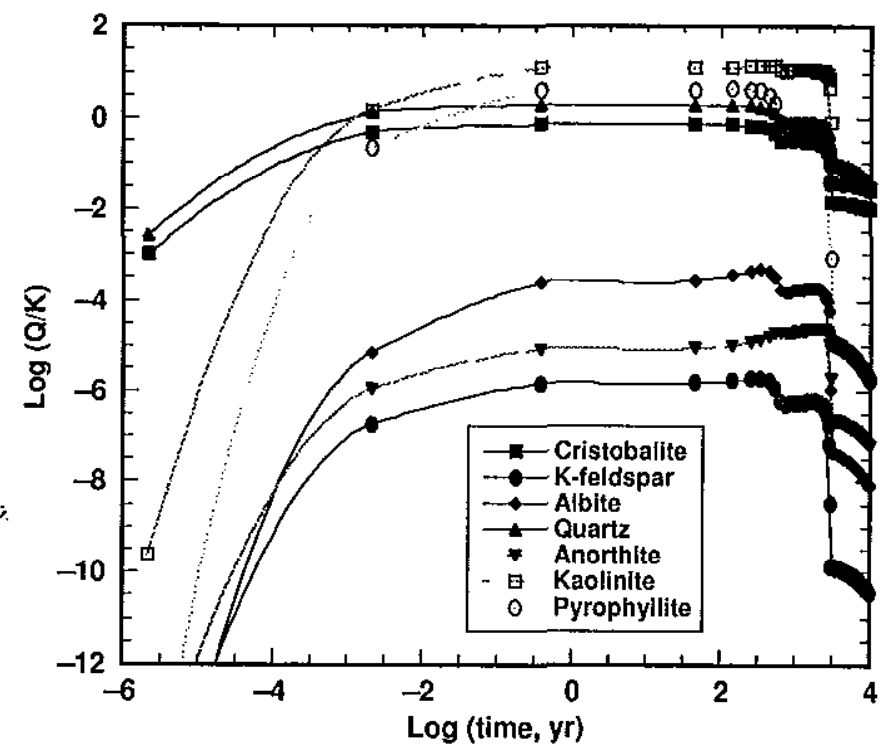

Figure 5-28. Mineral saturation indices $(\log Q / K)$ as a function of time at the inlet node $(0.25 \mathrm{~m})$ of a GIMRT simulation at $95^{\circ} \mathrm{C}$, where initial composition of the $10-\mathrm{m}, 1-\mathrm{D}$, fluid-rock system is given in Table 5-1. Solid symbols denote primary minerals; open symbols denote secondary minerals.

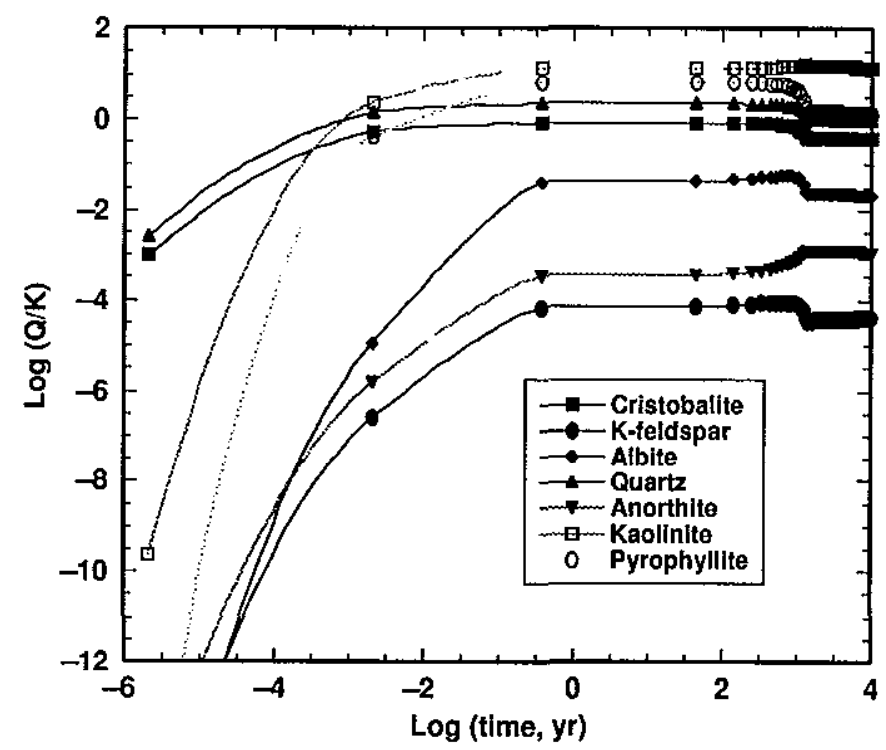

Figure 5-29. Mineral saturation indices $(\log Q / K)$ as a function of time at the center node $(5 \mathrm{~m})$ of a GIMRT simulation at $95^{\circ} \mathrm{C}$.

As shown in Fig 5-31, at the inlet (pure dissolution) node, behavior analogous to the center and outlet of the domain is observed until cristobalite has been

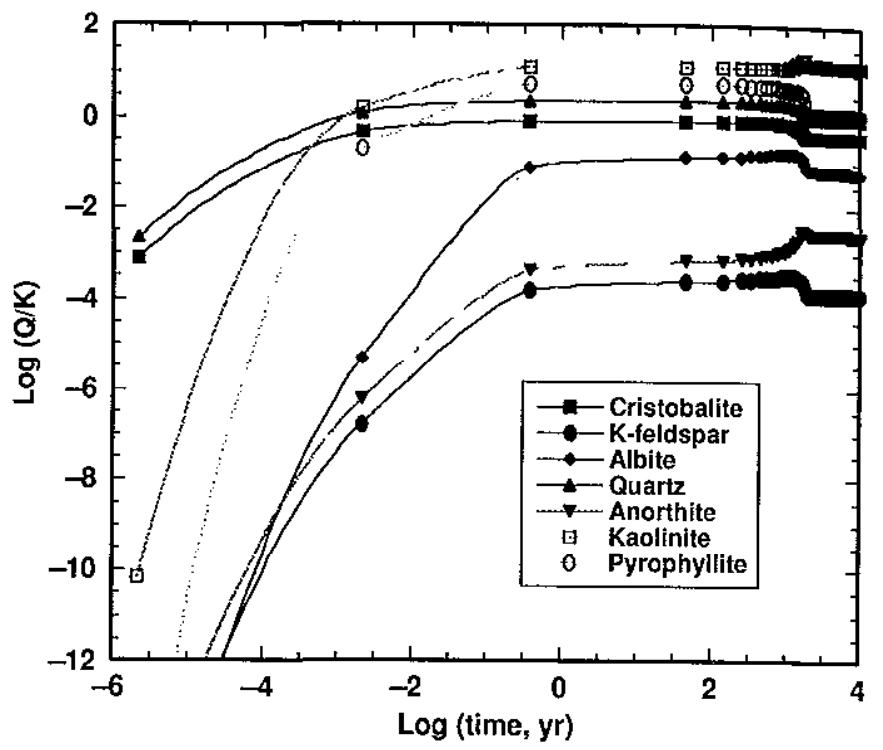

Figure 5-30. Mineral saturation indices $(\log \mathrm{Q} / \mathrm{K})$ as a function of time at the outlet node $(10 \mathrm{~m})$ of a GIMRT simulation at $95^{\circ} \mathrm{C}$.

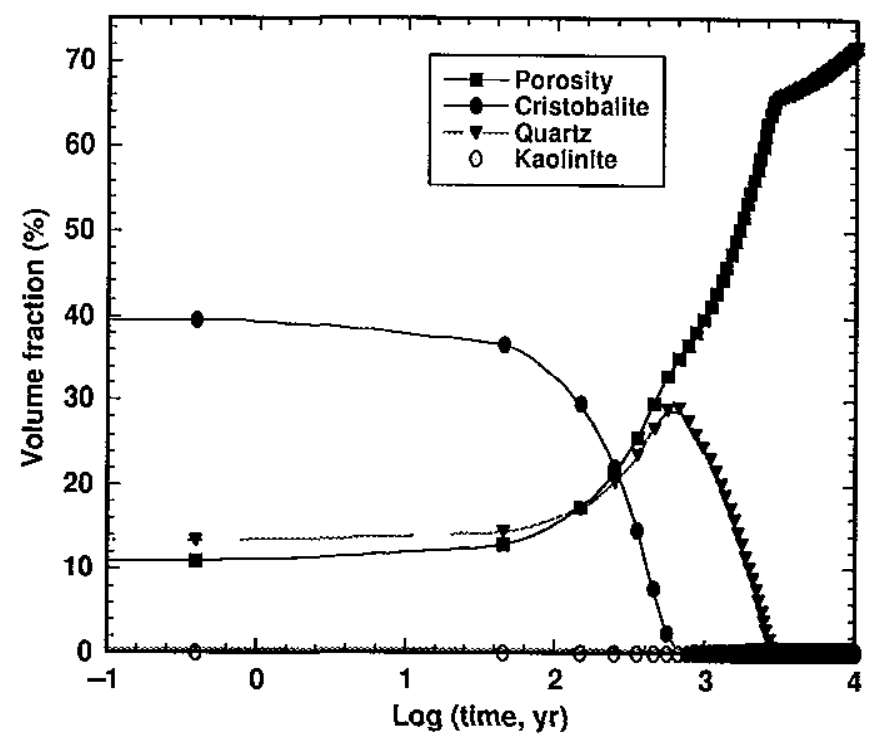

Figure 5-31. Porosity and volume fractions of primary and secondary minerals as a function of time at the inlet node $(0.25 \mathrm{~m})$ of a GIMRT simulation at $95^{\circ} \mathrm{C}$.

completely dissolved at about 650 yr Subsequently, the dilute inlet fluid begins to dissolve quartz, which disappears completely after 3,100 yr, and then albite

Figures 5-32 through 5-35 show time-integrated spatial variations in porosity and mineral volume fractions The complete replacement of cristobalite (initial 


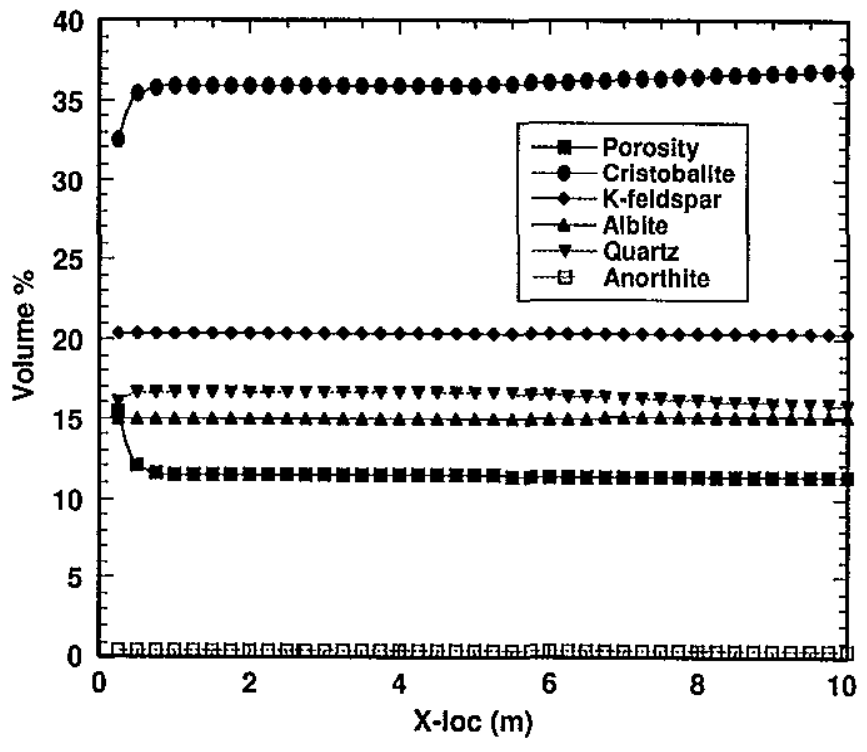

Figure 5-32. Porosity and volume fractions of primary and secondary minerals as a function of distance after $\mathbf{1 0 0} \mathrm{yr}$ for a GIMRT simulation. Temperature for the first $5 \mathrm{~m}$ is $95^{\circ} \mathrm{C}$, then decreases by $1^{\circ} \mathrm{C} / \mathrm{m}$ over the last $5 \mathrm{~m}$.

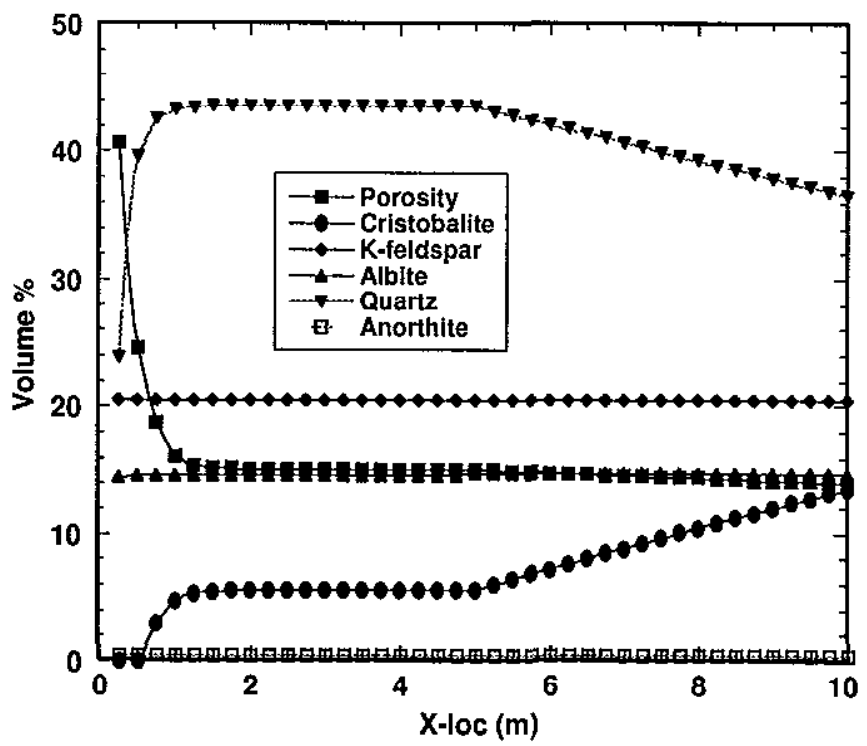

Figure 5-33. Porosity and volume fractions of primary and secondary minerals as a function of distance after $1000 \mathrm{yr}$ for a GIMRT simulation. Temperature for the first $5 \mathrm{~m}$ is $95^{\circ} \mathrm{C}$, then decreases by $1^{\circ} \mathrm{C} / \mathrm{m}$ over the last $5 \mathrm{~m}$.

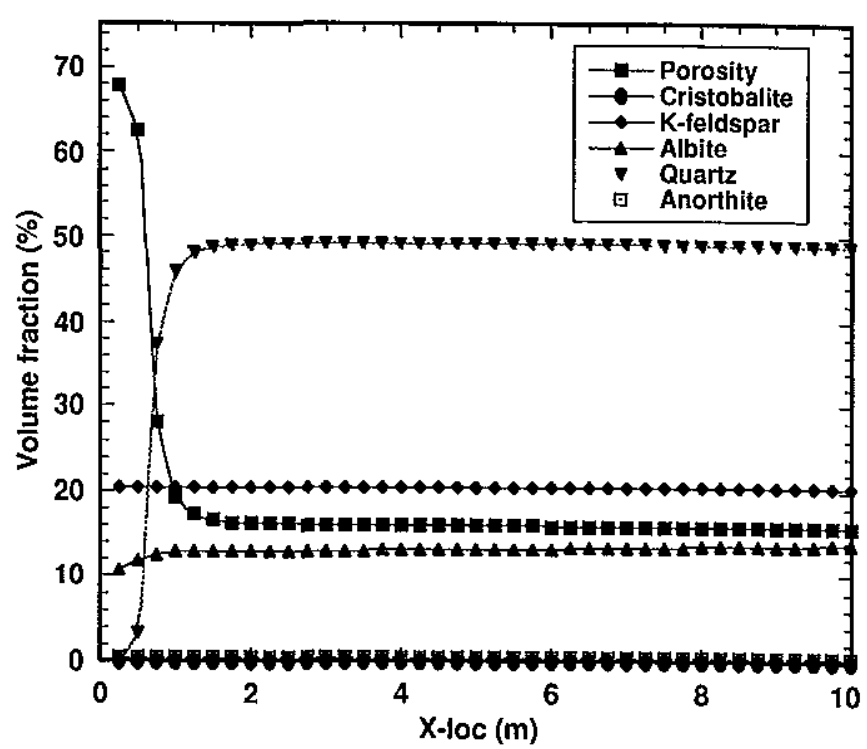

Figure 5-34. Porosity and volume fractions of primary and secondary minerals as a function of distance after $5000 \mathrm{yr}$ for a GIMRT simulation. Temperature for the first $5 \mathrm{~m}$ is $95^{\circ} \mathrm{C}$, then decreases by $1^{\circ} \mathrm{C} / \mathrm{m}$ over the last $5 \mathrm{~m}$.

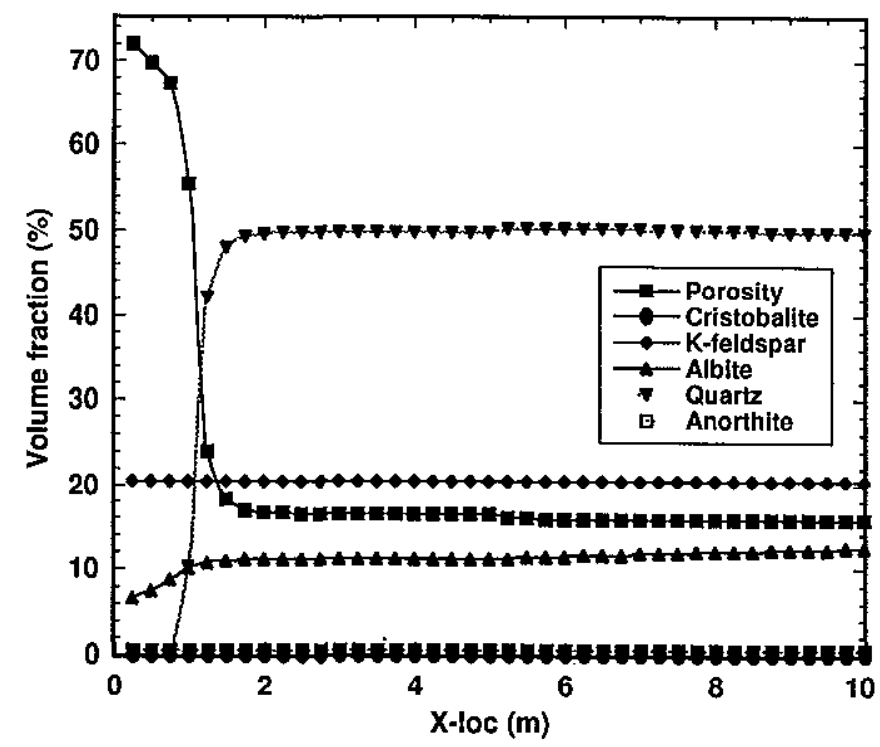

Figure 5-35. Porosity and volume fractions of primary and secondary minerals as a function of distance after 10,000 yr for a GIMRT simulation. Temperature for the first $5 \mathrm{~m}$ is $95^{\circ} \mathrm{C}$, then decreases by $1^{\circ} \mathrm{C} / \mathrm{m}$ over the last $5 \mathrm{~m}$. 
volume fraction $=396 \%$ ) by quartz throughout the reaction domain leads directly to a background increase in porosity from $11 \%$ to about $16 \%$ after roughly $3,100 \mathrm{yr}$ (Figs 5-34 and 5-35) Superimposed is a secondary porosity enhancement, resulting from quartz dissolution (initiated following complete cristobalite consumption) at the first few inlet nodes, beginning with the inlet node at $650 \mathrm{yr}$ Because the $90^{\circ}$ to $95^{\circ} \mathrm{C}$ dissolution rate of quartz is only about $40 \%$ that of cristobalite, it takes dilute inlet fluid roughly 2,500 years to completely dissolve the inlet-node quartz from its maximum concentration ( 29 volume\%), which coincided with cristobalite disappearance at $650 \mathrm{yr}$. This secondary quartz dissolution front advances quite slowly, and the advection of quartz-derived $\mathrm{SiO}_{2}(\mathrm{aq})$ maintains nearly uniform levels of slight quartz supersaturation and resultant minor quartz precipitation over the entire downstream reaction domain As a result, this secondary porosity enhancement is characterized by steep gradients that advance downstream quite slowly (Figs. 5-34 and 5-35).

Important implications for the post-emplacement evolution of porosity in the $\mathrm{AZ}$ can be drawn from this simulation First, thermodynamic, kinetic, and volumetric constraints strongly suggest that longterm ( $>3,000 \mathrm{yr}$ ), gravity-driven flow of vaporderived dilute condensate at $90^{\circ}$ to $95^{\circ} \mathrm{C}$ will result in nearly $50 \%$ background porosity enhancement (from $11 \%$ to $16 \%$ ) as a consequence of mole-for-mole, quartz-for-cristobalite replacement Should this local "condensation" zone persist for longer time periods, the in situ porosity may further increase dramatically, albeit slowly, to more than $65 \%$ as quartz dissolution occurs It is conceivable, if not likely, that the post-emplacement $A Z$ will evolve toward extreme porosity heterogeneity, characterized by relatively large porosities in the condensation-zone "cap" above the repository and relatively low porosities (which never theless exceed pre-emplacement porosity) in the outlying margins of this cap. In addition, these extremes may be joined by a narrow, steep-gradient interface All of the dissolved silica will, of course, eventually precipitate farther downstream, presuming gravity-driven flow continues down thermal gradients Hence, it is anticipated that a zone of very low (less-than-ambient) porosity may develop at depth, perhaps below and radially outward from the tepository Above the condensate cap, there will also be porosity decreases

5.4.5.3 Conclusions. Recognizing the abundance of compositional and hydrologic approximations, assumptions, and simplifications that are necessarily embodied in these still-preliminary models, they nevertheless serve to elucidate the fundamental time scales (thousands of years) and geochemical processes (e g , cristobalite-for-quartz replacement) likely to govern active evolution of the $\mathrm{AZ}$ They can also be used to imply the distant-future porosity distributions that are so critically important Our initial modeling efforts suggest that post-emplacement reactive transport will lead to porosity enhancement in the $A Z$, most dramatically in the condensation "cap" overlying the repository Further modeling of fluid transport to regions below the emplacement drifts will evaluate the extent to which flow bar riers may form due to porosity reduction

Our results to date strongly suggest that significant porosity changes will occur in the post-emplacement, repository-block environment Long-term performance assessment of this environment must explicitly account for such porosity evolution and its effect on dependent geochemical and hydrologic processes Porosity changes in the backfill would also be significant because the purpose of the backfill is to act as a hydrological barrier Buscheck has pointed out that backfill may need to be quartz sand, not crushed tuff, to provide diversion of percolation without wicking. A further consideration is the geochemical alteration of backfill materials, particularly crushed tuff If porosity, hence permeability and matric potential, significantly change, then the backfill may not serve its intended function 


\subsection{Performance Implications}

The near-field and altered-zone environments impact the overall performance of the repository system in three general areas

- Performance of the waste container materials, particularly metallic container materials

- Dissolution/mobilization and transport of radionuclides from the waste.

- Flow fields and retardation characteristics of the natural system

\subsection{Impacts on Waste Container Performance}

The current repository concept includes the use of metal containers that consist of outer corrosionallowance materials in concert with inner corrosionresistant materials Combined, the materials are intended to prevent contact of water with the waste materials and to provide for containment, thus isola tion, of the waste The length of time that these containers will function and how well they function very much depends on how much water can contact the WPs, the chemistry of the water, and the relative humidity of air surrounding the WPs

Estimates of water volumes that can potentially contact the WPs have been based on the Project's understanding of ambient percolation fluxes and the thermohydrologic response of the system to the repository heat load as envisioned in the current design for the repository. In terms of WP water contact, this revision of the NFER has placed more emphasis on flux that is created by displaced water combining with ambient percolation flux than on the saturation conditions and timing for those conditions This change of emphasis from that of the Preliminary NFER is due to two factors

First, as the YMP has continued to study water flow through the mountain, it has become apparent that the flow is dominated by fracture flow more than by matrix hydrologic conditions This was recognized at the time the Preliminary NFER was written and was the basis for the statement " Thus, fracture flow is the only credible mechanism to bring liquid water into contact with the WPs"

The second change arises from the recent recognition that ambient percolation fluxes may be much higher than values originally considered possible At the time the Preliminary NFER was written, the general feeling was that the total percolation flux was very low or zero Current estimates for flux-based, in part, on neution logging measurements and isotopes released by atmospheric nuclear weapons tests-range as high as 10 to $15 \mathrm{~mm} / \mathrm{yr}$, with $5 \mathrm{~mm} / \mathrm{yr}$ as the most accepted value (Bodvarsson and Bandurraga, 1996) However, such estimates are based largely on analyses that used assumed hydrologic property values, the representativeness of which has not been demonstrated and is not entirely consistent with the findings of others (Buscheck, 1997)

Although it was previously recognized that periodic or episodically higher fluxes could occur, data were not available to quantify the significance of these transient fluxes Hence, greater emphasis in the Preliminary NFER was placed on the conditions of overall saturation as an indicator of potential water contact with the waste The current revision places much less emphasis on saturation changes and their duration as an indicator of WP performance (it is still important in AZ processes, as discussed in Section 5) Instead, more emphasis is placed on actual flux estimates, which will be dominated by fracture flow. It is difficult to relate saturation to flux directly because saturation that exists in the matrix is relatively immobile and does not contribute to flux to the same extent that the same saturation in fractures would Because the saturation profiles shown in Figure 5-6 are based on assumptions of equilibrium between the moisture in matrix and pores, they do not relate directly to flux of water that could enter the drifts

One possible way to assess the flux entering drifts is to account for the current or ambient percolation flux in the mountain-which is an indication of flux within fractures because the matrix will contribute such a small percentage to the overall flow-and then to assess the quantity of additional water that can be added to this flux by thermal mobilization or redistribution of water In this regard, it is important to note that the total condensate flux reported in Section 43 represents the total amount of water that can be vaporized by the heat available, which consists of both meteoric percolation and thermally mobilized water Thus, if the meteoric percolation flux is greater, then the amount of water that can be vaporized will be 
reduced The total flux will remain constant for any given heat flux.

The influence of percolation flux on drift-scale thermal-hydrological behavior was investigated in Section 1106 of Volume II for the flux range of 0 to $5 \mathrm{~mm} / \mathrm{yr}$ It is important to realize that the decayheat-mobilized, liquid-phase flux in the condensate zone overlying the repository is much greater than this range for about $1000 \mathrm{yr}$ For the 834 -MTU/acre repository design, the maximum decay-heat-mobilized liquid-phase flux can be as large as $1000 \mathrm{~mm} / \mathrm{yr}$ during the first $100 \mathrm{yr}$ The maximum liquid-phase flux declines to about $200 \mathrm{~mm} / \mathrm{yr}$ at $200 \mathrm{yr}, 100 \mathrm{~mm} / \mathrm{yr}$ at $500 \mathrm{yr}$, and $20 \mathrm{~mm} / \mathrm{yr}$ from 1000 to $3000 \mathrm{yr}$ These flux values are for homogeneous conditions, spatial variability in heating conditions or fracture properties can cause fluctuations about these averages For example, greater fluxes can occur in regions of focused condensate flow or where the decay-heat flux is less than average On the basis of test results from air permeability, it is likely that the fracture network within the TSw unit can easily accommodate fluxes of up to hundreds of millimeters per year

Two significant cautions apply to this assessment First, the same problems in defining flux based on satu ation apply to estimating the ambient flux; that is, assumptions must be made to evaluate the current flux These assumptions deal with the equilibrium between fracture and matrix flow, as well as the rock mass properties versus those determined from intact, small-scale samples Current estimates of flux are as high as 10 to $15 \mathrm{~mm} / \mathrm{yr}$, but these values are not confirmed by direct measurements within the TSw2 Shallow infiltration flux is estimated by periodic neutron logging of shallow boreholes Analyses of these measurements provide a lower bound estimate of the flux from the surface to the depth of measurement This measurement will not detect water moving rapidly though the fractures because large fluxes can be handled with no measurable change in water content. Only the water actually imbibed into the matrix will be measured by the neutron log These relatively shallow measurements do not account for diversion and other processes, and thus may not be representative of the percolation flux at the repository horizon (See Section 43 for further information on flux)

As explained in Section 4.3, the amount of water that can contact waste depends on both the meteoric water percolation flux and on the flux of water that is mobilized by being driven out of the pores of the rock Furthermore, depending on the repository design, there can be local areas where water is more readily able to enter the drifts than others because the thermal output of waste will drive water away from the waste for many years For the percolation flux cases analyzed in this report, up to $5 \mathrm{~mm} / \mathrm{yr}$, the estimate of how much water could contact the WPs is less than $1 \mathrm{~mm} / \mathrm{yr}$ In addition, studies by both Nitao (1997) and Bodvardsson and Bandurraga (1996) indicate that there will be very little or no flow into the drifts at the percolation fluxes that are believed to exist at YM Even after the thermal pulse no longer restricts inflow, after thousands of years, Nitao found that unless percolation flux exceeded $10 \mathrm{~mm} / \mathrm{yr}$, there would not be influx into the drifts Further, as noted in Section 45 , the use of a concrete liner will moderate or inhibit any inflow that might occur during the early times when the liner remains intact It is also recognized that inflow will not be uniform but, rather, restricted mostly to major inflow zones The inflowing water will interact with emplaced materials that have been altered in response to repository conditions This alteration is expected to evolve over time It is anticipated that the result of these interactions will be a solution of moderately high $\mathrm{pH}$ (9 to 11), with an ionic strength greater than that of the piesent ambient pore waters Depending on how inflow is distributed both spatially and temporally, inflow could accelerate corrosion, but inflow is not seen as a major determinant of WP lifetime The corrosion-allowance material can be designed with thickness necessary to provide for long-lived containers if general corrosion, not pitting or microbial-induced corrosion, is the concern.

Relative humidity, on the other hand, is perhaps the most significant environmental variable affecting corrosion rate of the outer barrier, therefore survival of the WPs As discussed in Section 4.3, both the magnitude and time distribution of $R H$ depend on the repository design/layout The design can prevent conditions in which corrosion is most aggressive, namely when temperatures and relative humidities are high, for many thousands of years, or it can create conditions that will be adverse to container survival This is especially true for individual waste containers having low heat output or those located near the edge of the repository The ACD and LL designs have different $R H$ conditions associated with them, and the ACD design has great variability in $R H$ conditions from package to package (see Section 43 and Table 4-4)

The period of time during which design influences $R H$ also depends on percolation flux The relationship between relative humidity on the WP $\left(R H_{\mathrm{wp}}\right)$ and 
percolation flux falls into three flux ranges For a percolation flux of less than $03 \mathrm{~mm} / \mathrm{yr}$, the duration of reduced $R H_{\mathrm{wp}}$ increases strongly with decreasing flux For the range 03 to $1.0 \mathrm{~mm} / \mathrm{yr}$, the duration of reduced $R H_{w p}$ is relatively insensitive to percolation flux For percolation flux greater than $10 \mathrm{~mm} / \mathrm{yr}$, the duration of reduced $R H_{w p}$ decreases with increasing flux Increasing the percolation flux from 1 to 5 $\mathrm{mm} / \mathrm{yr}$, reduces the period during which $R H_{\mathrm{wp}}<65 \%$ from $1660 \mathrm{yr}$ to $1200 \mathrm{yr}$ For the first $1000 \mathrm{yr}, R H_{\mathrm{wp}}$ is only moderately sensitive to flux between 03 and 5 $\mathrm{mm} / \mathrm{yr}$ Even if the flux is as large as 10 to $20 \mathrm{~mm} / \mathrm{yr}$, the decay-heat-driven liquid-phase flux is much larger than the percolation flux during the first $500 \mathrm{yr}$ Therefore, percolation flux will only have a moderate impact on $R H$ after 500 to 1000 years If the percolation flux is as high as $10 \mathrm{~mm} / \mathrm{yr}$, the $R H$ will essentially be ambient (close to 100\%)

Preliminary unpublished analyses of thermal variability have been made for the ACD and the 1997 modified designs (Blink et al , 1977) Figure 6-1 shows the package arrangement for the modified design that had been described earlier in Fig 1-4, but with both the axial position and the WP heat output shown Figure 6-2 shows the initial heat output as a function of axial position along an emplacement drift As can be seen, there will be a very significant peak of thermal output around the 21 PWR assembly, which will result in much higher local temperatures around these packages with associated lower ing of $R H$ In contrast, much cooler temperatures prevail around the $44 \mathrm{BWR}$ assemblies This design will result in much higher $R H$ in the areas of lower heat output and possibly even condensate collection and dripping in the cooler at eas

Figure 6-3 shows the effect of the time-dependent (calculated) $R H$ and $T$ environment on general corrosion rate for an ACD layout but with only $24 \mathrm{MTU} /$ acre, compared with cor rosion predicted for ambient (fixed) $R H$ and $T$ This was considered to be a conservative estimate of the impact of waste-heat generation on corrosion because it represents the smallest MTU/acre value that has been considered to be feasible Even for this conservative case, the difference between ambient and thermally perturbed conditions is dramatic The corrosion rate does not change much, compared to ambient conditions, until a few years after emplacement, then drops rapidly at closure as the $R H$ drops to very low values For several hundred years after closure, the calculated corrosion rate is less than $10^{-10}$ microns per year As humidity increases from the minimum value reached shor tly after closure, the corrosion rate increases rapidly but does not reach the ambient corrosion rate until almost 100,000 years after closure

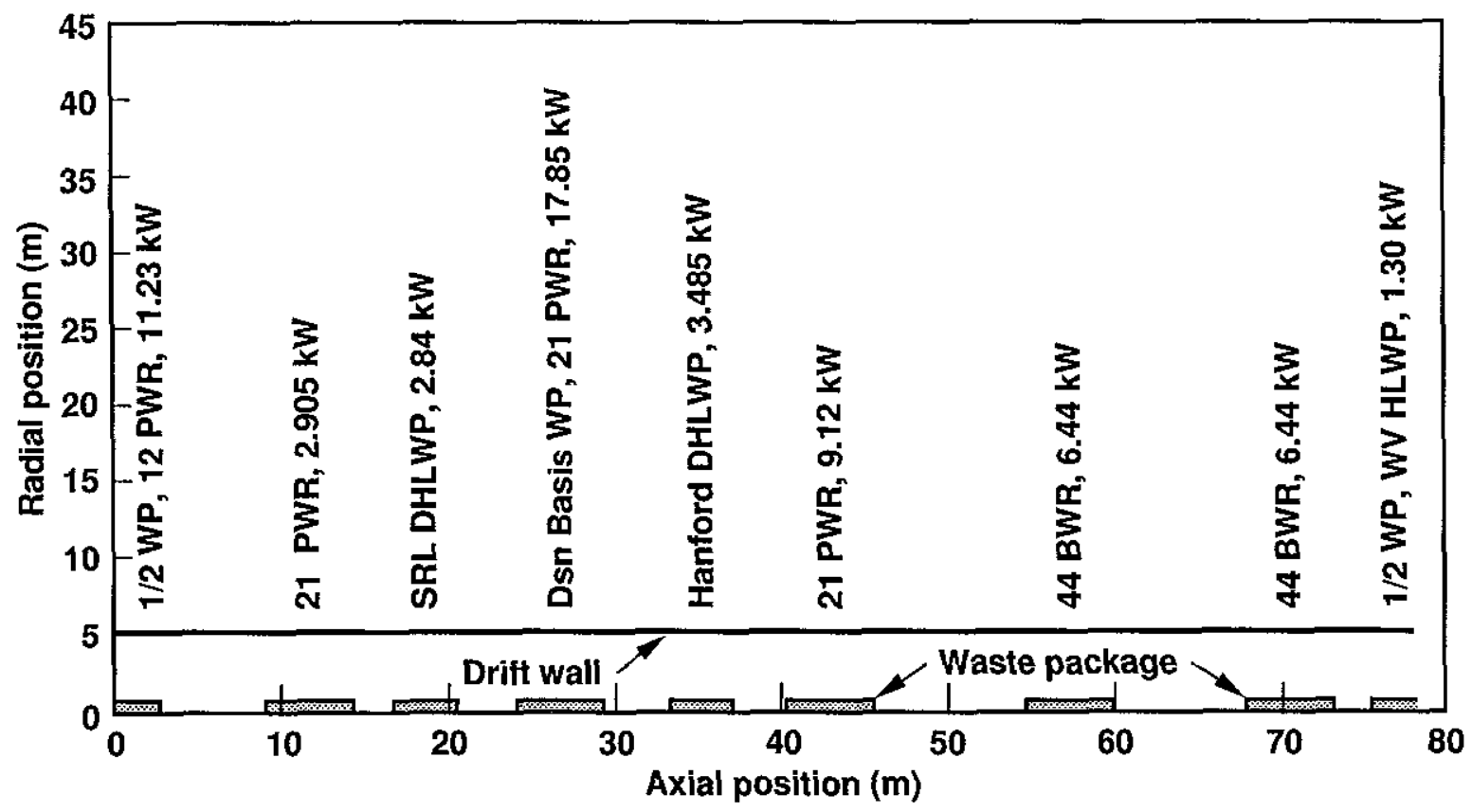

Figure 6-1. Location of individual waste packages for the modified design. 


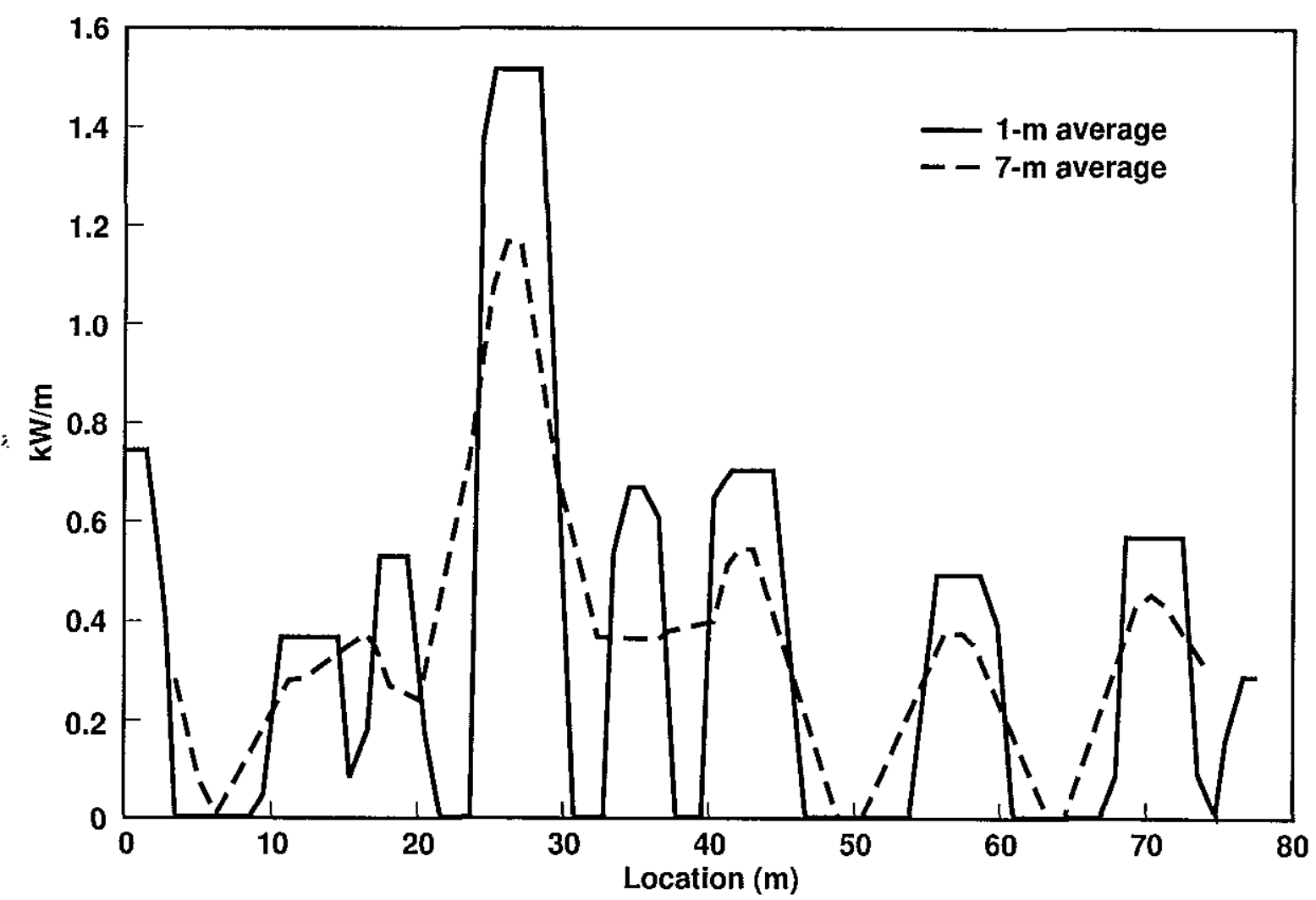

Figure 6-2 Heat output $(\mathrm{kW} / \mathrm{m})$ as a function of the location (axial position) of individual waste packages for various averaging lengths.

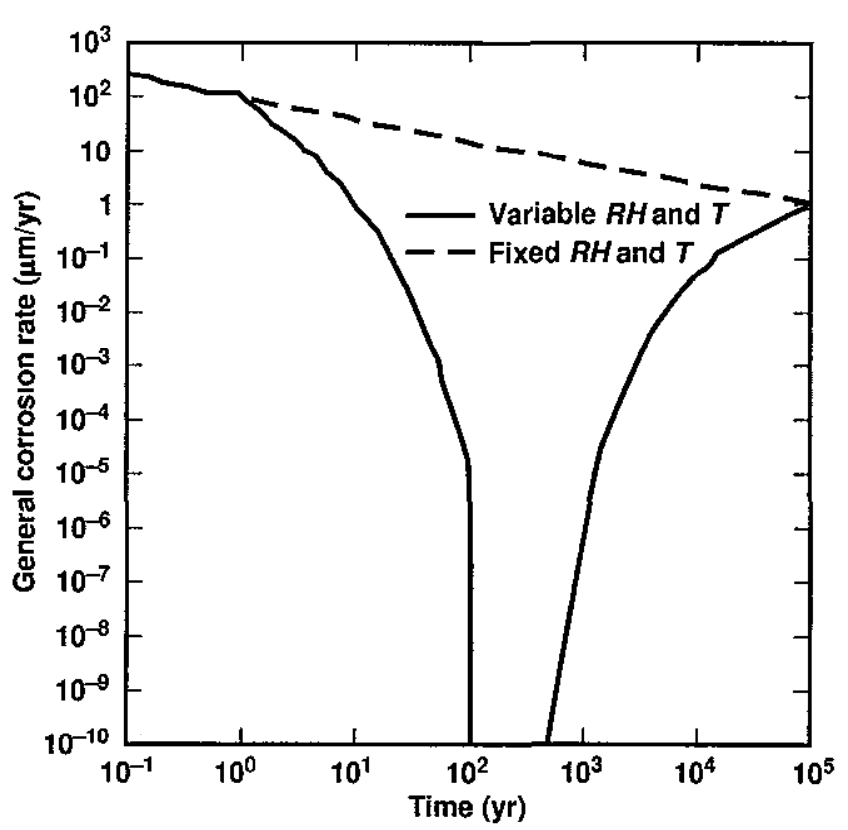

Figure 6-3. Corrosion rate of the outer WP barrier at ambient conditions compared with the rate predicted for the 24-MTU/acre repository.
Figure 6-4 shows the cumulative depth of corrosion of the outer WP barrier for both an ambient (fixed) $R H$ and $T$ environment and for the predicted $R H$ and $T$ repository conditions representative of the conservative 24-MTU/acre case The predictions show that almost 100,000 years would be required to remove half the original outer barrier thickness by general corrosion for the repository $R H$ and $T$, as contrasted with approximately 10,000 years for the ambient conditions These predictions do not take into account localized attack Analyses using a Monte Carlo approach, as well as analyses for the 83 4-MTU/acre design, will be reported in the future Such simulations of the propagation of millions of pits per WP suggest failure of the outer barrier in only a few thousand years

In addition, the preliminary analyses of $\mathrm{J}$ Blink et al , 1977) have also identified the periods of time during which WPs in the ACD, 83 4-MTU/acre design will be exposed to especially adverse environments The simultaneous occurrence of high $R H$ and $T$ promotes rapid corrosion, whereas lowering the $R H$ retards corrosion at all temperatures Figures 6-5 and 6-6 show the conditions 


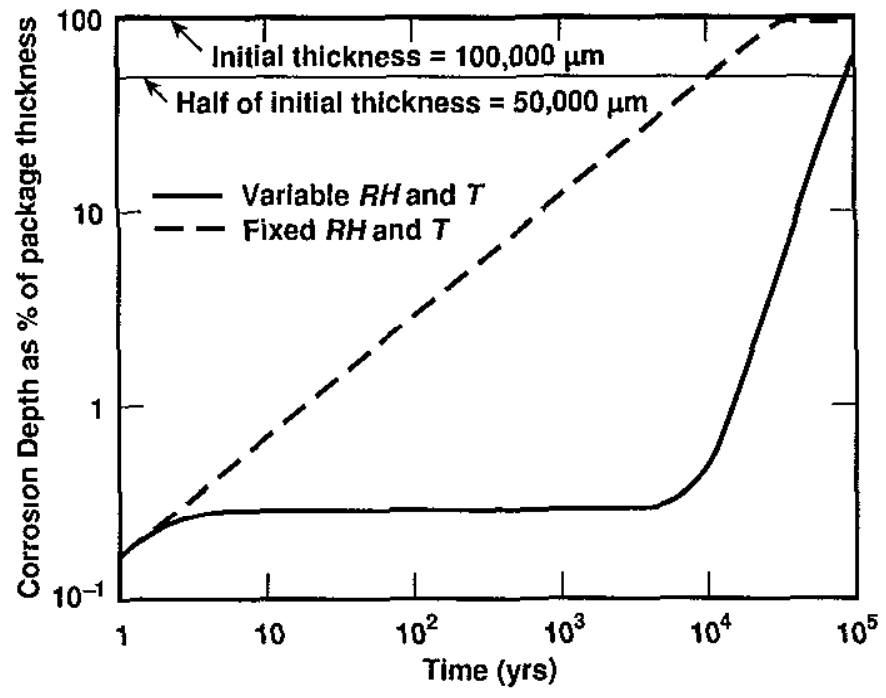

Figure 6-4. Cumulative corrosion depth of the outer WP barrier at ambient conditions compared with the values predicted for the 24-MTU/acre repository. of corrosion susceptibility for two design options with an assumed 6-mm/yr ambient flux Figure 6-5 shows results for the ACD design case without backfill Fig 6-6 shows results for the LL case with 0.1-m gaps between WPs and with sand backfill Recall that these two designs represent the bounding cases for corrosion For the ACD design case, both "hot" and "cool" waste packages enter the window of susceptibility-that is, the combinations of $R H$ and $T$ that cause rapid corrosionwithin a few hundred years and do not exit this region until after 70,000 years In contrast, model calculations for the LL design (Fig 6-6) show that the "hot" packages never enter the aggressive corrosion region The "cool' packages enter the aggressive region at about 10,000 years and exit at about 18,000 years For the LL design with backfill, water evapor ates within the backfill and salt is not deposited on the WPs Therefore, the $R H$ at which corrosion starts is not lowered by the presence of salts on the WP surfaces Other engineering options, such as drip shields, limit contact by liquid

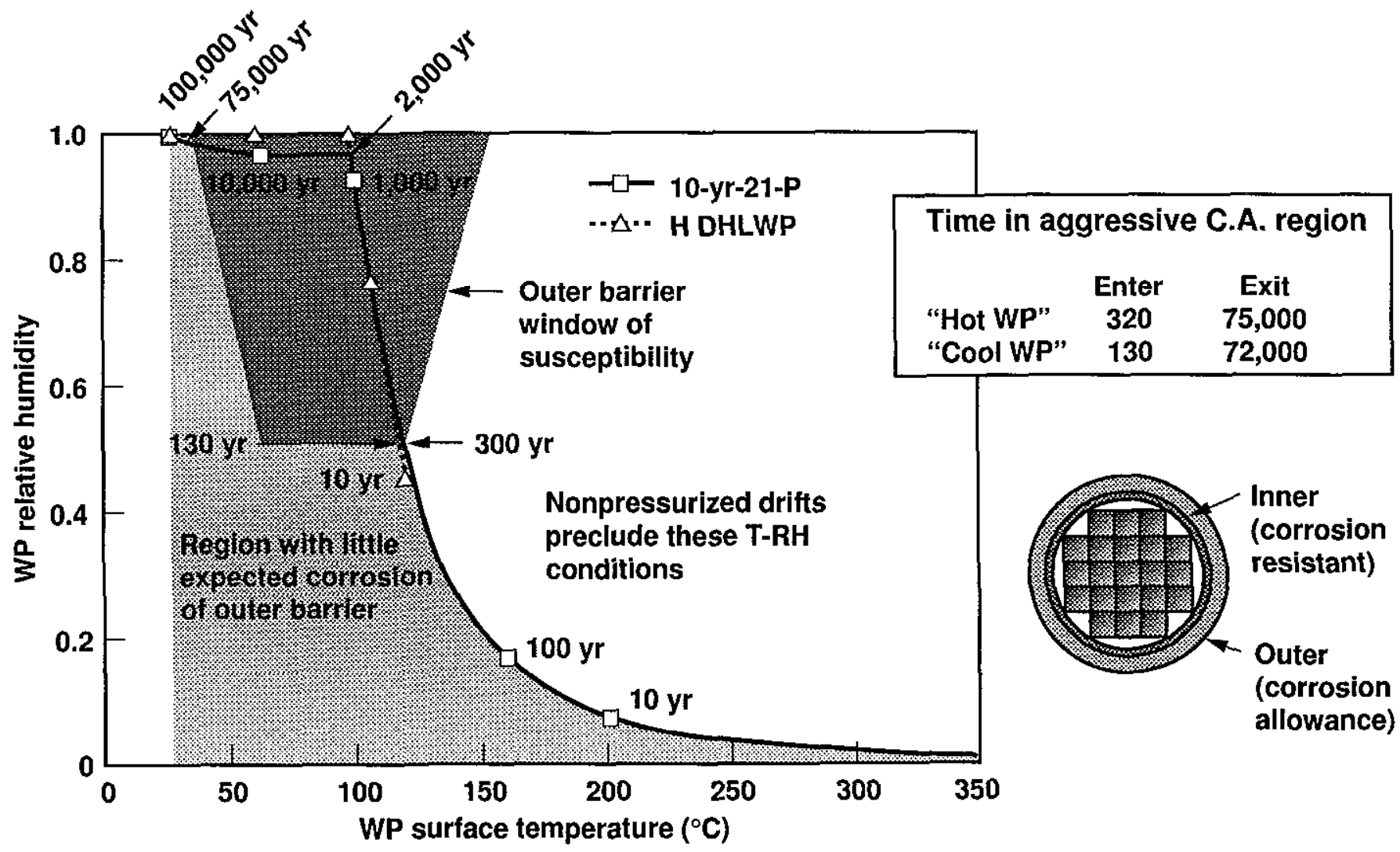

Figure 6-5. WP relative humidity versus surface temperature for the ACD design with an AML of 83 MTU/acre, no backfill, and an ambient flux of $6.2 \mathrm{~mm} / \mathrm{yr}$ (Blink et al., 1977). 


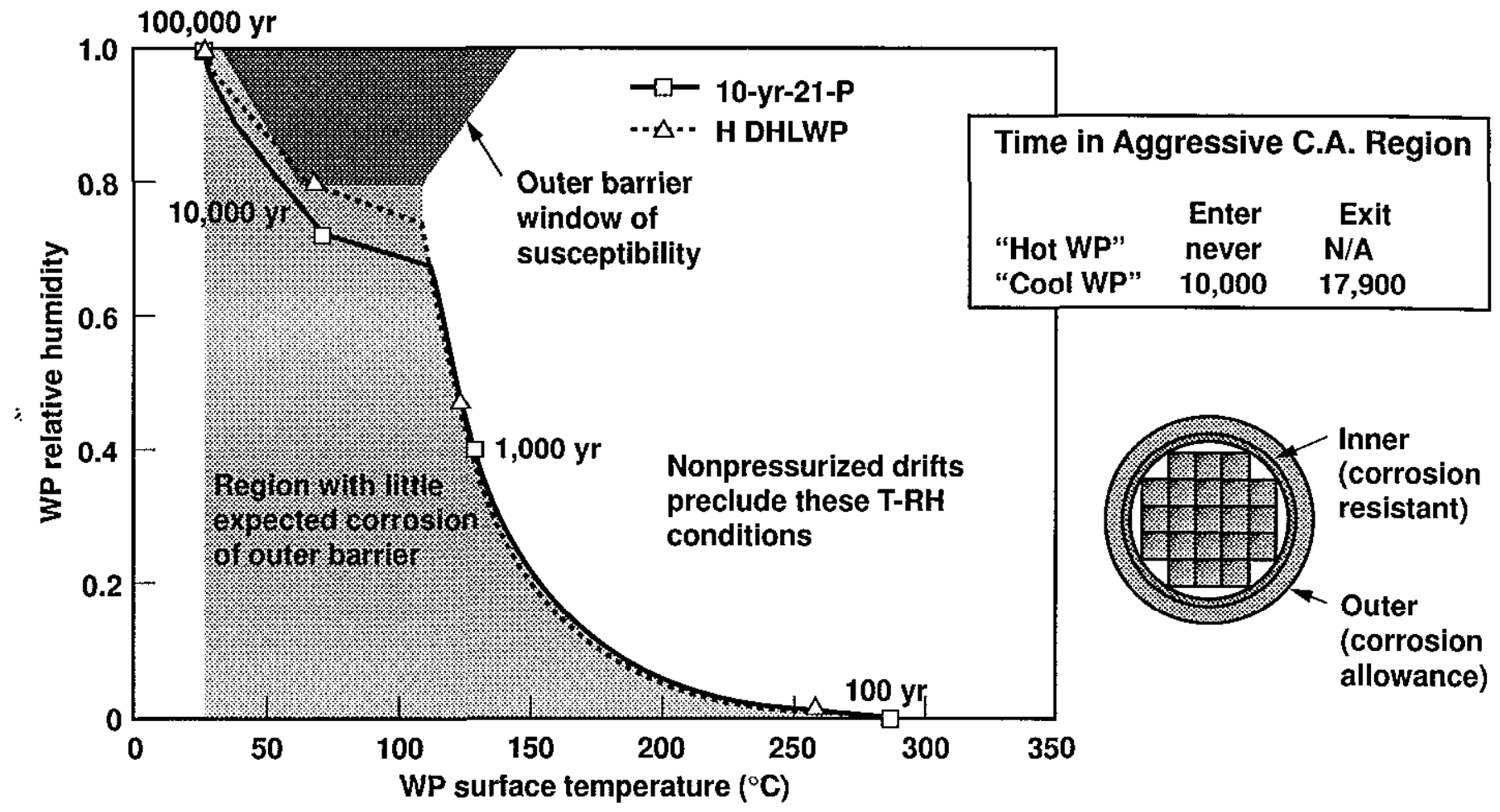

Figure 6-6. WP relative humidity versus surface temperature for the 0.1-m LL design with an AML of 83 MTU/acre, sand backfill, and an ambient flux of $6.2 \mathrm{~mm} / \mathrm{yr}$ (Blink and Chesnut, 1997).

water, but they may not provide the controls on $R H$ to achieve desired WP protection Even continuous drift liners would only prevent such exposure if they could be designed to have lifetimes that exceed 10,000 years Thus, the most effective engineering option that offers protection from corrosion is the simple selection of WP placement and backfill.

At present, the program is considering ceramic coatings or other options to make the WP lifetime less sensitive to environmental variables. However, unless $100 \%$ defect-free manufacturing and inspection can be guaranteed, the environment will still be of concern

\subsection{Impacts on the Waste Form}

Several issues regarding waste form dissolution and radionuclide release/mobilization are related to the NFE First, the amount and timing of dissolution or radionuclide release is directly related to the amount of water contacting the waste, its chemistry at the time of contact, and the temperature of the waste at the time of contact (which influences the kinetics or rapidity of reactions) The amount of water that contacts the waste provides an upper bound on the amount of water that contacts the WPs This value would tend to be conservative in that the WP container would have to first fail before water could contact the waste itself It is possible that the WP could be penetrated by humid air corrosion, exacerbated by microbes and crevice processes, before any actual flow of liquid water contacts the WPs Another source of conservativism is introduced by assuming that all water contacting a failed WP also contacts the waste itself Much of the water will never contact waste, especially that fraction of waste protected by cladding remaining intact after the decay of the thermal pulse Part of the water contacting WPs will also be consumed in corrosion processes and products Thus, depending on the design, the waste would not likely be contacted by water until well after the thermal pulse and its impact on overall flux had decayed

Water chemistry will be very much influenced by interactions with introduced materials and possibly microbes, and by the temperatures of the system at the 
time of those interactions. Studies are not mature in this area, but it is likely that the $\mathrm{pH}$ will be elevated by the significant amount of concrete in the system. If crushed backfill is used, the water will probably be elevated in silica How much influence on water chemistry the corrosion products will have is not currently known The amount of impact would depend on whether failures had occurred by general corrosion-in which case there would be large volumes of corrosion product that would both hinder water flow and also influence its chemistry-or whether the failures resulted from localized failures, such as pitting Insufficient information is available on the design or the interaction with materials to allow definitive discussion at this time

\subsection{Impacts on Flow Fields and Transport}

The impacts on system performance that involve flow and transport are essentially due to the $\mathrm{AZ}$ as it develops with time The major conclusion that can be reached at this time is that there will be a significant zone that will be exposed to both elevated temperatures and moisture (saturations) As shown in Fig 5-6, a zone of elevated temperatures between $60^{\circ}$ and $96^{\circ} \mathrm{C}$ and saturations between 60 and $100 \%$ moves away from the repository horizon and increases in size Below the repository is a zone from 425 to $500 \mathrm{~m}$ below surface that remains at elevated temperatures and saturations for at least 9,000 years A similar zone is located above the repository around $250 \mathrm{~m}$ below the ground surface; however, this zone is not as longlived and extensive.

The conditions in these zones are conducive to chemical/mineralogical reactions These zones are likely to experience equilibrium conditions Estimates of the alteration potential show that during early times, the TSw3 unit may develop alteration products of zeolites and clays However, the kinetics of the zones close to the repository are such that these zones may not have water present for sufficiently long periods to allow the chemical reactions to go to completion Farther away from the repository, nearly complete chemical reactions are expected so that the mineralogy and water chemistry will be in equilibrium
As described in Sec 545, long-term condensate zones will allow considerable porosity enhancement (from 11 to $16 \%$ ), and the values could be even larger if the zones persist for long time periods This would certainly be the case in the zone below the repository that is stable for many thousands of years, and for the condensate cap if condensate is able to develop above the repository Dissolved silica would be deposited further out Thus, a zone of enhanced porosity would develop around the repository, and a zone with reduced porosity would develop farther out Studies of fracture healing indicate that the zones where water flows through will potentially have healing of fractures Therefore, there is the potential to have increased porosity (and possibly permeability) around the repository with a zone of decreased porosity and permeability further out If these zones developed, they would tend to divert percolating meteoric water away from the repository area, would restrict the downward flow of water that might have flowed through the repository (thus reducing waste transport), and create an enlarged porosity around the repository that would be able to store water so that it would not flow through the fractures On the other hand, the zone wherein the temperatures and saturations are high is much larger and more stable (in duration) below the repository than above it This might imply that the restrictions to flow above the repository would not develop to the same extent as below the repository In this case, environmental conditions might develop wherein water could build up (bathtub scenario) over time However, the development of heat-pipes in this region could cause greater rock-water interactions that would potentially cause greater changes to occur above the repository

The $A Z$ is less sensitive to repository design than is $R H$, water contact, and other parameters within the drifts and on the WPs Therefore, it is the WP and waste form performance issues that need to be considered in design of the repository The AZ is more sensitive to total mass of waste emplaced and on its density Thus, for any given AML, the general AZ development will be similar, especially at longer time frames Nevertheless, a zone that is part of both the $\mathrm{AZ}$ and NFE can be influenced by design, namely, the one that develops in the pillars between waste emplacement drifts Condensate will tend to drain 
down the pillars during early emplacement times Depending on the spacing of drifts, the pillars may be in the environment of elevated temperatures and saturations (between 60 and $97^{\circ} \mathrm{C}$, and greater than $60 \%$ saturation) Because condensate will be elevated in temperature, it may not require that the conduction of heat cause elevated temperatures to create conditions conducive to porosity/permeability changes.

However, the larger the pillar, the longer the time for drainage to occur before the temperatures are elevated to the extent that kinetics will result in these hydrologic changes Therefore, design options that include

"wider drift spacing would result in a larger percentage of the condensate draining away from the zone above the repository This would reduce the amount of flux to re-enter the drifts and would also reduce the heat pipes that may form above the repository horizon An additional performance implication of the AZ is the significant amounts of zeolites and secondary minerals that are likely to form below the repository The extent of changed sorptive capacity of the over all system is not known at this time However, preliminary indications suggest tundamental increases in both amounts of and lateral extent of these minerals

Finally, if the thermal conditions that extend into the water table create the types of convection cells that are postulated, they might contribute to increased mixing/dilution of any radionuclides Of course, increases in temperatures within the saturated zone may also cause the rocks to be out of thermodynamic equilibrium with the water, which could cause mineralogical changes that are unknown at present

\section{Acknowledgments}

The author would like to acknowledge the significant contributions that were made by W E Glassley, $T$ A Buscheck, A Meike, and S Blair for their contributions and for their review of the materials of this report, which were summations of individual sections of Volume II for which they were authors The author would also like to acknowledge the assistance of J. Blink and $\mathrm{D}$ A Chesnut for their contributions regarding the corrosion implications A special note of apprecia- tion is given to $\mathrm{R}$ Kirvel for long hours in editing and in producing much of the material that is contained in this report Appreciation is expressed to $\mathrm{M}$ Lewis for assisting in the production of this report and to T. Carey and D. Fletcher for invaluable assistance with the illustrations contained in this report The author would also like to express gratitude to L Ramspott for his careful review of this report and for his insightful technical suggestions 


\section{References}

Albin, A L , W L. Singleton, T. C Moyer, A C. Lee, R C Lung, G L W Eatman, and D L Barr (1997), Geology of the Main Drift-Station 28+00 to 55+00, Exploratory Studies Facility, Yucca Mountain Project, Yucca Mountain, Nevada, Bureau of Reclamation and US Geological Survey, Denver, CO

Anderson, J G, J N. Brune, D dePolo, J Gomberg, S C Harmsen, M K Savage, A K. Sheehan, and K D Smith (1993), Preliminary Report The Little Skull Mountain Earthquake, June 29, 1992, Dynamic Analysis and Design Considerations for High-Level Nuclear Waste Repositories, Structural Div /ASCA, pp 162-175 (NNA 19920930 0015)

Archambault, G., S Gentier, J Riss, and R Flamand (1997), "The Evolution of Void Spaces (Permeability) in Relation with Rock Joint Shear Behavior," Int $J$ Rock Mech Min Sci 343-4, paper no 14

Atkins, M, D Bennett, A Dawes, F Glasser, A Kindness, and D. Read (1992), A Ther modynamic Model for Blended Cements, DOE report DOE-HMIP-92-005

Atkins, M , F Glasser, L P Moroni, and J J Jack (1994), Thermodynamic Modeling of Blended Cements at Elevated Temperatures $\left(50-90^{\circ} \mathrm{C}\right)$, DOE report DOE-HMIP-94-001

Bandis, S , A C Lumsden, and N R Barton (1983), "Fundamentals of Rock Joint Deformation," Int J Rock Mech Min Sci and Geomech Abstr 20, 249-268.

Barton, N. R, S Bandis, and K Bakhtar (1985), "Strength, Deformation, and Conductivity Coupling of Rock Joints," Int J Rock Mech Min Sci and Geomech Abstr 22(3), 121-140.

Blair, S C and P A Berge (1996) "Uniaxial Compression Behavior of Small Blocks of Welded Tuff, " in Proc 1996 Intl High Level Radioactive Waste Management Conf, April 29-May 3, 1996, Las Vegas, NV, published by American Nuclear Society and American Society of Civil Engineers, pp 409-411

Blink, J et al (1977), Year-End Status Report on Design Basis Models, Rev 00A, CRWMS M\&O, Las Vegas, NV (B00000000-01717-5703-00006)
Boitnott, G N (1997), "Experimental Characterization of the Nonlinear Rheology of Rock," Int J Rock Mech Min Sci 343-4, paper no 33

Bodvarsson, G S and T M Bandurraga (1996), Development and Calibration of the Three-Dimensional Site-Scale Unsaturated Zone Model of Yucca Mountain, Nevada, Lawrence Berkeley National Laboratory, Earth Sciences Division, Berkeley, CA

Brechtel, C E, M Lin, E. Martin, and D S Kessel (1995), Geotechnical Characterization of the North Ramp of the Exploratory Studies Facility, SNAD95-0488/1 and 2, Yucca Mountain Site Characterization Project, Sandia National Laboratories, Albuquerque, NM (MOL 19950502 0004)

Brodsky, N. S, M Riggins, and J Connolly (1997), "Thermal Expansion, Thermal Conductivity, and Heat Capacity Measurements at Yucca Mountain, Nevada," Int J Rock Mech Min Sci 343-4, paper no 40

Brown, S R (1994), Simple Mathematical Model of a Rough Fracture, Sandia National Laboratories, Albuqueruqe, NM, SAND92-2216] (MOL 19941106 0040)

Bruton, C. J (1995), "Testing EQ3/6 and GEMBOCHS Using Fluid-Mineral Equilibria in the Wairakei Geothermal System Yucca Mountain Project Letter Report, Milestone MOL206," in Chemical and Mineralogical Properties of the Waste Package Environment Natural System Simulations, WBS Element 123121 , August 28, 1995

Buesch, D. C., R. W Spengler, T C Moyer, and J K Geslin (1996), Revised Stratigraphic Nomenclature and Macroscopic Identification of Lithostratigraphic Units of the Paintbrush Group Exposed at Yucca Mountain, US Geologic Survey Open File Report 94-469

Buscheck, T A (1997), personal communication

Buscheck, T A , D G. Wilder, and J J Nitao (1993), Large-Scale In Situ Heater Tests for Hydrothermal Characterization at Yucca Mountain, Lawrence Livermore National Laboratory, Livermore, CA, UCRL-JC-112445 
Buscheck, T A, and J J Nitao (1992), The Impact of Thermal Loading on Repository Performance at Yucca Mountain, Lawrence Livermore National Laboratory, Livermore, CA, UCRL-JC-109232 (NNA 920408 0008)

Buscheck, T A., and J J. Nitao (1993a), The Impact of Repository Heat on Thermo-Hydrological Performance at Yucca Mountain, Lawrence Livermore National Labor atory, Livermore, CA, UCRL-JC-114791

Buscheck, T A, and J J Nitao (1993b), "Repository-HeatDriven Hydrothermal Flow at Yucca Mountain, Part I

Modeling and Analysis," Nucl Technol 104(3), 418-448

Buscheck, T A, and J J Nitao (1993c), The Impact of Repository-Heat-Driven Hydrothermal Flow on Hydrological Performance at Yucca Mountain, Lawrence Livermore National Laboratory, Livermore, CA, UCRL-JC-112444

Buscheck, T A., and J J Nitao (1994a), The Importance of Thermal Loading Conditions to Waste Package Performance at Yucca Mountain, Lawrence Livermore National Laboratory, Livermore, CA, UCRL-JC-116429

Buscheck, T A, and J J Nitao (1994b), The Impact of Buoyant Gas-Phase Flow and Heterogeneity on ThermoHydrological Behavior at Yucca Mountain, Lawrence Livermore National Laboratory, Livermore, CA, UCRL-JC-115351

Buscheck, T A, J J Nitao, and L D Ramspott (1996), Near-Field Thermal-Hydrological Behavior for Alternative Repository Designs at Yucca Mountain, Lawrence Livermore National Laboratory, Livermore, CA, UCRL-JC-124629, Materials Research Society, Proc Mat Res Soc XX Internat Symp Sci Basis Nuclear Waste Management, Dec 2, 1996, Boston, MA.

Buscheck, T. A , J J Nitao, and S F Saterlie (1994), "Evaluation of Thermo-Hydrological Performance in Support of the Thermal Loading Systems Study," in Proceedings of the 5th International High Level Nuclear Waste Management Conference, Las Vegas, NV (American Nuclear Society, La Grange, IL), pp. 592-610.

Carlos, B (1985), Minerals in Fractures of the Unsaturated Zone from Drill Core USW-G4, Yucca Mountain, Nye County, Nevada, Los Alamos National Laboratory, Los Alamos, NM, LA-10415-MS. (NNA 920506 0037)
Carlos, B (1989), Fracture-Coating Minerals in the Topopah Spring Member and Upper Tuff of Calico Hills from Drill Hole J-13, Los Alamos National Laboratory, Los Alamos, NM, LA-11504-MS (NNA 881220 0001)

Chesnut, D A (1992), "Characterizing the Altered Zone at Yucca Mountain The Beginning of a Testing Strategy," Proc Third Internat High-Level Radioactive Waste Management Conf, Las Vegas, NV

Civilian Radioactive Waste Management System Management and Operating Contractor (CRWMS M\&O) (1996), Characterization of the ESF Thermal Test Area, Rev 1 (B0000000-01717-5705-00047), pp 5-1 to 5-2

Civilian Radioactive Waste Management System Management and Operating Contractor (CRWMS M\&O) (1996), Mined Geologic Disposal System Advanced Conceptual Design Report, Vol 2 (B00000000-017175705-00027), Rev 00

Civilian Radioactive Waste Management System Management and Operating Contractor (CRWMS M\&O) (1997), ISM2 0 A 3D Geologic Framework and Integrated Site Model of Yucca Mountain (Clayton, R W, W P Zelinski, and C A Rautman) (B00000000-017175700-00004), Rev 00

Daily, W, W Lin, and T Buscheck (1987), "Hydrological Properties of Topopah Spring Tuff-Laboratory Measurements," J Geophys Res 92(B8), 7854-7864 (NNA 900123 0064)

Delany, J M (1985), Reaction of Topopah Spring Tuff with J-13 Water A Geochemical Modeling Approach Using the EQ3/6 Reaction Path Modeling Code, Lawrence Livermore National Laboratory, Livermore, CA, UCRL-53631

DOE (U.S. Department of Energy) (1988), Site Characterization Plan, Yucca Mountain Site, Nevada Research and Development Area, Nevada, Office of Civilian Radioactive Waste Management, Washington, DC, DOE/RW-0199 (HQO 881201 0002)

DOE (US Department of Energy) (1995), Yucca Mountain Project Reference Information Base, Version 4, Yucca Mountain Site Characterization Project Office, Las Vegas, NV, YMP/CC-0002 (NNA 890330 0077) 
DOE (U S Department of Energy) (1997), Quality Assurance Requirements and Description for the Civilian Radioactive Waste Management Program, Office of Civilian Radioactive Waste Management, Washington, DC, DOE/RW-0333, Rev 7.

Dudley, Jr , W W, W E Wildon, and D T Hoxie (1990), "Hydrologic Framework of the Yucca Mountain Area, Nevada," Proc Int Symp on Unique Underground Structures, (Colorado School of Mines Press, Colorado) (NNA 900403 0205)

Elayer, R (1997), Determination of Available Volume for Repository Siting, YMP-M\&O Design Analysis Document BCA000000-01717-0200-00007, Rev. 00

Finley, R E, S R Sobolik, N D. Francis, S Ballard, J. T. George, and L S Costin (1997), "Preliminaty Thermomechanical Results of a Heater Test in Welded Tuff," Int J Rock Mech Min Sci 34 3-4, paper no 080

Flint, L E (1997), Matrix Properties of Hydrogeologic Units at Yucca Mountain, Nevada, US Geological Survey, Denver, CO, Open File Report MOL.19970324 0046 [GS950308312231002(Q)]

Flint, A (1991), personal communication with Alan Flint from the US Geological Survey on the topic of "Annual Precipitation Measurements at Yucca Mountain " (N/A)

Gentier, S S and D L Hopkins (1997), "Mapping Fracture Aperture as a Function of Normal Stress Using a Combination of Casting, Image Analysis and Modeling Techniques," Int J Rock Mech Min Sci 34:3-4, paper no 132 .

Glassley, W E (1986), Reference Waste Package Environment Report, Lawrence Livermore National Laboratory, Livermore, CA, UCRL-53726 (NNA.920506.0035)

Glassley, W E (1995), "Characterization of Chemical and Mineralogical Changes in the Post-Emplacement Environment," YMSCP Study Plan for SCP Section $834241, R 1, \mathrm{p} 69$.

Glassley, W E (1995), Report on Near-Field Geochemistry Water Composition Changes Due to Evaporation, Yucca Mountain Milestone MOL206
Glassley, W E (in preparation), Near Field Environmental Models Report, deliverable ID SP3100M3

Hardin, E L and D A Chesnut (1997), Synthesis Report on Thermally Driven Coupled Processes, Lawrence Livermore National Laboratory, Livermore, CA, Milestone report SP3005M3 (in preparation)

Harrar, J E, J F Carley, W F Isher wood, and E Raber (1990), Report of the Committee to Review the Use of J-13 Well Water in Nevada Nuclear Waste Storage Investigations, Lawrence Livermore National Laboratory, Livermore, CA, UCID-21867 (NNA 910131 0274)

Harrison-Giesler, D J , R P Morissett, and L J. Jardine (1991), Yucca Mountain Site Characterization Project Waste Package Plan, YMP-90/62, Lawrence Livermore National Laboratory, Liver more, CA, UCRL-JC-106161 (NNA 9205290030 )

Horn, J M and A Meike (1996), "A Program to Assess Microbial Impacts on Nuclear Waste Containment," Proc 1996 High-Level Radioactive Waste Meeting, Las Vegas, NV, Lawrence Livermore National Laboratory, Livermore, CA, UCRL-JC-122732

Horn, J M , B Economides, A Meike, and R D McCright (1996), "Initial Studies to Assess Microbial Impacts on Nuclear Waste Disposal" Proc 1996 High-Level Radioactive Waste Meeting, Las Vegas, NV; Lawrence Liver more National Laboratory, Livermore, CA, UCRL-JC-122587

Hudson, J A (1989), Rock Mechanics Principles in Engineering Practice (Butterworths, London), p 72

Jiao, Y, and J A Hudson (1995), "The Full-Coupled Model for Rock Engineering Systems," Int J Rock Mech Min Sci Geomech Abst 32(5), 491-512

Kemeny, J , and N Cook (1990), "Rock Mechanics and Crustal Stress," Demonstration of a Risk-Based Approach to High-Level Waste Repository Evaluation, R K McGuire, Ed, Electric Power Research Institute, Palo Alto, CA, EPRI NP-7057 (NNA 910813 0004)

Klavetter, E A, and R R Peters (1986), Estimation of Hydrologic Properties of an Unsaturated, Fractured Rock Mass, Sandia National Laboratories, Albuquerque, NM, SAND84-2642 (NNA 870317 0738) 
Klavetter, E A, and R R. Peters (1987), An Evaluation of the Use of Mercury Porosimetry in Calculating Hydrologic Properties of Tuffs from Yucca Mountain, Nevada, Sandia National Laboratories, Albuquerque, NM, SAND86-0286-UC-70 (NNA 890327 0056)

Klavetter, E A, and R R Peters (1988), "A Continuum Model for Water Movement in an Unsaturated Fracture Rock Mass," Water Resources Research 24, 416-430 (NNA 900719 0082)

Knauss, K G (1987), "Zeolitization of Glassy Topopah "Spring Tuff under Hydrothermal Conditions," Mat Res Soc Symp Proc 84, 737-745 (NNA 920302 0050)

Knauss, K G, and D W Peifex (1986), Reaction of Vitric Topopah Spring Tuff and J-13 Groundwater under Hydrothermal Conditions Using Dickson-Type, Gold-Bag Rocking Autoclaves, Lawrence Livermore National Laboratory, Livermore, CA, UCRL-53795 (NNA 891102 0117)

Knauss, K G, J M Delany, W J Beiriger, and D W. Peifer (1986), "Hydrothermal Interaction of Topopah Spring Tuff with J-13 Water as a Function of Temperature," Mat Res Soc Symp Proc, vol 44, pp 539-546 (NNA 870407 0364)

Knauss, K G, W J Beiriger, and D W Peifer (1987), Hydrothermal Interaction of Solid Wafers of Topopah Spring Tuff with J-13 Water and Distilled Water at 90 and $150^{\circ} \mathrm{C}$ Using Dickson-Type, Gold-Bag Rocking Autoclaves Long-Term Experiments, Lawrence Livermore National Laboratory, Livermore, CA, UCRL-53722 (NNA 19870713 0081)

Levy, S S (1984a), "Studies of Altered Vitrophyre for the Prediction of Nuclear Waste Repository Induced Thermal Alteration at Yucca Mountain, Nevada," in Scientific Basis for Nuclear Waste Management VII, G L McVay, Ed (Elsevier, New York), pp 959-966

Levy, S S (1984b), Petrology of Samples from Drill Holes USW H-3, H-4, and H-5, Yucca Mountain, Nevada, Los Alamos National Laboratory, Los Alamos, NM, LA-9706-MS

Lin, W (1990), Variation of Permeability with Temperature in Fractured Topopah Spring Tuff Samples, Lawrence Livermore National Laboratory, Livermore, CA, UCRL-JC-104765 (NNA 910523 0105)
Lin, W and W D Daily (1989), "Laboratory Study of Fracture Healing in Topopah Spring Tuff-Implications for Near Field Hydrology," Proc of the ANS Topical Mtg on Nuclear Waste Isolation in an Unsaturated Zone, Focus '89 (American Nuclear Society, La Grange Park, IL), p 443 (Readily available)

MacDougall, H R, L W Scully, and J R Tillerson, (Compilers) (1987), Site Characterization Plan Conceptual Design Report, Sandia National Laborator ies, Albuquerque, NM, SAND84-2641 (NNI 880902 0014)

Macintyre, A T, D Chesnut, and W J O'Connell (1990), Disruptive Scenario Aspects Important to Source Term Performance, " Lawrence Livermore National Laboratory, Livermore, CA, UCRL-JC-104769 (Abstract)

Martin, R J , J S Noel, P J Poyd, and R H Price (1997), "Creep and Static Fatigue of Welded Tuff from Yucca Mountain, Nevada," Int I Rock Mech Min Sci 34 3-4, paper no 190

Martin, R J, R H. Price, P J Boyd, and J S Noel (1994), Bulk and Mechanical Properties of the Paintbrush Tuff Recovered from Borehole USW NRG-6 Data Report, Sandia National Laboratories, Albuquerque, NM, SAND93-4020 (MOL 19940811 0001)

Martin, R. J, R H Price, P J Boyd, and J S Noel (1995a), Bulk and Mechanical Properties of the Paintbrush Tuff Recovered from Borehole USW NRG-7/7A Data Report, Sandia National Laborator ies, Albuquerque, NM, SAND94-1996 (MOL 19930116 0087)

Martin, R. J , R H Price, P J Boyd, and J S Noel (1995b), Creep in Topopah Spring Member Welded Tuff, Sandia National Laboratories, Albuquerque, NM, SAND94-2585 (MOL.19950502 0006)

Montazar, P, and W E Wilson (1984), Conceptual Hydrologic Model of Flow in the Unsaturated Zone, Yucca Mountain, Nevada, U S Geological Survey, Lakewood, CO, WRIR-84-4345 (NNA 890327 0051)

Moore, D E , C Morrow, and J Byerlee (1986), "HighTemperature Permeability and Groundwater Chemistry of Some Nevada Test Site Tuffs," J Geophys Res 91(B2), 2163-2171 (Readily available) 
Nimick, F G, and B M Schwartz (1987), Bulk, Thermal, and Mechanical Properties of the Topopah Spring Member of the Paintbrush Tuff, Yucca Mountain, Nevada, Sandia National Laboratories, Albuquerque, NM, SAND85-0762 (NNA 870723 0015)

Nitao, J J (1988), Numerical Modeling of the Thermal and Hydrological Environment Around a Nuclear Waste Package Using the Equivalent Continuum Approximation Horizontal Emplacement, Lawrence Livermore National Labor ator y, Livermore, CA, UCID-21444

(NNA 890317 0021)

Nitao, J J (1997), Preliminary Bounds for the Drift-Scale Distribution of Percolation and Seepage at the Repository Level under Pre-Emplacement Conditions, Lawrence Livermore National Laboratory, Livermore, CA. (LLYMP 9703034), letter report to CRWMS Management and Operating Contractor, Las Vegas, NV).

Nitao, J J and T A Buscheck (1995), "Discrete-Fracture Modeling of Thermal-Hydrological Processes at Yucca Mountain and the LLNL G-Tunnel Field Test," Materials Research Society, Pittsburgh, PA, Proc Mat Res Soc XIX Internat Symp Sci Basis Nuclear Waste Management, Nov 27-Dec 1, 1995

Olsson, W. A (1987), Rock Joint Compliance Studies, Sandia National Laboratories, Albuquerque, NM, SAND86-0177

Olsson, W A (1988), Compliance and Strength of Artificial Joints in Topopah Spring Tuff, Sandia National Laboratories, Albuquerque, NM, SAND88-0660

Olsson, W A and S R Brown (1994), Mechanical Properties of Seven Fractures from Drillholes NRG-4 and NRG-6 at Yucca Mountain, Nevada, Sandia National Laboratories, Albuquerque, NM, SAND94-1995. (MOL 19941007 0081)

Ortiz, T S , R L Williams, F B Nimick, B. C Whittet, and D L South (1985), A Three-Dimensional Model of Reference Thermal/Mechanical and Hydrologic Stratigraphy at Yucca Mountain, Southern Nevada, Sandia National Laboratories, Albuquerque, NM, SAND84-1076 (NNA 890315 0013)
Price, R H (1986), Effects of Sample Size on the Mechanical Behavior of Topopah Spring Tuff, Sandia National Laboratories, Albuquerque, NM, SAND85-0709 (NNA 891106 0125)

Price, R H, J R Connolly, and K Keil (1987), Petrologic and Mechanical Properties of Outcrop Samples of the Welded, Devitrified Topopah Spring Member of the Paintbrush Tuff, Sandia National Laboratories, Albuquerque, NM, SAND86-1131 (NNA 870601 0013)

Pruess, K, J S Y Wang, and X W Tsang (1990), "On Thermohydıologic Conditions near High-Level Nuclear Wastes Emplaced in Partially Saturated Fractured Tuff, Part I Simulation Studies with Explicit Consideration of Fracture Effects," Water Resources Research 26(6), 1235-1248

Pruess, K and Y W Tsang (1994), Thermal Modeling for a Potential High-Level Nuclear Waste Repository at Yucca Mountain, Nevada, Lawrence Berkeley National Laboratory, Berkeley, CA, LBL-35381 (HQO.19940506 0005)

Ramirez, A, T Buscheck, R Carlson, W Daily, K Lee, W Lin, N-H Mao, T-S Ueng, H Wang, and D Watwood (1991), Prototype Engineered Barrier System Field Tests (PEBSFT), Final Report, Lawrence Livermore National Laboratory, Livermore, CA, UCRL-ID-106159 (NNA910711 0047)

Roberts, J J and W Lin (1997), "X-Ray Radiography of Fracture FLow and Matrix Imbibition in Topopah Spring Tuff Under a Thermal Gradient," Int J Rock Mech Min Sci 34(3-4), paper no 259

Sawyer, D A , R J Fleck, M A Lanphere, R G Warren, D E Broxton, and M R Hudson (1994), "Episodic Caldera Volcanism in the Miocene Southwestern Nevada Volcanic Field Revised Stratigraphic Framework," Geol Soc Am Bull 106, 1304-1318

Scott, R B , and M Catellanos (1984), Stratigraphic and Structural Relations of Volcanic Rocks in Drill Holes USW GU-3 and USW G-3, Yucca Mountain, Nye County, Nevada, US Geological Survey, Denver, CO, OFR-84491 (NNA 870519 0095) 
Stock, J M, J H Healy, and S H Hickman (1984), Report on Televiewer Log and Stress Measurements in Core Hole USW G-2, Nevada Test Site, US Geological Survey, Denver, CO, OFR-84-172 (NNA 870406.0157)

Stock, J M , J H Healy, S H Hickman, and M D Zoback (1985), "Hydraulic Fracturing Stress Measurements at Yucca Mountain, Nevada, and Relationship to Regional Stress Field," J Geophys Res 90(B10), 8691-8706 (Readily available)

: Stout, R B and H R Leider (1997), Waste Form Characteristics Report, Revision 1, Lawrence Livermore National Laboratory, Livermore, CA, UCRL-ID108314, Rev 12

Van, K, D McCright, A K Roy, and D. Jones (1994), Engineered Materials Characteristics Report, Lawrence Livermore National Laboratory, Livermore, CA, UCRLID-119564, 3 vols, Vol 3, Rev 1 in preparation, 1997

Warren, R S , F M Byers, and F A Caporuscio (1984), Petrography and Mineral Chemistry of Units of the Topopah Spring, Calico Hills, and Crater Flat Tuffs, and Older Volcanic Units, with Emphasis on the Samples from Drill Hole USW G-1, Yucca Mountain, Nevada Test Site, Los Alamos National Laboratory, Los Alamos, NM, LA-10003-MS (HQS 19880517.2569)

Wilder, D G (1986), Inelastic Deformations of Fault and Shear Zones in Granitic Rock, Lawrence Livermore National Laboratory, Livermore, CA, UCRL-93422
Wilder, D G (1987), Influence of Stress-Induced Deformations on Observed Water Flow in Fractures at the Climax Granitic Stock, Lawrence Livermore National Laboratory, Livermore, CA, UCRL-95539, Rev 1

Wilder, D. G (1990), "Engineered Barrier Systems and Canister Or ientation Studies for the Yucca Mountain Project, Nevada," Proc Int Symp on Unique Underground Structures, (Colorado School of Mines Press, Colorado) (NNA 9107110041 )

Wilder, D G (1993), Preliminary Near-Field Environment Report, Volume I Technical Bases for EBS Design, Lawrence Livermore National Laboratory, Livermore, CA, UCRL-LR-107476 Vol 1

Wolery, T J. (1992), EQ3/6, A Software Package for Geochemical Modeling of Aqueous Systems Package Overview and Installation Guide, Lawrence Livermore National Laboratory, Livermore, CA, UCRL-MA-110662

Yang, C, and Daemen, J J K (1997), "Temperature Effects on Creep of Tuff and Its Time-Dependent Damage Analysis," Int J Rock Mech Min Sci 34 3-4, paper no 345

Yow, L J , Jr and D G Wilder (1983), "Planning Exploratory Drilling The Effect of Blind Zones and Level of Logging Effort," Proc 24th U S Symp Rock Mech, College Station, TX, 807-812 


\title{
Appendix A Identification of $Q$ and NonQ Data
}

\author{
(Appendix B of Volume II)
}

The NFER and the LLNL conducted work reported in the NFER have all been performed in accordance with QARD or predecessor QA program procedures and therefore the material in the NFER is considered "Q" This determination is in accordance with DOE guidance dated 8/19/96 states "All reports, analyses, or models must be done under the QA program and are considered " $Q$ ", if they describe, predict, or defend how the natural barriers will or are performing their function to isolate waste (their safety function) These $Q$ reports/analyses/models can use non-Q data that is clearly identified as such-the report is still $Q$ "

The planning for the activities reported in the NFER has long recognized that studies to understand mechanistic processes, lab tests on non YM materials or on non-qualified samples, or scoping calculations and lab tests may not be used directly in license activities related to Site Characterization, but will provide a basis for design, planning, or judging the ranges of conditions within which the conditions of Yucca Mountain will fall As such the strategy incorporated in planning of these activities included a series of studies that were performed under the LLNL approved QA program that implements the QARD or predecessor YMP QA programs The strategy provided for qualification of any data that had been determined to be non-Q, but later was deemed necessary for licensing etc, through any of a number of possible approaches including peer review; comparison of the results with studies in which the stringent controls were applied; reperforming of the specific studies that were found applicable, or review of the procedures applied to determine if they met all requirements of qualified data In keeping with the DOE guidance discussed above, the $Q$ status of data used or reported in the NFER are reflected in Appendix $C$ following the TDIF number This $Q$ status is listed to identify which data would need to be qualified or verified for use in quality affecting work

Model results (viewed by some as data, but not rigorously defined as data) fall into another category which needs to be considered First, for the results to be relied on, any codes used in the analyses must be properly qualified. Qualification of the codes is only a small part of the process of qualifying results of models Other portions relate to whether the parameters used were appropriate, whether the model itself (which includes the conceptualization and the abstraction process) is appropriate to, or valid for, Yucca Mountain The codes used in work reported in this Rev 1 of the NFER are as follows

\begin{tabular}{|c|c|}
\hline \multicolumn{2}{|l|}{ Hydrologic Codes: } \\
\hline V-Tough & Fully QA qualified \\
\hline NUFT & $\begin{array}{l}\text { LLNL developed outside of YMP } \\
\text { Not qualified, but comparisons to } \\
\text { qualified codes have been performed }\end{array}$ \\
\hline \multicolumn{2}{|l|}{ Geochemistry Codes: } \\
\hline $\mathrm{EQ} 3 / 6$ & Fully QA qualified \\
\hline GEMBOCHS (data base) & $\begin{array}{l}\text { Some data qualified, some QA status } \\
\text { indeterminate }\end{array}$ \\
\hline GEMBOCHS suite of codes & $\begin{array}{l}\text { not qualified-qualification left to } \\
\text { user by comparison with analytical } \\
\text { solutions of th appropriate sets }\end{array}$ \\
\hline $\begin{array}{l}\text { SUPCRT92 (code) } \\
\text { (data base) }\end{array}$ & $\begin{array}{l}\text { commercial/academic code-not qualified } \\
\text { Published (peer reviewed) but not } \\
\text { qualified }\end{array}$ \\
\hline OS3D/GIMRT & Commercial Code- \\
\hline REACT & Commercial Code \\
\hline \multicolumn{2}{|l|}{ Geomechanics Codes } \\
\hline FLAC & commercial code-not qualified \\
\hline ABAQUS & commercial code-not qualified \\
\hline FRACROCK & $\begin{array}{l}\text { LLNL developed outside of YMP } \\
\text { Not qualified }\end{array}$ \\
\hline \multicolumn{2}{|c|}{ Man-Made Materials Codes } \\
\hline $\mathrm{EQ3} / 6$ & Fully QA qualified \\
\hline GEMBOCHS (data base) & $\begin{array}{l}\text { Some data qualified, some QA status } \\
\text { indeterminate Microbial will be } \\
\text { added }\end{array}$ \\
\hline GEMBOCHS suite of codes & $\begin{array}{l}\text { not qualified-qualification left to } \\
\text { user by comparison with analytical } \\
\text { solutions of the appropriate sets }\end{array}$ \\
\hline
\end{tabular}

As was the case for data qualification, the codes that are found to be of importance in characterization of the Near-Field Environment, if not already qualified, will need to be qualified The QA procedures for qualifying codes will be followed which will start with an Individual Software Plan to determine the appropriate way to qualify the code 


\section{Appendix B \\ NFER Vol. II Chapter Data Status}

\section{(Appendix C of Volume II)}

Overall NFER-LL960807504241 012 (non-Q)

Chapter 1 Hydrothermal Modeling

This chapter does not report data, it reports results of modeling only, using data RIB or referenced data from other sources Because the codes used in the models varies, model information by section is listed

Section 1.1 Introduction-no data

Section 12 No new data-refers to published data or data from other sources

Section 13 No data-model analyses only using V-TOUGH (This section is 0 and therefore was based on $\mathrm{V}$ TOUGH prior to its qualification)

Section 14 No data, refers to work of others

Section 15 No new data, refers to work of others

Utilizes Log-Normal Model which is unqualified but used and in outside literature

Section 16 No new data, analyses based on V-TOUGH prior to qualification

Section 17 No data, analyses/models only based on V-TOUGH

Section 18 No data, model results based on Qualified V-TOUGH

Section 19 No data, model results based on Qualified V-TOUGH

Section 1 10.1-1.103 No data, model results based on both V-TOUGH and NUFT as well as hybrid model

Section 1104 No data, model results based on V-TOUGH and hybrid

Sections 11051 through 1.1053 used qualified V-Tough code

Sections 11054 through 1107 are model results (no data) using NUFT

Chapter 2. Laboratory Determined Hydrologic

Properties and Processes

LL950404604242 012 (non-Q)

LL950812704242 017 (non-Q)
LL960201404244 011 (non-Q)

LL960100604244 007 (non-Q)

LL960201304244 010 (non-Q)

LL960100704244 008 (non-Q)

LL950916504242 018 (non-Q)

LL950406104242 016 (non-Q)

LL940800704242 002 (non-Q)

Chapter 3 Geochemistry

None Modeling only based on use of qualified EQ3/ 6 as well as unqualified and REACT

Chapter 4 Geomechanics LL960101004243 005 (non-Q)

LL960401704243 008 (non-Q)

LL960201104243 006 (non-Q)

Modeling results based on use of non-qualified codes

Chapter 5 Radiation Effects

No new data

Chapter 6 Man-Made Materials

LL950813104245 004 (Q)

LL940803904245 001 (non-Q)

LL960807404245 008 (non-Q)

Chapter 7 Integrated Testing

LL960401051051 007 (non-Q)

LL960400951051 006 (non-Q)

LL940803851051 002 (non-Q)

Chapter 8 Electrical Potentials

No new data

Chapter 9 Field Thermal Tests

LL950103004244 004 (non-Q)

Chapter 10. Altered Zone, Geochemistry (10 4)

Section 101 , and 102 contain no data, model results only based on qualified $\mathrm{V}$ TOUGH code

Section 103 No data

Section 104 LL960201004241 011 (non-Q)

Chapter 11 Introduction to the Thermodynamic Data Determination

Data from NEA sources 


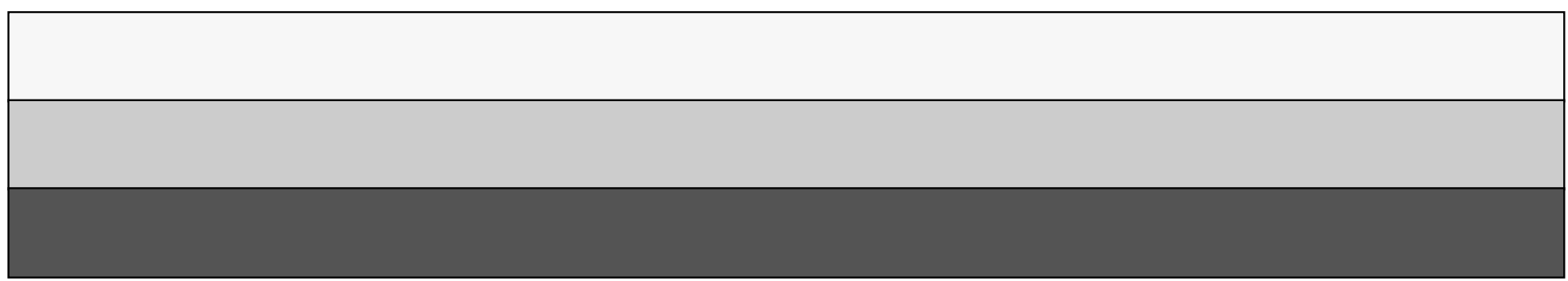

